\title{
Die Reise des Entomologen Hermann Loew nach Kleinasien in den Jahren 1841-1842
}

\section{[Entomologist Hermann Loew’s trip to Asia Minor in the years 1841-1842]}

Mit 14 Abbildungen und 8 Tabellen

Joachim Ziegler ${ }^{1}$, Jenny POHL ${ }^{2}$ und Neal L. EVenhuis ${ }^{3}$

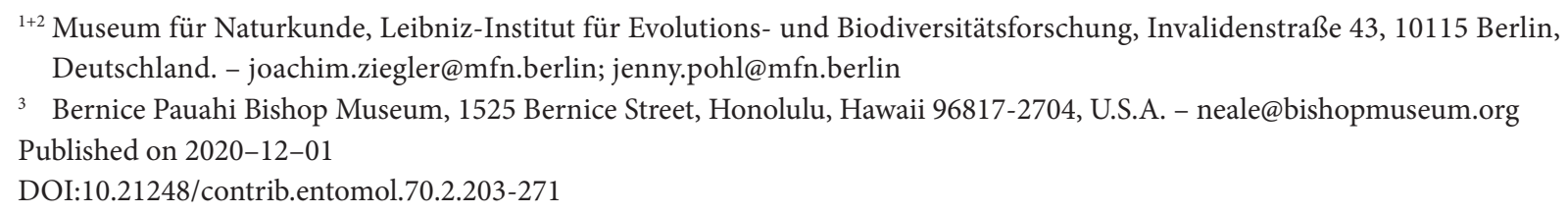

\section{Zusammenfassung}

Die Reise des Lehrers und Naturforschers Hermann Loew (1807-1879) in das Osmanische Reich in den Jahren 1841 und 1842 wird rekonstruiert. Sie führte ihn in die heutige westliche Türkei und auf die östlichen griechischen Inseln. LoEw ist vor allem als Dipterologe bekannt geworden. Seine wissenschaftlich sehr wertvolle und typenreiche Zweiflügler-Sammlung wird hauptsächlich im Museum für Naturkunde in Berlin aufbewahrt. Sie enthält auch das von ihm auf dieser Expedition nach Kleinasien gesammelte Material. Da diese Reise nie zusammenfassend publiziert wurde und das Sammlungsmaterial nur unzureichend dokumentiert ist, bestand die Notwendigkeit durch entsprechende Recherchen zur Klärung des Typenmaterials beizutragen.

Im Abschnitt Material und Methoden werden die verwendeten Informationsquellen genannt und die Arbeit mit dem Archivmaterial wird beschrieben. Anhand der verfügbaren Unterlagen wurde der Reiseverlauf in vier Abschnitten rekonstruiert: 3.1 Vorbereitung und Anreise bis Constantinopel. - 3.2 Von Constantinopel quer durch das Land bis Adalia und Rhodus (Spätsommer und Herbst 1841). - 3.3 Von Rhodus via Smyrna durch die Gebirge und Küstenländer und zurück nach Rhodus (Winter und Frühjahr 1842). - 3.4 Abschluss der Expedition im Sommer 1842 und Heimreise. Die Reiseroute wird auf zwei Karten getrennt für die Jahre 1841 und 1842 dargestellt. Die erwähnten topographischen Namen und Ortsbezeichnungen (einschließlich aller Typenfundorte), werden lokalisiert und tabellarisch zusammengestellt. Den historischen Namen werden ihre modernen Entsprechungen zugeordnet und die heutige administrative und politische Zugehörigkeit dieser Orte sowie ihre geographischen Koordinaten werden genannt. Die verwendeten historischen Quellen sind in einem separaten Verzeichnis aufgeführt. Aus dem von LoEw während dieser Reise gesammelten zoologischen Material wurden 254 Arten beschrieben. Sie werden mit den dazugehörigen Literaturstellen genannt. Es folgt eine Übersicht zur vorgefundenen historischen Etikettierung des von der Reise mitgebrachten Materials in der Dipterensammlung LoEw.

\section{Stichwörter}

Griechenland, Türkei, Coleoptera, Diptera, Hymenoptera, Lepidoptera, Mollusca, Typenfundorte, Forschungsreise 


\begin{abstract}
The journey of the teacher and naturalist Hermann Loew (1807-1879) to the Ottoman Empire (today's western Turkey and eastern Greek islands) in 1841 and 1842 is reconstructed. LoEw is best known as a dipterologist. His scientifically very valuable and type-rich collection of two-winged flies is kept primarily in the Museum of Natural History in Berlin. It also contains the material he collected on this expedition to Asia Minor. Since the account of this trip has never been published and the collection material is only insufficiently documented, there was a need to contribute to the clarification of the type material by doing appropriate research.

In the Material and Methods section, the studied information sources are listed and the work with the archival material is described. Based on the available documents, the itinerary was reconstructed in four sections: 3.1 Preparation and arrival to Constantinople. - 3.2 From Constantinople across the country to Adalia and Rhodus (late summer and autumn 1841). - 3.3 From Rhodus via Smyrna through the mountains and coastal countries, and back to Rhodus (winter to spring 1842). - 3.4 Completion of the expedition in summer 1842 and the journey home. The route is shown separately on two maps for the years 1841 and 1842. The mentioned topographical names and place names (including all type localities) were pinpointed and compiled in a table. The historical names are assigned their modern equivalents and the current administrative and political assignment of these places as well as their geographical coordinates are given. The historical sources are listed in a separate directory. The 254 species described from the zoological material collected by Loew during this journey are also named with their associated literature. The following is an overview of the historical labeling found on the material brought back from the trip in the LoEw Diptera collection.
\end{abstract}

\title{
Key words
}

Greece, Turkey, Coleoptera, Diptera, Hymenoptera, Lepidoptera, Mollusca, loci typici, scientific expedition

Inhalt

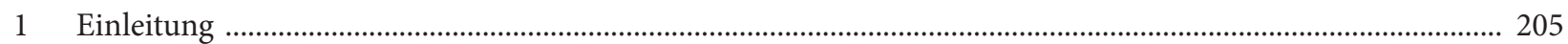

2 Material und Methoden ................................................................................................................................... 205

2.1 Publizierte Angaben über das während der Reise gesammelte zoologische Material ......................................... 205

2.2 Persönliche Informationen aus der Hand der zeitweilig Mitreisenden .............................................................. 206

2.3 Überlieferte Archivakten im Zusammenhang mit der Reise .............................................................................. 206

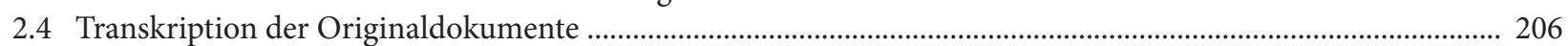

2.5 Publikationen von und über die Mitreisenden .................................................................................................. 206

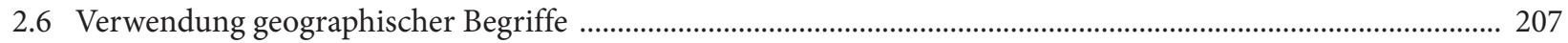

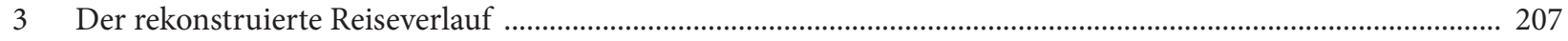

3.1 Vorbereitung und Anreise bis Constantinopel ................................................................................................... 207

3.2 Von Constantinopel quer durch das Land bis Adalia und Rhodus (Spätsommer und Herbst 1841) ................ 215

3.3 Von Rhodus via Smyrna durch die Gebirge und Küstenländer und zurück nach Rhodus

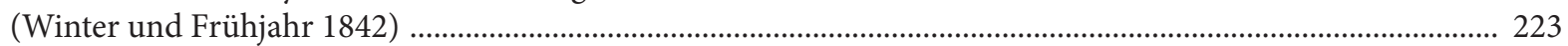

3.4 Abschluss der Expedition im Sommer 1842 und Heimreise ................................................................................ 233

3.5 Zusammenstellung der erwähnten historischen Orts- und topographischen Namen ........................................ 237

4 Das von Loew während der Reise gesammelte zoologische Typenmaterial ......................................................... 244

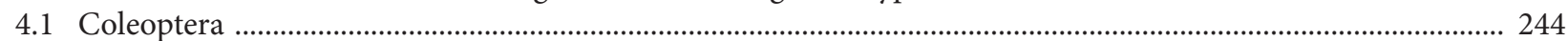

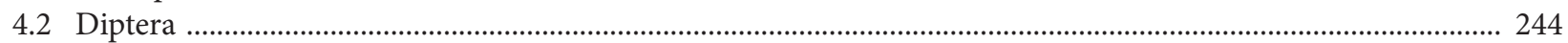

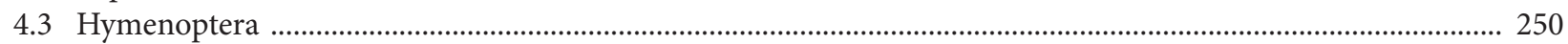

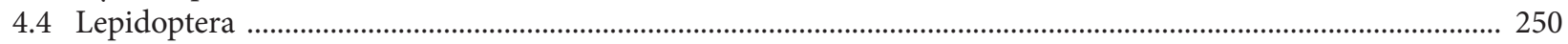

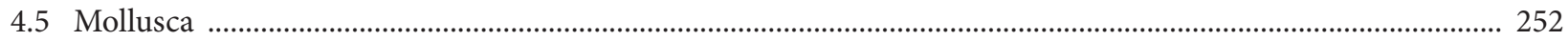

4.6 Loews Sammlungsetiketten ......................................................................................................................... 254

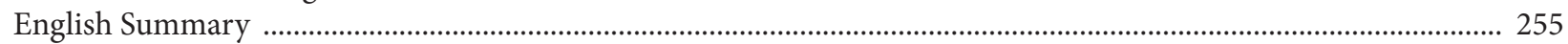

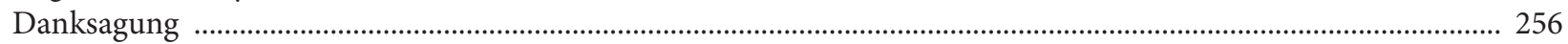

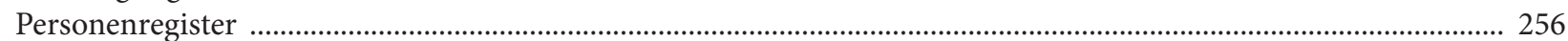

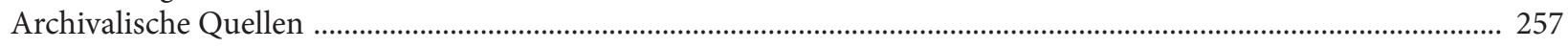

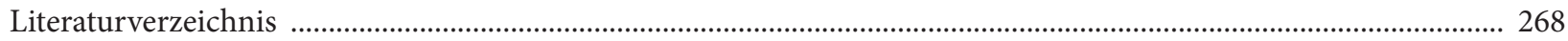




\section{Einleitung}

Im Jahre 1878 kam die umfangreiche entomologische Privatsammlung des Professors Hermann Loew (18071879) an das Zoologische Museum, das jetzige Museum für Naturkunde in Berlin. Sie enthielt überwiegend europäische Fliegen und Mücken und bildet bis heute einen wesentlichen Grundstock der Dipteren-Sammlung des Museums. Übergeben wurden damals 240 Kästen mit etwa 60000 Exemplaren. Die Artenzahl bei den Zweiflüglern wurde auf etwa 7500 beziffert (KrAATZ 1879, Ziegler 2010). Die zweite von Loew gemeinsam mit Baron Carl Robert von DER Osten-SACKEN angelegte Sammlung nordamerikanischer Dipteren wurde bereits 1877 an das Museum of Comparative Zoology, Harvard University, Cambridge, Massachusetts, United States of America, übergeben. Daneben sind von ihm bearbeitete Sammlungsteile und Typenmaterial unter anderem auch in die Museen von Dublin, Halle, Helsinki, London, Oxford, Stockholm und Wien gelangt.

Hermann Loew wurde am 19. Juli 1807 in Weißenfels, im heutigen Bundesland Sachsen-Anhalt, geboren. Seine Ausbildung erhielt er in der Klosterschule Rossleben und an der Universität Halle, wo er auch promovierte. Anschließend arbeitete er als Lehrer und Erzieher in Berlin. Im Jahr 1833 wurde LoEw als Oberlehrer an das Friedrich-Wilhelms-Gymnasium nach Posen (heute Poznań, Polen) berufen und war ab 1850 Direktor der Realschule und des daraus hervorgegangenen Gymnasiums in Meseritz (heute Międzyrzecz, Polen). Darüber hinaus war LoEw von 1848 bis 1849 Mitglied des ersten deutschen Parlaments in Frankfurt am Main. Mit Eintritt in den beruflichen Ruhestand siedelte er 1868 nach Guben über. Neben seinem vielfältigen beruflichen und politischen Engagement widmete sich LoEw über vier Jahrzehnte intensiv der Dipterologie. Als sich in seinen letzten Lebensjahren sein Gesundheitszustand verschlechterte, sorgte er für den Erhalt seiner Sammlungen, indem er sie renommierten Museen zu Forschungszwecken übereignete. Hermann LoEw verstarb am 21. April 1879 im Diakonissenhaus in Halle an der Saale. Neben vielen historischen Publikationen erschien eine moderne Übersicht zu LoEw und seiner Publikationstätigkeit durch EvenHuIs (1997). Eine aktuelle Würdigung LoEws und seiner Sammlung ist auch in dem Beitrag von Ziegler (2010) zu finden. Außerdem ist eine ausführliche Biographie, Bibliographie und eine vollständige Liste der von Hermann Loew vergebenen Namen der Gattungs-Gruppe in Vorbereitung und schon weitgehend zusammengestellt (EvenHuis et al. in Vorbereitung).

LoEw beschrieb die enorme Zahl von 3708 DipterenArten und auch wenige andere Insekten. Viele davon stammen aus der Paläarktischen Region und ihr Typenmaterial befindet sich heute überwiegend in der Sammlung des Museums für Naturkunde in Berlin. Ähnlich wie bei anderen Zeitgenossen, ist die Etikettierung der gesammelten Insekten auch bei Loew mangelhaft oder sie fehlt sogar ganz. Daraus ergeben sich viele Probleme bei der wissenschaftlichen Bearbeitung insbesondere des Typenmaterials, die sich oft nur durch zeitintensive Recherchen und mit kriminalistisch anmutenden Methoden lösen lassen. LoEw war auch Forschungsreisender, konnte aber nur an einer großen Expedition teilnehmen, welche ihn in Begleitung des Geographen Kiepert und des Altertumsforschers und Philologen SCHÖNBORN in den Jahren 1841-1842 in das Osmanische Reich führte (heutige westliche Türkei und östliche griechische Inseln). Leider wurden die Ergebnisse dieser Reise nicht zusammenfassend publiziert und die Erschließung der verstreuten Informationen stellte einen besonders schwierigen Problemkomplex bei der Arbeit mit der Sammlung LoEws dar. Die von Loew publizierten Typenfundorte kann man meist nicht auf den modernen Karten Kleinasiens finden, da in den Jahren seit dieser Reise viele historische Ortsnamen in der Türkei umbenannt oder zumindest stark verändert wurden. Deshalb wird in der hier vorgelegten Arbeit versucht, diese Reise geographisch und zeitlich zu rekonstruieren. Auf diese Weise können die von LoEw in seinen Beschreibungen genannten Typenlokalitäten interpretiert und heutigen Ortsbezeichnungen zugeordnet werden. Da Loew während dieser Reise nicht nur Dipteren gesammelt hat, waren in gleicher Weise die loci typici für die beschriebenen Coleoptera, Lepidoptera, Hymenoptera und Mollusca zu klären. Nicht zuletzt wird beabsichtigt, die schwierigen Rahmenbedingungen einer solchen Expedition vor fast 180 Jahren in ihrem historischen Kontext sichtbar zu machen.

\section{Material und Methoden}

Da die Etikettierung des mitgebrachten zoologischen Materials ungenügend ist oder ganz fehlt und von Hermann Loew kein Reisetagebuch bekannt geworden ist, konnten als primäre Informationsquelle nur die publizierten Angaben in den Artbeschreibungen genutzt werden. Weitere Hinweise fanden sich in der erhalten gebliebenen Korrespondenz, in den Aufzeichnungen der Mitreisenden, sowie in den Publikationen Dritter über die an der Reise beteiligten Wissenschaftler.

\subsection{Publizierte Angaben über das während der Reise gesammelte zoologische Material}

Loew beschrieb zwei Coleopteren (Loew 1843d) und 218 Arten von Dipteren im Ergebnis seiner Reise, oft leider nur mit dem Fundort „Kleinasien“ und ohne Datum (Loew 1843-1873). Der Text zu den mitgebrachten 183 Arten Lepidopteren, einschließlich der 27 neu beschriebenen Arten, ist in den daraus hervorgegangenen Publikationen (Zeller 1846, 1847) etwas reicher mit Fundortangaben versehen. Diese Publikationen von 
Loew und ZelLer bilden die Basis der Informationen zu Sammelorten und Reiseverlauf. Die Angaben bei zwei beschriebenen Hymenopteren und einer Landschnecke (Gerstaecker 1869, Philippi 1844, Stein 1876) bringen hinsichtlich der Reiseroute keine weiteren Erkenntnisse.

\subsection{Persönliche Informationen aus der Hand der zeitweilig Mitreisenden}

Hermann LoEw begann die Reise im Jahr 1841 gemeinsam mit seinem Lehrerkollegen am Königlichen FriedrichWilhelms-Gymnasium in Posen, dem Philologen Julius August Schönborn (8. November $1801-1$. September 1857), und dem jungen Geographen Johann Samuel Heinrich KiePERT (31. Juli 1818 - 21. April 1899) von der Universität in Berlin. LOEw und SCHÖNBORN trennten sich aber wegen der unterschiedlichen wissenschaftlichen Interessen und Arbeitsweisen im weiteren Reiseverlauf mehrfach. KIEPERT gehörte nur bei der Anreise sowie im September 1841 zur Reisegruppe. Er führte detailliert Tagebuch. Vom Original sind aber nur wenige Seiten bruchstückhaft erhalten. Der ganz überwiegende Teil seiner Tagebuchaufzeichnungen ist offensichtlich verloren gegangen. Dazu schreibt ZöGner (1999): „Wie so viele andere Materialien hat der wissenschaftliche Nachlass Kieperts durch den Zweiten Weltkrieg große Verluste erlitten“. Weitgehend verlorengegangen ist auch das Reisetagebuch von Julius August SchönBorn. Es stand sowohl Heinrich Kiepert als auch Carl RitTer zur Verfügung und ist wahrscheinlich in Teilen schon im 19. Jahrhundert verschollen (STARKE 1884, BENNDORF \& NiEMANN 1889). Gegenwärtig konnten nur noch wenige Blätter der ScHÖNBORNschen Reiseaufzeichnungen im Nachlass von Heinrich KIEPERT in der Staatsbibliothek $\mathrm{zu}$ Berlin gefunden werden.

\section{3 Überlieferte Archivakten im Zusammenhang mit der Reise}

In den Archiven folgender Institutionen konnten Akten mit Bezug zu der Reise von Hermann Loew gefunden werden:

- Museum für Naturkunde, Leibniz-Institut für Evolutions- und Biodiversitätsforschung, Historische Arbeitsstelle. Berlin, Invalidenstraße 43.

- Geheimes Staatsarchiv, Preußischer Kulturbesitz. Berlin, Archivstraße 12-14.

- Staatsbibliothek zu Berlin, Preußischer Kulturbesitz, Handschriftenabteilung. Berlin, Unter den Linden 8.

Die Akten sind überwiegend durch Findbücher erschlossen, teilweise auch schon mittels digitaler Suche in Datenbanken zu finden. Im Einzelfall gestaltete sich die jahrelange Recherche aber durch viele vergebliche Versuche sehr zeitaufwendig. Eine detaillierte Aufstellung aller verwendeten Akten ist im Anhang unter „Archivalische
Quellen“ zu finden. Einige Schriftstücke werden auszugsweise im Text dieser Arbeit zitiert. Der Verweis auf die archivalischen Quellen erfolgt dabei durch den Vorsatz "Acta“ mit der nachfolgenden laufenden Nummer des Quellenverzeichnisses. Die Transkriptionen weiterer wichtiger Schriftstücke sind im Anhang den archivalischen Quellen direkt zugeordnet. Darüber hinaus wurden die Namen und Funktionen der handelnden Personen im Anhang dieser Arbeit in einem „Personenregister“ zusammengestellt.

\subsection{Transkription der Originaldokumente}

Die handschriftlich verfassten Dokumente in deutscher Kurrentschrift aus der Mitte des 19. Jahrhunderts sind für Ungeübte heute kaum mehr lesbar. Die Originale (Abschriften der Entwürfe) sind an die Adressaten gegangen. Bei den Absendern sind üblicherweise nur die handschriftlichen Konzepte (Entwürfe) für die Briefe in ihrer Urschrift verblieben und dort so archiviert worden. Diese Texte enthalten viele Abkürzungen und sind besonders schwer lesbar. Mitunter wurden die Schreiben im diplomatischen Schriftverkehr auch in (nicht immer perfektem) Französisch verfasst. Für die Verwendung als Quellen zum Reiseverlauf war daher zuvor eine vorlagengetreue Wiedergabe der deutschen Kurrentschrift in die heute genutzte lateinische Schrift nötig. Dabei wurden die Texte weitgehend in der „Urfassung“ beibehalten, einschließlich der ursprünglichen Orthographie und Zeichensetzung. Das Ergebnis, eine sogenannte „Diplomatische Transkription“, wurde als Arbeitsversion verwendet. Für den Abdruck solcher Texte wurden darüber hinaus weitere kleinere Veränderungen vorgenommen. So wurde der Geminationsstrich bei $m$ und $n$ in $\mathrm{mm}$ und nn aufgelöst. Aus Platzgründen wurden auch die Zeilenschaltung und die Seitenumbrüche nicht übernommen. Unsichere Textstellen sind im Druck durch spitze Klammern gekennzeichnet $<>$, Auslassungen durch [...]. Für das bessere Verständnis einer Textstelle wurden durch die Autoren in einigen Fällen in eckigen Klammern [] Zusätze oder Erläuterungen eingefügt.

\subsection{Publikationen von und über die Mitreisenden}

Loews Reisebegleiter, der Geograph Heinrich KIEPERT und der Philologe August SCHÖNBORN, sind nachfolgend recht bekannt geworden. Deshalb existieren zahlreiche Publikationen mit Beiträgen zu ihrer Person. KIEPERT verwendete die eigenen Reiseaufzeichnungen, ebenso wie die von SchönborN, zur Erstellung seiner Karten (KIEPERT 1843, 1844, 1890-92). Informationen aus den Tagebüchern beider Reisenden sind außerdem von RitTER in seine „Erdkunde von Asien“ eingearbeitet worden, teilweise mit direkten Zitaten (RITTER 1859). Biographische Angaben zu Kiepert hat PARTsCH (1901) 
zusammengestellt, einschließlich einiger Details zur Reise 1841-42. Dagegen legte eine Ausstellung in der Staatsbibliothek zu Berlin im Jahre 1999 den Schwerpunkt auf die späteren Reisen von Heinrich KIEPERT (ZÖgner 1999). DÉBARRE $(2016,2017)$ widmete sich dem deutschen Orientalismus im 19. Jahrhundert und speziell der Entstehungsgeschichte der zwischen 1830 und 1890 in Berlin publizierten Karten Kleinasiens. Ein Kapitel ist der Reise von Kiepert, Loew und Schönborn gewidmet. Die nur in der Buchausgabe von 2016 auf Seite 383 $\mathrm{zu}$ findende Abbildung mit der Reiseroute von Loew und SснÖNBORN ist sehr unvollständig und fehlerhaft.

Pinder \& Friedlaender (1851) berichten über die von SCHÖNBORN mitgebrachten Münzen und nennen deren Fundorte. Nicht alle Münzen wurden aber selbst gesammelt, auch aufgekaufte finden sich darunter. Die von SchönBorN und LoEw kopierten griechischen Inschriften wurden von BöckH \& FrANZ (1853) in Band 3, Teile 22-24, mit ihren Fundorten veröffentlicht. Weiterhin hat ScHMIDT 1868 auch die von ScHÖNBORN und Loew mitgebrachten lykischen Inschriften publiziert. Zwar enthalten diese drei letztgenannten Quellen diverse Fundorte, aber keine Daten, die eine zeitliche Einordnung ermöglichen würden. Die biographischen Beiträge von Carl SchöNBoRN $(1858,1868)$ über seinen Bruder August sind für das Verständnis des Reiseablaufs aufschlussreicher. Vom Zusammentreffen Loews und Schönborns mit den englischen Reisenden Thomas SPRATT und Edward Forbes auf Rhodus berichten letztere in ihrem zweibändigen Reisebericht (SPRATT \& ForbEs 1847).

Julius August SCHÖNBORN selbst publizierte 1843 und 1849 zwei Artikel, in die Erkenntnisse aus seiner Reise eingeflossen sind, sowie das 1858 posthum erschienene Buch „Die Skene der Hellenen“ mit einem aufschlussreichen Vorwort seines Bruders Carl. Außerdem teilte er FALKENER eine Beschreibung des Heroons mit, welcher diese in seiner Zeitschrift „The Museum of Classical Antiquities"veröffentlichte (SCHÖNBORN 1851). Ein ähnlicher Text findet sich auch bei RitTer 1859 (vergl. BENNDORF \& Niemann 1889). In seinen weiteren Publikationen, die unter anderem auch Latein-Lehrbücher umfassten, verwandte SchönBoRN neben der Vornamen-Kombination Julius August teilweise auch nur den Vornamen August oder auch August S. SchÖNBORN (SCHÖNBORN $1835,1854)$.

Das sogenannte „Heroon von Trysa“, SchöNBORN nannte den Fundort „Gjölbaghtsche“, ist eine 2400 Jahre alte ganz außergewöhnliche Grabanlage mit figurengeschmückten Friesen, die von ihm entdeckt und später von BENNDORF wieder aufgefunden und 1882 in das Kunsthistorische Museum in Wien gebracht wurde. Dieses besondere Bauwerk war seitdem Gegenstand vieler Publikationen. Das Buch von Benndorf \& Niemann (1889) würdigt ausführlich SсHÖNBORN als Person sowie seine Entdeckungen während der Reisen und nutzt zahlreiches Archivmaterial, welches im Original inzwischen nicht mehr vollständig überliefert ist. Die Beschäftigung mit diesem Fund wurde unter anderem mit den Publikationen von Eichler (1950), OBERleitner (1994), Marksteiner (2002), Szemethy (2005) und LANDSKRon (2016) fortgesetzt und kulminiert wohl in der für 2022 geplanten erstmaligen Ausstellung des gesamten Bauwerkes mit 150 Friesplatten in Wien.

\subsection{Verwendung geographischer Begriffe}

Im folgenden Text spiegeln sich die Gegebenheiten im 19. Jahrhundert wider. Deshalb werden Ortsnamen und topographischen Begriffe, wie in den historischen Schriften, in der überwiegend gebrauchten Form verwendet. Bei wichtigen Orten folgt in Klammern der heute verwendete Name. Darüber hinaus sind alle historischen topographischen Namen und Ortsbezeichnungen mit ihren verschiedenen Schreibweisen und ihren modernen Entsprechungen einschließlich der Lagebeschreibung und der Koordinaten in den Tabellen 1 bis 3 genannt und als Karten in den Abbildungen 4 und 9 dargestellt. Die auf diesen Karten dargestellten Fundorte werden auch im nachfolgenden Text mit ihrer Nummerierung genannt (getrennt für die Jahre 1841 und 1842). Die Nummern stehen direkt hinter dem jeweiligen Ortsnamen und sind durch den Vorsatz des Sonderzeichens • gekennzeichnet $(\bullet 1)$ bis $(\bullet 45)$.

LOEW und ScHÖNBORN verwendeten generell den Begriff Kleinasien im Zusammenhang mit ihrem Reiseziel und wir haben es so belassen. Nach heutiger Terminologie bezieht sich der Begriff Kleinasien aber nur auf das Anatolische Festland, nicht auf den europäischen Teil des damaligen Osmanischen Reiches einschließlich der Altstadt von Constantinopel und nicht auf die Inseln Rhodus, Stanchio, Leros, Chios und Syra, die von Loew besucht wurden. Die Insel Syra gehörte zur Zeit der Reise auch nicht zum Osmanischen Reich sondern zu Griechenland.

\section{Der rekonstruierte Reiseverlauf}

\subsection{Vorbereitung und Anreise bis Constantinopel}

Die Reise von Hermann Loww in das Osmanische Reich geht auf die Initiative seines Posener Lehrerkollegen Julius August SchÖNBORN zurück (BENNDORF \& Niemann 1889; Schönborn, C. 1868; Starke 1884). Der Philologe SchönBorn bereitete diese Reise seit Jahren vor und arbeitete einen Plan zur geographischen Erforschung von Pisidien, Pamphylien und Lykien aus. Am 15. Februar 1841 reichte er diesen Plan ein und beantragte bei dem Provinzial-Schul-Collegium in Posen 
und dem Kultusministerium in Berlin Urlaub von den Dienstverpflichtungen für den Zeitraum vom 1. August 1841 bis zum 1. April 1842 (Acta 3). Er bat bei seinem Dienstherrn um eine sehr mäßige Reiseunterstützung von 300 Talern. In seinem Gutachten zum Antrag von Schönborn verdoppelte Carl Ritter, Professor für Erdkunde in Berlin, diesen Betrag (Acta 4, 6, 24). RitTeR vermittelte außerdem die Teilnahme des sehr jungen Geographen Heinrich KIEPERT an dieser für die damalige Zeit sehr besonderen Reise. Am 23. Mai wurde SchÖNBORns Antrag auf Urlaub und ein Reisezuschuß von 600 Talern durch den König genehmigt (Acta 8). Das Kultusministerium bewilligte daraufhin jedoch nur eine auf 500 Taler begrenzte Reiseunterstützung (Acta 24).

Der von ScHöNBORN gewählte Zeitrahmen für das Vorhaben überrascht aus heutiger Sicht. Für ihn und den dazugekommenen KIEPERT, die sich beide vor allem die geographische Erkundung des gebirgigen Landes abseits der bekannten Verkehrswege zum Ziel gesetzt hatten, dürften einsame Wanderungen in winterlich verschneiten Gebirgen weit entfernt von optimalen Voraussetzungen bei der Vermessung der Region sein. Für Loew stellt sich die Situation noch ungünstiger dar. Bei der langen An- und Abreise waren entomologische Forschungen bei diesem Zeitplan nur noch im Herbst und Winter möglich.

SchöNBORN konnte seinen späteren Schwager, den Naturwissenschaftler Hermann LoEw, wohl auch erst recht spät als Reisegefährten gewinnen. LoEw stellte mit einiger Verzögerung am 26. April 1841 bei dem Provinzial-Schul-Collegium in Posen den Antrag auf Urlaub zur Begleitung von ScHÖNBORN auf seiner geplanten Reise und sicherte dem Collegium in diesem Zusammenhang die private Übernahme von Kosten für seine Urlaubsvertretung $\mathrm{zu}$ (Acta 5). Die Schulleitung unterstützte Loews Antrag jedoch nicht, da sie der Ansicht war, dass der Ausfall von zwei Lehrern zu große Probleme bereiten würde (Acta 7, 9). Befürwortung für seinen Antrag erhielt Loew von dem Naturwissenschaftler und Universitätsprofessor Friedrich KLUG in Berlin (Acta 10). Trotzdem drohte die Ablehnung seiner Reise. Deshalb entschloss sich LoEw am 6. Juni mit einem direkten Schreiben an das Kultusministerium seinen Antrag auf Urlaub weitergehend $\mathrm{zu}$ begründen. Er führte dafür vor allem gesundheitlichen Probleme an und fügte zwei medizinische Gutachten bei (Acta 11). Nach dem daraufhin erfolgten Schreiben des Kultusministers vom 24. Juni an das Provincial Schul-Colloquium Posen (Acta 12) und der Antwort dieses Gremiums vom 12. Juli 1941 an den Minister (Acta 13) waren die Widerstände gegen Loews Reise beseitigt.

Schon wenige Tage später war LoEw, zuerst wohl inoffiziell, von der bevorstehenden Genehmigung seiner Reise informiert. Durch die Kurzfristigkeit seiner Reisevorbereitungen hatte er mit diversen organisatorischen
Problemen zu kämpfen. In einem Brief vom 18. Juli 1841 schreibt Loww (unter der Angabe der Adresse seines Vaters in Magdeburg) an Wilhelm Ferdinand ERICHsoN (1809-1848), Spezialist für Käfer (Coleoptera) und Kustos im Berliner Museum, und bittet ihn um Unterstützung (Acta 1). Als erstes bittet er den befreundeten ERICHSON darum, ihm während seiner Abwesenheit bei der technischen Fertigstellung seiner zuvor eingereichten dipterologischen Publikationen behilflich zu sein. Interessant ist dabei auch, dass Heinrich KIEPERT „Candidat Kiepert (Heilige Geist Str. No II.)“ ihn dabei unterstützte und für Loew in diesen Tagen den Abschluss von Unterhandlungen über die Ausführung von Lithographien übernommen hat. LoEw bittet ERICHSON „Gewiß haben Sie die Güte, die Probedrücke nebst den Originalzeichnungen von denselben [KIEPERT] anzunehmen, erstere nöthigen Falls zu korrigiren ed eventuell durch eine kurze schriftliche Notiz zu approbiren, letztere aber für mich aufzubewahren“. Dann kommt er zu seinem brennendsten Problem: „Noch bin ich mit meiner Litanei nicht ganz zu Ende; der schlimmste Fall kömmt erst noch. Es wird nämlich das von mir zur Reise bestellte Mikroskop nicht mehr zur rechten Zeit fertig. Das von mir bisher benutzte war nicht mein Eigenthum und ist nicht disponibel. Ich bin daher in die Nothwendigkeit versetzt in Wien ein Plösselsches [Firma Plössl, Wien], wenn anders eines vorräthig ist, zu kaufen ed mit jeder Qualität ed jedem beliebten Preise zufrieden zu sein, da mir das Instrument absolut unentbehrlich ist. Viel lieber hätte ich ein Schicksches [Firma Pistor \& Schick, Berlin], an dessen Gebrauch ich gewöhnt bin. Auf starke Vergrößerungen würde es mir wenig ankommen, wenn die bis 100 (Linear) untadelhaft sind. Vielleicht ist in Berlin eines entbehrlich ed verkäuflich. Sie würden mich durch die Vermittelung eines solchen Ankaufes auf das äußerste verpflichten“. Er schließt den Brief wie folgt: „Haben Sie mir wegen des Insektenfanges und namentlich des Insektentransportes noch besondere Anweisungen $\mathrm{zu}$ geben so bitte ich dringend sie mir vor dem 28. Aug. hierher, oder bis zu derselben Zeit an Oberlehrer Schönborn, (jetzt in Berlin, Rosenstraße No 1 - 2 Treppen) gelangen zu lassen“. Aus diesen Zeilen ist auch ersichtlich, dass sich SchÖNBORN zu dieser Zeit bereits in Berlin aufhielt.

Am 26. Juli teilt der Kultusminister EICHHORN der Posener Schulverwaltung (Acta 14) und am 28. Juli auch LoEw selbst (Acta 15) die Genehmigung mit, wenn auch ohne eine zusätzliche Reiseunterstützung und überaus knapp vor der geplanten Abreise. Das Schreiben erreichte LoEw im Hause seines Vaters in Magdeburg. Dort, in der Obhut seiner Eltern und nicht in der unruhigen Provinz Posen, hatte er auch seine Familie für die Zeit seiner Reise untergebracht. LoEw reagierte in seinem Antwortbrief an das Kultusministerium vom 30. Juli überglücklich mit den Zeilen: „Ew. Excellenz Den allerunterthänigsten, aber auch innigsten und wärmsten Dank für die hochgeneigte Gewährung des gehorsamst erbetenen Urlaubes und Gehaltsvorschusses sagend, darf ich zu gleicher Zeit 
nicht verfehlen pflichtschuldigst anzuzeigen, dass ich die beabsichtigte Reise nach Kleinasien in Gemeinschaft mit dem Oberlehrer Schönborn so eben anzutreten im Begriff stehe“ (Acta 16, 56; Abbildung 1).

In Berlin fand sich ein weiterer prominenter Unterstützer des Vorhabens in dem Generaldirektor der Königlichen Museen, Ignaz v. OlfERs. Schönborn suchte ihn Ende Juli auf. Offensichtlich war es zu diesem Zeitpunkt bereits bekannt, dass die Reise so wie geplant stattfinden kann. Denn zeitgleich mit der durch das Kultusministerium gegenüber der Schulverwaltung in Posen ausgesprochenen Urlaubsgenehmigung für Loew (Acta 14) ist in den Archiven ein mit dem 26. Juli 1841 datiertes Unterstützungsschreiben von v. OlFERS an den preußischen Außenminister v. WerTHER erhalten (Acta 27, Abbildung 2). Der erste Teil des Briefes lautet: „Drei junge Gelehrte, die Herrn Kiepert, Schönborn und Löw haben sich vereinigt, um theils auf eigene Kosten, theils mit Unterstützung mehrerer Regierungen eine Reise in den weniger besuchten Gegenden des Orients zu machen, von welcher mit allem Grunde die herrlichsten Ergeb-

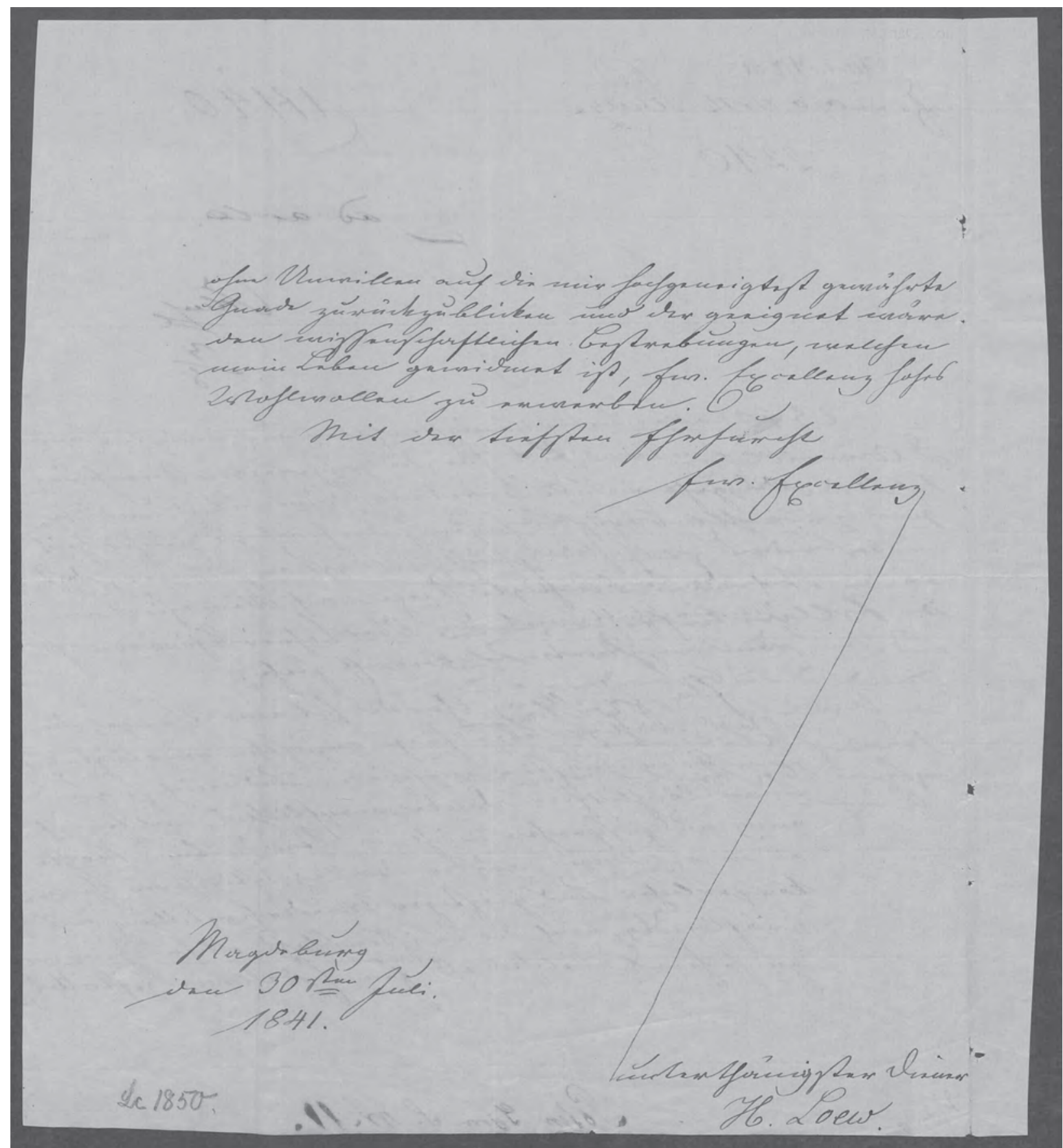

Abb. 1: Faksimile eines Briefs vom 30. Juli 1841 von Hermann Loew in Magdeburg an den Kultusminister Johann Albrecht Friedrich EICHHORN in Berlin (Acta 56, Seite 2 von 2).

[Fig. 1: Facsimile of a letter dated 30 July1841 from Hermann Loew in Magdeburg to the Minister of Education Johann Albrecht Friedrich EICHHORN in Berlin (acta 56, page 2 of 2).] 


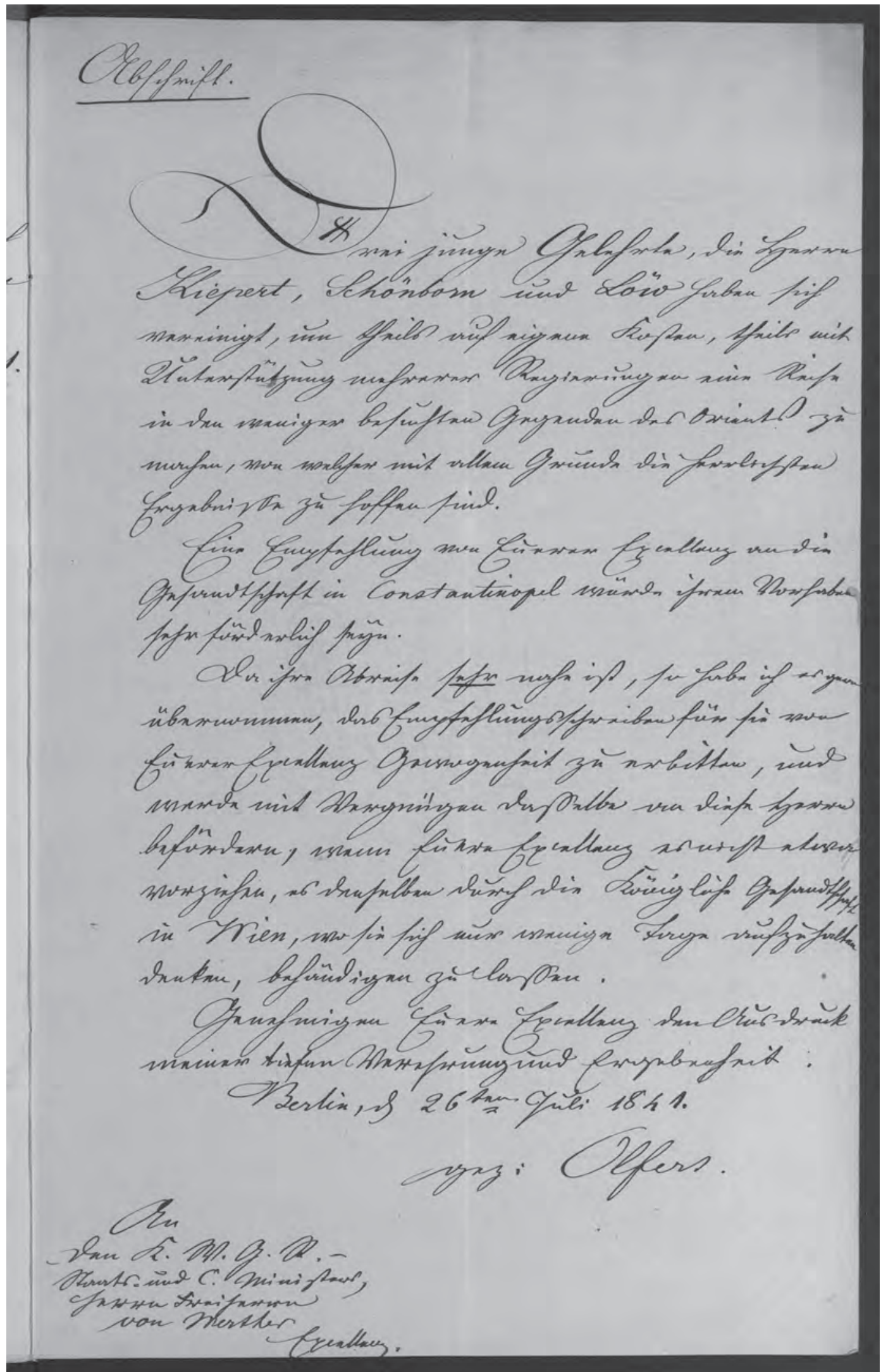

Abb. 2: Faksimile der Abschrift eines Briefs vom 26. Juli 1841 vom Generaldirektor der königlichen Museen in Berlin, Ignaz v. Olfers, an den Außenminister Heinrich Wilhelm v. Werther in Berlin (Acta 27).

[Fig. 2: Facsimile of a copy of a letter dated 26 July 1841 by the Director General of the Royal Museums in Berlin, Ignaz v. Olfers, to the Foreign Minister Heinrich Wilhelm v. Werther in Berlin (acta 27).] 


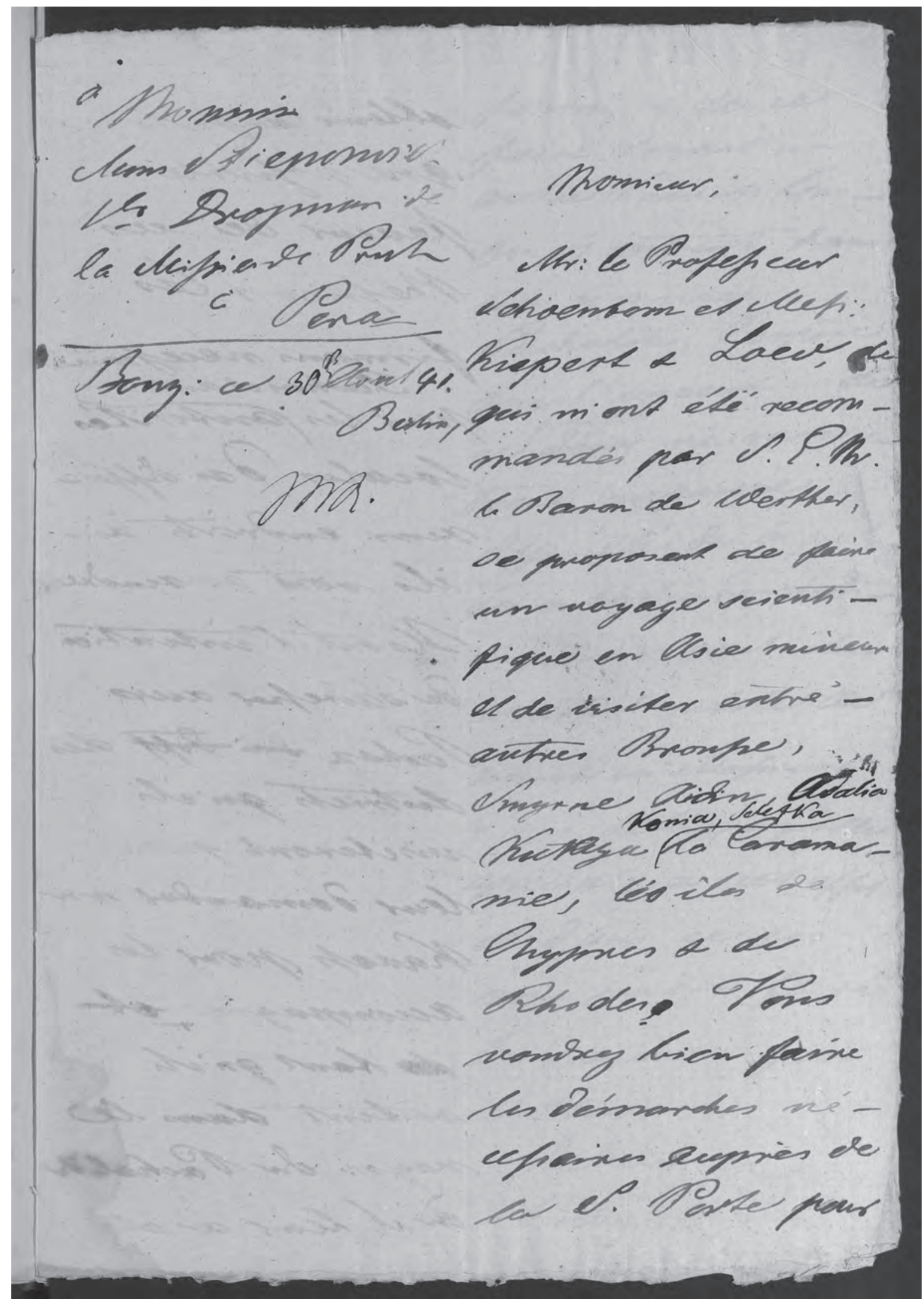

Abb. 3: Faksimile einer Vorlage für einen Brief vom 30. August 1841 vom preußischen Gesandten Graf v. KöNIGSMARCK an den Ersten Drogman der Gesandtschaft zu Constantinopel, Stiepovich (Acta 30, Seite 1, in Französisch).

[Fig. 3: Facsimile of a template for a letter dated 30 August 1841 from the Prussian Ambassador Count v. KöNigsmarCK to the First Drogman of the Embassy to Constantinople, Stiepovich (acta 30, page 1, in French).] 
nisse $\mathrm{zu}$ hoffen sind. Eine Empfehlung von Euerer Excellenz an die Gesandtschaft in Constantinopel würde ihrem Vorhaben sehr förderlich seÿn“. Bereits am 28. Juli veranlasste v. Werther die Ausfertigung von Reisepässen für die drei Reisenden (Acta 53). Am gleichen Tag leitete er das Schreiben von v. OlfERs mit eigener Note an den Gesandten Preußens bei der Hohen Pforte in Constantinopel, Graf v. KöNIGsmarcK, weiter (Acta 28). Dieser beauftragte daraufhin am 30. August 1841 den Dragoman Stiepovich (Acta 30, Abbildung 3) und am 5. September die Herren Maeulen (Konsularbeamter in Brussa), Pezzer (Konsul in Smyrna) und Matthei (Konsul auf Zypern) (Acta 31) mit der Unterstützung der Reisenden. Von diesen Schreiben sind, wie damals üblich, nur die handschriftlichen Konzepte (Entwürfe) in ihrer Urschrift archiviert worden. Diese Vorlagen enthalten viele Abkürzungen und sind besonders schwierig $\mathrm{zu}$ lesen. Die Abschriften davon, dann mit ausgeführtem Formelapparat (den ausgeschriebenen Grußformeln, Titeln und Abkürzungen), sind als Originalbriefe an die Adressaten gegangen.
Für den gerade 34jährigen Loew begann die Reise in Magdeburg, während der 40jährige ScHÖNBORN sich schon länger in Berlin aufhielt und von dort über Dresden und Prag nach Wien abreiste, wo alsbald auch KIEPERT eintraf. Letzterer beging wenige Tage zuvor seinen 23. Geburtstag (PARTsCH 1901). Eventuell reisten die drei auch gemeinsam von Berlin nach Wien, doch das ist nicht überliefert. Auf ihrem weiten Weg mussten sie wohl mit der Pferdekutsche vorliebnehmen. Die ersten Eisenbahnlinien wurden in Deutschland zwar ab 1835 in Betrieb genommen, allerdings waren längere Strecken mit Personenverkehr, welche LoEw und Gefährten vielleicht hätten nutzen können, im Jahre 1841 erst im Bau. Nach einigen Besorgungen und Reisevorbereitungen in Wien bestiegen sie am 14. August $1841 \mathrm{zu}$ dritt ein Schiff der „Oesterreichischen Donau-Dampfschiffahrts-Gesellschaft", dass sie flussabwärts in das Osmanische Reich brachte. Nach langer Fahrt erreichten sie Küstendye, eine Hafenstadt am Schwarzen Meer (heute Constanţa in Rumänien). Von dort ging die Reise über See weiter

Tabelle 1: Zusammenstellung der Ortsbezeichnungen auf der Reiseroute 1841 (Nummerierung wie in Abbildung 4).

[Table 1: Compilation of the place names on the 1841 expedition route (numbering as in Figure 4).]

\begin{tabular}{|c|c|c|}
\hline Nummer & Im Text benutzte historische Bezeichnung & $\begin{array}{l}\text { Moderne Ortsbezeichnung (wie in Tab. 3) } \\
\text { Antike Siedlungsplätze in Kapitälchen. }\end{array}$ \\
\hline 01 & Bujukdere & Büyükdere \\
\hline 02 & Constantinopel, Pera & İstanbul-Stadt, İstanbul-Beyoğlu \\
\hline 03 & Gemlik & Gemlik \\
\hline 04 & Brussa & Bursa \\
\hline 05 & Olympus & Uludağ (Gebirge) \\
\hline 06 & Adirnas, Serdschilar & Orhaneli, Serçeler \\
\hline 07 & Bolat & Dursunbey \\
\hline 08 & Bohadsch, Kysarköi (Hisarköi) & Bigadiç, Hisarköy \\
\hline 09 & Balikesri (Balukhissar) & Balıkesir \\
\hline 10 & Kiresun & Savaştepe \\
\hline 11 & Soma & Soma \\
\hline 12 & Pergamon & PERGaMon \\
\hline 13 & Manisa & Manisa \\
\hline 14 & Smyrna & İzmir \\
\hline 15 & Tokboi & Torbalı \\
\hline 16 & Tireh, (Eski) Bain Dir & Tire, Bayındır \\
\hline 17 & Birkeh & Birgi \\
\hline 18 & Baliambo, Messogis & Beydağ, Aydın Dağları (Gebirge) \\
\hline 19 & Nosli, Mäandertal & Nazilli, Büyük Menderes-Tal \\
\hline 20 & Laodikeia, Denislü & LAODIKEIA, Denizli \\
\hline 21 & Tefenü & Tefenni \\
\hline 22 & Istenas & Korkuteli \\
\hline 23 & Kestel Göl, Padam Aghatsch & Kestel Gölü, Bademağacı \\
\hline
\end{tabular}




\begin{tabular}{|c|c|c|}
\hline Nummer & Im Text benutzte historische Bezeichnung & $\begin{array}{l}\text { Moderne Ortsbezeichnung (wie in Tab. 3). } \\
\text { Antike Siedlungsplätze in Kapitälchen. }\end{array}$ \\
\hline 24 & Adalia (Attalia) & Antalya \\
\hline 25 & Almalü & Elmali \\
\hline 26 & Arycanda & ARYCANDA \\
\hline 27 & Phinika, Limyra, Gagai & Finike, Limyra, Yeniceköy \\
\hline 28 & Phaselis & Phaselis \\
\hline 29 & Olympus, Jannartagh, Promontorium sacrum & Olympus, Yanartaş, Gelidonya Burnu \\
\hline 30 & Demre, Andriake, Myra, Gjölbaghtsche & Demre, ANDriake, Myra, Trysa \\
\hline 31 & Kassaba, Ernez & Kasaba, ARNEAI \\
\hline 32 & Antiphellus & ANTIPHELlOS \\
\hline 33 & Xanthus & Xanthos \\
\hline 34 & Makri, Sidyma, Pinara & Fethiye, Sidyma, Pinara \\
\hline 35 & Rhodus & Insel Rhodos \\
\hline 36 & Indus & Dalaman Çayı (Fluss) \\
\hline 37 & Kaunos & KaUnOS \\
\hline 38 & Kadyanda & KADYANDA \\
\hline 39 & Bubon & Boubon \\
\hline 40 & Kestros, Perge & Aksu Çayı (Fluss), PERGE \\
\hline 41 & Milyas, Kysylly, Baulo & MiLYOS, Kızıl1, AdADA \\
\hline 42 & Eghirdir & Eğirdir \\
\hline 43 & Badamli & Yenışarbademli \\
\hline 44 & Eurymedon, Selge & Köprüçay (Fluss), Selge \\
\hline 45 & Aspendus & ASPENDOS \\
\hline
\end{tabular}

in die beeindruckend große Hauptstadt Constantinopel (İstanbul), die sie nach fast zwei Wochen am 27. August 1841 erreichten (Schönborn, C. 1868). Zu diesem Zeitpunkt lebten dort mehr als 600.000 Einwohnern, fast doppelt so viele wie im damaligen Berlin (Turan, NusSER \& MAYER 2008).

Neben weiteren Reisevorbereitungen nutzte LoEw den dortigen Aufenthalt, um im nahen Bujukdere $(\bullet 1)$, in Constantinopel $(\bullet 2)$ und in Pera $(\bullet 2)$ Insekten $\mathrm{zu}$ sammeln (Karte in Abbildung 4). So meldet ZELLER (1847), der Loews lepidopterologische Ausbeute bearbeitete, von dort zahlreiche Nachweise und beschreibt die Geometride Boarmia correptaria ZelLer, 1847 als neue Art aus Pera. Gleich in den ersten Tagen seines Aufenthaltes, noch im August, sammelte Loew bereits bei Bujukdere $(\bullet 1)$ die Lauxaniidae Sapromyza biseriata Loew 1847 (jetzt Gattung Minettia), wie die Beschreibung der Art verrät: „Bujukdere bei Constantinopel im August“ (LoEw 1847g). Er bringt so umfangreiches Material zusammen, dass er von den Fundorten Bujukdere $(\bullet 1)$ und Constantinopel $(\bullet 2)$ später insgesamt neun neue Dipteren-Arten beschreiben kann. Darunter sind auch die Dolichopodidae Psilopus flavicinctus LoEw, 1857 (=Sciapus) von Constantinopel (LoEw 1857a) und die Tachinidae Ocyptera pilipes Loew, 1844 (= Cylindromyia) sowie die Ephydridae Psilopa nana Loew, 1860 aus Bujukdere (Loew 1844e, 1860). Daraus lässt sich ableiten, dass LoEw an vielen Tagen seines Aufenthaltes die Möglichkeit gehabt hat, in der Umgebung von Constantinopel intensiv entomologisch $\mathrm{zu}$ arbeiten. Am 9. September, einen Tag vor der Abreise aus Pera $(\bullet 2)$, bedankte sich SCHÖNBORN in einem Brief bei dem Grafen v. KöNigsmarck für die Unterstützung der drei Wissenschaftler durch die Gesandtschaft (Acta 32). Bei dieser Gelegenheit verwahrt er sich, sehr vorsichtig und diplomatisch, auch gegen den Versuch, den Reisenden zusätzliche sachfremde Aufträge zu erteilen, nämlich „die Handelsverhältnisse in Kleinasien $\mathrm{zu}$ erforschen“. Auch entschuldigt er sich bei dem Gesandten, wegen der nicht erfolgten nochmaligen „Aufwartung“ mit übermäßiger Beanspruchung durch die Reisevorbereitungen: „Ew. Excellenz haben die Gewogenheit gehabt sich meiner Reisegefährten und meiner so gnädigst rücksichtlich unserer Reise nach Kleinasien anzunehmen, daß wir um die Ehre Ew. Excellenz nochmals persönlich aufwarten und unsren ergebensten Dank mündlich aussprechen $\mathrm{zu}$ dürfen sicherlich würden angehalten haben, wenn uns nicht die manchfaltigen Ankäufe und Besorgungen, die uns 


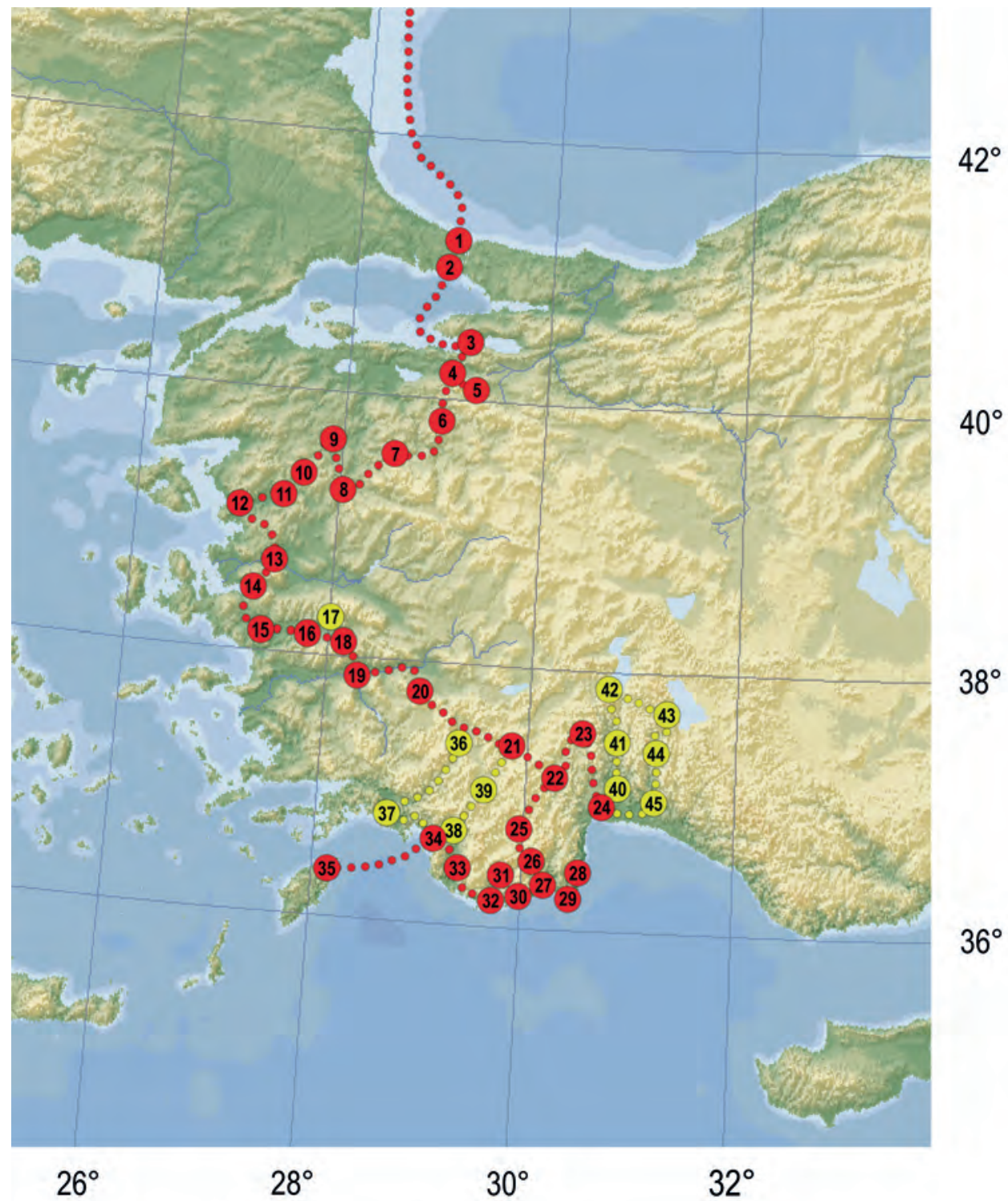

Abb. 4: Die Reiseroute im Jahr 1841. Die roten Punkte markieren den Reiseweg von Loew bzw. Loew und Kollegen. Die gelben Punkte kennzeichnen zusätzliche Routen, die SснӧмвоRN allein unternommen hat. Die Nummern und Namen der durch Punkte dargestellten Orte sind in Tabelle 1 zusammengestellt. Im Text werden die auf den Karten dargestellten Fundorte mit ihren Nummern genannt und durch den Vorsatz des Sonderzeichens • direkt hinter dem Ortsnamen gekennzeichnet, $(\bullet 1)$ bis $(\bullet 45)$.

[Fig. 4: The travel route in 1841. The red dots mark the travel route of Loew or Loew and colleagues. The yellow dots indicate additional routes that SснӧnвoRn had undertaken alone. The numbers and names of the locations represented by dots are shown in Table 1. In the text, the localities shown on the maps are named with their numbers and identified by the prefix of the special character $\bullet$ directly after the place name $(\bullet 1)$ to $(\bullet 45)$.]

für unsere wissenschaftlichen Untersuchungen nöthig schienen, so anhaltend in Constantinopel festgehalten hätten, daß wir selbst auf jede Tour in die Umgebungen haben verzichten müssen und uns bis zu dieser Stunde dennoch mancherlei zu besorgen obliegt“. Wie an den oben genannten entomologischen Ergebnissen abzu- lesen ist, trifft diese Bemerkung, zumindest auf Loew, nicht zu. Möglicherweise diente diese Darstellung auch nur als Vorwand, um nicht in einem zweiten Gespräch durch die Gesandtschaft wieder unerwünschte Aufträge zu erhalten. 


\subsection{Von Constantinopel quer durch das Land bis Adalia und Rhodus (Spätsommer und Herbst 1841)}

Am 10. September setzten Kiepert, Loew und SchöNBORN von Constantinopel $(\bullet 2)$ mit einem Dampfschiff nach Gemlik (•3) über (РARTsCH 1901). Von dort ging es zuerst auf der Landstraße in die nahe gelegene Stadt Brussa $(\bullet 4)$ (Abbildung 4). Hier und im benachbarten OlympusGebirge $(\bullet 5)$ hielt sich die Gruppe relativ lange auf und reiste erst am 19. September weiter. LoEw sammelte im Gebiet um Brussa zahlreiche Insekten. Zum Fundort der Asilide Heteropogon succinctus Loew, 1847 vermerkt er: „die Gegend von Brusa, wo ich sie im Hochsommer auf dem Olympus fing“ (Loew 1847d). Aus dem im weiteren Umkreis der Stadt gesammelten Dipteren-Material beschreibt LoEw noch vier Arten, darunter Conops brevicornis Loew, 1847 (jetzt Gattung Brachyceraea) (LoEw 1847f). Der Holotypus von Conops brevicornis trägt das Etikett „Brusa / 8/42 A. m“ (vergl. Abbildung 13:9 auf Seite 255 sowie Stuke \& ZIEgler 2019). Mit „A. m“ ist wahrscheinlich „Asia minor" gemeint, während man die Zahlen als „August 1842“ interpretieren könnte. Aber entweder bedeuten sie etwas Anderes oder sie sind ein Fehler Loews, da das Tier nur zwischen dem 10. und 19. September 1841 gefangen worden sein kann. Weiterhin sind auch die erstmals beschriebenen Lepidopteren Lithosia costalis ZELLER, 1847 und Sericoris artemisiana ZELLER, 1847 von LoEw bei Brussa gefunden worden (ZELLER 1847).

Am 19. September brachen die Reisenden in Brussa zu einem zwölftägigen Ritt auf, der sie quer durch das Land über Adirnas $(\bullet 6)(19$. September) und Serdschilar $(\bullet 6)$, Bolat $(\bullet 7)$ (22. September), Bohadsch und Kysarköi $(\bullet 8)$, Balikesri $(\bullet 9)$, Kiresun $(\bullet 10)$, Soma $(\bullet 11)$, Pergamon $(\bullet 12)$ und Manisa $(\bullet 13)(29$. September) nach Smyrna (İzmir) $(\bullet 14)$ führte, das am 30. September 1841 erreicht wurde (Acta 54, 57; SCHÖNBORN, C. 1868; PARTSCH 1901; RITTER 1859). Viel Zeit zum Sammeln von Insekten blieb LoEw dabei wohl nicht. Allerdings hat er von Adirnas die Lepidopteren-Art Cosmopteryx argyrogrammos ZELLER, 1847 mitgebracht (Zeller 1847) und aus dem Material von Bohadsch beschrieb er die Stilettfliege Thereva didyma Loew, 1847 (=T. spinulosa) und die Bremse Tabanus unifasciatus Loew, 1859 (Loew 1847b, 1859a). Für diesen Reiseabschnitt sind auch einige wenige Blätter des Reisetagebuches von KIEPERT erhalten geblieben (Acta 54, Abbildung 5). Die in das Tagebuch eingefügten Skizzen deuten das zeichnerische Talent KIEPERTs an und illustrieren den locker geschriebenen und doch inhaltsreichen Text, der auch sehr persönliche Eindrücke enthält. In Abbildung 5a sind die von den Einheimischen erfragten Entfernungsangaben mit denen aus der Literatur und eigenen Erfahrungen kombiniert. Daraus wird deutlich, wie KIEPERT das Datenmaterial für seine späteren Karten sammelte. Während der gemeinsamen Reisetage von Constantinopel bis Smyrna hatte er sich mit SснÖNвORN allabendlich über die Führung seines Itinerars [Verzeichnis der Wegeaufnahmen bei Forschungsreisen] ausgetauscht. SсHÖNBORN hat dann während seiner Reise ein Tagebuch nach solchen Grundsätzen geführt und die Daten anschließend KIEPERT uneigennützig zur Vervollkommnung seiner Karten zur Verfügung gestellt (KIEPERT 1844). Später konnte auch RitTER die Schönbornschen Aufzeichnungen für den zweiten Teil des Bandes „Klein Asien“ im Rahmen seiner „Erdkunde von Asien“ verwenden (RITTER 1859).

Bei Durchsicht der verbliebenen Reiseaufzeichnungen KIEPERTs wird deutlich, wie groß der Verlust ist, der durch das Fehlen des ganz überwiegenden Teils seines lebhaften Itinerars hervorgerufen wird (Acta 54). So beschreibt ein Tagebuchtext KiEPERTs den Aufbruch der Reisenden am Morgen des 19. September aus der großen Stadt Brussa $(\bullet 4)$, die damals etwa 60.000-100.000 Einwohner hatte (STEwig 1970). Diese Darstellung ist wahrscheinlich für die folgenden Abschnitte der gemeinsamen Reise und für die Art der Landeserkundung typisch: „Sonntag, 19 Sept. Nach der für das erstemal besonders schwierigen Anordnung des Gepäcks nahmen wir von unsern Landsleuten, ihnen eine ebenso glückliche Reise als wir selbst zu haben hofften, wünschend und vom Consul Abschied, sowie von unserem Wirth, der seine italienische Natur nicht verleugnend uns noch prellen und die auf dem Gebirge [auf dem Olympus bei Brussa] zugebrachten Tage mitbezahlen lassen wollte, sich aber doch mit 2 Dritteln seiner Forderung zufrieden gab und uns obendrein gratis den Schutz aller möglichen Heiligen empfahl. Um $71 \frac{12}{2}$ Uhr verließen wir die Locanda, um möglichst noch vor der Nacht Adranas zu erreichen, das 10 St entfernt sein sollte, mit 7 Pferden, davon jeder von uns und der Dragoman eins, das 5te der Suridschi [Pferdekecht] ritt, die beiden Packpferde waren eins mit dem nöthigsten Gepäck in den beiden großen türkischen Ledersäcken (zusammen wohl 2 Centner Last) und allerhand Kleinigkeiten obendrein, das andre mit Loews Naturalien Kisten beladen und eins an das andere, und das vordere an das Pferd des Suridschi Schwanz mit dem Halfterstrick angebunden, eine ziemlich unsichere Mode, wobei das Gepäck öfters litt und manche störende Fälle sich ereigneten“. Wie aus einem Schreiben Loews an v. OlfERs vom 26. März 1842 hervorgeht (Acta 50), haben sich die Reisenden für ihre Expedition auch bewaffnet: „Wir sahen uns so genöthigt, Pferde, Waffen, Reisegeräth u. s. w. [vor der erwarteten Rückreise] zu verkaufen, einzupacken u alles zu schleunigster Abreise vorzubereiten“.

Sehr ausführlich geht KIEPERT an anderer Stelle auch auf die landestypische Küche ein. In einem weiteren Text wird lebhaft beschrieben, wie die Reisenden in den besuchten Ortschaften aufgenommen wurden (Acta 54). Nur in bedeutenderen Orten gab es ein Herbergshaus, ein Konak. In den kleinen Dörfern wurde üblicherweise eine Gaststube, die für die Übernachtung von Reisenden vorgesehen war, zur Verfügung gestellt. Kaum ange- 


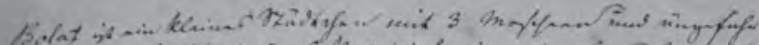

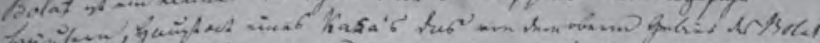

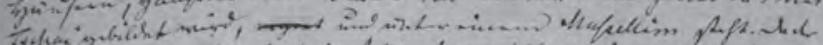

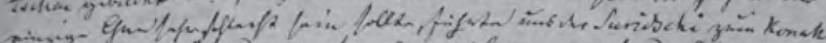

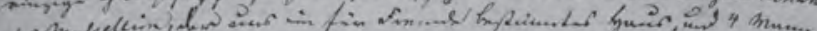

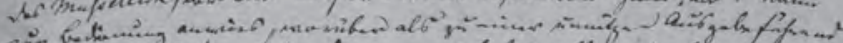

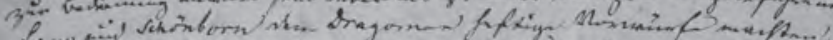

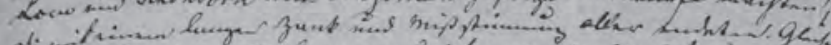

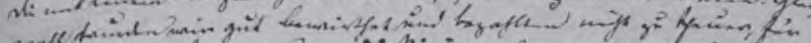

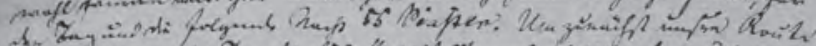

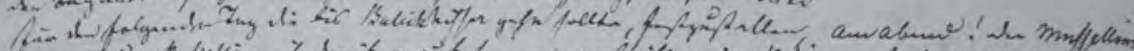

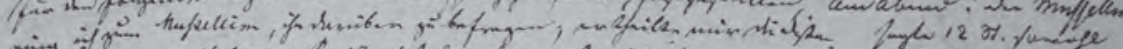

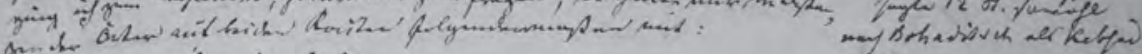

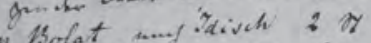
Lankitanger 1 . axbavhlar I, Dada anter? artuchalaul. 2 . tives linhr $1 / 2$, kidichuteles 1 ,

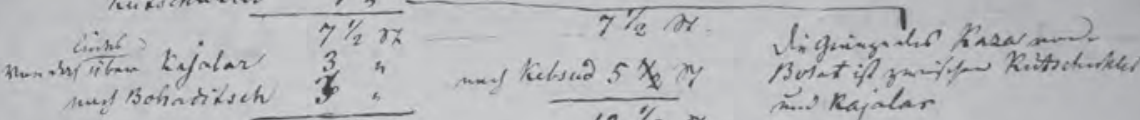

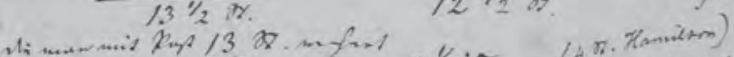

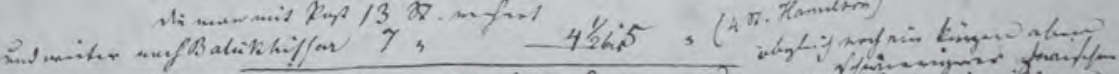

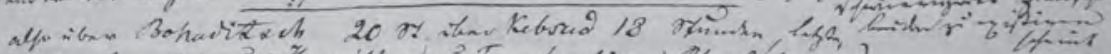

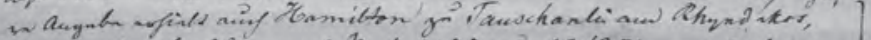

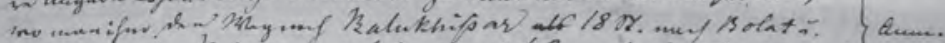

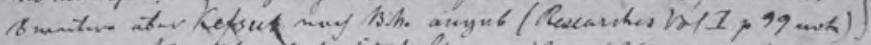

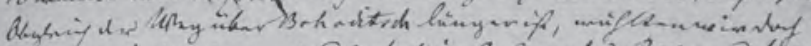

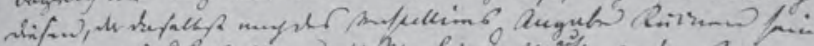

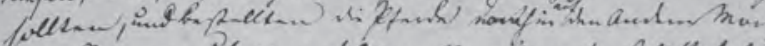

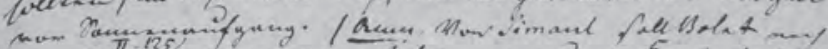

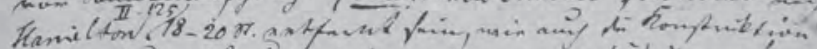

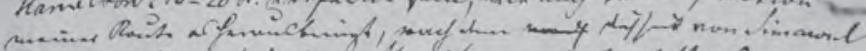

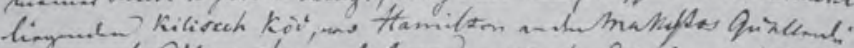

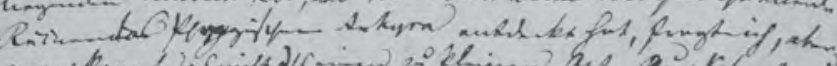

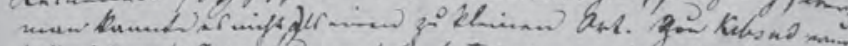

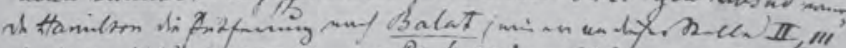

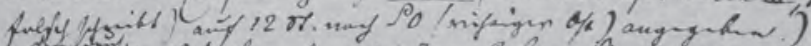
this $r 6$.

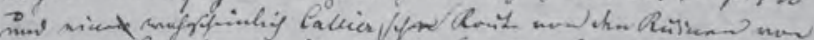

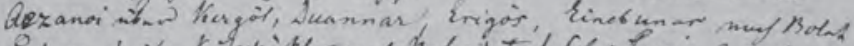

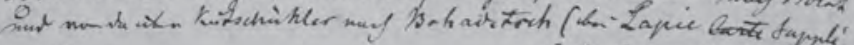

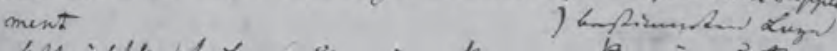

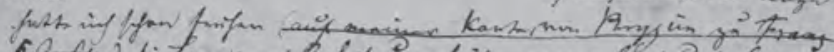

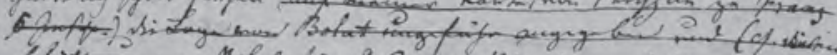

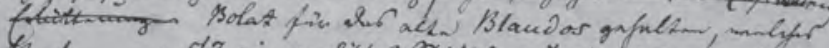

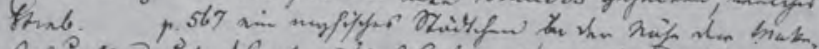

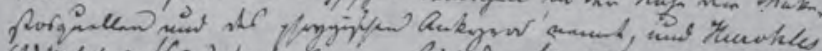

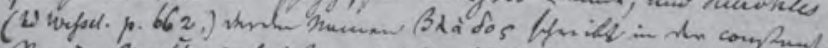

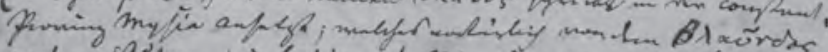

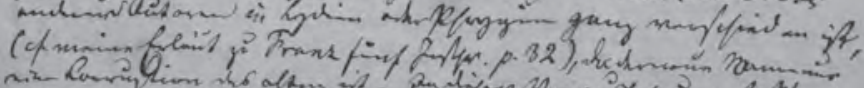

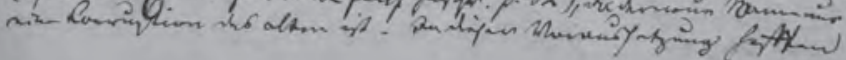

Abb. 5a: Faksimile von Auszügen aus dem Reisetagebuch von Heinrich KiEPERT (Acta 54)

[Fig. 5a: Facsimile of excerpts from Heinrich Kiepert's travel diary (acta 54). 


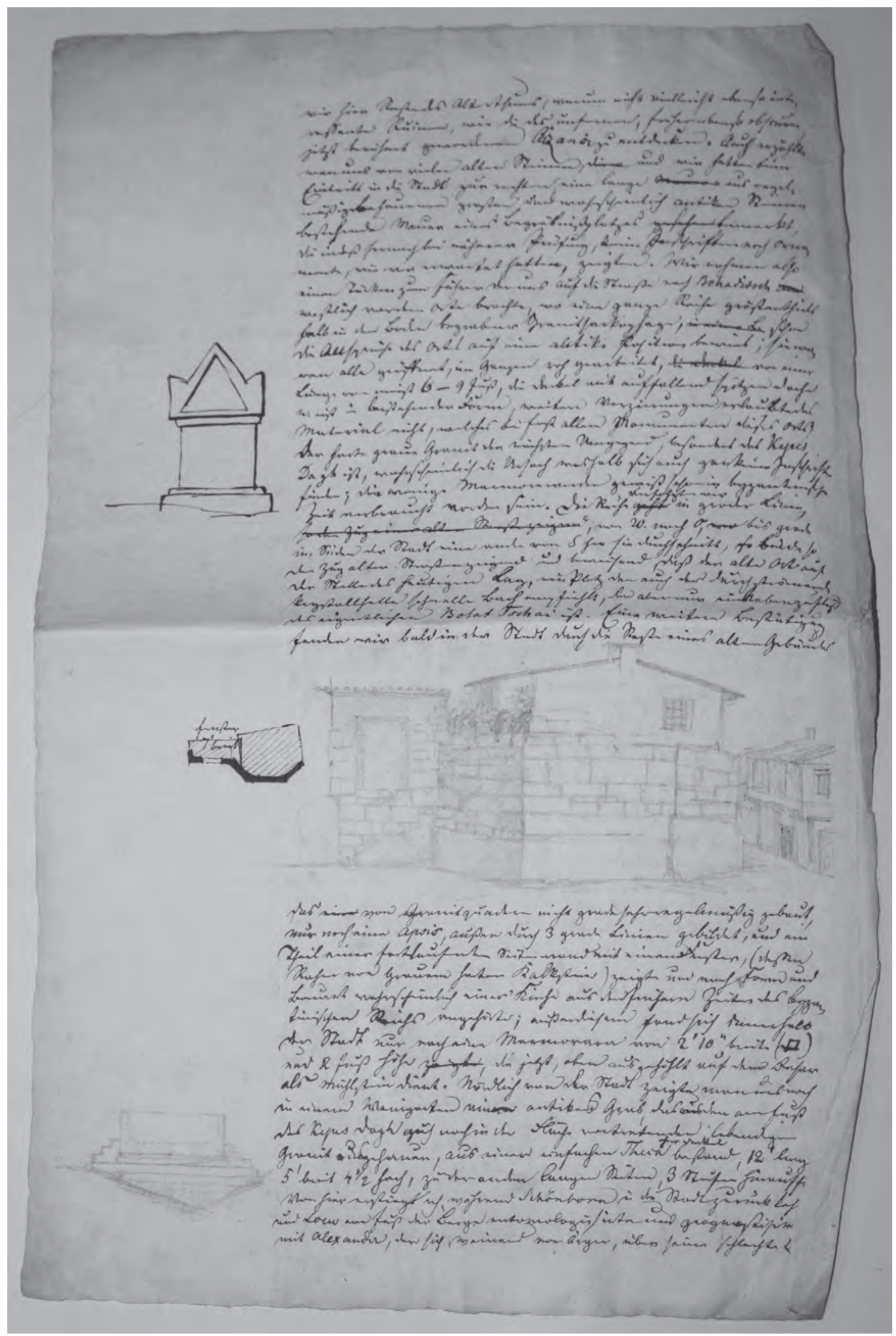

Abb. 5b: Faksimile von Auszügen aus dem Reisetagebuch von Heinrich KiePert (Acta 54).

[Fig. 5b: Facsimile of excerpts from Heinrich KiePERT's travel diary (acta 54).] 


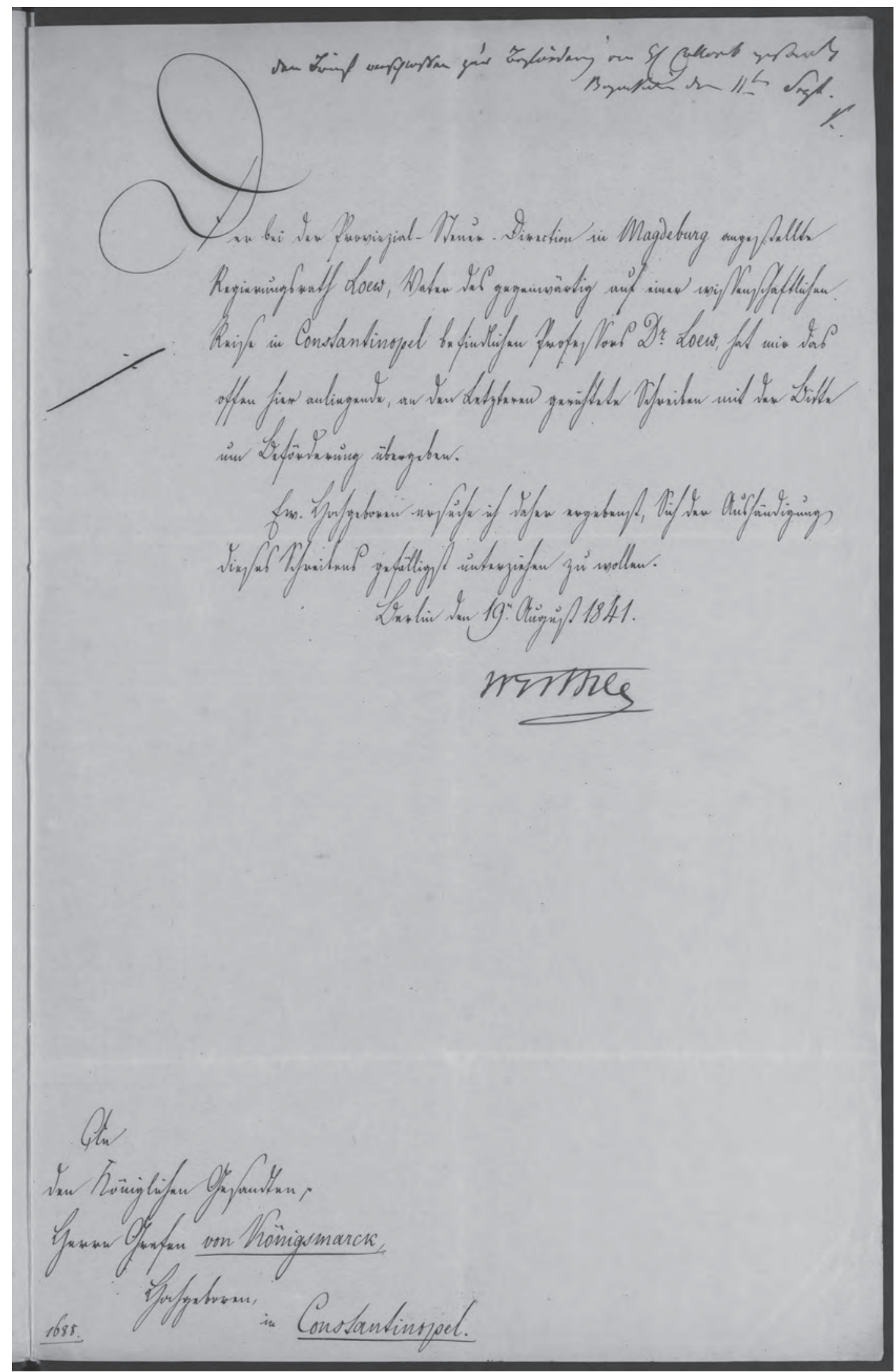

Abb. 6: Faksimile eines Begleitschreibens des Außenministers v. Werther vom 19. August 1841 für ein beiliegendes Schreiben des Vaters von Hermann Loew, dem Regierungsrat Loew aus Magdeburg, an den Gesandten zu Constantinopel, mit der Bitte um Übergabe an den Reisenden (Acta 29).

[Fig. 6: Facsimile of an accompanying letter from the Foreign Minister v. Werther dated 19 August 1841 for an enclosed letter from Hermann Loew's father, the Government Councilor Loew from Magdeburg, to the ambassador to Constantinople, requesting delivery to the traveler (acta 29).] 
kommen, füllte sich dieser Raum rasch mit der älteren männlichen Bevölkerung des Dorfes, „der jüngere zahlreichere Theil der Gesellschaft und wer sonst aus Neugier gekommen war, um die Europäer als Wunderthiere anzustaunen mußte im Hintergrund und zum Theil vor Thür u. Fenster [...] meist stehend Platz nehmen“. Den Bericht zu Bolat (Abbildung 5a) beginnt er folgendermaßen: „Bolat ist ein kleines Städtchen mit 3 Moscheen und ungefähr [kein Eintrag] Häusern, Hauptort eines Kasa's [Kasa war damals die kleinste administrative Flächeneinheit], das von dem oberen Gebiet des Bolat Tschai [des Flusses Bolat] gebildet wird, und unter einem Mussellim [Stadt-Gouverneur] steht“.

Die drei Wissenschaftler, die sich in ihren Arbeitsgebieten thematisch eigentlich so gut ergänzten, mussten nach dem ersten Reiseabschnitt feststellen, dass sich die jeweilige Arbeitsweise und damit verbunden die Reisegeschwindigkeit und die Reiseziele sehr unterschieden. KiePert empfand das als besonders ungünstig. Gleichzeitig war er unabhängiger, da er nicht in die von ScHöNBORN beantragte Reiseplanung und Finanzierung eingebunden war. Seine Reisekosten wurden vollständig von seiner Mutter übernommen (Acta 33, PARTSCH 1901). So trennte sich KIEPERT nun nach bisheriger gemeinsamer Reise von LoEw und Schönborn. Am 4. Oktober reiste er von Smyrna zur Insel Lesbos, erkrankte dort im November schwer und konnte erst im März 1842 seine Arbeit wieder in vollem Umfang aufnehmen (РARTSCH 1901).

Smyrna war damals eine kosmopolitische Stadt mit ungefähr 100.000 Einwohnern (ANONYMUs 1890). Über das dortige preußische Konsulat wurde die Post der Reisenden abgewickelt. Der Versand der Briefe erfolgte auf dem Dienstweg, zusammen mit einem persönlichen Anschreiben des Ministers oder des Gesandten. Auch die privaten Briefe von Familienangehörigen wurden so befördert und die dazugehörigen Begleitschreiben wurden archiviert (Acta 29, Abbildung 6). Während des Aufenthaltes in Smyrna Anfang Oktober 1841 hatte LoEw auch Gelegenheit zum entomologischen Sammeln, wie die von ihm beschriebene Rhagionidae Chrysopila obscuribarba Loew, 1869 zeigt. Als Fundort gibt er an "Smyrna, wo sie im October flog“ (Loew 1869a). Von Smyrna aus sandten Loew und SchönBoRn am 6. Oktober 1841 einen Brief über die Preußische Gesandtschaft in Constantinopel an den Kultusminister EICHHORN (Acta 17, 57; Abbildung 7). Sie berichteten von den ersten Ergebnissen ihrer Reise und baten um eine Urlaubsverlängerung über den genehmigten Zeitraum bis Ende März 1842 hinaus. Einige Auszüge aus diesem Brief sollen das breite Spektrum der Untersuchungen von LOEw und SCHÖNBORN verdeutlichen: „Von allen den durchreisten Gegenden ist eine genaue geographische Aufnahme gemacht worden. Zur Aufnahme des Olympus und der seinem Systeme angehörigen Gebirgszüge, zur genauen Messung seiner Meereshöhe und der Höhe einiger der interessanteren
Vegetationsgrenzen auf ihm, so wie $\mathrm{zu}$ einer freilich nur oberflächlichen Untersuchung seiner höchst interessanten geognostischen Verhältnisse, der an seinem Fuße bei Brussa entspringenden heißen Quellen, so wie zur Ermittlung von mehreren lehrreichen zoologischen und botanischen Verhältnissen reichte ein Zeitraum von 8 Tagen nur notdürftig aus. Die Höhe des Berges dürfte sich nach genauerer Berechnung der Beobachtungen ganz nahe auf $2500 \mathrm{~m}$ herausstellen [2.543 m nach modernen Methoden]“. Geologische Erkenntnisse nehmen einen sehr großen Anteil der Berichterstattung ein. Es wird darauf hingewiesen, dass auch Gesteinsproben gesammelt wurden. Auch das Interesse an antiken Stätten und ihren Inschriften wird überall deutlich. So berichten die Reisenden: „Eine große Menge von Resten antiker Sarkophage und viele in den Felsen ausgehauene Gräber machen es durch ihre Lage unzweifelhaft, daß auf der Stelle des heutigen Bolat ein antiker Ort gestanden habe" (Acta 17, 57). Wie weiter daraus hervorgeht, sammelte LoEw nicht nur zoologische Objekte, sondern war auch als Botaniker unterwegs: „Wie arm auch die Ausbeute an lebenden Pflanzen wegen der bereits $\mathrm{zu}$ weit vorgerückten Jahreszeit war, so besitzen wir doch manche interessante Notiz über Pflanzenverbreitung und von vielen Gewächsen wenigstens den Samen“. Das Hauptaugenmerk Loews galt natürlich den Insekten. Aus dem Text konnten auch erstmals Informationen zum Umfang der Aufsammlungen entnommen werden: „Die zoologische Sammlung enthält über 700 Arten Insekten, darunter verhältnismäßig ziemlich viel neue Arten, auch ein neues Genus. Zum Sammeln von Wirbelthieren fand sich mehrfach gute Gelegenheit, doch mußten wir sie wegen der zu großen Kostspieligkeit und Schwierigkeit des Transportes unbenutzt lassen. Das Beobachtete ist in die Verzeichnisse eingetragen worden“ (Acta 17, 57). Leider werden fast nie konkrete Daten zum Reiseablauf angegeben. Allerdings erklären sich die zwei Reisenden aufgrund ihrer bis dahin gesammelten Erkenntnisse nun zum weiteren geplanten Reiseablauf: „Diejenige Erfahrung dieser 20tägigen Reise von Constantinopel nach Smyrna aber, welche für die Reisenden selbst von der größten Wichtigkeit war, ist die unabweisbare Bemerkung, daß Landessitte und Klima derartige Untersuchungen zeitraubender und kostspieliger machen als voraus berechnet war und daß somit der vorgestreckte Kreis der Untersuchungen nicht in der gegebenen Zeit vollendet werden kann. Um ihrerseits alles $\mathrm{zu}$ thun, was möglich ist um dem Ziele nahe $\mathrm{zu}$ kommen, haben sie Trennung und Theilung der Arbeit beschlossen“. Aus dieser Situation heraus baten sie um eine Urlaubsverlängerung um drei Monate und um weitere finanzielle Unterstützung. Die Antwort darauf haben sie sich an die Konsulate in Adalia und Larnaka erbeten (Acta 17, 57).

Zwei Tage später, am 8. Oktober 1841, setzten LoEw und Schönborn ihre Reise fort (Acta 19; Schönborn, C. 1868). Aus den ersten Tagen dieses Reiseabschnittes 


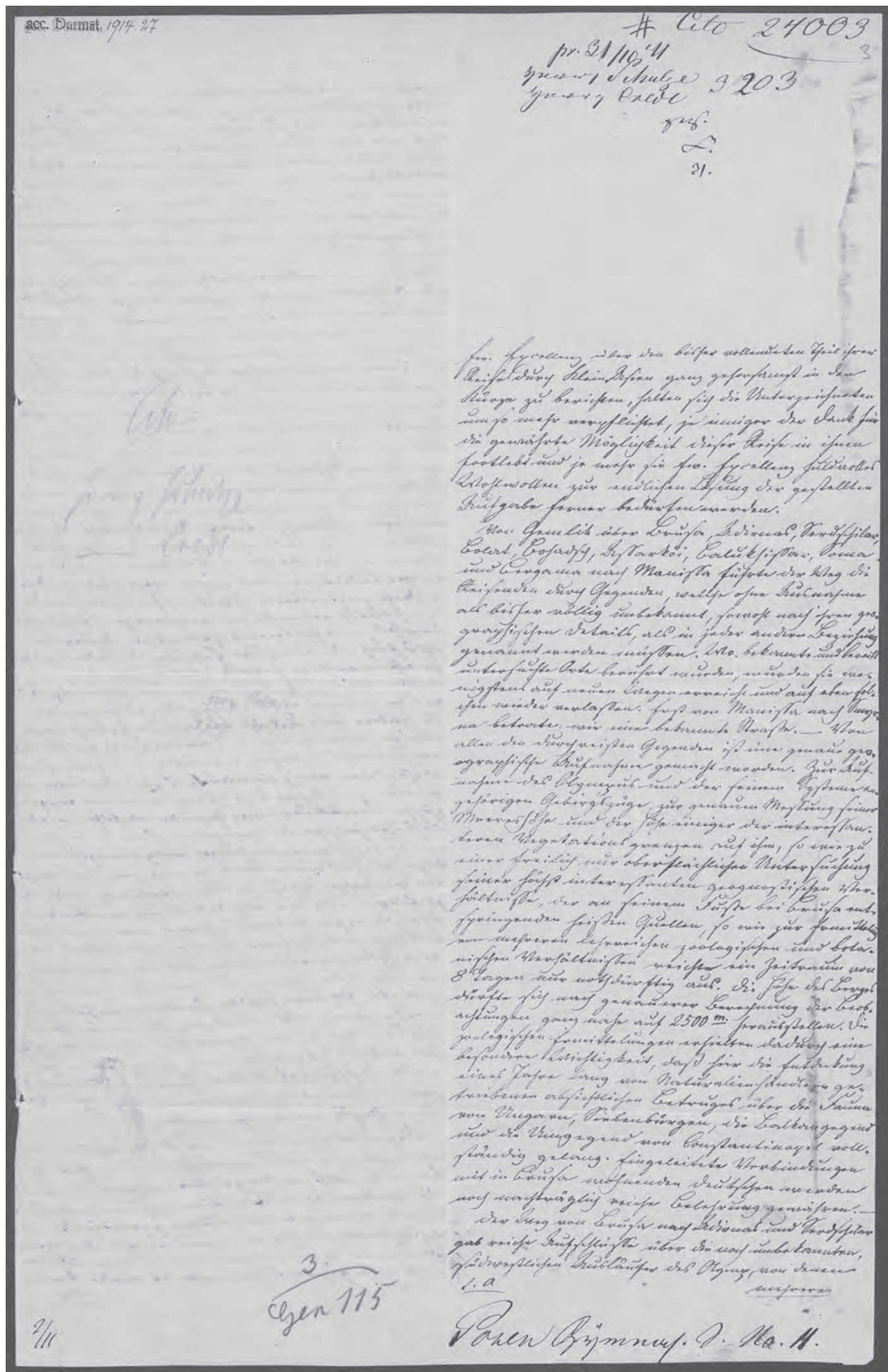

Abb. 7: Faksimile eines Briefs vom 6. Oktober 1841 von SCHÖNBORN und LOEW an den Kultusminister EICHHORN (Seite 1 von 4). Bericht vom ersten Reiseabschnitt (Acta 57).

[Fig. 7: Facsimile of a letter of 6 October 1841, from Schönborn and Loew to the Minister of Education EicHHORN (page 1 of 4). Report from the first part of the trip (acta 57).] 


\section{Fhovitom 1}

1841. 800h. axt fomprar …7 doid

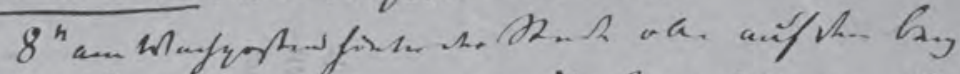

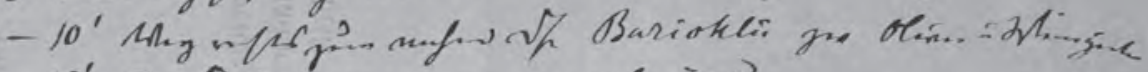

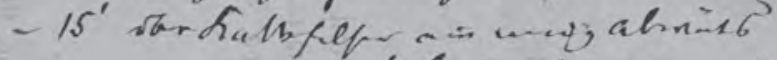

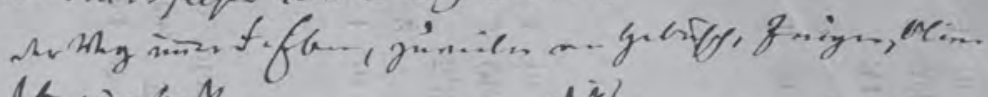

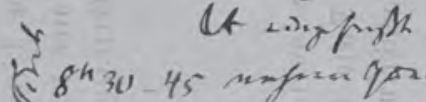

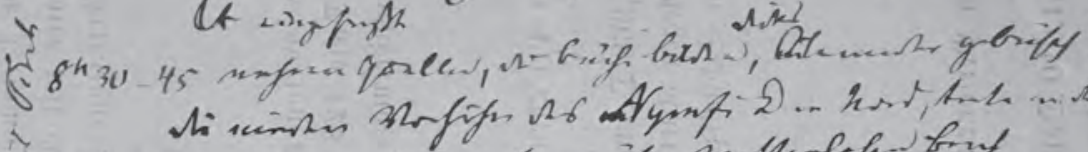

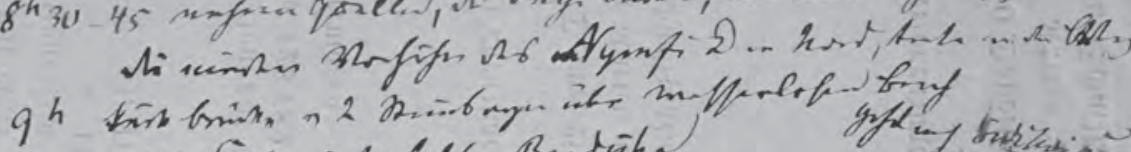

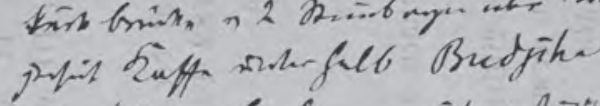

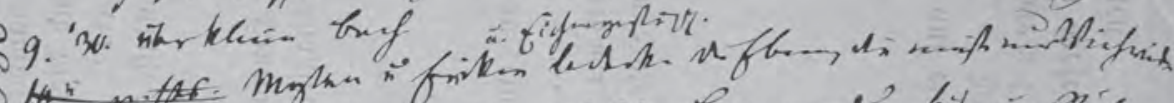

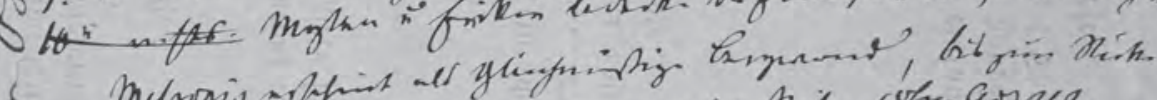

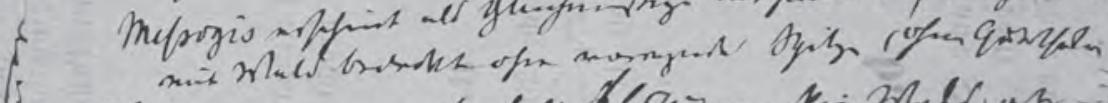

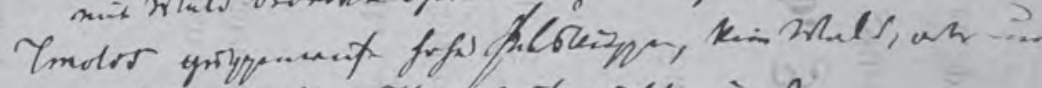

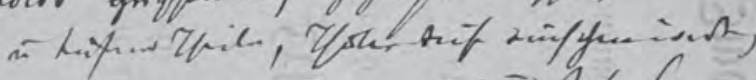

Sto

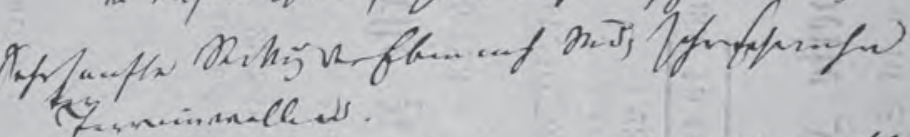

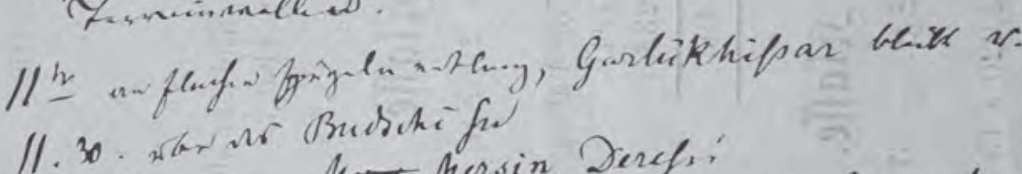

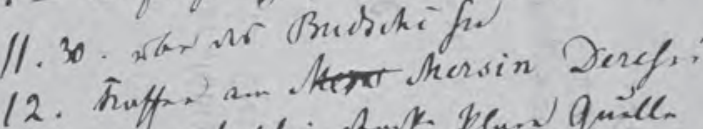

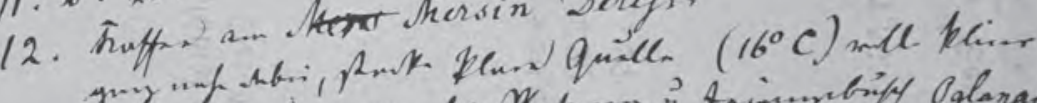

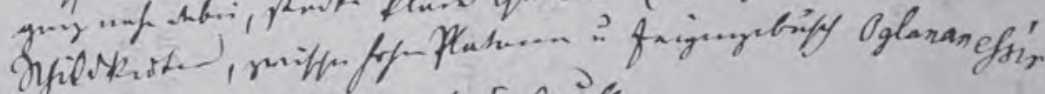

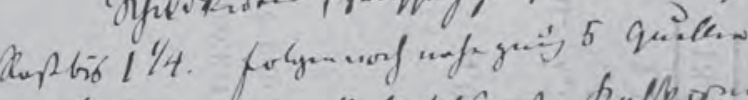

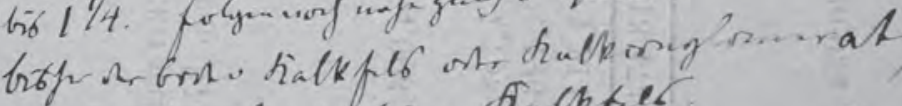

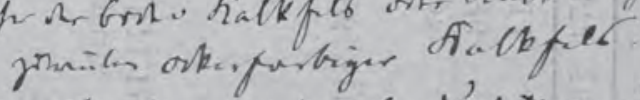

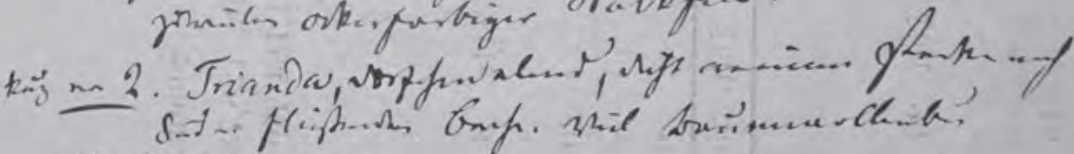

$2 \frac{1}{2}$ Forturá sop

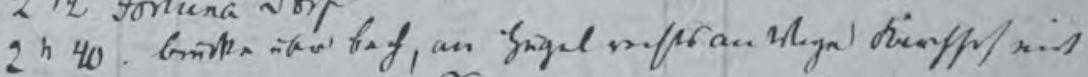

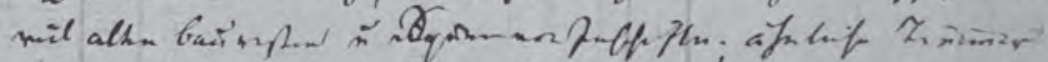

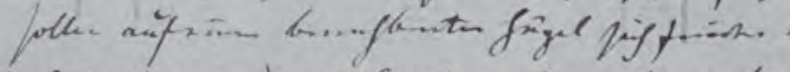

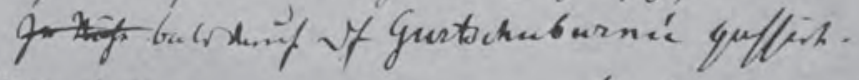

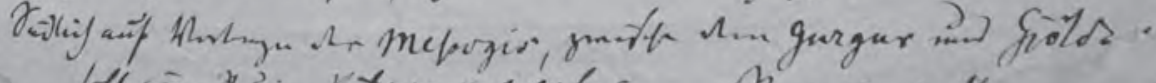

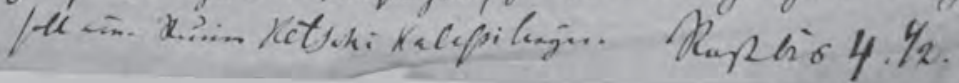

Abb. 8: Faksimile eines Auszugs aus dem Itinerar von Julius August SchÖNBORN (Acta 55).

[Fig. 8: Facsimile of an excerpt from the itinerary of Julius August SchönBorN (acta 55).] 
sind auch wenige Blätter der Tagebuchaufzeichnungen SchÖNBORNs erhalten geblieben (Acta 55, Abbildung 8). Für SchÖNBORN standen geographische und archäologische Erkundungen im Mittelpunkt, während LoEw darüber hinaus vor allem entomologische Aufsammlungen machte. An den antiken Siedlungsplätzen haben sie möglichst viele der historischen Inschriften mittels Papierabklatschen reproduziert. Wie dem Vorwort zur Veröffentlichung der lykischen Inschriften zu entnehmen ist (SCHMIDT 1868), war LoEw nicht unerheblich an dieser Inschriftensammlung beteiligt: "The greater part of these inscriptions, eighteen of which have not been published by Fellows and Daniell, are drawn after the correct paper-casts of Prof. A. Schoenborn and collated with the copies of Prof. Loew, his fellow-traveller, and so we are able to publish for the first time a 'corpus of Lycian inscriptions', on the accuracy of which even the most cautious scholar may rely".

Da die zum Zeitpunkt der Reise verfügbaren Landkarten völlig unzureichend waren, konnten neue geographische Erkenntnisse und die oft unbekannte Lage von antiken Stätten nur durch Wanderungen abseits der bekannten Wege, entlang der Flüsse und quer durch die Gebirge gefunden werden. So reisten LoEw und SchöNBORN vom 8. bis 22. Oktober im Tal des Kleinen Mäander über Tokboi $(\bullet 15)$ und Tireh $(\bullet 16)$ nach Baliambo $(\bullet 18)$ und weiter über das Gebirge des Hohen Messogis $(\bullet 18)$ nach Nosli $(\bullet 19)$ im Tal des Großen Mäander $(\bullet 19)$ sowie über Laodikeia $(\bullet 20)$ nach Denislü $(\bullet 20)$ (Acta 19, 57; Benndorf \& Niemann 1889; Schönborn, C. 1868). Während dieses Reiseabschnittes trennten sich beide Reisenden für kürzere Zeit. Daher wurde Eski Bain Dir $(\bullet 16)$ nur von LoEw und Birkeh $(\bullet 17)$ nur von ScHöNBORN besucht (Acta 19). Im Oktober konnte LoEw im Mäandertal oberhalb Nosli $(\bullet 19)$ zahlreiche Raubfliegen finden, von denen er 1848 und 1849 vier Arten als neu beschrieb: Asilus adpressus, A. angustifrons, A. nubecula und A.truncatus - alles gültige Namen, heute aber in andere Gattungen gestellt (LoEw 1848a, 1849a). Etwas weiter im Gebirge, unweit des oberen linken Nebenflusses des Mäanders, dem heutigen Çürüksu Çayı, liegen Laodikeia $(\bullet 20)$ und Denislü $(\cdot 20)$. Trotz der fortgeschrittenen Jahreszeit, in der „das Thermometer [...] hier gegen Ende des Oktobers des Morgens bis ganz nahe zum Gefrierpunkte [fiel]“, konnte LoEw dort weitere Insekten finden (Acta 19). So meldet Zeller (1847) mit dem Fundort Denizlü bzw. Denizli einige Loewsche Schmetterlingsfunde.

Zwei Wochen nach dem Aufbruch in Smyrna trennen sich Schönborn und LoEw in Denislü $(\bullet 20)$ erneut für eine Woche, um sich am 29. Oktober in Tefenü $(\bullet 21)$ wiederzutreffen. Durch die getrennten Wege ließen sich größere Landesteile erkunden und auch die persönlichen Interessen besser berücksichtigen (Acta 19, 57; BENNDORF \& Niemann 1889; Schönborn, C. 1868). SChÖNBorn wählte eine schwierige Route, die ihn entlang des Indus $(\bullet 36)$ zur Küste und über Kaunos $(\bullet 37)$, Makri $(\bullet 34)$, Kadyanda $(\bullet 38)$ und Bubon $(\bullet 39)$ wieder zurück in die Berge und nach Tefenü $(\bullet 21)$ führte (in Abbildung 4 gelb markiert). Um einen Eindruck vom praktischen Reiseablauf zu bekommen, sei hier die Schilderung August SchönboRns aus der Erinnerung seines Bruders Carl zitiert: „Mein Bruder engagierte daher auf kürzere oder längere Touren einen Einheimischen, anfangs einen Griechen, später lieber einen Türken, kaufte für sich und seinen Begleiter zwei, zuweilen drei Pferde, belud sie mit dem nöthigsten Gepäck, und durchzog nun das Land nach allen Richtungen. Auf ein nächtliches Unterkommen war in dem spärlich bewohnten Lande nicht immer zu rechnen. Manchmal wurde es auch geradezu verweigert. In den wärmeren Jahreszeiten waren die Dörfer der südlichen Gegenden menschenleer, weil die Viehzucht treibenden Einwohner mit ihren Heerden auf die Jailas (die Almen im Gebirge) gezogen waren, die im Winter fast unbewohnt sind. Sehr oft mussten die Reisenden froh sein, eine verlassene Hütte zu finden und in ihr die Nacht hinzubringen. Gelang auch dies nicht, so blieb nichts übrig, als unter freiem Himmel zu campieren. Dies war im Spätherbst, als die 8000-9000 Fuss hohen Berge sich bis tief herunter mit Schnee bedeckten, oder bei ungünstigem Wetter, schwer zu ertragen. Manchen Tag begegnete er auch nicht einem Menschen. So zog er wiederholt wochenlang in den Berglandschaften umher, und musste sich natürlich mit der kärglichsten und schlechtesten Nahrung begnügen, bis er dann wieder an die Küste zurückkehren konnte“ (SchönBORN, C. 1868). Im Gegensatz zu einigen urbanen Zentren waren damals große Landesteile nur dünn besiedelt und in einigen Gegenden war die Bevölkerung zusätzlich durch Pestepidemien und die Malaria dezimiert.

Von Tefenü $(\bullet 21)$ reisten LoEw und SchönborN am 30. Oktober gemeinsam nach Istenas $(\bullet 22)$ ab, das sie schon am nächsten Tag erreichten, und setzten ihre Reise dann zum Kestel Gölü $(\bullet 23)$ und nach Padam Aghatsch $(\cdot 23)$ fort (3. November). Nach Überschreiten eines Passes im Taurus-Gebirge trafen beide am 4. November 1841 in Adalia (•24) (Antalya) ein (Acta 19; Schönborn, C. 1868). Der Ort war damals eine Kleinstadt mit höchstens 5000 Einwohnern (ANONYMUs 1890). In seiner Beschreibung der Schwebfliegenart Eumerus angustifrons Loew, 1848 nennt er als Ort und Zeit des Fundes „die Gegend von Adalia, [...] im October" (Loew 1848b, siehe auch Abbildung 13:6). Ebenso erwähnt ZelLer (1847) auf Seite 24 einen Fund der Noctuide Halias quercana (Denis \& Schiffermüller, 1775) „,bey Pera im October gefangen" und auf Seite 26 den Wickler Grapholita gundiana (HüBNER, 1799) „von Brussa [...] im October“. Auf der Basis unserer Rekonstruktion der Reise ist es überaus unwahrscheinlich, dass Loew schon im Oktober in Adalia $(\cdot 24)$ war oder im gleichen Oktober 1841 noch einmal nach Pera $(\bullet 2)$ oder Brussa $(\bullet 4)$ zurückgekommen sein könnte. Es handelt sich wohl um Erinnerungslücken von Loew. 
Kaum in Adalia (•24) angekommen, brach SchöNBorN schon am darauffolgenden Montag, den 7. November, wieder allein $\mathrm{zu}$ einer weiteren abenteuerlichen Tour quer durch das Taurus-Gebirge nordöstlich der Stadt auf (in Abbildung 4 gelb markiert). Er begann die Reise im Kestros-Tal (•40) und ging von der Mündung des Flusses über Perge $(\bullet 40)$, Milyas $(\bullet 41)$, Kysylly $(\bullet 41)$ und Baulo $(\bullet 41)$ bis zu dessen Quellflüssen und weiter zum Eghirdir-See $(\bullet 42)$. Danach reiste er über Badamli $(\bullet 43)$ und bei Wintereinbruch und starkem Schneefall durch das Tal des Eurymedon $(\bullet 44)$ wieder in Richtung Küste. Auf seinem Weg entdeckte er das antike Selge $(\bullet 44)$ und besuchte die Ruinen von Aspendus (•45), bevor er am 4. Dezember wieder Adalia $(\bullet 24)$ erreichte (RitTeR 1859).

LoEw war zu diesem Zeitpunkt bereits in Richtung Rhodus (•35) abgereist, da er „durch Führung des gemeinschaftlichen Reisegepäckes und durch die Art seiner Untersuchungen zu langsamerem Reisen genöthigt war" (Acta 19). Er nahm schon Anfang November den Landweg von Adalia $(\bullet 24)$ über Istenas $(\bullet 22)$, Almalü $(\bullet 25)$ und Phinika $(\bullet 27)$, wie die loci typici „Istenas“ für Trichosoma löwii ZelLer, 1846 und „Phinik“ für Eudorea coarctata ZelLer, 1847 bzw. „Phinika“ für Asilus tessellatus Loew, 1849 zeigen (Zeller 1846, 1847; Loew 1849a). Bei letzterer Art schreibt LoEw allerdings eigenartigerweise „bei Attalia und Phinika von mir im Oktober und November gefangen“. Auf diesem Weg von Adalia (•24) nach Phinika $(\bullet 27)$ fand er im Gebirge bei Istenas $(\bullet 22)$ in einer Höhenlage von etwas mehr als $1.000 \mathrm{~m}$ ü. NHN „zu Anfang Novembers einen Bach bereits mit Eise überfroren" (Acta 19). Wenig später vom Hochplateau bei Almalü (•25) kommend, besuchte er auf dem Weg zur Küste unter anderem auch die Ruinen von Arykanda $(\bullet 26)$. In Phinika $(\bullet 27)$ angekommen, wendet er sich aber erst einmal nicht in Richtung Rhodus nach Westen, sondern unternimmt eine längere Exkursion nach Nordosten und Osten mit Besuchen in Limyra $(\cdot 27)$, Gagai $(\bullet 27)$, Olympus $(\bullet 29)$, Phaselis $(\bullet 28)$, zu dem Naturschauspiel der ewigen Flammen der Chimaera bei Jannartagh $(\bullet 29)$, und dem Promontorium sacrum (•29), dem heutigen Kap Gelidonya (Acta 19). Nachdem er nach Phinika (•27) zurückgekehrt war, setzte er seine Reise nun nach Westen fort und besuchte Demre (•30) und Andriake $(\bullet 30)$. Danach folgte er in einer weiteren Exkursion abseits der Hauptrichtung dem Demre-Fluss aufwärts nach Nordwesten in die Berge bis Kassaba $(\cdot 31)$ und Ernez $(\bullet 31)$. Von dort wieder an das Mittelmeer zurückgekehrt, versuchte er an der Küste bis zur Mündung des Xanthus (•33) zu kommen, um von dort über Makri (•34) nach Rhodus (•35) zu gelangen (Acta 19). Die nun verstärkt einsetzenden winterlichen Niederschläge, die schlechten Wege und die oft fehlenden Möglichkeiten, Nahrungsmittel zu erwerben, machten diesen Reiseabschnitt in dem damals ärmlichen Landstrich zu einem großen Problem. LoEw schreibt dazu „Das häufig nöthige ab und aufladen des Gepäckes, die zur Passirung unumgänglich nöthige
Besserung vieler Wegstrecken, Ermattung der Menschen und Thiere, ließen nur ganz kleine Tagemärsche zu. Die Nächte wurden größtentheils mit Trocknungsversuchen der gesammelten Naturalien in Hütten, die längst nicht mehr vor dem Regen schützten, zugebracht. Ein Theil der Mineralien mußte zurückgelassen werden und von Pflanzen und Insekten gieng viel durch Wasser und Feuer, mehr noch durch später eintretenden Moder verloren“. Erkrankt und geschwächt erreichte er nur mit Mühe Makri $(\bullet 34)$, von wo er nach einwöchiger Erholung „um Weihnachten“ nach Rhodos (•35) übersetzte (Acta 19). Einige Tage später, am 29. Dezember 1841, sandte Loew von Rhodus aus einen Brief an Museumsdirektor v. OlfEers, in dem er vom Auffinden zweier klassische Statuen berichtet (Acta 45).

SснӧNBORN hielt sich vom 4 . bis zum 8. Dezember in Adalia (•24) auf. Das Antwortschreiben des Kultusministeriums (Acta 18), dass sich die Reisenden nach Adalia [und Larnaka] erbeten hatten (Acta 17, 57), erreichte ihn dort aber nicht (Acta 23). Er musste also davon ausgehen, dass der Antrag auf Verlängerung des Urlaubes abgelehnt sein könnte. SснӧnboRn folgte am 8. Dezember Loews Weg über Almalü (•25) und Phinika (•27) bis Myra (•30), welches er am 15. Dezember erreichte (Acta 19; BenNdorf \& Niemann 1889; Schönborn, C. 1868). Dort blieb er einige Tage im Kloster des Heiligen Nikolaus. Bei seiner Weiterreise in Richtung Xanthus (•33) entdeckte er nicht weit von Myra $(\bullet 30)$ am 20. Dezember die 2400 Jahre alten Ruinen von Gjölbaghtsche $(\bullet 30)$. Diese ganz eigentümliche Grabanlage erlangte später unter dem Namen „Das Heroon von Trysa“ eine besondere kunst- und kulturgeschichtliche Bedeutung. Auf der Weiterreise gelangte er über Antiphellus (•32) am 27. Dezember nach Xanthus $(\bullet 33)$. Dort traf er erstmals mit dem bekannten Engländer Fellows zusammen, der „eben in grosser Gesellschaft angekommen war, um so viele Kunstdenkmäler als möglich nach England bringen zu lassen“" (BenNdorf \& Niemann 1889, SCHÖNBorn, C. 1868). SснӧNBoRN setzte seinen Weg über Sidyma $(\bullet 34)$, Pinara $(\bullet 34)$ und Makri $(\bullet 34)$ nach Rhodus $(\bullet 35)$ fort, wo er am 5. Januar 1842 ankam und LoEw wieder traf (BenNdorf \& Niemann 1889, Ritter 1859, SChÖNBORN, C. 1868).

\subsection{Von Rhodus via Smyrna durch die Gebirge und Küstenländer und zurück nach Rhodus (Winter und Frühjahr 1842)}

Den Januar 1842 verbrachten Loew und SснӧNBORN in ihrem „Winterquartier" auf der Insel Rhodus (•1) (Abbildung 9). Auch aus dieser Zeit liegen einige Nachweise von Insekten vor. So hat Loew den Mittelmeer-Nelkenwickler Cacoecimorpha pronuba (HüBNER, 1799) schon im Januar hier gefunden (Zeller 1847, unter Tortrix). Aus der Dipteren-Ausbeute beschreibt Loew später die Heleomyzidae Helomyza variegata 


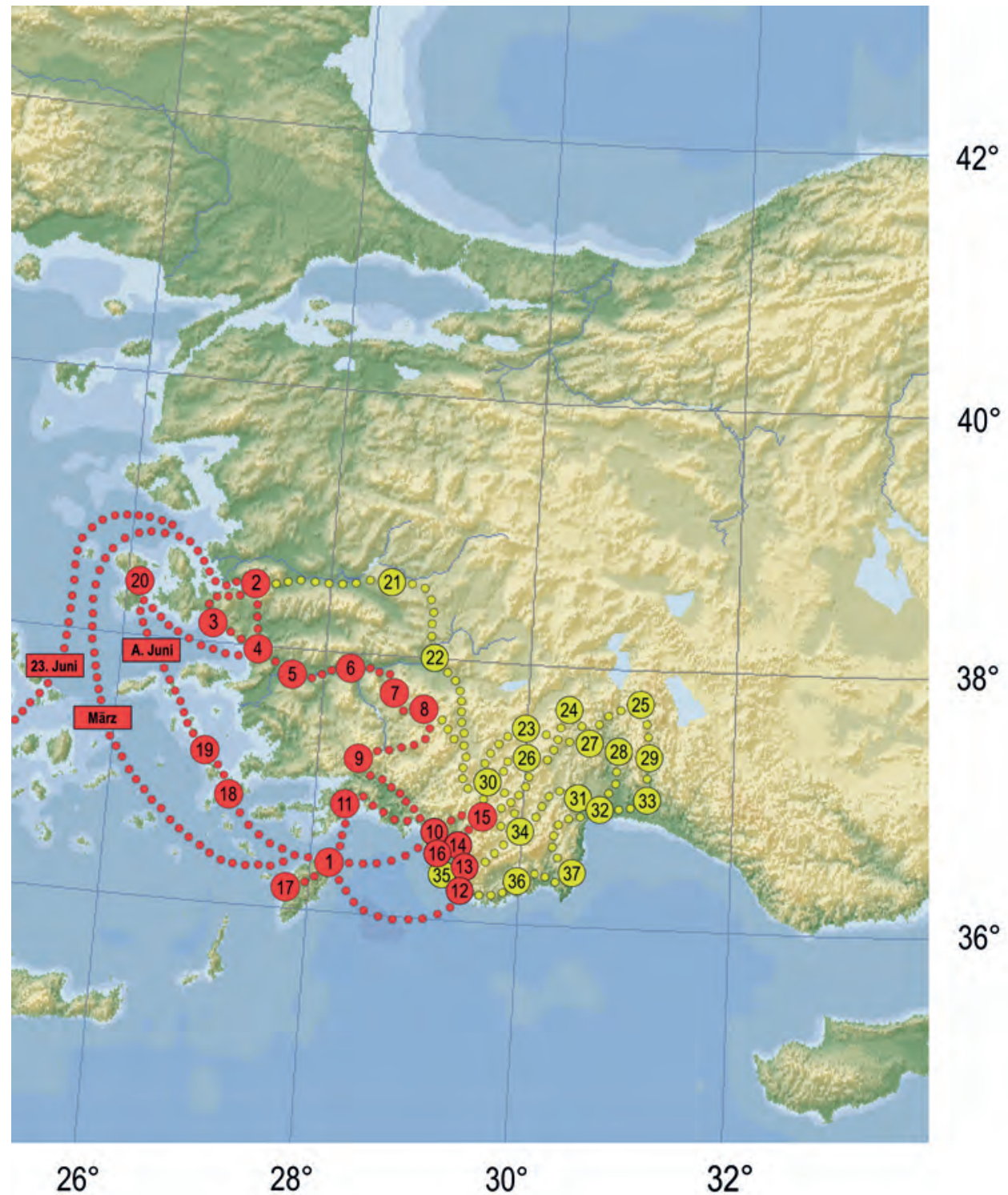

Abb. 9: Die Reiseroute im Jahr 1842. Die roten Punkte markieren den Reiseweg von Loew bzw. Loew und Kollegen. Die Schifffahrtswege sind idealisiert dargestellt und entsprechen nicht dem genauen Verlauf der tatsächlichen Route. Die gelben Punkte kennzeichnen zusätzliche Reisen, die SснӧnвoRn allein unternommen hat. Die Nummern und Namen der durch Punkte dargestellten Orte sind in Tabelle 2 zusammengestellt. Im Text werden die auf den Karten dargestellten Fundorte mit ihren Nummern genannt und durch den Vorsatz des Sonderzeichens • direkt hinter dem Ortsnamen gekennzeichnet, $(\bullet 1)$ bis $(\bullet 36)$. SCHÖNBORNs Reisewege lassen sich auf dieser Karte nicht chronologisch darstellen, da es vielfache Überschneidungen und Mehrfachbesuche gibt. Sie sind detaillierter bei BENNDORF \& NiEMANN (1889) dokumentiert.

[Fig. 9: The travel route in 1842. The red dots mark the travel route of LoEw or LoEw and colleagues. The shipping routes are idealized and do not correspond to the exact course of the actual route. The yellow dots indicate additional trips that SCHÖNBORN undertook alone. The numbers and names of the locations represented by dots are shown in Table 2 . In the text, the localities shown on the maps are named with their numbers and identified by the prefix of the special character $\bullet$ directly after the place name $(\bullet 1)$ to $(\bullet 36)$. SснÖNBORN's itineraries cannot be shown chronologically on this map as there are multiple overlaps and multiple visits. They are documented in more detail by BENNDORF \& Niemann (1889).] 
Tabelle 2: Zusammenstellung der Ortsbezeichnungen auf der Reiseroute 1842 (Nummerierung wie in Abbildung 9). [Table 2: Compilation of the place names on the 1842 expedition route (numbering as in Figure 9).]

\begin{tabular}{|c|c|c|}
\hline Nummer & $\begin{array}{l}\text { Im Text benutzte historische } \\
\text { Bezeichnung }\end{array}$ & $\begin{array}{l}\text { Moderne Ortsbezeichnung (wie in Tab. 3). } \\
\text { Antike Siedlungsplätze in Kapitälchen }\end{array}$ \\
\hline 01 & Rhodus & Insel Rhodos \\
\hline 02 & Smyrna & İzmir \\
\hline 03 & Sigadschick & Siğacik \\
\hline 04 & Ephesus, Aiasoluk, Skalanova & EpHesos, Ayasoluk (Selçuk), Kuşadasi \\
\hline 05 & Aidin & Aydin \\
\hline 06 & Nosli-Basar, Mäander-Thal & Nazilli, Büyük Menderes-Tal \\
\hline 07 & $\begin{array}{l}\text { Karajasu, Ghera (Gera), Babatagh, } \\
\text { Karadschatagh }\end{array}$ & $\begin{array}{l}\text { Karacasu, Geyre, Babadağ (= Karcı Dagı), Karıncalı Dağ } \\
\text { (Gebirge) }\end{array}$ \\
\hline 08 & Kisilhissar, Davas & Serinhisar, Tavas \\
\hline 09 & Mulah & Muğla \\
\hline 10 & Makri & Fethiye \\
\hline 11 & Mermeriza & Marmaris \\
\hline 12 & Xanthus, Furnas, Kellemish, Patara & Xanthos, Yeşilköy, Gelemiş, Patara \\
\hline 13 & Xanthus-Thal & Eşen Ovasi \\
\hline 14 & Tlos & Tlos \\
\hline 15 & Bubon (Chorsun), Oenoanda, Balbura & Boubon, OinoAnda, BALboura \\
\hline 16 & Kragus & Sandak Dağ (Gebirge) \\
\hline 17 & Ateiro (Monte Ateiro) & Attaviros (Gebirge) \\
\hline 18 & Cos, Stanchio & Insel Kos \\
\hline 19 & Lerus & Insel Leros \\
\hline 20 & Chios & Insel Chios \\
\hline 21 & Kuhla & Kula \\
\hline 22 & Hierapolis & HIERAPOLIS \\
\hline 23 & Jaryschly & Yarışlı \\
\hline 24 & Sagalassos & SAGALASSOS \\
\hline 25 & Dipoirasdagh & Dipoyraz Dağh (Gebirge) \\
\hline 26 & Olbasa & Olbasa \\
\hline 27 & Kestel Göl, Ürkütlü, Padam Aghatsch & Kestel Golü, Ürkütlü, Bademağacı \\
\hline 28 & Milyas, Kremna, Pednelissus & Milyos, Kremna, Pednelissos \\
\hline 29 & Eurymedon, Kesme, Selge & Köprüçay (Fluss), Kesme, SELGE \\
\hline 30 & Gülhissar, Kibyra (Cibyra) & Gölhisar, KIBYRA \\
\hline 31 & Termessos & TERMESSOS \\
\hline 32 & Adalia, Sillyon & Antalya, SiLLyON \\
\hline 33 & Aspendus & AsPENDOS \\
\hline 34 & Almalü & Elmali \\
\hline 35 & Gjölbaghtsche (Gjöl Bachi), Kassaba & Trysa, Kasaba \\
\hline 36 & Olympus [Lycia] & OLympos \\
\hline
\end{tabular}


Loew, 1862 (= Suillia) als neue Art mit der Bemerkung „Ich fing sie auf Rhodus schon zu Ende Januar und Anfang Februar" (Loew 1862a, c). Aus Loews späterem Bericht an das Kultusministerium vom 26. März 1842 (Acta 19) geht hervor, dass er in der für entomologische Untersuchungen ungeeigneten Winterzeit auf Rhodus sich vorwiegend mit der Geologie, mit Fossilien und Mollusken beschäftigte: „Die genauere Untersuchung dieser tertiären Formationen nun und besonders der in ihnen vorkommenden Versteinerung machte ich mir zur nächsten Aufgabe; ich darf hoffen sie in einiger Vollständigkeit gelöst zu haben; wenigstens 4000 Stück gesammelte Versteinerungen dürften bei genauerer Untersuchung leicht über 200 verschiedene Spezies nachweisen, unter denen gar vieles Neue und Schöne ist. Diese Untersuchung aber zu ganz wissenschaftlichem Ende zu führen, knüpft sich daran als nothwendige zweite eine möglichst genaue Beobachtung der jetzt lebenden Konchilien des Mittelmeeres“.

Hier auf Rhodus haben Loew und Schönborn auch eine erste Bilanz gezogen. In den Archiven sind drei Briefe aus diesem Zeitraum überliefert. Ein Brief von Loew an v. Olfers ist mit dem 29. Dezember 1841 (Acta 45) datiert und weist eine Besonderheit auf. Er ist unterzeichnet von LoEw, aber auch der Name ScHöNBORNs steht darunter. Bei einem Schriftenvergleich stellt sich aber schnell heraus, dass es nicht SCHÖNBORNs Unterschrift ist. Sie kann es auch nicht sein, da die Aufzeichnungen seines Bruders Carl und die auf dem Tagebuch SсHÖNBORNs beruhenden Informationen RITTERs glaubhaft belegen, dass er erst am 5. Januar die Insel erreicht hat (BENNDORF \& NIEMANN 1889, RitTER 1859, Schönborn, C. 1868). Loew bezieht sich in diesem Schreiben auf eine briefliche Aufforderung von v. Olfers „Hochwohlgeboren haben die Geneigtheit gehabt durch einen an den Kandidat Kiepert gerichteten Brief denselben und die unterzeichneten Reisenden zu beauftragen für Erwerbung von Antiquitäten thätig zu sein" (Acta 45). Er weist auf hohe Preise und diverse Schwierigkeiten hin und informiert, dass ein „Ferman“, eine spezielle Genehmigung zur Ausfuhr von „altem Marmor" benötigt wird. Weiterhin berichtet LoEw von zwei Statuen, die er und SснӧNBORN im Verlauf ihrer Reise gefunden hätten, und die eventuell für das Königliche Museum in Berlin geeignet wären. Nach Erhalt des Briefes von Loew wendet sich v. Olfers in dieser Sache am 7. Februar 1842 an den Außenminister v. Werther (Acta 35) und bittet um die Vermittlung einer solchen Genehmigung durch die Gesandtschaft. Dabei wendet er die gleiche Formulierung „zur Ausfuhr von altem Marmor" an. Dieser Brief von v. Olfers wird am 10. Februar mit einem Begleitschreiben des Außenministers an die Gesandtschaft in Constantinopel weitergeleitet (Acta 37).

In zwei anderen Briefen entschließt sich SCHÖNBorN erst am 27. Januar 1842, dem Legationsrat v. WAGNER in Constantinopel (Acta 34) und dem Museumsdirektor v. Olfers in Berlin (Acta 46) seine Entdeckung des Monuments von Gjölbaghtsche mitzuteilen. Der Legationsrat v. WAGNer sandte nach dem Erhalt das an ihn gerichtete Schreiben (Acta 34) am 9. Februar mit einem Begleitschreiben (Acta 36) an v. Olfers weiter. Das Begleitschreiben enthält die Bemerkung „werde, bei der Pforte die Erlaubniß zur Ausführung der [...] Basreliefs zu erwirken suchen". Dieses Vorhaben setzte v. WAGNER am 12. Februar im Sinne des Schreibens von SCHÖNBORN (Acta 34) und seiner eigenen Ankündigung gegenüber v. Olfers (Acta 36) um, indem er den ersten Dragoman der Gesandtschaft mit der Erwirkung eines Fermans bei der Hohen Pforte beauftragte. Der auf Französisch entworfene Text dieses Auftrags wurde als Briefvorlage archiviert (Acta 38): « Mr. le Prof Schönborn chargé par le gouvernement du Roi de faire des recherches scientifiques dans l'Asie Mineure vient de m'informer qu'il a trouvé près des villages de Gjöl Bachi et de Tschakal Bejat dans les environs de Kassaba sous le Mougla de Mentecha un vieux mur tombant en ruines sur lequel se trouvent des pierres carrées avec quelques sculptures qui seront bientôt entièrement détruites et ensevelies sous la terre. Ces vieilles pierres ne peuvent être absolument d'aucune utilité pour personne dans leur état actuel mais comme elles offrent quelque intérêt sous le rapport des sciences et de l'histoire ancienne, le Professeur Schönborn désirerait en emporter une partie. » DÉBARRE (2017) hat diesen Text auf Seite 57 wie folgt kommentiert: «Sous la plume du comte de Königsmarck, on le voit, le < monument > dont 〈aucun musée ne possède [d]'équivalent 〉 de Schönborn, se transforma soudainement en < vieilles pierres > (d'aucune utilité pour personne .» Die deutsche Entsprechung dieses Kommentars lautet etwa: „Unter der Feder des Grafen v. KöNIGSMARCK sah man plötzlich SCHÖNBORNS Monument, das in den Museen seinesgleichen sucht, sich in einen Haufen alter Steine verwandeln, die für Niemanden mehr von Nutzen waren." Dazu ist zu sagen, dass Graf v. KöNIGSMARCK sich zu diesem Zeitpunkt seit mehr als vier Monaten nicht mehr in Constantinopel aufhielt. In der Tageszeitung „Oesterreichischer Beobachter“ vom 27. Oktober 1841 wird mitgeteilt, dass „Am 9. d. M. [9. Oktober 1841] [...] der königl. preußische Gesandte, Graf von Königsmark, auf dem Dampfboote des österreichischen Lloyd „Arciduca Ludovico“ seine Urlaubsreise [nach Deutschland] angetreten [hat] [...] Während seiner Abwesenheit führt der Legationsrath von Wagner die Geschäfte der Preußischen Gesandtschaft" (ANonymus 1841). Graf v. KöNigsmarck kam auch nicht nach Constantinopel zurück, sondern wurde im Juli 1842 zum königlichen Gesandten am Niederländischem Hof berufen (Acta 26). Der von DébARRe (2017) kommentierte Text ist also ganz sicher nicht " sous la plume du comte de Königsmarck » - „unter der Feder des Grafen v. KöNIGSMARCK“ entstanden. Weiterhin wird aus den Formulierungen im vorausgegangenen Schriftverkehr von Loew und von v. Olfers und in den späteren Schreiben der Gesandtschaft in Constantinopel deutlich, 
dass es damals bei solchen Exporten üblich war, einen Ferman zur Ausfuhr „alten Marmors“ oder eben „alter Steine“ zu beantragen. Auch ist aus dem obigen Text der Briefvorlage ersichtlich, dass es sich um Antiquitäten handelt. Der Inhalt lautet übertragen etwa, dass Professor SchÖNBORN mitgeteilt hat, er hätte „eine alte Mauer gefunden, die in Trümmer fällt, auf der sich quadratische Steine mit einigen Skulpturen befinden, die bald vollständig zerstört und unter der Erde begraben werden. Diese alten Steine können für niemanden in ihrem gegenwärtigen Zustand von irgendwelchem Nutzen sein, aber da er sich für Wissenschaft und alte Geschichte interessiert, möchte Professor SchönBorn einige davon mitnehmen“ (Acta 38). Im daraufhin von den Osmanischen Behörden erstellte Vizirialschreiben (Acta 40) ist dann auch direkt von „Antiquitäten“ zu lesen „die in Europa sehr geschätzt werden“: " $\mathrm{Vu}$ les bonnes relations existant entre les 2 Cours, il convient aquiescer à de pareilles sollicitations, puisque de telles antiquités sont très estimées en Europe ».

Museumsdirektor v. Olfers antwortete auf LoEws Brief vom 29. Dezember 1841 (Acta 45) nicht nur durch seine Bemühungen, über den Außenminister einen Ferman zu erwirken (Acta 35), sondern auch direkt, indem er LoEw und SchönвoRN am 17. Februar ein Schreiben nach Smyrna mit Duplikat nach Rhodus sandte (Acta 47). Darin gibt er genaue Anweisungen, die zwei von Loew beschriebenen Statuen zu erwerben und zu verschiffen, und sorgt mit einem Wechsel über 3000 Thaler (einzulösen bei dem Handlungshaus van Lennep in Smyrna), für die Finanzierung. Das spätere Schreiben ScHöNBORNS an v. OlfERs (Acta 46) war zu dieser Zeit noch unterwegs. Von OlfERs reagierte nach dessen Erhalt mit einem Brief an v. WAgner (Acta 48). In dieses Schreiben schloss er einen ausführlichen Brief an SchöNBORN ein (Acta 49). Beide wurden am 10. März gemeinsam aus Berlin abgesandt. An SchönBoRn schreibt er: „Ew. gefälliges Schreiben aus Rhodus vom 27. Januar ist mir erst am 2. d. [Monats] [2. März 1842] zugegangen. Ich habe keine Zeit verloren um wegen der in demselben angeregten Sache die erforderlichen Einleitungen zu treffen [...] Ist eine von denselben [den Gestalten neben der Tür des Monumentes von Gjölbaghtsche] wenigstens so viel erhalten, daß man, wenn sie als Friese in den geräumigen und hellen Sälen unseres Museums aufgestellt werden, sie noch zur Genüge erkennen, und ihren Eindruck mit Behagen geniessen, auch das Einzelne ohne zu große Competencen aufzufinden und zu deuten vermag, so sind sie es allerdings wohl werth, hieher geschafft zu werden [...] Obwohl ich von S. M. [Seiner Majestät] mehrfach angewiesen bin, bei Verwendung für Kunstwerke mit aller Sparsamkeit zu Werke zu gehen, so trage ich daher unter den obigen Voraussetzungen keine Bedenken Ihnen und Ihren Hn Reisegefährten abermals einen Creditbrief bis zur Höhe von 3000 Th [preußische Thalern] oder 11.000 Francs [französische Francs] auf das Haus J. v. Lennep \& Companie in Smyrna zu <über- senden> [...] Ew. erwähnen in Ihrem Schreiben vom 27 Januar gar nicht das frühere vom 29./12.41 <welches> Sie gemeinschaftlich mit dem Hr Prof. Loew an mich sandten, und worauf meine <Antwort> vom 14. v. M. [Februar] inzwischen Ihnen zugegangen sein wird [...]". Von Olfers hat also über den ersten Kreditbrief hinaus, den er im Schreiben vom 17. Februar (Entwurf vom 14. Februar) erwähnt (Acta 47), den Reisenden einen zweiten Kredit in gleicher Höhe über die GeneralDirektion der Seehandlungs-Sozietät in Berlin und das niederländische Handlungshaus vAN LENNEP \& Co. in Smyrna zur Verfügung gestellt.

All diese geschilderten Aktivitäten verliefen im Februar wohl ohne Kenntnis von Loew und Schönborn. Da die Reisenden weder in Adalia noch auf Rhodus eine Nachricht über eine Verlängerung ihres Urlaubes vom Kultusminister EICHHORN erhielten, mussten sie davon ausgehen, dass sie im März in Smyrna ein Schiff zur Rückreise nach Deutschland erreichen müssen. LoEw hielt sich noch den ganzen Februar auf Rhodus auf und konnte hier auch einige Insekten sammeln. So nennt ZeLler (1827) den lepidopterologischen Fund von Plutella cruciferarum Zeller, 1843 - ein Synonym für die Kohlschabe Plutella xylostella (Linnaeus, 1758). LoEw selbst beschreibt später aus den im Februar auf Rhodus gesammelten Dipteren acht neue Arten. Darunter sind zwei Arten, die er bereits „im Anfange des Februar" auf Rhodus $(\bullet 1)$ gefunden hat und denen er wegen ihres frühen Auftretens im Kalenderjahr den passenden Namen "praecox" gab: die Tephritidae Trypeta praecox Loew, 1844 (= Tephritis) und die Empididae Empis praecox Loew, 1867 (Loew 1844c, 1867). Vor seiner Abreise aus Rhodos nach Smyrna verkaufte LoEw in Erwartung der Rückreise nach Deutschland die nicht mehr benötigte Ausrüstung und machte seine Sammlungen versandfertig (Acta 50). In seinem Bericht an das Kultusministerium vom 26. März teilt LoEw mit „die Unterbrechung aller Verbindung mit Rhodus durch mehrfache Havarie der Dampfschiffe dieser Lienie und durch die Stärke der Aequinoktialstürme hielt mich dort bis zum 15st März fest und erst am 22st gelangte ich nach einer schwierigen Fahrt in einem kleinen türkischen Kutter hier [in Smyrna] an" (Acta 19).

SchönBORN reiste am 7. Februar 1842 allein von Rhodus $(\bullet 1)$ nach Makri $(\bullet 10)$ ab (Schönborn, C. 1868). Von dort führte sein Weg über Tlos $(\bullet 14)$ nach Xanthus $(\bullet 12)$, wo er sich zum zweiten Mal mit Fellows traf (BenNDORF \& NIEMANN 1889). Er setzte die Reise nach Furnas $(\bullet 12)$ fort, ging von dort bei winterlichem Wetter durch die Gebirge über Almalü $(\bullet 34)$ und Gülhissar $(\bullet 30)$ und erreichte am 21. Februar Bubon $(\bullet 15)$. Von dort reiste er über Kisilhissar $(\bullet 8)$, Davas $(\bullet 8)$, Nosli-Basar $(\bullet 6)$, Aidin $(\bullet 5)$ und Ephesus $(\bullet 4)$ nach Smyrna $(\bullet 2)$, wo er am 27. Februar 1842 eintraf (BENNDORF \& NiEMANN 1889, Schönborn, C. 1868) (Abbildung 9). In Loews Bericht ist Schönborns Ankunft allerdings auf den 1. März 
datiert (Acta 19). In Smyrna erhielt er durch Konsul Pezzer die bisher für ihn und Loew eingetroffene Post. Darunter war auch die Zusage der Urlaubsverlängerung durch den Kultusminister EICHHORN vom 3. Dezember 1841 verbunden mit der Genehmigung einer weiteren Reiseunterstützung von 500 Talern und praktischen Ratschlägen, wie sich von den lykischen Inschriften wohl die besten „Papierabklatsche“ anfertigen ließen (Acta 18).

Die zwei Schreiben von v. OlfERs vom 17. Februar (Acta 47) und vom 10. März (Acta 48) haben SchöNBORN jedoch nicht erreicht, da er bereits am 10. März aus Smyrna abreiste (BENndorf \& NiEMANn 1889, SchöNBORN, C. 1868). LoEw hat SchönBorns Abreise dagegen mit dem 14. März angegeben (Acta 19). Zu dieser Zeit bemühte sich der Legationsrat v. WAGNER weiter um einen Ferman. Am 8. März schreibt er dem Dragoman Stiepovich in einem Brief, dass Schönborn und Loew angekündigt hätten, Smyrna um den 25. März verlassen zu wollen (Acta 39). Er drängte ihn deshalb, jetzt schnell eine Entscheidung bezüglich des am 12. Februar beantragten Fermans herbeizuführen. Am 9. März meldete der Dragoman, dass die Osmanischen Behörden zwar keinen Ferman genehmigten, aber ein Vizirialschreiben für die lokalen Behörden der Region Aydın erlassen haben, in dem diesen Behörden nahegelegt wird, den Kauf und Transport von Antiquitäten zu ermöglichen. Dieses Vizirialschreiben sandte v. WAGNER am 17. März 1842 an SchönBorN in Smyrna (Acta 41).

Loew hatte sich, wie er im Brief vom 26. März an v. Olfers schrieb (Acta 50), mit seiner Ankunft in Smyrna verspätet: „Ich selbst wurd in Rhodus wider Willen festgehalten; Stürme u Havarien verzögerten meine Ankunft in Smyrna“. In dieser Antwort auf den Brief von v. Olfers vom 17. Februar schreibt LoEw weiter: „Oberlehrer Schönborn versuchte noch auf ein paar Wochen in das Innere von Mentecha einzudringen. Mitte des März war zum gemeinschaftlichen Eintreffen in Smyrna bestimmt. Der unerhört harte Nachwinter hat den Oberlehrer Schönborn alle weiteren Vordringen gehindert und schon zu Anfang des Monats nach Smyrna genöthigt. Hier hat er die Hohe Bewilligung des erbetenen Urlaubes vorgefunden, mich über den verabredeten Termin vergeblich erwartet und ist dann in das Innere abgereist um noch einmal durch Pamphilien womöglich bis zu den thaurischen Städten vorzudringen“.

Einige Verhaltensweisen SCHÖNBORNs lassen sich aus der Rückschau nicht recht interpretieren. Warum er auf Rhodus drei Wochen verstreichen ließ, bevor er der Gesandtschaft in Constantinopel und v. Olfers in Berlin von seiner Entdeckung in Gjölbaghtsche berichtete und damit den Zeitraum für eine Antwort so verkürzte, dass es wenig wahrscheinlich war, dass sie ihn bis Mitte März erreichen konnte, bleibt rätselhaft. Noch eigenartiger ist es, dass Schönborn schon am 10. März (oder nach Loew am 14. März) von Smyrna in Richtung Kuhla (•21) abreiste und erst Anfang Juli wieder nach Smyrna $(\bullet 2)$ zurückkehrte. Er wartete im März weder das Eintreffen der von ihm selbst in seinen Briefen vom Januar zu Mitte März erbetenen Zusagen des Museumsdirektors v. OlfERs ab, noch auf die von ihm von der Gesandtschaft gewünschte Genehmigung zur Ausfuhr der Antiquitäten (Acta 34, 46; Schönborn, C. 1868).

Etwa mit der Ankunft von Loew Ende März in Smyrna begannen die Osterferien an der Posener Schule. Eine pünktliche Heimkehr zum Sommersemester wäre wohl nicht mehr möglich gewesen. Doch LoEw fand bei seinem Eintreffen in Smyrna ebenfalls die Urlaubsverlängerung vor (Acta 18). In seinem späteren Brief vom 20. August 1842 an das Kultusministerium (Acta 23) erklärt er auch, weshalb diese Nachricht ihn nicht früher erreicht hat: „Die bereits längst bei dem Königl. Konsul eingetroffne gnädige Verfügung eines hohen Ministerii hatte derselbe einem Segelschiff nicht anvertrauen zu dürfen geglaubt und sie deshalb, da die Dampfschiffverbindung unterbrochen war, zurückbehalten, so daß der Unterzeichnete jetzt erst davon in Kenntniß gesetzt, genöthigt war von Neuem sämmtliche Reiseutensilien anzuschaffen, davon er sich bei aufgegebener Hoffnung auf Fortsetzung der Reise bereits in Rhodus entledigt hatte“.

Insbesondere für LoEws entomologische Forschung hatte diese Nachricht mit der genehmigten Urlaubsverlängerung überaus positive Auswirkungen. Konnte er doch nun in der günstigsten Jahreszeit von April bis Juni eine reichhaltige Insektensammlung zusammentragen. Auch das von der Gesandtschaft erlangte Vizirialschreiben hat ihn jetzt erreicht (Acta 41). Gleich nach Ankunft verfasst er einen Brief an die Gesandtschaft (Acta 42), den er am 26. März gemeinsam mit einem Schreiben an v. OlfERs und an Minister EICHHORN absandte. Dem Legationsrat v. WAGNER teilt er mit: „Ew. Hochwohlgeboren haben die große Geneigtheit gehabt uns ein Vizirialschreiben $\mathrm{zu}$ erwirken, wofür wir unseren gehorsamsten Dank auszusprechen uns erlauben. Die Verknüpfung von mancherlei ungünstigen Umständen macht die Erwerbung der bezeichneten Monumente für den Augenblick unmöglich, was ich Hr. Geh. Rath von v. Olfers pflichtschuldigst darzulegen mir erlaubt habe, mit unmaßgeblichen Gesuche die Sache von der Hand ganz ruhen zu lassen, um nicht eine unwillkommene Aufmerksamkeit darauf $\mathrm{zu}$ lenken. - Ich vermute, daß diese Lage der Sache auch Ew. Hochwohlgeboren bestimmen wird, in dieser Angelegenheit weiter nichts zu thuen“. Das Schreiben von v. OlFERS vom 17. Februar (Acta 47) könnte LoEw schon durch ein Duplikat, dass nach Rhodos ging, bekannt gewesen sein. Falls nicht, hat er den Brief zumindest jetzt in Smyrna erhalten, denn er antwortet am 26. März darauf (Acta 50): „Ewer Hochwohlgeboren erlaube ich mir auf ein hochgeneigtes Schreiben vom 14. [abgesandt am 17.] Febr. a. c., welches mir heute vom Königl. Konsul hieselbst nebst den Kreditbriefen der Königl. Seehandlung übergeben worden ist, ganz gehorsamst $\mathrm{zu}$ berichten, daß 


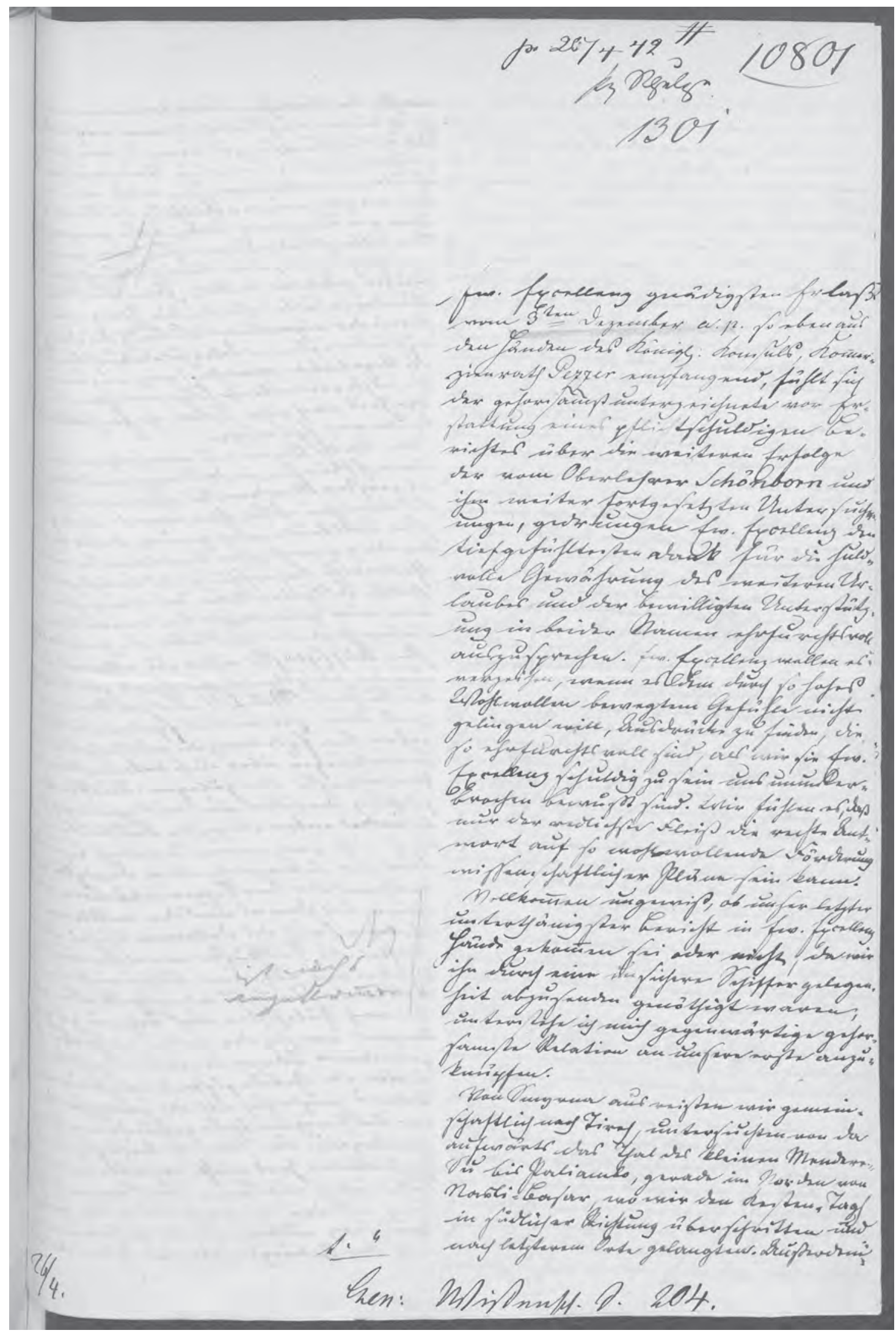

Abb. 10: Faksimile eines Briefes von Loew aus Smyrna vom 26. März 1842 an den Kultusminister EichHORN in Berlin, eingegangen am 26. April. Zweiter Teil des Reiseberichtes (Acta 19, Seite 1 von 8).

[Fig. 10: Facsimile of a letter from LoEw from Smyrna of 26 March 1842 to the Minister of Education EichHORN in Berlin, received on 26 April. Second part of the travelogue (acta 19, page 1 of 8).] 
sich alle Umstände auf eine unglückliche Weise so gestaltet haben, daß für den Augenblick es unmöglich ist, wegen der beiden Statuen und des Grabmonumentes etwas zu unternehmen. [...] Ew. Hochwohlgeboren hochgeneigtes Schreiben ist leider erst einige Tage nach seiner [SCHÖNBORNs] Abreise angelangt und ihm so der Inhalt desselben unbekannt geblieben. [...] Sähe ich eine Möglichkeit dazu, so würde ich es für erste Pflicht halten Ew. Hochwohlgeboren Befehlen zu genügen und es würde mir die größte Freude sein dem Vaterlande besonders das von Schönborn entdeckte merkwürdige Monument zuzuführen, über dessen Auffindung er im Februar Ew. Hochwohlgeboren von Rhodos aus berichtet hat. Leider bin ich es nicht im Stande. Ankauf der nothwendigen Instrumente und Maschienen, der nur hier in Smyrna, und auch hier schwer zu erhaltenden Breter [Bretter] von gehöriger Stärke für die nöthigen 200 und mehr Kisten, deren Maaß ich hier ohne Schönborns Tagebücher nicht einmal zu bestimmen vermag, Anwerbung und Hinführung der nöthigen Arbeiter würde sehr viel Zeit kosten. Außerdem sind, wie ich aus Schönborns Mittheilungen weiß, die Steine viel zu groß um auf Kamelen transportirt $\mathrm{zu}$ werden, der Weg für Wagen, die überdies auch von hier mitgenommen werden müßten, ganz unbrauchbar, so daß die Alternative einträte entweder den Weg herzustellen, oder Steinmetze zur Abnahme der Hinterseite der Steine mit zu nehmen. Alles dies würde die Arbeit in eine Zeit verschieben, wo sie theils des Klimas, theils des Ablaufenden Urlaubes wegen nicht mehr möglich wäre. Wäre Schönborn nur hier, oder wüßte ich ihn zu erlangen, so sollte den vereinten Kräften es doch wohl noch gelingen. Mich tröstet das, daß ich Ew. Hochwohlgeboren die bestimmte Versicherung geben zu können glaube, daß dennoch die Erwerbung dieses merkwürdigen Denkmales für die vaterländischen Museen, und zwar ohne große Kosten, als ziemlich sicher angesehen werden kann. Den näheren Plan hoffe ich bei der Rückkehr in das Vaterland Ew. Hochwohlgeboren darlegen zu dürfen“.

Dieser Brief und die anderen Schreiben an und von der Generaldirektion der Königlichen Museen sind von den Autoren erst jetzt wieder im Geheimen Staatsarchiv in Berlin aufgefunden worden. Der Text wurde zwar schon von BENNDORF \& NiEMANN (1889) in ausführlichen Passagen zitiert, blieb aber im 20. Jahrhundert verschollen und war auch DÉBARRE (2017) im Original unbekannt. Obwohl es sich inhaltlich nur um Altertümer und die von v. Olfers gewünschten Antiquitäten handelt, hat er doch große Bedeutung für den weiteren Ablauf der Reise. Deshalb werden Teile des Inhalts hier relativ ausführlich wiedergegeben. LoEw beschreibt in seinem Brief recht realistisch die Unmöglichkeit, in der verbleibenden Zeit und mit den zur Verfügung gestellten Mitteln, die große Grabanlage von Gjölbaghtsche zu bergen und zu verschiffen. Die Berichte von BENNDORF \& NiemanN (1889) über den 40 Jahre später tatsächlich erfolgten Abbau und Transport, welcher mit dem vorherigen Bau einer Straße zwischen dem Heroon und dem nächsten Hafen verbunden war, geben ihm nachträglich recht. Loews gegenteilige optimistische Prognose in den letzten zwei Sätzen ist deshalb etwas überraschend. Vielleicht sollte diese Aussage auch nur über die enttäuschende grundsätzliche Mitteilung „daß für den Augenblick es unmöglich ist, wegen der beiden Statuen und des Grabmonumentes etwas zu unternehmen“ hinweghelfen. Ähnlich werten BenNdorf \& NiemanN (1889) auch den anschließenden umfangreichen Bericht über lykische Altertümer in diesem vierseitigen Brief Loews (Acta 50).

Noch wesentlicher als die Akten der Generaldirektion der Königlichen Museen waren die im Geheimen Staatsarchiv in Berlin erstmals aufgefunden Akten des Kultusministeriums, die speziell zu SCHÖNBORN und Loew angelegt wurden. Durch diese separate Ablage fehlten die Unterlagen in dem chronologisch angelegten allgemeinen Aktenbestand des Ministeriums und wurden bisher übersehen. Diese Akten scheinen, im Gegensatz zu den Unterlagen aus dem Königlichen Museum, nahezu komplett erhalten zu sein. Sie bestehen aus 248 beschriebenen Seiten, darunter das Gutachten RitTers zur ersten Reise (Acta 4), das Gutachten von Alexander von Humboldt, Carl Ritter und Ignaz von Olfers zur zweiten Reise von SснӧNвоRN und drei Briefe LoEws an den Minister EICHHORN, die zusammen einen Reisebericht ergeben. Es handelt sich um den Brief aus Smyrna vom 6. Oktober 1841 (gemeinsam mit SchönBorN) (Acta 17, 57), den Brief aus Smyrna vom 26. März 1842 (Acta 19) (Abbildung 10) und den Abschlussbericht aus Berlin vom 20. August 1842 (Acta 23). Diese Berichte gehen oft sehr ausführlich auf geographische und geologische Beobachtungen ein, enthalten aber leider kaum konkrete Daten zum zeitlichen Ablauf.

Anfang April ist Loew noch in Smyrna (•2). Ob das von v. OlFERS am 10. März aus Berlin an SCHÖNBORN abgesandte Schreiben (Acta 49) inzwischen hier vorlag, ist nicht bekannt. Am 3. April schreibt LoEw einen Brief an seine Frau Ottilie und teilt ihr mit, dass er eine Urlaubsverlängerung erhalten hat. Dieses Schreiben ist uns im Original unbekannt geblieben. Ottilie Loew erwähnt diesen Brief aber in ihrem Schreiben an Minister EichHorn (Acta 20). Am nächsten Tag, den 4. April, unterzeichnet Loew in Smyrna die Quittung für den Erhalt der 500 Taler, die Kultusminister EichHORN als weitere Unterstützung für beide Reisende gewährt hatte (Acta 18, 43). Dem Kultusminister teilt er in seinem späteren Abschlussbericht vom 20. August mit, dass er wegen der eingetretenen Umstände erst am 5. April 1842 seine Untersuchungen fortsetzen konnte (Acta 23). Er wendet sich von Smyrna $(\bullet 2)$ zuerst in Richtung Westen, dann nach Süden und folgt danach dem Küstenverlauf von Sigadschick $(\bullet 3)$ bis Aiasoluk $(\bullet 4)$ nach Südosten. In seinem Bericht geht er wiederum sehr ausführlich auf die Geologie und Geographie dieses Gebietes und der anderen durchwanderten Landschaften ein. Bereits 
am 7. April ist Loew in Ephesus $(\bullet 4)$. Von diesem Fundort sind viele Nachweise von Lepidoptera bekannt, die ZeLler (1847) publizierte. Aus der „Gegend von Ephesus, wo ich sie im April fing“ (LoEw 1847e) stammt auch die Asselfliege Rhinophora lucidiventris LoEw, 1847, nach STEIN (1924) ein Synonym von Stevenia atramentaria (MEIGEN, 1824), sowie zahlreiche andere später von Loew beschriebene Dipteren. Loew bemerkt dazu: „In Ephesus selbst wurde zu möglichst vollständiger Sammlung der Frühlingsflora ein längerer Aufenthalt gemacht. Auch die Ausbeute an Insekten fiel hier schon ziemlich gut aus“ (Acta 23). Von Ephesus $(\bullet 4)$ reiste er nach Skalanova $(\bullet 4)$ und von dort am 9 . April weiter über Aidin $(\bullet 5)$ und Nosli Basar $(\bullet 6)$ durch das Mäandertal $(\bullet 6)$. Nachfolgend erreichte er am 11. April Karajasu $(\bullet 7)$ und am 12. April Ghera $(\bullet 7)$, beide Orte liegen am Südwesthang des Babatagh $(\bullet 7)$ und am Nordosthang des Karadschatagh $(\bullet 7)$. In dieser Berggegend zogen gerade erst die Vorboten des Frühlings ein. Loew schreibt: „Die ziemlich bedeutende Meereshöhe beider Orte [Karajasu und Ghera], die Nähe noch viel höherer, weitherab noch mit Schnee bedeckter Berge und die dadurch bedingte Kälte der Wasserzuflüsse hatten hier (Mitte April) die eben erst erwachte Vegetation sichtlich zurückgehalten. Ein zweitägiger Aufenthalt in und um Karajasu gab so nur mittelmäßige botanische und entomologische Ausbeute, unter letzterer indeß einige noch unbeschriebene interessante Insektenspezies“ (Acta 23). Am 13. April 1842 erreichte LoEw bei ungünstigem Wetter Davas $(\bullet 8)$. Sein Weg führte ihn von dort weiter über Mulah $(\bullet 9)$, Makri $(\bullet 10)$ und Mermeriza $(\bullet 11)$ zurück nach Rhodus $(\bullet 1)$, wo er Ende des Monats eintraf (Acta 23). Von diesen Fundorten hat LoEw zahlreiche Insekten, vor allem Diptera und Lepidoptera, mitgebracht, wodurch sich sein Reiseweg auch im Zeitablauf rekonstruieren ließ. Darunter waren die Sackträgermotte Coleophora fuscicornis LIENIG \& ZELler, 1846, die bei Karajasu gefunden wurde, und der Zitronenfalter Rhodocera farinosa ZELLER 1847 aus Makri. Loew selbst publizierte schon 1843 die Beschreibung von zwei neuen Käferarten aus der Umgebung von Mulah (Loew 1843d). Durch die Funde der Asilide Dasypogon megilliformis LoEw, 1847 (=Crobilocerus) sind gleich drei der genannten Orte belegt. Loew schreibt zu dieser Art: „die Gegend von Karajasu, Muhla und Mermeriza, wo ich sie im April fing“" (LoEw 1847d). Mermeriza und Makri gehören zu LoEws ergiebigsten Sammelorten. An den wenigen Tagen seines Aufenthaltes Ende April und wieder Ende Mai hat er so viele Dipteren dort gesammelt, dass er später mehr als 40 neue Arten aus diesem Material beschrieb.

Nach der Wanderung im noch winterkargen Gebirge war der Eindruck des inzwischen an den Küsten voll eingezogenen Frühlings auf LoEw bemerkenswert (Acta 23). Er beschreibt den Blick von der letzten Passhöhe mit den Worten: „Vor mir lag eine in üppiger Blüthenfülle weit ausgedehnte Ebene; rechts war sie vom Meere bei Giwa [Gjöwa], links von dem Meere bei Ködschaß [Keug- hez] begrenzt; gegenüber die Halbinsel von Mermeriza mit ihren manchfaltig gestalteten, der Serpentinhebung angehörigen Bergen. Fast von Schritt zu Schritt bei dem stundenlangen Hinabsteigen am schroffen Gehänge des Berges, mehrte sich Reichthum und Entfaltung der Vegetation und der flüchtigste Blick erkannte, daß jetzt Ort und Zeit zu einer reichen botanischen und entomologischen Beute gefunden sei [...] Am nächsten Tage wurde die Reise bis Makri fortgesetzt. Trotz dem ohne alle Ausnahme ungünstigen Wetter war hier der Pflanzen und Thierreichthum bereits so groß, daß alle Kräfte zum Sammeln desselben aufgeboten und jede Ruhestunde zur Fortführung des darauf bezüglichen Tagebuchs benutzt werden mußte. Nach einem längeren Aufenthalte in Mermeriza wurde eine Schiffsgelegenheit benutzt um nach Rhodus zu gelangen“"

Zur Zeit des orthodoxen Osterfestes hielt sich Loew auf der überwiegend von Griechen bewohnten Insel Rhodus $(\bullet 1)$ auf, wo er von Ende April bis Anfang Mai 1842 auch Insekten sammelte. Genauere Daten seines Aufenthaltes sind nicht bekannt. Nur für den Fund der Geometride Idaea ostrinaria (HüBNER, 1813) gibt ZelLer (1847) den 25. April als konkretes Datum an. Den weiteren Reiseverlauf beschreibt LoEw in einem Bericht an das Kultusministerium (Acta 23) mit folgenden Sätzen: „In der Verlegenheit um eine Schiffsgelegenheit nach der lycischen Küste boten die Offizire des zur Abholung der Antiken in Xanthus bestimmten englischen Kriegsdampfbotes eine willkommene Auskunft durch das Anerbieten eines Platzes an ihrem Bord. Unmittelbar nach der Landung an der Mündung des Xanthus und nach Besichtigung sämmtlicher von ihnen [...] überzuführenden Antiken, verließ der unterzeichnete ihre Gesellschaft [...] Genauere Untersuchung der Gegend zeigte, daß die sumpfigen Umgebungen von Kellemisch (Patara) die reichste Ausbeute bieten würden. Obgleich die dieses Jahr so tödtlich auftretenden typhösen Fieber die Bevölkerung längst weit weg gescheucht hatten und die ungeheuren Schwärme der Mosquitos wenig Ruhe hoffen ließen, konnte doch ein längerer Aufenthalt in dieser Gegend nicht vermieden werden. Fast gänzlicher Mangel an Nahrungsmitteln und Trinkwasser und die wahrhaft unbeschreibliche Menge der Mosquitos wurden leicht über den Reichthum der Ausbeute vergessen, deren Erlangung vom ersten Grauen des Morgens bis in die Nacht hinein reiche Beschäftigung gab. Nachdem ein in den letzten Tagen durch reichliche Bezahlung zur Herbeischaffung von Milch und Wasser bewogener Gebürgshirt dem Fieber erlegen und sich bei dem unterzeichneten wie bei dessen Diener beunruhigende Krankheitssymptome zu zeigen anfingen, wurde dieser Aufenthalt, wiewohl mit Bedauern aufgegeben und die Reise über Furnas in das Gebürge der Südküste fortgesetzt. Entomologische und botanische Forschungen beschäftigten hier so sehr, daß keine andere Untersuchung auf nur einigermaßen befriedigende Weise geführt werden konnte“. Mit Hilfe der in 
Lycien aktiven Engländer konnte LoEw also wieder bequem auf das Festland kommen. Bei dieser Gelegenheit studierte er auch die in Xanthus für den Abtransport nach England vorbereiteten Antiquitäten und äußert sich dazu fachspezifisch in dem genannten Bericht an Minister EICHHORN (Acta 23). Bereits am 11. Mai war er in Kellemish $(\bullet 12)$ und danach in der näheren Umgebung dieses Ortes bei Patara $(\bullet 12)$ und Furnas $(\bullet 12)$ aktiv. Die reiche, vor allem entomologische Ausbeute, veranlasste ihn hier einige Tage zu verbringen - trotz der klimatischen und gesundheitlichen Belastungen in diesem damals malariaverseuchten Landstrich. Am 18. Mai reiste er zum Xanthus-Tal $(\bullet 13)$ und nach Tlos $(\bullet 14)$ und weiter in das Gebirge bis Boubon (Chorsun) $(\bullet 15)$. Von dort nach Makri $(\bullet 10)$ zurückgekehrt, hielt er sich vom 21. bis zum 25. Mai erneut in der Umgebung der Stadt auf und untersuchte dabei auch das Küstengebirge, den Kragus $(\bullet 16)$ (Acta 23, Zeller 1847). Auch dieses Gebiet war hinsichtlich der entomologischen Ergebnisse sehr ergiebig: „Makris Umgegend zeigte fast denselben Pflanzen und Insektenreichthum, wie die Gegend von Kellemisch; Fieber waren hier äußerst häufig, doch viel weniger gefährlich, so daß ein längerer Aufenthalt rathsam schien. Exkursionen weit in den Kragus hinein, nördlich an der Küste hin und höher hinauf in das Küstengebürge lohnten durch reichliche Ausbeute, besonders an Insekten, deren Erscheinen jetzt so aufeinander drängte, daß selbst die Ermittlung der Vegetationsverhältnisse größten Theils aufgegeben werden mußte.“ Am 26. Mai 1842 setzte Loew wieder nach Rhodus $(\bullet 1)$ über, um die Rückreise nach Deutschland vorzubereiten (Acta 23).

Hier blieb er bis Anfang Juni. Das Dampfschiff nach Smyrna war in Rhodus wegen der sich in Syrien ausbreitenden Pest mit Quarantäne belegt worden, so dass Loew noch einige Tage Zeit hatte, um den südwestlichen Teil der Insel bis zum Monte Ateiro $(\bullet 17)$ zu erkunden und dann mit einem Segelschiff aufzubrechen (Acta 23). Von Rhodus $(\bullet 1)$, wo er insgesamt die längsten Aufenthalte hatte, brachte LoEw eine reiche entomologische Ausbeute mit. Er beschrieb aus dem dort gesammelten Material insgesamt 35 Dipterenarten. Darunter ist die Asselfliege Rhinophora triangulata LoEw, 1847, ein Insel-Endemit, jetzt in die Gattung Stevenia gestellt (Loew 1847e). Von dieser Art sind die Syntypen erhalten und erlauben so eine klare Zuordnung. Von einer weiteren Asselfliegenart von Rhodus, Rhinophora laeviventris Loew, 1847, ist dagegen der Holotypus bereits vor langer Zeit durch Insektenfraß zerstört worden, wie schon STEIN (1924) feststellten musste. Deshalb bleibt dieser Artname ein Nomen dubium, der keinem Taxon auf Artniveau sicher zugeordnet werden kann. Beide Arten wurden im April bzw. im April und Mai 1842 gefunden (LoEw 1847e). Weiterhin hat Loew von Rhodus auch die Tachinidae Ocyptera rufifrons Loew, 1844 (= Cylindromyia) beschrieben (Loew 1844e).
In der Zeit vom 10. (oder 14.) März bis zum 31. Mai 1842 war SchönboRn von Smyrna $(\bullet 2)$ aus über die Gebirge kreuz und quer durch das Land gezogen. Seine Reisewege sind auf der Karte in Abbildung 9 wegen vielfacher Überschneidungen und Mehrfachbesuche nur grob skizziert. Detailliertere Angaben sind bei BENNDORF \& NiEMANN (1889) sowie bei RitTer (1859) zu finden. Im März ging Schönborn über Kuhla $(\bullet 21)$, Hierapolis $(\bullet 22)$, Gülhissar $(\bullet 30)$ und Kibyra $(\bullet 30)$ nach Jaryschly $(\bullet 23)$. Sowohl am 1 . April als auch am 1 . Mai besuchte er noch einmal den Kestel Göl $(\cdot 27)$. In der Zwischenzeit war er im April in Milyas (•28), Adalia $(\bullet 32)$, Olympus $(\bullet 36)$ und erreichte am 20 . April ein zweites Mal Gjölbaghtsche $(\bullet 35)$. Von hier aus ging er wieder in das höhere Gebirge und war zwischen Almalü $(\bullet 34)$, Oenoanda $(\bullet 15)$ und Balbura $(\bullet 15)$, Olbasa $(\bullet 26)$, Sagalassos $(\cdot 24)$ und Kremna $(\cdot 28)$ unterwegs. Seine Wanderungen setzte er im Mai vom Kestel Göl $(\cdot 27)$ über den Dipoirasdagh $(\bullet 25)$, den Eurymedon $(\bullet 29)$ herunter über Kesme $(\bullet 29)$ und Selge $(\bullet 29)$ nach Aspendus $(\bullet 33)$ fort und ging dann an der Küste weiter bis Adalia $(\bullet 32)$. Auf dem Rückweg von dort nach Rhodus studierte er zuerst Termessos $(\bullet 31)$ und erreichte am 31. Mai Xanthus $(\bullet 12)$ (Benndorf \& Niemann 1889, Ritter 1859, Schönborn, C. 1868). Nach Benndorf \& Niemann (1889) wurden ihm dort die Pferde gestohlen Er hatte aber die Gelegenheit von Xanthus aus mit der „Monarch“, dem englischen Schiff, welches unter Regie von Fellows die Antiquitäten von dort abtransportierte, nach Rhodus zu gelangen (SPRATT und Forbes 1847). Ob er auf Rhodus LoEw noch persönlich antraf ist nicht überliefert, da dieser „Anfang Juni“ nach Stanchio abgereist ist (Acta 23). Loew hatte sich auf Rhodus zuvor schon mit den englischen Reisenden Spratt und Forbes in der Villa von W. SANDFord getroffen. Spratt und Forbes (1847) berichten im 2. Band auf Seite 8 wie folgt darüber: "During our stay with Mr. Sandford we fell in with Herr Loew of Posen, one of the party of German savants who had been sent by the King of Prussia on a mission of discovery in Asia Minor. This gentleman and Professor Schönbrun had chosen Lycia as the field of their researches; but, though we had all been in the country at the same time, and had often crossed each other's paths, we had never chanced to come in contact." Danach kam es auch zur einer Begegnung von SpRATT und Forbes mit SchöNBORN: "After the departure of Mr. Daniell from Rhodes, Professor Schönbrun arrived, having opportunely fallen in with the officers of the Monarch, in which ship he crossed from Xanthus. We had a very delightful interview and conversation on the antiquities of Lycia, whilst he was in quarantine." (SPRATT und Forbes 1847). SCHÖNBORN berichtete den Engländern bei diesem Zusammentreffen offensichtlich auch von seiner Entdeckung der bisher unbekannten Ruinen des wirklichen Selge. Spratt und Forbes informierten umgehend ihren zuvor nach Adalia abgereisten Freund DANIELL in einem Brief darüber. Dieser hatte daraufhin Gelegen- 
heit sich selbst auf den beschriebenen Weg nach Selge $\mathrm{zu}$ machen und erreichte es am 22. Juli 1842. Trotzdem DANIELl kurz darauf so schwer erkrankte, dass er verstarb, wurden die Ergebnisse seines Besuchs SPRATT und Forbes zugänglich gemacht (SPRATT und Forbes 1847). Auf Seite 26 des 2 . Bands berichten sie davon und fügen folgende Anekdote von DANiell an: "[In Selge] I was wonderfully well received by these mountaineers, who had never seen but one Frank before, and him a few months ago, only for a night. He was a man with a beard, they said, who did nothing but pick up stones, throw some down again, and put others into his pocket. It was quite clear who my friend was." Weiter unten folgt als Fußnote zu diesem Text: "The Frank alluded to was, doubtless, Professor Schonbrun, who, when at Rhodes, after Mr. Daniell's departure, told us that he had visited the Selge of Sir C. Fellows, and proved it to be Cremna; and that he had found another large city, which he believed to be the true Selge. This we communicated by letter to Mr. Daniell when he was at Adalia. ['Frank' im übertragenen Sinne für einen Franken, einen Germanen]".

\subsection{Abschluss der Expedition im Sommer 1842 und Heimreise}

SchönBorn reiste im Juni von Rhodus $(\bullet 1)$ über Makri $(\bullet 10)$ und wieder durch die Gebirge über Bubon $(\bullet 15)$ und Kibyra $(\bullet 30)$ nach Smyrna $(\bullet 2)$ (Benndorf \& NiemanN 1889, RitTER 1859, SCHÖNBORN, C. 1868).

LoEw verließ Anfang Juni Rhodus $(\bullet 1)$ auf einem Schoner in Richtung Stanchio $(\bullet 18)$. Von dieser Insel gibt es zahlreiche entomologische Nachweise aber nur ein konkretes Datum, den 9. Juni 1842. Zeller (1847) berichtet von LoEws Schmetterlingsfunden dort. Darunter ist auch die neu beschriebene Art Sesia trivittata ZELLER, 1847. LoEW selbst beschreibt die Raubfliege Asilus denticulatus LoEw, 1849 (= Cerdistus) von Stanchio (LoEw 1849a) und auch die interessante Spinnenfliege Philopota murina Loew, 1844 (jetzt in der Gattung Oligoneura) (Abbildung 11 auf Seite 255). Von letzterer gibt er einen anschaulichen Bericht zum Verhalten der Art (Loew 1844d): „Ich traf beide Geschlechter am 9. Juni auf Stanchio an einer erhitzten Erdwand in der Mittagsstunde in lebhaftem Fluge, nach Art der Bombylier bald stossweise fliegend, bald an einem Punkte schwebend; das Männchen in lebhafter Verfolgung des Weibchens begriffen; es nahm seinen Platz stets etwa einen Fuss über dem Weibchen, dem es in allen Bewegungen folgte. Beide Geschlechter waren sehr beweglich. Das Weibchen fand ich bei Makri im Mai vor einer Blüthe schwebend, den Körper vollkommen senkrecht tragend und den Rüssel fortwährend auf- und abklappend, während die Beine am Körper herunterhingen und fortwährend an einander gerieben wurden; zuletzt versenkte sie den Rüssel, ihn gerade nach vorn richtend, in die Blume, und wurde von mir gefangen, ohne dass ich beobachten konnte, ob sie sich des Blüthenhonigs oder des Pollens bemächtigte“.

Auf der anschließend besuchten Insel Lerus $(\bullet 19)$ erlebt Loew, wie die dortige Landbevölkerung das sehr spezifische Befruchtungssystem von Feigenbaum und Feigenwespe im Interesse einer guten Ernte unterstützt. Er berichtet darüber in seiner Arbeit „Über die Caprification der Feigen“ (Loew 1843a) folgendermaßen: „Man hat so viel von der Caprification der Feigen geschrieben und gesprochen und zum Theil Widersprechendes über die dabei thätigen Insekten gemeldet, dass ich schon längst begierig war, sie selbst $\mathrm{zu}$ beobachten. [...] Auf Leros bot sich nun eine viel $\mathrm{zu}$ günstige Gelegenheit, als dass ich sie hätte entschlüpfen lassen können. Schnell war ich drüben im benachbarten Garten und mitten unter den Frauen und Mädchen von Leros, die mich nicht ungern an ihrer Arbeit theilnehmen liessen [...] Nachdem so ein genügender Vorrath wilder [caprificierter] Feigen gesammelt war, ging es mit lautem Jubel zu den riesigen Feigenbäumen des Gartens zurück. Binsenhalme lagen noch in Menge bereit. Mit ihnen wurden die wilden Feigen am untersten Ende durchbohrt und festgebunden, so dass jeder Halm an jedem seiner beiden Enden eine Feige trug. Mit diesen Feigenpärchen behing man zuerst die untersten Zweige des Baumes, der die Caprification erhalten sollte, in möglichst gleichen Entfernungen. Dann wurden die höhern, und zuletzt die höchsten Zweige unter fortwährendem Scherze durch geschickte Würfe fast eben so regelmässig beladen. “ Es waren wohl Form und Funktion der Feigenpärchen, welche die Beteiligten dabei zu naheliegenden Scherzen veranlassten. In dieser Publikation nennt er auch ein Datum für seinen Aufenthalt auf der Insel, den 19. Juni 1842. Möglicherweise ist dieses Datum ein Druckfehler, denn es passt so gar nicht in den weiteren Reiseablauf. In seinem Bericht an das Kultusministerium berichtet LoEw von einer Überfahrt bei heftigen Stürmen und Schäden am Schiff, nennt aber keine Daten für seine Aufenthalte auf Stanchio und Leros. Die Insel Chios $(\bullet 20)$ erwähnt er gar nicht (Acta 23). Da er von dort aber weitere interessante dipterologische Ergebnisse mitbrachte, die später zur Beschreibung der Stilettfliege Thereva flavescens Loew, 1847 und der Raubfliege Asilus tenuicornis Loew, 1848 (= Erax) führten, ist davon auszugehen, dass er diese Insel anschließend besuchte (LoEw 1847b, 1848a). Wie LoEw in seinem Bericht an den Kultusminister schreibt, lässt er sich „am 15ten Tage“ der Abreise von Rhodus in Skalanova $(\bullet 4)$ an Land bringen und setzt seine Reise nach Smyrna $(\bullet 2)$ auf dem Landweg über Ephesus $(\bullet 4)$ fort (Acta 23). Die Bombyliidae Exoprosopa telamon Loew 1869 (jetzt Gattung Pachyanthrax) hat er im Juni sowohl auf Stanchio („Cos“) $(\bullet 18)$ als auch bei Smyrna (•2) gesammelt (Loew 1869a). Auch die Muscide Lispe scalaris Loew 1847 stammt von „Smyrna, wo ich sie im Juni fing“ (LoEw 1847a). 
Loews Verhalten war offensichtlich darauf ausgerichtet, auch sein persönliches Ziel dieser Reise, das Zusammentragen eines möglichst umfangreichen und interessanten Insektenmaterials, zu ermöglichen. Das wird auch aus der Notiz von Spratt und Forbes (1847) in Band 2 auf Seite 80 nach ihrem Treffen mit Loew auf Rhodus deutlich: "A large collection of insects was made in Lycia by Herr Löew of Posen, who specially attended to this branch of natural history. He had found many undescribed forms." Sein Vorhaben ist ihm durchaus gelungen und er hat praktisch sein ganzes Leben lang Material aus diesem Fundus bearbeitet und Arten neu beschrieben. So lag es wohl auch kaum in seinem Interesse, während der Reise viel Zeit und Mittel für den Erwerb von Antiquitäten einzusetzen. Seine Darstellung in dem Brief vom 26. März 1842 an v. Olfers (Acta 50) über den enormen Aufwand das Heroon von Trysa nach Berlin zu bringen, ist zudem ziemlich realistisch, wie der spätere tatsächliche Export nach Wien gezeigt hat. Allerdings spricht v. Olfers in seinem Schreiben ja auch gar nicht davon, für den dafür viel zu kleinen Betrag von 3000 Thalern die ganze Anlage zu erwerben und $\mathrm{zu}$ transportieren, sondern wäre wohl mit repräsentativen Einzelstücken zufrieden gewesen (Acta 49). Es ist deshalb erstaunlich, dass nicht wenigstens der Versuch gemacht wurde, eine Friesplatte aus Trysa oder eine der vorher genannten Statuen für den Förderer der Reise v. Olfers und das Königliche Museum zu erwerben. Wenn aus verständlichen Gründen Loew daran wenig Interesse hatte, so wäre doch sicher ScHönBORN dazu in der Lage gewesen. Nach seinem "fluchtartigen“ Verlassen von Smyrna am 10. oder 14. März hat er doch spätestens in den ersten Junitagen auf Rhodus von den Schreiben aus Berlin und Constantinopel durch LoEw direkt oder durch schriftliche Mitteilung Kenntnis gehabt und hätte sicherlich auch jetzt noch in dem verbleibenden Monat etwas erreichen können. Stattdessen schreibt ScHÖNBORN am 7. Juli 1842 in dem Brief an die Gesandtschaft (Acta 44): „Ich bin aber seit Mitte März nicht mehr nach Smyrna gekommen, und habe darauf Ew Hochwohlgeb: geehrtes Schreiben erst vor wenigen Tagen empfangen. $\mathrm{Zu}$ gleicher Zeit habe ich auch einen Brief von den Generaldirektor der Königl Museen, $\mathrm{Hr}$ von Olfers vorgefunden, und in demselben die Ermächtigung erhalten, das fragliche Monument für das Königl. Museum zu Berlin fortzuschaffen. Ich würde daher sogleich jetzt, das von Ew Hochwohlgeb: gnädigst übersandte Vizirialschreiben benutzend, an die Ausführung des Werkes gehen, wenn nicht in dem Brief des Hr Generaldirektors der Königl Museen Bedingungen aufgestellt wären, die mir eine mündliche Rücksprache in Berlin vor Beginn des Werkes als höchst wünschenswerth erscheinen lassen.“ und teilt weiter mit „Ich gedenke darum, heut die Rückreise nach Europa anzutreten."
Von Olfers wollte nach Erhalt des von Loew am 26. März aus Smyrna an ihn gerichteten Briefes (Acta 50) offensichtlich wohl doch etwas Genaueres über die Ursachen für das Misslingen der Antiquitätenerwerbung erfahren. Der Geschäftsführer der Gesandtschaft zu Constantinopel v. WAgner wurde vom Außenminister v. BüLOw in Berlin aufgefordert, zu seinen Bemühungen in dieser Sache Stellung zu nehmen. Die Antwort v. WAgNers (Acta 51) gab v. Bülow am 3. Juli 1842 an v. Olfers weiter, der davon einen Auszug anfertigen ließ und zu den Akten nahm (Acta 52).

Am 7. Juli 1842 trat Schönborn von Smyrna (•2) aus die Rückreise nach Deutschland an, wie er in dem Brief vom gleichen Tage mitteilt (Acta 44). Loew und KIEPERT erwähnt er nicht. Wie aus den Schifffahrtsplänen des Österreichischen Lloyd hervorgeht, der damals größten Schifffahrtsgesellschaft des Mittelmeeres, war die Abfahrt des Dampfschiffs dieser Linie, das zwischen Constantinopel nach Syra (= Syros) pendelte, am 7. Juli in Smyrna vorgesehen. Die Schiffahrtspläne sind in den „Tafeln zur Statistik der Österreichischen Monarchie für das Jahr 1842" veröffentlicht (ANONYmus 1846). Es ist wahrscheinlich, dass ScHÖNBORN diese Schiffsverbindung nutzte. Das Schiff erreichte laut Plan am 8. Juli die griechische Insel Syra und fuhr von dort wieder mit Zwischenhalten in Smyrna und auf den Dardanellen nach Constantinopel zurück. In Syra war die Weiterfahrt mit einem anderen Schiff der Linie, dass zwischen Syra und Triest pendelte, eigentlich am 11. Juli möglich. Da auf Syra zu dieser Zeit wohl alle aus dem Osten kommenden Reisenden eine zweiwöchige Quarantäne durchmachen mussten, konnte ScHÖNBORN erst die nächste Schiffsmöglichkeit am 26. Juli nutzen. Nach den üblichen Zwischenhalten in Piräus, Patras, Corfu und Ancona wurde dieses Schiff planmäßig am 3. oder spätestens 4. August in Triest erwartet (Anonymus 1846). Dieser Ablauf passt gut zu der Mitteilung seines Bruders Carl, dass Schönborn Ende August wieder in Posen eintraf (SCHÖNBORN, C. 1868).

LoEw erwähnt als letztes Datum in seinem Abschlussbericht an den Kultusminister die Abreise von Makri nach Rhodus am 26. Mai 1842. Bei der Schilderung des Reiseverlaufs in den folgenden zwei Monaten fehlt jedes konkrete Datum (Acta 23). Sein erstes Schreiben nach der Rückkehr ist mit Berlin, den 2. August 1842, datiert (Acta 21). Da LoEw somit schon früher in Berlin war, als SchöNBoRN in Triest, konnte er also nicht erst am 7. Juli gemeinsam mit SCHÖNBORN aus Smyrna abgereist sein. Eine frühere Verbindung von Smyrna aus bestand am 22. Juni (ANonymus 1846). Sehr wahrscheinlich nahm LoEw schon dieses Schiff und erreichte damit Syra am 23. Juni 1842. Die dortige 14tägige Quarantäne war für den Reisenden eine große Belastung. Hinzu kam die sommerliche Hitze. Loew klagt in seinem Brief vom 20. August 1842 auch über „Unterleibsübel“, die ihn aufgrund der schwierigen 
Verhältnisse auf Syra befallen hatten (Acta 23). Seine Aussage, dass er erst fünf Tage nach Ablauf der Quarantäne mit dem Dampfschiff weiter nach Athen reisen und von dort über Ancona bis nach Triest gelangen konnte, passt zu diesem Abreisetermin. Das geplante Schiff mit Abfahrt von Syra am 26. Juni konnte er wegen der noch anhaltenden Quarantäne nicht nehmen. Das nächste Schiff ging erst am 11. Juli. Von seiner Ankunft auf Syra bis zu seiner Weiterreise vergingen also $14+$ 5 Tage (23. Juni bis 11. Juli) (Acta 23, Anonymus 1846). Auf diese Weise hatte LoEw aber noch Gelegenheit, ein paar Tage auf Syra zu sammeln (auch wenn es in seinem Bericht anders klingt). Aus diesem dipterologischen Fundus beschrieb er später zwei Arten: die Waffenfliege Nemotelus argentifer LoEw, 1846 und die Schwebfliege Eumerus pulchellus LoEw, 1848 (LoEw 1846a, 1848c). LoEw gibt bei Eumerus pulchellus dazu einigermaßen passend an, er hätte die Art „auf Leros und Syra im Juni“ gefangen. Mit dem am 11. Juli abgehenden Schiff, mit dem eigentlich auch ScHönBoRn reisen wollte, der aber als später Angekommener zu diesem Zeitpunkt auf Syra in Quarantäne bleiben musste, konnte LoEw am 12. Juli nach Piräus, den Hafen von Athen, gelangen. Das Linienschiff erreichte bei der Weiterreise laut Fahrplan am 19. oder spätestens am 20. Juli Triest. Möglicherweise musste er dort, so wie es von KIEPERT berichtet wird, nochmals eine dreitägige Quarantäne einhalten. Jedenfalls schreibt Loew weiter, dass er „von da [Triest] in sieben mal vierundzwanzig Stunden fast ununterbrochener Landreise hierher [nach Berlin]“ gekommen sei. Das passt gut zu dem Datum seines ersten überlieferten Briefs aus Berlin, den 2. August 1842 (Acta 21, 23).

Die Beschreibung der Bombyliide Oligodranes obscuripennis LoEw, 1844 enthält allerdings ein weiteres Problem. Loew schreibt: „In Kleinasien an vielen Orten, auf den griechischen Inseln sowie bei Athen von mir in den Frühjahrsmonaten gefangen" (LoEw 1844d). Bei welcher Gelegenheit Loew die Art bei Athen gefangen haben will, ist fraglich. Ein Aufenthalt über mehrere Tage ist nicht denkbar, da LoEw sonst wohl kaum noch bis zum 2. August nach Berlin gekommen sein könnte. Das nächste Linienschiff ging sogar erst zwei Wochen später. Bleibt die Möglichkeit, dass er beim Zwischenstopp in Piräus für einige Stunden an Land gehen konnte ...

Kaum in Berlin angekommen, bittet er in einem Brief vom 2. August 1842 den Kultusminister um eine weitere Verlängerung seines Urlaubs bis Ende September (Acta 21). Bis Michaelis, dem 29. September, ging noch das laufende Sommersemester, danach begann der Schuldienst mit dem Wintersemester erneut. Loew bittet „den ihm zu einer Reise durch Klein-Asien gewährten Urlaub, behufs eines Aufenthaltes in Berlin zu wissenschaftlicher Bearbeitung und Bestimmung der mitgebrachten naturhistorischen Sammlungen und $\mathrm{zu}$ Zusammenstellung der übrigen auf der Reise gemach- ten Messungen und Beobachtungen, bis zum letzten September a. c. hochgeneigtest verlängern $\mathrm{zu}$ wollen“. Loew gibt im Brief die Adresse Berlin, Mauerstraße 56, bei Almstedt, an.

Am 16. August berichtet Loew in einem weiteren Brief an das Kultusministerium, jetzt mit der Adresse Berlin, Jägerstraße 16, 1 Treppe, dass er gleich nach der Antragstellung auf weitere Urlaubsverlängerung vom 2. August pflichtschuldig selbst nach Posen weitergereist ist, um mit der Schule zu klären, ob seine Vertretung bis Ende September abgesichert ist. Das war der Fall und Loew konnte also wie geplant in Urlaub verbleiben (Acta 22). Am 20. August 1842 fertigt Loew den schon mehrfach zitierten umfangreichen Brief an Minister EICHHORN mit dem Abschlussbericht zur Reise an (Acta 23). Wahrscheinlich schickte LoEw am gleichen Tage auch einen Bericht an v. Olfers. Das geht zumindest aus dem von Szemethy (2005) auf Seite 26 zitierten Brief vom 27. September 1886 von Richard SснӧNE, Generaldirektor der Königlichen Museen in Berlin, an Otto BENNDORF in Wien, hervor. SCHÖNE teilt darin mit: „Von Schönborn selbst liegt über die erste Reise [im Ministerium] kein Bericht vor [...] wol aber ein Brief von Loew aus Smyrna v 26/3 42 und ein längerer Bericht desselben aus Berlin 20/8 42“. Dieser Bericht vom 20. August an v. OlfERs war aber in den Archiven nicht auffindbar.

Ein Schreiben vom 10. November 1842 vom Kultusminister EICHHORN an seine Majestät den König erhellt auch die finanzielle Situation, unter der die Reise von Schönborn und Loew stattfand (Acta 24). Die Gehälter wurden weitergezahlt, SснӧnBorns Jahresgehalt betrug 700 Taler. Allerdings mussten beide für den zuerst beantragten Reiseabschnitt bis 1. April einen Teil der Finanzierung ihrer Vertretung selbst übernehmen, Schönborn 120, LoEw 150 Taler. Als Reisezuschuss für SChÖNBORN hat der König 600 Taler genehmigt, das Kultusministerium aber nur 500 ausgezahlt. Bei Verlängerung der Reise wurden noch einmal 500 Taler an die Reisenden nach Smyrna überwiesen (Acta 18). Für seine Freizügigkeit bei dieser zweiten Zahlung musste sich der Minister aber noch 1844 vor der Ober-RechnungsKammer verantworten und den König um nachträgliche Genehmigung bitten (Acta 25). Allerdings erhöhte sich durch die Verlängerung der Reise auch der Eigenanteil für die Vertretung bei SchönboRn auf 190 Taler und bei Loew sogar auf 400 Taler. Das bedeutete, dass LoEw, auch wenn ScHÖNBORN seinen Zuschuss mit ihm geteilt hat, die Reise praktisch privat finanzierte. Da für seine Vertretung ab dem Sommersemester, ohne seine Kenntnis, die Bezahlung verdreifacht wurde, blieben seiner Familie nach Abzug dieser Vertretungskosten von LoEws Gehalt monatlich nicht ganz 9 Taler zum Leben, wie er am 16. August 1842 dem Kultusminister mitteilte (Acta 22). Weiter schreibt er in diesem Brief: „so befinde ich mich nicht nur für den Augenblick in der dringends- 
ten Geldverlegenheit, sondern bin auch in der üblen Lage meinen Hausstand mit bedeutenden Schulden von Neuem zu beginnen. Jeder Tag aber verwickelt mich tiefer in diese traurige Lage, da bei dem geringen Theile des Gehaltes, der mir verbleibt, sich von Tag zu Tag mehr Schulden aufhäufen müssen." Mit dem Schreiben vom 10. November 1842 beantragt der Kultusminister, die Höhe der privaten Zahlungen für die Vertretung beider Reisenden auf je 150 Taler zu begrenzen (Acta 24). Dem wurde durch den König stattgegeben. Doch noch Anfang 1843 teilt LOEw in einem Brief an ERICHSON mit, dass er aus Geldsorgen zusätzliche Privatstunden geben muss (Acta 2).

Dass es nicht am Wollen Loews lag, diese Reise und ihre vielfältigen Ergebnisse in ihrer Gesamtheit zu dokumentieren, wird aus einem Brief von ihm an ERICHSON vom Berliner Museum deutlich (Acta 2). Loew schreibt einige Monate nach seiner Rückkehr von der Reise: „Ich habe nämlich bis jetzt für das Reisewerk noch keinen Verleger, wie ich ihn haben möchte; da es keiner von denen, mit welchen ich unterhandelt habe so ausstatten will, wie es ausgestattet sein muß, wenn es etwas nutzen soll. Ich kann zweierlei Anerbietungen machen.

\section{Mein und Schönborns Reise vereinigt.}

a) Geograph. Bericht mit Karten von Schönborn

b) Griechische Inschriften etwa $500 \mathrm{v}$. Franz

c) Lycische Inschriften von Schönborn.

d) geologischer Bericht von mir

e) Petrefakten (sehr reichhaltig.)

f) Botanischer Bericht (weniger erheblich, ich finde da für schon noch eine tüchtige Hülfe)

g) Zoologischer Bericht, besonders Insekten. Von Ihnen bekannten Bearbeitern

Unser Wunsch würde eine Quartausgabe mit anständiger Ausstattung sein.

a. gab. etwa 2 Karten ed vielleicht noch etliche Durchschnitte.

b. könnten lithographirt, vielleicht blos gedruckt werden

c.) müssen lithographirt werden

d würde nur ein Paar Durchschnittszeichnungen geben.

e.) enthielt am besten ed wohl auch am Vortheilhaftesten für den Buchhändler sämmtliche Spezies, gut lithographirt; gabe für etwa 350-400 Spezies, da die Mehrzahl klein ist etwa 30 lithographirte Tafeln. f.) dürfte keine Abbildungen enthalten.

g.) dafür wäre es mein dringenster Wunsch alle neuen Spezies abbilden lassen zu können; die Tafeln müßten natürlich größtentheils illuminirt werden.

Bei vollkommen anständiger Ausstattung wir wegen Honorarbedingungen nicht schwierig sein.

2. Ich trenne mich darin von Schönborn, was ich indeß nicht gern thun würde. Derem fiele $\mathrm{a}-\mathrm{c}$ aus und ich gäbe nur eine kurze Lokalitätsschilderung in Verbindung mit d. so reduzirte sich das auf 3 Bde angelegte Werk auf 2. Auch hier sähe ich vom Verleger gern die bei d ed g gemachten Bedingungen artistischer Beilagen erfüllt“.

Es ist sehr bedauerlich, dass die Umstände es nicht zugelassen hatten, diese Pläne zu verwirklichen. Wie anders wäre die allgemeine Wahrnehmung dieser Reise gewesen und unsere mühsame Rekonstruktion nach fast 180 Jahren wäre unnötig.

Mit Hilfe der rekonstruierten Reiseroute konnten sämtliche Typenfundorte des von LoEw mitgebrachten zoologischen Materials geklärt werden. Damit wurde ein wesentliches Ziel dieser Arbeit erreicht. Immer wieder finden sich aber einzelne Orts- und Zeitangaben, die nicht in den Reiseverlauf passen. Das betrifft auch Reiseabschnitte, die gut belegt sind. Beispiele sind „Brussa im Oktober“ oder „bey Pera im October“. Dazu gegenteilige Aussagen finden sich in Kieperts und Schönborns genauen Tagebuchaufzeichnungen vom September und Oktober 1842 und in allen anderen Quellen. Die Erklärung liegt wohl in der fehlenden Aufarbeitung von LoEws eigenen Aufzeichnungen und den natürlicherweise entstehenden Erinnerungslücken in den langen Zeiträumen bis zu der oft erst nach Jahren und Jahrzehnten erfolgten Publikation der Ergebnisse.

Dieser Bericht soll auch ein Beispiel dafür sein, wie einzelne begeisterte Entomologen im 19. und 20. Jahrhundert praktisch ohne finanzielle staatliche Unterstützung (aber auch ohne staatliche Behinderungen), mit enormen persönlichen Einsatz, großartige wissenschaftliche Leistungen vollbracht haben. LoEw hat die Entomologie neben seinem Beruf als Lehrer betrieben und in 41 Jahren 3708 Dipteren-Arten neu für die Wissenschaft beschrieben. 


\subsection{Zusammenstellung der erwähnten historischen Orts- und topographischen Namen}

Tabelle 3: Zusammenstellung der erwähnten historischen topographischen und Ortsnamen mit ihren verschiedenen Schreibweisen und ihren modernen Entsprechungen (Loci typici in fett und mit *, die Namen von antiken Siedlungsplätze in KAPITÄLCHEN und die antiken Namen der Landschaften in eckigen Klammern).

[Table 3: Compilation of the mentioned historical topographical and place names with their variant spellings and their modern equivalents (Type localities in bold and with ${ }^{*}$, the names of ancient settlements in SMALL CAPITALs and the ancient names of the landscapes in square brackets).

\begin{tabular}{|c|c|c|c|c|c|}
\hline \multirow{2}{*}{$\begin{array}{l}\begin{array}{l}\text { Zitierte histori- } \\
\text { sche Namen }\end{array} \\
\text { ADADA [Pisidia] }\end{array}$} & \multicolumn{3}{|c|}{$\begin{array}{l}\text { Rezente Namen, Lagebeschreibung und Koordinaten } \\
\text { [E= östlich, } W=\text { westlich, } N=\text { nördlich, } S=\text { südlich] }\end{array}$} & \multirow{2}{*}{\begin{tabular}{|l|}
$\begin{array}{l}\text { Provinz oder } \\
\text { Region }\end{array}$ \\
Isparta \\
\end{tabular}} & \multirow{2}{*}{\begin{tabular}{|r|} 
Staat \\
Türkei \\
\end{tabular}} \\
\hline & $\begin{array}{l}\text { ADADA bei Sağrak N von } \\
\text { Sütçüler }\end{array}$ & $37^{\circ} 35^{\prime} \mathrm{N}$ & $30^{\circ} 59^{\prime} \mathrm{E}$ & & \\
\hline Adalia & Antalya $^{*}$ & $36^{\circ} 53^{\prime} \mathrm{N}$ & $30^{\circ} 42^{\prime} \mathrm{E}$ & Antalya & Türkei \\
\hline Adirnas & Orhaneli $S$ von Bursa & $39^{\circ} 54^{\prime} \mathrm{N}$ & $28^{\circ} 59^{\prime} \mathrm{E}$ & Bursa & Türkei \\
\hline Adranos & Orhaneli S von Bursa & $39^{\circ} 54^{\prime} \mathrm{N}$ & $28^{\circ} 59^{\prime} \mathrm{E}$ & Bursa & Türkei \\
\hline $\begin{array}{l}\text { ADRIANOI } \\
\text { [Mysia] }\end{array}$ & Orhaneli S von Bursa & $39^{\circ} 54^{\prime} \mathrm{N}$ & $28^{\circ} 59^{\prime} \mathrm{E}$ & Bursa & Türkei \\
\hline Aiasoluk & $\begin{array}{l}\text { Ayasoluk = Selçuk N von } \\
\text { Kuşadası }\end{array}$ & $37^{\circ} 57^{\prime} \mathrm{N}$ & $27^{\circ} 33^{\prime} \mathrm{E}$ & Aydın & Türkei \\
\hline Aidin & Aydin & $37^{\circ} 51^{\prime} \mathrm{N}$ & $27^{\circ} 51^{\prime} \mathrm{E}$ & Aydın & Türkei \\
\hline AKARASSUS & Elmali W von Antalya & $36^{\circ} 44^{\prime} \mathrm{N}$ & $29^{\circ} 55^{\prime} \mathrm{E}$ & Antalya & Türkei \\
\hline Almalü & Elmali W von Antalya & $36^{\circ} 44^{\prime} \mathrm{N}$ & $29^{\circ} 55^{\prime} \mathrm{E}$ & Antalya & Türkei \\
\hline ANDRIAKE & $\begin{array}{l}\text { ANDRIAKE bei Demre SW } \\
\text { von Antalya }\end{array}$ & $36^{\circ} 14^{\prime} \mathrm{N}$ & $29^{\circ} 57^{\prime} \mathrm{E}$ & Antalya & Türkei \\
\hline $\begin{array}{l}\text { ANTIPHELLUS } \\
\text { [Lycia] }\end{array}$ & $\begin{array}{l}\text { ANTIPHELLOS bei Kaş SW } \\
\text { von Antalya }\end{array}$ & $36^{\circ} 12^{\prime} \mathrm{N}$ & $29^{\circ} 38^{\prime} \mathrm{E}$ & Antalya & Türkei \\
\hline $\begin{array}{l}\text { APHRODISIAS } \\
\text { [Caria] }\end{array}$ & Geyre W von Denizli & $37^{\circ} 43^{\prime} \mathrm{N}$ & $28^{\circ} 43^{\prime} \mathrm{E}$ & Aydın & Türkei \\
\hline $\begin{array}{l}\text { ARIASSUS } \\
\text { [Pisidia] }\end{array}$ & $\begin{array}{l}\text { Bademağacı bei Dağbeli } \\
\text { NW von Antalya }\end{array}$ & $37^{\circ} 13^{\prime} \mathrm{N}$ & $30^{\circ} 28^{\prime} \mathrm{E}$ & Antalya & Türkei \\
\hline ARYKANDA & ARYKANDA N von Finike & $36^{\circ} 31^{\prime} \mathrm{N}$ & $30^{\circ} 04^{\prime} \mathrm{E}$ & Antalya & Türkei \\
\hline $\begin{array}{l}\text { AsPEndus } \\
\text { [Pamphylia] }\end{array}$ & $\begin{array}{l}\text { Aspendos bei Serik E von } \\
\text { Antalya }\end{array}$ & $36^{\circ} 56^{\prime} \mathrm{N}$ & $31^{\circ} 10^{\prime} \mathrm{E}$ & Antalya & Türkei \\
\hline Assarkoy & $\begin{array}{l}\text { SILLYON bei Asar Köyü } \\
\text { NE von Antalya }\end{array}$ & $36^{\circ} 59^{\prime} \mathrm{N}$ & $30^{\circ} 59^{\prime} \mathrm{E}$ & Antalya & Türkei \\
\hline Ateiro (Berg) & $\begin{array}{l}\text { Attavyros (Gebirge) SE } \\
\text { von Rhodus-Stadt }\end{array}$ & $36^{\circ} 13^{\prime} \mathrm{N}$ & $27^{\circ} 52^{\prime} \mathrm{E}$ & $\begin{array}{l}\text { South Aegean } \\
\text { region }\end{array}$ & Griechenld. \\
\hline Athina & Athen $^{*}$ & $37^{\circ} 59^{\prime} \mathrm{N}$ & $23^{\circ} 44^{\prime} \mathrm{E}$ & Attica & Griechenld. \\
\hline $\begin{array}{l}\text { AtTAleia } \\
\text { [Pamphylia] }\end{array}$ & Antalya & $36^{\circ} 53^{\prime} \mathrm{N}$ & $30^{\circ} 42^{\prime} \mathrm{E}$ & Antalya & Türkei \\
\hline Attalia & Antalya $^{*}$ & $36^{\circ} 53^{\prime} \mathrm{N}$ & $30^{\circ} 42^{\prime} \mathrm{E}$ & Antalya & Türkei \\
\hline $\begin{array}{l}\text { Babatagh } \\
\text { (Gebirge) }\end{array}$ & $\begin{array}{l}\text { Babadağ = Karc1 Dağ } \breve{~ S W} \\
\text { von Denizli }\end{array}$ & $37^{\circ} 44^{\prime} \mathrm{N}$ & $28^{\circ} 53^{\prime} \mathrm{E}$ & Denizli & Türkei \\
\hline Badamli & $\begin{array}{l}\text { Yenışarbademli W von } \\
\text { Beysehir Gölü }\end{array}$ & $37^{\circ} 42^{\prime} \mathrm{N}$ & $31^{\circ} 23^{\prime} \mathrm{E}$ & Isparta & Türkei \\
\hline Balat & $\begin{array}{l}\text { Dursunbey E von } \\
\text { Balıkesir }\end{array}$ & $39^{\circ} 36^{\prime} \mathrm{N}$ & $28^{\circ} 38^{\prime} \mathrm{E}$ & Balıkesir & Türkei \\
\hline $\begin{array}{l}\text { BALBURA } \\
\text { [Lycia] }\end{array}$ & $\begin{array}{l}\text { BALBOURA bei Altınyayla } \\
\text { S von Gölhisar }\end{array}$ & $36^{\circ} 57^{\prime} \mathrm{N}$ & $29^{\circ} 35^{\prime} \mathrm{E}$ & Burdur & Türkei \\
\hline
\end{tabular}




\begin{tabular}{|c|c|c|c|c|c|}
\hline \multirow{2}{*}{$\begin{array}{l}\text { Zitierte histori- } \\
\text { sche Namen }\end{array}$} & \multicolumn{3}{|c|}{$\begin{array}{l}\text { Rezente Namen, Lagebeschreibung und Koordinaten } \\
\text { [E=östlich, } W=\text { westlich, } N=\text { nördlich, } S=\text { südlich] }\end{array}$} & \multirow{2}{*}{\begin{tabular}{|l|} 
Provinz oder \\
Region \\
İzmir \\
\end{tabular}} & \multirow{2}{*}{\begin{tabular}{|r|} 
Staat \\
Türkei \\
\end{tabular}} \\
\hline & Beydağ SE von İzmir & $36^{\circ} 05^{\prime} \mathrm{N}$ & $28^{\circ} 13^{\prime} \mathrm{E}$ & & \\
\hline Baliamboli & Beydağ SE von İzmir & $36^{\circ} 05^{\prime} \mathrm{N}$ & $28^{\circ} 13^{\prime} \mathrm{E}$ & İzmir & Türkei \\
\hline Balikesri & Balıkesir & $39^{\circ} 39^{\prime} \mathrm{N}$ & $27^{\circ} 53^{\prime} \mathrm{E}$ & Balıkesir & Türkei \\
\hline Balukhissar & Balıkesir & $39^{\circ} 39^{\prime} \mathrm{N}$ & $27^{\circ} 53^{\prime} \mathrm{E}$ & Balıkesir & Türkei \\
\hline BAUlo [Pisidia] & $\begin{array}{l}\text { ADADA bei Sağrak N von } \\
\text { Sütçüler }\end{array}$ & $37^{\circ} 35^{\prime} \mathrm{N}$ & $30^{\circ} 59^{\prime} \mathrm{E}$ & Isparta & Türkei \\
\hline Bain Dir & Bayındır SE von İzmir & $38^{\circ} 13^{\prime} \mathrm{N}$ & $27^{\circ} 39^{\prime} \mathrm{E}$ & İzmir & Türkei \\
\hline Bergama(h) & $\begin{array}{l}\text { Bergama SW von } \\
\text { Balıkesir }\end{array}$ & $39^{\circ} 07^{\prime} \mathrm{N}$ & $27^{\circ} 11^{\prime} \mathrm{E}$ & İzmir & Türkei \\
\hline Birkeh & Birgi NE von Ödemiş & $38^{\circ} 14^{\prime} \mathrm{N}$ & $28^{\circ} 05^{\prime} \mathrm{E}$ & İzmir & Türkei \\
\hline Bohadsch & Bigadiç* SE von Balıkesir & $39^{\circ} 24^{\prime} \mathrm{N}$ & $28^{\circ} 08^{\prime} \mathrm{E}$ & Balıkesir & Türkei \\
\hline Boheditsch & Bigadiç ${ }^{*}$ SE von Balıkesir & $39^{\circ} 24^{\prime} \mathrm{N}$ & $28^{\circ} 08^{\prime} \mathrm{E}$ & Balıkesir & Türkei \\
\hline Böjuk-Dere & $\begin{array}{l}\text { Büyükdere }{ }^{\star} \mathrm{N} \text { von } \\
\text { İstanbul }\end{array}$ & $41^{\circ} 10^{\prime} \mathrm{N}$ & $29^{\circ} 04^{\prime} \mathrm{E}$ & İstanbul & Türkei \\
\hline Bolat & $\begin{array}{l}\text { Dursunbey E von } \\
\text { Balıkesir }\end{array}$ & $39^{\circ} 36^{\prime} \mathrm{N}$ & $28^{\circ} 38^{\prime} \mathrm{E}$ & Balıkesir & Türkei \\
\hline Bosdagh & $\begin{array}{l}\text { Bozdağh (Berg) SE von } \\
\text { Tavas }\end{array}$ & $37^{\circ} 18^{\prime} \mathrm{N}$ & $29^{\circ} 12^{\prime} \mathrm{E}$ & Denizli & Türkei \\
\hline Bosdagh & $\begin{array}{l}\text { Bozdağh (Stadt \& Berg) } \\
\text { NE von Ödemiș }\end{array}$ & $38^{\circ} 21^{\prime} \mathrm{N}$ & $28^{\circ} 05^{\prime} \mathrm{E}$ & İzmir & Türkei \\
\hline Brusa & Bursa $^{\star}$ & $40^{\circ} 11^{\prime} \mathrm{N}$ & $29^{\circ} 04^{\prime} \mathrm{E}$ & Bursa & Türkei \\
\hline Brussa & Bursa $^{*}$ & $40^{\circ} 11^{\prime} \mathrm{N}$ & $29^{\circ} 04^{\prime} \mathrm{E}$ & Bursa & Türkei \\
\hline Bubon [Lycia] & $\begin{array}{l}\text { Boubon bei İbecik S von } \\
\text { Gölhisar }\end{array}$ & $36^{\circ} 58^{\prime} \mathrm{N}$ & $29^{\circ} 24^{\prime} \mathrm{E}$ & Burdur & Türkei \\
\hline Bujukdere & $\begin{array}{l}\text { Büyüikdere }{ }^{\star} \mathrm{N} \text { von } \\
\text { İstanbul }\end{array}$ & $41^{\circ} 10^{\prime} \mathrm{N}$ & $29^{\circ} 04^{\prime} \mathrm{E}$ & İstanbul & Türkei \\
\hline $\begin{array}{l}\text { CADYANDA } \\
\text { [Lycia] }\end{array}$ & $\begin{array}{l}\text { KADYANDA bei Üzümlü } \\
\text { NE von Fethiye }\end{array}$ & $36^{\circ} 43^{\prime} \mathrm{N}$ & $29^{\circ} 15^{\prime} \mathrm{E}$ & Muğla & Türkei \\
\hline Carajasu & Karacasu $^{\star}$ SE von Aydin & $37^{\circ} 44^{\prime} \mathrm{N}$ & $28^{\circ} 36^{\prime} \mathrm{E}$ & Aydın & Türkei \\
\hline Chio & Insel Chios & $38^{\circ} 24^{\prime} \mathrm{N}$ & $26^{\circ} 10^{\prime} \mathrm{E}$ & North Aegean & Griechenld. \\
\hline Chios & Insel Chios ${ }^{\star}$ & $38^{\circ} 24^{\prime} \mathrm{N}$ & $26^{\circ} 10^{\prime} \mathrm{E}$ & North Aegean & Griechenld. \\
\hline $\begin{array}{l}\text { CIBYRA } \\
\text { [Phrygia] }\end{array}$ & $\begin{array}{l}\text { KIBYRA NW von Gölhisar } \\
\text { SW von Tefenni }\end{array}$ & $37^{\circ} 10^{\prime} \mathrm{N}$ & $29^{\circ} 29^{\prime} \mathrm{E}$ & Burdur & Türkei \\
\hline Constantinopel & İstanbul* ${ }^{\star}$ & $41^{\circ} 01^{\prime} \mathrm{N}$ & $28^{\circ} 58^{\prime} \mathrm{E}$ & İstanbul & Türkei \\
\hline $\begin{array}{l}\text { Constantinopo- } \\
\text { lis }\end{array}$ & İstanbul ${ }^{\star}$ & $41^{\circ} 01^{\prime} \mathrm{N}$ & $28^{\circ} 58^{\prime} \mathrm{E}$ & İstanbul & Türkei \\
\hline $\operatorname{Cos}$ & Insel Kos (Dodekanes) & $36^{\circ} 49^{\prime} \mathrm{N}$ & $27^{\circ} 07^{\prime} \mathrm{E}$ & $\begin{array}{l}\text { South Aegean } \\
\text { region }\end{array}$ & Griechenld. \\
\hline $\begin{array}{l}\text { CREMNA } \\
\text { [Pisidia] }\end{array}$ & $\begin{array}{l}\text { KREMNA nr Girme } \\
\text { (= Çamlık) SE von Burdur }\end{array}$ & $37^{\circ} 30^{\prime} \mathrm{N}$ & $30^{\circ} 41^{\prime} \mathrm{E}$ & Burdur & Türkei \\
\hline Davas & Tavas $^{\star}$ S von Denizli & $37^{\circ} 34^{\prime} \mathrm{N}$ & $29^{\circ} 04^{\prime} \mathrm{E}$ & Denizli & Türkei \\
\hline Demre, Dembre & Demre SW von Antalya & $36^{\circ} 15^{\prime} \mathrm{N}$ & $29^{\circ} 59^{\prime} \mathrm{E}$ & Antalya & Türkei \\
\hline Denislü & Denizli* $^{*}$ & $37^{\circ} 46^{\prime} \mathrm{N}$ & $29^{\circ} 05^{\prime} \mathrm{E}$ & Denizli & Türkei \\
\hline Denizlü & Denizli* $^{*}$ & $37^{\circ} 46^{\prime} \mathrm{N}$ & $29^{\circ} 05^{\prime} \mathrm{E}$ & Denizli & Türkei \\
\hline
\end{tabular}




\begin{tabular}{|c|c|c|c|c|c|}
\hline \multirow{2}{*}{$\begin{array}{l}\text { Zitierte histori- } \\
\text { sche Namen } \\
\text { Dipoirasdagh }\end{array}$} & \multicolumn{3}{|c|}{$\begin{array}{l}\text { Rezente Namen, Lagebeschreibung und Koordinaten } \\
\text { [E= östlich, } W=\text { westlich, } N=\text { nördlich, } S=\text { südlich }]\end{array}$} & \multirow{2}{*}{\begin{tabular}{|l|}
$\begin{array}{l}\text { Provinz oder } \\
\text { Region }\end{array}$ \\
Isparta \\
\end{tabular}} & \multirow{2}{*}{\begin{tabular}{|r|} 
Staat \\
Türkei \\
\end{tabular}} \\
\hline & $\begin{array}{l}\text { Dipoyraz Dağh (Gebirge) } \\
\text { E Isparta }\end{array}$ & $37^{\circ} 40^{\prime} \mathrm{N}$ & $31^{\circ} 18^{\prime} \mathrm{E}$ & & \\
\hline Dirmil & $\begin{array}{l}\text { Altınyayla bei BALBOURA } \\
\text { S von Gölhisar }\end{array}$ & $37^{\circ} 00^{\prime} \mathrm{N}$ & $29^{\circ} 33^{\prime} \mathrm{E}$ & Burdur & Türkei \\
\hline $\begin{array}{l}\text { Dollomantschai } \\
\text { (Fluss) }\end{array}$ & $\begin{array}{l}\text { Dalaman Çayı (Fluss) bei } \\
\text { Kelekçi SE Denizli }\end{array}$ & $\begin{array}{l}36^{\circ} 53^{\prime} \mathrm{N} \\
36^{\circ} 42^{\prime} \mathrm{N}\end{array}$ & $\begin{array}{l}29^{\circ} 19^{\prime} \mathrm{E} \\
28^{\circ} 44^{\prime} \mathrm{E}\end{array}$ & $\begin{array}{l}\text { Denizli, } \\
\text { Muğla }\end{array}$ & Türkei \\
\hline Duden-Su & $\begin{array}{l}\text { Duden (Karst-Fluss), } \\
\text { Abschnitt bei Antalya }\end{array}$ & $\begin{array}{l}36^{\circ} 58^{\prime} \mathrm{N} \\
36^{\circ} 51^{\prime} \mathrm{N}\end{array}$ & $\begin{array}{l}30^{\circ} 44^{\prime} \mathrm{E} \\
30^{\circ} 47^{\prime} \mathrm{E}\end{array}$ & Antalya & Türkei \\
\hline Durdurkar & $\begin{array}{l}\text { Dodurga bei Gölbent S } \\
\text { von Fethiye }\end{array}$ & $36^{\circ} 24^{\prime} \mathrm{N}$ & $29^{\circ} 12^{\prime} \mathrm{E}$ & Muğla & Türkei \\
\hline Egedir & Eğirdir NE von Isparta & $37^{\circ} 53^{\prime} \mathrm{N}$ & $30^{\circ} 51^{\prime} \mathrm{E}$ & Isparta & Türkei \\
\hline Egerdir & Eğirdir NE von Isparta & $37^{\circ} 53^{\prime} \mathrm{N}$ & $30^{\circ} 51^{\prime} \mathrm{E}$ & Isparta & Türkei \\
\hline Eghirdir & Eğirdir NE von Isparta & $37^{\circ} 53^{\prime} \mathrm{N}$ & $30^{\circ} 51^{\prime} \mathrm{E}$ & Isparta & Türkei \\
\hline Elmalü & Elmali W von Antalya & $36^{\circ} 44^{\prime} \mathrm{N}$ & $29^{\circ} 55^{\prime} \mathrm{E}$ & Antalya & Türkei \\
\hline $\begin{array}{l}\text { EPHESUS } \\
\text { [Ionia] }\end{array}$ & $\begin{array}{l}\text { EPHESOS }{ }^{\star} \text { bei Selçuk S } \\
\text { von Izmir }\end{array}$ & $37^{\circ} 56^{\prime} \mathrm{N}$ & $27^{\circ} 21^{\prime} \mathrm{E}$ & İzmir & Türkei \\
\hline Ernez & $\begin{array}{l}\text { ARNEAI = Günçali NE } \\
\text { von Kaş }\end{array}$ & $36^{\circ} 17^{\prime} \mathrm{N}$ & $30^{\circ} 21^{\prime} \mathrm{E}$ & Antalya & Türkei \\
\hline Eski Baindir & Bayındır SE von İzmir & $38^{\circ} 13^{\prime} \mathrm{N}$ & $27^{\circ} 39^{\prime} \mathrm{E}$ & İzmir & Türkei \\
\hline Eski Kale & Kale SW von Tavas & $37^{\circ} 26^{\prime} \mathrm{N}$ & $28^{\circ} 51^{\prime} \mathrm{E}$ & Denizli & Türkei \\
\hline $\begin{array}{l}\text { Eurymedon } \\
\text { (Fluss) }\end{array}$ & $\begin{array}{l}\text { Köprüçay (Fluss) NW von } \\
\text { Kesme }\end{array}$ & $\begin{array}{l}37^{\circ} 37^{\prime} \mathrm{N} \\
36^{\circ} 50^{\prime} \mathrm{N}\end{array}$ & $\begin{array}{l}31^{\circ} 10^{\prime} \mathrm{E} \\
31^{\circ} 10^{\prime} \mathrm{E}\end{array}$ & $\begin{array}{l}\text { Isparta } \\
\text { Antalya }\end{array}$ & Türkei \\
\hline Fineka & Finike SW von Antalya & $36^{\circ} 18^{\prime} \mathrm{N}$ & $30^{\circ} 09^{\prime} \mathrm{E}$ & Antalya & Türkei \\
\hline Firnaz & $\begin{array}{l}\text { Yeşilköy bei Patara SE von } \\
\text { Fethiye }\end{array}$ & $36^{\circ} 17^{\prime} \mathrm{N}$ & $29^{\circ} 23^{\prime} \mathrm{E}$ & Antalya & Türkei \\
\hline Furnas & $\begin{array}{l}\text { Yeşilköy }{ }^{\star} \text { bei PATARA SE } \\
\text { von Fethiye }\end{array}$ & $36^{\circ} 17^{\prime} \mathrm{N}$ & $29^{\circ} 23^{\prime} \mathrm{E}$ & Antalya & Türkei \\
\hline Gagai & Yeniceköy E von Finike & $36^{\circ} 17^{\prime} \mathrm{N}$ & $30^{\circ} 21^{\prime} \mathrm{E}$ & Antalya & Türkei \\
\hline Gemlik & Gemlik N von Bursa & $40^{\circ} 26^{\prime} \mathrm{N}$ & $29^{\circ} 09^{\prime} \mathrm{E}$ & Bursa & Türkei \\
\hline Geyra & Geyre W von Denizli & $37^{\circ} 43^{\prime} \mathrm{N}$ & $28^{\circ} 43^{\prime} \mathrm{E}$ & Aydin & Türkei \\
\hline Ghera & Geyre W von Denizli & $37^{\circ} 43^{\prime} \mathrm{N}$ & $28^{\circ} 43^{\prime} \mathrm{E}$ & Aydin & Türkei \\
\hline Giresun & $\begin{array}{l}\text { Savaştepe SW von } \\
\text { Balıkesir }\end{array}$ & $39^{\circ} 23^{\prime} \mathrm{N}$ & $27^{\circ} 39^{\prime} \mathrm{E}$ & Balıkesir & Türkei \\
\hline Girme & $\begin{array}{l}\text { Girme (= Çamlık) SE von } \\
\text { Burdur }\end{array}$ & $37^{\circ} 30^{\prime} \mathrm{N}$ & $30^{\circ} 41^{\prime} \mathrm{E}$ & Burdur & Türkei \\
\hline Giwa, Gjöwa & Gökova S von Muğla & $37^{\circ} 03^{\prime} \mathrm{N}$ & $28^{\circ} 22^{\prime} \mathrm{E}$ & Muğla & Türkei \\
\hline Gjölbaghtsche & $\begin{array}{l}\text { TrYsa W von Demre SW } \\
\text { von Antalya }\end{array}$ & $36^{\circ} 17^{\prime} \mathrm{N}$ & $29^{\circ} 54^{\prime} \mathrm{E}$ & Antalya & Türkei \\
\hline Gölbaşi & $\begin{array}{l}\text { Trysa W von Demre SW } \\
\text { von Antalya }\end{array}$ & $36^{\circ} 17^{\prime} \mathrm{N}$ & $29^{\circ} 54^{\prime} \mathrm{E}$ & Antalya & Türkei \\
\hline Gülhissar & Gölhisar SW von Tefenni & $37^{\circ} 08^{\prime} \mathrm{N}$ & $29^{\circ} 30^{\prime} \mathrm{E}$ & Burdur & Türkei \\
\hline Gül-Hissar & Gölhisar SW von Tefenni & $37^{\circ} 08^{\prime} \mathrm{N}$ & $29^{\circ} 30^{\prime} \mathrm{E}$ & Burdur & Türkei \\
\hline Güzelhisar & Aydın & $37^{\circ} 51^{\prime} \mathrm{N}$ & $27^{\circ} 51^{\prime} \mathrm{E}$ & Aydin & Türkei \\
\hline $\begin{array}{l}\text { HIERAPOLIS } \\
\text { [Phrygia] }\end{array}$ & $\begin{array}{l}\text { HIERAPOLIS bei Pamuk- } \\
\text { kale N von Denizli }\end{array}$ & $37^{\circ} 56^{\prime} \mathrm{N}$ & $29^{\circ} 08^{\prime} \mathrm{E}$ & Denizli & Türkei \\
\hline
\end{tabular}




\begin{tabular}{|c|c|c|c|c|c|}
\hline $\begin{array}{l}\text { Zitierte histori- } \\
\text { sche Namen }\end{array}$ & $\begin{array}{l}\text { Rezente Namen, Lage } \\
{[E=\text { östlich, W= westl }}\end{array}$ & $\begin{array}{l}\text { eschreibu } \\
\text { ch, } \mathrm{N}=\text { nö }\end{array}$ & $\begin{array}{l}\text { Koordinaten } \\
=\text { südlich] }\end{array}$ & $\begin{array}{l}\text { Provinz oder } \\
\text { Region }\end{array}$ & Staat \\
\hline HYPAIPA & $\begin{array}{l}\text { HYPAEPA bei Ödemiş SE } \\
\text { von İzmir }\end{array}$ & $38^{\circ} 14^{\prime} \mathrm{N}$ & $27^{\circ} 58^{\prime} \mathrm{E}$ & İzmir & Türkei \\
\hline Indus (Fluss) & $\begin{array}{l}\text { Dalaman Çayı (Fluss) bei } \\
\text { Kelekçi SE Denizli }\end{array}$ & $\begin{array}{l}36^{\circ} 53^{\prime} \mathrm{N} \\
36^{\circ} 42^{\prime} \mathrm{N}\end{array}$ & $\begin{array}{l}29^{\circ} 19^{\prime} \mathrm{E} \\
28^{\circ} 44^{\prime} \mathrm{E}\end{array}$ & $\begin{array}{l}\text { Denizli, } \\
\text { Muğla }\end{array}$ & Türkei \\
\hline Istenas & $\begin{array}{l}\text { Korkuteli* NW von } \\
\text { Antalya }\end{array}$ & $37^{\circ} 04^{\prime} \mathrm{N}$ & $30^{\circ} 12^{\prime} \mathrm{E}$ & Antalya & Türkei \\
\hline Jannartagh & $\begin{array}{l}\text { Yanartaş bei Çıralı E von } \\
\text { Kumluca }\end{array}$ & $36^{\circ} 26^{\prime} \mathrm{N}$ & $30^{\circ} 27^{\prime} \mathrm{E}$ & Antalya & Türkei \\
\hline Jaryschly & Yarışlı SW von Burdur & $37^{\circ} 36^{\prime} \mathrm{N}$ & $29^{\circ} 56^{\prime} \mathrm{E}$ & Burdur & Türkei \\
\hline $\begin{array}{l}\text { KADYANDA } \\
\text { [Lycia] }\end{array}$ & $\begin{array}{l}\text { KADYANDA bei Üzümlü } \\
\text { NE von Fethiye }\end{array}$ & $36^{\circ} 43^{\prime} \mathrm{N}$ & $29^{\circ} 15^{\prime} \mathrm{E}$ & Muğla & Türkei \\
\hline Kaleköy & $\begin{array}{l}\text { TLos bei Güneşli E von } \\
\text { Fethiye }\end{array}$ & $36^{\circ} 34^{\prime} \mathrm{N}$ & $29^{\circ} 25^{\prime} \mathrm{E}$ & Muğla & Türkei \\
\hline $\begin{array}{l}\text { Karabaulo } \\
\text { [Pisidia] }\end{array}$ & $\begin{array}{l}\text { PEDNELISsus bei Kozan } \\
\text { NE von Antalya }\end{array}$ & $37^{\circ} 13^{\prime} \mathrm{N}$ & $30^{\circ} 55^{\prime} \mathrm{E}$ & Antalya & Türkei \\
\hline $\begin{array}{l}\text { Karadschatagh } \\
\text { (Gebirge) }\end{array}$ & $\begin{array}{l}\text { Karıncalı Dağı SE von } \\
\text { Nazilli (Gebirge) }\end{array}$ & $37^{\circ} 43^{\prime} \mathrm{N}$ & $28^{\circ} 32^{\prime} \mathrm{E}$ & Aydın & Türkei \\
\hline Karajasu & Karacasu^ ${ }^{\star}$ E von Aydin & $37^{\circ} 44^{\prime} \mathrm{N}$ & $28^{\circ} 36^{\prime} \mathrm{E}$ & Aydın & Türkei \\
\hline Kassaba & Kasaba NE von Kaş & $36^{\circ} 19^{\prime} \mathrm{N}$ & $29^{\circ} 44^{\prime} \mathrm{E}$ & Antalya & Türkei \\
\hline Kaunos [Caria] & $\begin{array}{l}\text { Kaunos bei Dalyan NW } \\
\text { von Dalaman }\end{array}$ & $36^{\circ} 50^{\prime} \mathrm{N}$ & $28^{\circ} 37^{\prime} \mathrm{E}$ & Muğla & Türkei \\
\hline Kellemisch & $\begin{array}{l}\text { Gelemiş* bei Patara W } \\
\text { von Kaş }\end{array}$ & $36^{\circ} 17^{\prime} \mathrm{N}$ & $29^{\circ} 19^{\prime} \mathrm{E}$ & Antalya & Türkei \\
\hline Kellemish & $\begin{array}{l}\text { Gelemiş* bei Patara W } \\
\text { von Kaş }\end{array}$ & $36^{\circ} 17^{\prime} \mathrm{N}$ & $29^{\circ} 19^{\prime} \mathrm{E}$ & Antalya & Türkei \\
\hline Kesme & $\begin{array}{l}\text { Kesme N von Selge SE } \\
\text { von Isparta }\end{array}$ & $37^{\circ} 28^{\prime} \mathrm{N}$ & $31^{\circ} 14^{\prime} \mathrm{E}$ & Isparta & Türkei \\
\hline Kestel & Kestel SW von Bucak & $37^{\circ} 25^{\prime} \mathrm{N}$ & $30^{\circ} 24^{\prime} \mathrm{E}$ & Burdur & Türkei \\
\hline Kestel Göl (See) & $\begin{array}{l}\text { Kestel Gölü (See) SW von } \\
\text { Bucak }\end{array}$ & $37^{\circ} 24^{\prime} \mathrm{N}$ & $30^{\circ} 29^{\prime} \mathrm{E}$ & Burdur & Türkei \\
\hline Kestros (Fluss) & Aksu Çayı (Fluss) & $\begin{array}{l}37^{\circ} 43^{\prime} \mathrm{N} \\
36^{\circ} 51^{\prime} \mathrm{N}\end{array}$ & $\begin{array}{l}30^{\circ} 32^{\prime} \mathrm{E} \\
30^{\circ} 55^{\prime} \mathrm{E}\end{array}$ & $\begin{array}{l}\text { Isparta, } \\
\text { Antalya }\end{array}$ & Türkei \\
\hline $\begin{array}{l}\text { KibYRA } \\
\text { [Phrygia] }\end{array}$ & $\begin{array}{l}\text { KIBYRA NW von Gölhisar } \\
\text { SW von Tefenni }\end{array}$ & $37^{\circ} 10^{\prime} \mathrm{N}$ & $29^{\circ} 29^{\prime} \mathrm{E}$ & Burdur & Türkei \\
\hline Kiresun & $\begin{array}{l}\text { Savaştepe SW von } \\
\text { Balıkesir }\end{array}$ & $39^{\circ} 23^{\prime} \mathrm{N}$ & $27^{\circ} 39^{\prime} \mathrm{E}$ & Balıkesir & Türkei \\
\hline Kisilhisar & Serinhisar SE von Denizli & $37^{\circ} 35^{\prime} \mathrm{N}$ & $29^{\circ} 16^{\prime} \mathrm{E}$ & Denizli & Türkei \\
\hline Ködschaß & $\begin{array}{l}\text { Keughez = Köyceğız SE } \\
\text { von Muğla }\end{array}$ & $36^{\circ} 58^{\prime} \mathrm{N}$ & $28^{\circ} 41^{\prime} \mathrm{E}$ & Muğla & Türkei \\
\hline Kos & Insel Kos (Dodekanes) & $36^{\circ} 49^{\prime} \mathrm{N}$ & $27^{\circ} 07^{\prime} \mathrm{E}$ & $\begin{array}{l}\text { South } \\
\text { Aegean } \\
\text { region }\end{array}$ & Griechenld. \\
\hline Kragus & $\begin{array}{l}\text { Sandak Dağ (Mt. Cragus), } \\
\text { Avdanc1k }\end{array}$ & $36^{\circ} 33^{\prime} \mathrm{N}$ & $29^{\circ} 12^{\prime} \mathrm{E}$ & Muğla & Türkei \\
\hline $\begin{array}{l}\text { KREMNA } \\
\text { [Pisidia] }\end{array}$ & $\begin{array}{l}\text { KREMNA nr Girme } \\
\text { (= Çamlık) SE von Burdur }\end{array}$ & $37^{\circ} 30^{\prime} \mathrm{N}$ & $30^{\circ} 41^{\prime} \mathrm{E}$ & Burdur & Türkei \\
\hline Kuhla & Kula E von Manisa & $38^{\circ} 33^{\prime} \mathrm{N}$ & $28^{\circ} 39^{\prime} \mathrm{E}$ & Manisa & Türkei \\
\hline
\end{tabular}




\begin{tabular}{|c|c|c|c|c|c|}
\hline \multirow{2}{*}{$\begin{array}{l}\text { Zitierte histori- } \\
\text { sche Namen } \\
\text { Kula }\end{array}$} & \multicolumn{3}{|c|}{$\begin{array}{l}\text { Rezente Namen, Lagebeschreibung und Koordinaten } \\
\text { [E= östlich, } W=\text { westlich, } N=\text { nördlich, } S=\text { südlich] }\end{array}$} & \multirow{2}{*}{\begin{tabular}{|l|}
$\begin{array}{l}\text { Provinz oder } \\
\text { Region }\end{array}$ \\
Manisa \\
\end{tabular}} & \multirow{2}{*}{\begin{tabular}{|r|} 
Staat \\
Türkei
\end{tabular}} \\
\hline & Kula E von Manisa & $38^{\circ} 33^{\prime} \mathrm{N}$ & $28^{\circ} 39^{\prime} \mathrm{E}$ & & \\
\hline Küstendschi & Constanţa & $44^{\circ} 11^{\prime} \mathrm{N}$ & $28^{\circ} 39^{\prime} \mathrm{E}$ & Dobruja & Rumänien \\
\hline Küstendye & Constanţa & $44^{\circ} 11^{\prime} \mathrm{N}$ & $28^{\circ} 39^{\prime} \mathrm{E}$ & Dobruja & Rumänien \\
\hline Kysarköi & Hisarköy NE von Bigadiç & $39^{\circ} 26^{\prime} \mathrm{N}$ & $28^{\circ} 17^{\prime} \mathrm{E}$ & Balıkesir & Türkei \\
\hline Kysylly & $\begin{array}{l}\text { Kızılı E von Karacaören } \\
\text { Baraji SE Bucak }\end{array}$ & $37^{\circ} 22^{\prime} \mathrm{N}$ & $30^{\circ} 54^{\prime} \mathrm{E}$ & Burdur & Türkei \\
\hline $\begin{array}{l}\text { LAODIKEIA } \\
\text { [Phrygia] }\end{array}$ & LAODIKEIA N von Denizli & $37^{\circ} 50^{\prime} \mathrm{N}$ & $29^{\circ} 06^{\prime} \mathrm{E}$ & Denizli & Türkei \\
\hline Leros & Insel Leros (Dodekanes) & $37^{\circ} 09^{\prime} \mathrm{N}$ & $26^{\circ} 51^{\prime} \mathrm{E}$ & South Aegean & Griechenld. \\
\hline Lerus & Insel Leros* (Dodekanes) & $37^{\circ} 09^{\prime} \mathrm{N}$ & $26^{\circ} 51^{\prime} \mathrm{E}$ & $\begin{array}{l}\text { South } \\
\text { Aegean }\end{array}$ & Griechenld. \\
\hline Lesbos & Insel Lesbos & $39^{\circ} 12^{\prime} \mathrm{N}$ & $26^{\circ} 18^{\prime} \mathrm{E}$ & North Aegean & Griechenld. \\
\hline LIMYRA [Lycia] & $\begin{array}{l}\text { LIMYRA bei Finike SW } \\
\text { von Antalya }\end{array}$ & $36^{\circ} 21^{\prime} \mathrm{N}$ & $30^{\circ} 11^{\prime} \mathrm{E}$ & Antalya & Türkei \\
\hline $\begin{array}{l}\text { (Großer) } \\
\text { Mäander (Fluss) }\end{array}$ & $\begin{array}{l}\text { Büyük Menderes (Großer } \\
\text { Mäander) }\end{array}$ & $\begin{array}{l}38^{\circ} 04^{\prime} \mathrm{N} \\
37^{\circ} 32^{\prime} \mathrm{N}\end{array}$ & $\begin{array}{l}30^{\circ} 11^{\prime} \mathrm{E} \\
27^{\circ} 10^{\prime} \mathrm{E}\end{array}$ & Aydın, Denizli & Türkei \\
\hline $\begin{array}{l}\text { (Kleiner) } \\
\text { Mäander (Fluss) }\end{array}$ & $\begin{array}{l}\text { Küçük Menderes (Kleiner } \\
\text { Mäander) }\end{array}$ & $\begin{array}{l}38^{\circ} 19^{\prime} \mathrm{N} \\
37^{\circ} 57^{\prime} \mathrm{N}\end{array}$ & $\begin{array}{l}28^{\circ} 10^{\prime} \mathrm{E} \\
27^{\circ} 16^{\prime} \mathrm{E}\end{array}$ & İzmir & Türkei \\
\hline Mäanderthal & $\begin{array}{l}\text { Büyüik Menderes }{ }^{\star} \text { Tal bei } \\
\text { Nazilli }\end{array}$ & $37^{\circ} 55^{\prime} \mathrm{N}$ & $28^{\circ} 19^{\prime} \mathrm{E}$ & Aydin & Türkei \\
\hline Macri & Fethiye $^{\star}$ & $36^{\circ} 37^{\prime} \mathrm{N}$ & $29^{\circ} 07^{\prime} \mathrm{E}$ & Muğla & Türkei \\
\hline Makri & Fethiye $^{\star}$ & $36^{\circ} 37^{\prime} \mathrm{N}$ & $29^{\circ} 07^{\prime} \mathrm{E}$ & Muğla & Türkei \\
\hline Makuf & $\begin{array}{l}\text { Makuf bei Gökkaya SE } \\
\text { von Manisa }\end{array}$ & $38^{\circ} 30^{\prime} \mathrm{N}$ & $27^{\circ} 52^{\prime} \mathrm{E}$ & Manisa & Türkei \\
\hline Manisa & Manisa & $38^{\circ} 37^{\prime} \mathrm{N}$ & $27^{\circ} 25^{\prime} \mathrm{E}$ & Manisa & Türkei \\
\hline Manissa & Manisa & $38^{\circ} 37^{\prime} \mathrm{N}$ & $27^{\circ} 25^{\prime} \mathrm{E}$ & Manisa & Türkei \\
\hline Meded & $\begin{array}{l}\text { TABAE bei Kale SW von } \\
\text { Tavas }\end{array}$ & $37^{\circ} 26^{\prime} \mathrm{N}$ & $28^{\circ} 51^{\prime} \mathrm{E}$ & Denizli & Türkei \\
\hline Memeritsa & Marmaris ${ }^{\star}$ S von Muğla & $36^{\circ} 51^{\prime} \mathrm{N}$ & $28^{\circ} 16^{\prime} \mathrm{E}$ & Muğla & Türkei \\
\hline Mentecha & $\begin{array}{l}\text { Menteşe Dağları, Gebirgs- } \\
\text { landschaft N und W von } \\
\text { Muğla }\end{array}$ & $37^{\circ} 23^{\prime} \mathrm{N}$ & $28^{\circ} 20^{\prime} \mathrm{E}$ & Aydın, Muğla & Türkei \\
\hline Mermeriza & Marmaris` S von Muğla & $36^{\circ} 51^{\prime} \mathrm{N}$ & $28^{\circ} 16^{\prime} \mathrm{E}$ & Muğla & Türkei \\
\hline $\begin{array}{l}\text { Messaghis } \\
\text { (Gebirge) }\end{array}$ & $\begin{array}{l}\text { Aydın Dağları SE von } \\
\text { İzmir (Gebirge) }\end{array}$ & $37^{\circ} 59^{\prime} \mathrm{N}$ & $27^{\circ} 58^{\prime} \mathrm{E}$ & İzmir & Türkei \\
\hline $\begin{array}{l}\text { Messogis Mons } \\
\text { (Gebirge) }\end{array}$ & $\begin{array}{l}\text { Aydın Dağları SE von } \\
\text { İzmir (Gebirge) }\end{array}$ & $37^{\circ} 59^{\prime} \mathrm{N}$ & $27^{\circ} 58^{\prime} \mathrm{E}$ & İzmir & Türkei \\
\hline $\begin{array}{l}\text { METROPOLIS } \\
\text { [Ionia] }\end{array}$ & $\begin{array}{l}\text { Yeniköy bei Torbalı SE } \\
\text { von İzmir }\end{array}$ & $38^{\circ} 08^{\prime} \mathrm{N}$ & $27^{\circ} 19^{\prime} \mathrm{E}$ & İzmir & Türkei \\
\hline Milli & $\begin{array}{l}\text { MiLyos bei Kocaaliler SE } \\
\text { Bucak }\end{array}$ & $37^{\circ} 18^{\prime} \mathrm{N}$ & $30^{\circ} 45^{\prime} \mathrm{E}$ & Burdur & Türkei \\
\hline MiLYAs [Lycia] & $\begin{array}{l}\text { MiLyos bei Kocaaliler SE } \\
\text { Bucak }\end{array}$ & $37^{\circ} 18^{\prime} \mathrm{N}$ & $30^{\circ} 45^{\prime} \mathrm{E}$ & Burdur & Türkei \\
\hline MiLYos [Lycia] & $\begin{array}{l}\text { MiLyos bei Kocaaliler SE } \\
\text { Bucak }\end{array}$ & $37^{\circ} 18^{\prime} \mathrm{N}$ & $30^{\circ} 45^{\prime} \mathrm{E}$ & Burdur & Türkei \\
\hline Muhla & Muğla ${ }^{*}$ & $37^{\circ} 13^{\prime} \mathrm{N}$ & $28^{\circ} 22^{\prime} \mathrm{E}$ & Muğla & Türkei \\
\hline
\end{tabular}




\begin{tabular}{|c|c|c|c|c|c|}
\hline \multirow{2}{*}{$\begin{array}{l}\text { Zitierte histori- } \\
\text { sche Namen } \\
\text { Myra [Lycia] }\end{array}$} & \multicolumn{3}{|c|}{$\begin{array}{l}\text { Rezente Namen, Lagebeschreibung und Koordinaten } \\
{[\mathrm{E}=\ddot{\text { ostlich}}, \mathrm{W}=\text { westlich, } \mathrm{N}=\text { nördlich, } \mathrm{S}=\text { südlich }]}\end{array}$} & \multirow{2}{*}{\begin{tabular}{|l|}
$\begin{array}{l}\text { Provinz oder } \\
\text { Region }\end{array}$ \\
Antalya \\
\end{tabular}} & \multirow{2}{*}{\begin{tabular}{|r|} 
Staat \\
Türkei \\
\end{tabular}} \\
\hline & $\begin{array}{l}\text { Myra bei Demre SW von } \\
\text { Antalya }\end{array}$ & $36^{\circ} 15^{\prime} \mathrm{N}$ & $29^{\circ} 59^{\prime} \mathrm{E}$ & & \\
\hline Nasli-Basar & Nazilli E von Aydin & $37^{\circ} 55^{\prime} \mathrm{N}$ & $28^{\circ} 19^{\prime} \mathrm{E}$ & Aydın & Türkei \\
\hline Nosli & Nazilli E von Aydin & $37^{\circ} 55^{\prime} \mathrm{N}$ & $28^{\circ} 19^{\prime} \mathrm{E}$ & Aydin & Türkei \\
\hline Nazlü & Nazilli E von Aydin & $37^{\circ} 55^{\prime} \mathrm{N}$ & $28^{\circ} 19^{\prime} \mathrm{E}$ & Aydın & Türkei \\
\hline $\begin{array}{l}\text { OENOANDA } \\
\text { [Lycia] }\end{array}$ & $\begin{array}{l}\text { OINOANDA bei İncealiler } \\
\text { S von Gölhisar }\end{array}$ & $36^{\circ} 49^{\prime} \mathrm{N}$ & $29^{\circ} 33^{\prime} \mathrm{E}$ & Muğla & Türkei \\
\hline $\begin{array}{l}\text { Olbasa } \\
\text { [Pisidia] }\end{array}$ & $\begin{array}{l}\text { Olbasa bei Belenli E von } \\
\text { Tefenni }\end{array}$ & $37^{\circ} 18^{\prime} \mathrm{N}$ & $30^{\circ} 00^{\prime} \mathrm{E}$ & Burdur & Türkei \\
\hline Olympus (Berg) & $\begin{array}{l}\text { Uluda } \breve{g}^{\star} \text { (Gebirge) SE } \\
\text { von Bursa }\end{array}$ & $40^{\circ} 04^{\prime} \mathrm{N}$ & $29^{\circ} 13^{\prime} \mathrm{E}$ & Bursa & Türkei \\
\hline $\begin{array}{l}\text { Olympus } \\
\text { [Lycia] }\end{array}$ & $\begin{array}{l}\text { Olympos bei Ciralı, E von } \\
\text { Kumluca }\end{array}$ & $36^{\circ} 24^{\prime} \mathrm{N}$ & $30^{\circ} 28^{\prime} \mathrm{E}$ & Antalya & Türkei \\
\hline Padam Aghatsch & $\begin{array}{l}\text { Bademağacı bei Dağbeli } \\
\text { NW von Antalya }\end{array}$ & $37^{\circ} 13^{\prime} \mathrm{N}$ & $30^{\circ} 28^{\prime} \mathrm{E}$ & Antalya & Türkei \\
\hline Pajamadsch & $\begin{array}{l}\text { Bademağacı bei Dağbeli } \\
\text { NW von Antalya }\end{array}$ & $37^{\circ} 13^{\prime} \mathrm{N}$ & $30^{\circ} 28^{\prime} \mathrm{E}$ & Antalya & Türkei \\
\hline Pajamatsch & $\begin{array}{l}\text { Bademağacı bei Dağbeli } \\
\text { NW von Antalya }\end{array}$ & $37^{\circ} 13^{\prime} \mathrm{N}$ & $30^{\circ} 28^{\prime} \mathrm{E}$ & Antalya & Türkei \\
\hline $\begin{array}{l}\text { PAlation } \\
\text { [Mysia] }\end{array}$ & $\begin{array}{l}\text { Dursunbey E von } \\
\text { Balıkesir }\end{array}$ & $39^{\circ} 36^{\prime} \mathrm{N}$ & $28^{\circ} 38^{\prime} \mathrm{E}$ & Balıkesir & Türkei \\
\hline Patara [Lycia] & $\begin{array}{l}\text { Patara }{ }^{\star} \text { bei Gelemiş W } \\
\text { von Kaş }\end{array}$ & $36^{\circ} 16^{\prime} \mathrm{N}$ & $29^{\circ} 19^{\prime} \mathrm{E}$ & Antalya & Türkei \\
\hline $\begin{array}{l}\text { PeDnelissus } \\
\text { [Pisidia] }\end{array}$ & $\begin{array}{l}\text { PEDNELISSUS bei Kozan } \\
\text { NE von Antalya }\end{array}$ & $37^{\circ} 13^{\prime} \mathrm{N}$ & $30^{\circ} 55^{\prime} \mathrm{E}$ & Antalya & Türkei \\
\hline Pera & İstanbul-Beyoğllu* & $41^{\circ} 02^{\prime} \mathrm{N}$ & $28^{\circ} 59^{\prime} \mathrm{E}$ & İstanbul & Türkei \\
\hline $\begin{array}{l}\text { PERGAMON } \\
\text { [Aeolis] }\end{array}$ & $\begin{array}{l}\text { PERGAMON bei Bergama } \\
\text { SW von Balıkesir }\end{array}$ & $39^{\circ} 07^{\prime} \mathrm{N}$ & $27^{\circ} 11^{\prime} \mathrm{E}$ & İzmir & Türkei \\
\hline $\begin{array}{l}\text { Perge } \\
\text { [Pamphylia] }\end{array}$ & $\begin{array}{l}\text { Perge bei Aksu NE von } \\
\text { Antalya }\end{array}$ & $36^{\circ} 58^{\prime} \mathrm{N}$ & $30^{\circ} 51^{\prime} \mathrm{E}$ & Antalya & Türkei \\
\hline Phaselis & Phaselis SW von Kemer & $36^{\circ} 31^{\prime} \mathrm{N}$ & $30^{\circ} 33^{\prime} \mathrm{E}$ & Antalya & Türkei \\
\hline Phineka & Finike* SW von Antalya & $36^{\circ} 18^{\prime} \mathrm{N}$ & $30^{\circ} 09^{\prime} \mathrm{E}$ & Antalya & Türkei \\
\hline Phinika & Finike* SW von Antalya & $36^{\circ} 18^{\prime} \mathrm{N}$ & $30^{\circ} 09^{\prime} \mathrm{E}$ & Antalya & Türkei \\
\hline Pinara [Lycia] & $\begin{array}{l}\text { PINARA bei Minare SE } \\
\text { von Fethiye }\end{array}$ & $36^{\circ} 29^{\prime} \mathrm{N}$ & $29^{\circ} 15^{\prime} \mathrm{E}$ & Muğla & Türkei \\
\hline $\begin{array}{l}\text { Promontorium } \\
\text { sacrum }\end{array}$ & $\begin{array}{l}\text { Gelidonya Burnu SE von } \\
\text { Kumluca }\end{array}$ & $36^{\circ} 12^{\prime} \mathrm{N}$ & $30^{\circ} 24^{\prime} \mathrm{E}$ & Antalya & Türkei \\
\hline $\begin{array}{l}\text { PrusA } \\
\text { [Bithynia] }\end{array}$ & Bursa & $40^{\circ} 11^{\prime} \mathrm{N}$ & $29^{\circ} 04^{\prime} \mathrm{E}$ & Bursa & Türkei \\
\hline Rhodus & Insel Rhodos ${ }^{\star}$ & $36^{\circ} 11^{\prime} \mathrm{N}$ & $27^{\circ} 58^{\prime} \mathrm{E}$ & $\begin{array}{l}\text { South Aegean } \\
\text { region }\end{array}$ & Griechenld. \\
\hline $\begin{array}{l}\text { SAgALASSOS } \\
\text { [Pisidia] }\end{array}$ & $\begin{array}{l}\text { SAGALASsos bei Ağlasun } \\
\text { E von Burdur }\end{array}$ & $37^{\circ} 41^{\prime} \mathrm{N}$ & $30^{\circ} 31^{\prime} \mathrm{E}$ & Burdur & Türkei \\
\hline Scalanova & $\begin{array}{l}\text { Kuşadası }{ }^{\star} \text { von Ephesos, } \\
\text { W von Aydin }\end{array}$ & $37^{\circ} 50^{\prime} \mathrm{N}$ & $27^{\circ} 16^{\prime} \mathrm{E}$ & Aydın & Türkei \\
\hline Selge [Pisidia] & SELGE NE Antalya & $37^{\circ} 14^{\prime} \mathrm{N}$ & $31^{\circ} 08^{\prime} \mathrm{E}$ & Antalya & Türkei \\
\hline
\end{tabular}




\begin{tabular}{|c|c|c|c|c|c|}
\hline $\begin{array}{l}\text { Zitierte histori- } \\
\text { sche Namen }\end{array}$ & $\begin{array}{l}\text { Rezente Namen, Lagel } \\
{[\mathrm{E}=\text { östlich, } \mathrm{W}=\text { westli }}\end{array}$ & $\begin{array}{l}\text { eschreibul } \\
\text { ch, } \mathrm{N}=\text { nör }\end{array}$ & $\begin{array}{l}\text { Koordinaten } \\
=\text { südlich] }\end{array}$ & $\begin{array}{l}\text { Provinz oder } \\
\text { Region }\end{array}$ & Staat \\
\hline Serdschilar & Serçeler SW von Orhaneli & $39^{\circ} 54^{\prime} \mathrm{N}$ & $28^{\circ} 57^{\prime} \mathrm{E}$ & Bursa & Türkei \\
\hline Sidyma [Lycia] & $\begin{array}{l}\text { SiDYma bei Dodurga S } \\
\text { von Fethiye }\end{array}$ & $36^{\circ} 25^{\prime} \mathrm{N}$ & $29^{\circ} 12^{\prime} \mathrm{E}$ & Muğla & Türkei \\
\hline Sigadschick & Siğacik SW von İzmir & $38^{\circ} 11^{\prime} \mathrm{N}$ & $26^{\circ} 47^{\prime} \mathrm{E}$ & İzmir & Türkei \\
\hline $\begin{array}{l}\text { SILLYON } \\
\text { [Pamphylia] }\end{array}$ & $\begin{array}{l}\text { SILLYON bei Asar Köyü } \\
\text { NE von Antalya }\end{array}$ & $36^{\circ} 59^{\prime} \mathrm{N}$ & $30^{\circ} 59^{\prime} \mathrm{E}$ & Antalya & Türkei \\
\hline Skalanova & $\begin{array}{l}\text { Kuşadası }{ }^{\star} \text { S von Ephesos, } \\
\text { W von Aydin }\end{array}$ & $37^{\circ} 50^{\prime} \mathrm{N}$ & $27^{\circ} 16^{\prime} \mathrm{E}$ & Aydin & Türkei \\
\hline Smyrna & İzmir ${ }^{\star}$ & $38^{\circ} 25^{\prime} \mathrm{N}$ & $27^{\circ} 09^{\prime} \mathrm{E}$ & İzmir & Türkei \\
\hline Soma & Soma NE von Akhisar & $39^{\circ} 11^{\prime} \mathrm{N}$ & $27^{\circ} 37^{\prime} \mathrm{E}$ & Manisa & Türkei \\
\hline Stanchio & Insel Kos*, (Dodekanes) & $36^{\circ} 49^{\prime} \mathrm{N}$ & $27^{\circ} 07^{\prime} \mathrm{E}$ & $\begin{array}{l}\text { South Aegean } \\
\text { region }\end{array}$ & Griechenld. \\
\hline Syra & Insel Syros* (Kykladen) & $37^{\circ} 27^{\prime} \mathrm{N}$ & $24^{\circ} 54^{\prime} \mathrm{E}$ & $\begin{array}{l}\text { South Aegean } \\
\text { region }\end{array}$ & Griechenld. \\
\hline TABAE [Caria] & $\begin{array}{l}\text { TABAE bei Kale SW von } \\
\text { Tavas }\end{array}$ & $37^{\circ} 26^{\prime} \mathrm{N}$ & $28^{\circ} 51^{\prime} \mathrm{E}$ & Denizli & Türkei \\
\hline TABAI [Caria] & $\begin{array}{l}\text { TABAE bei Kale SW von } \\
\text { Tavas }\end{array}$ & $37^{\circ} 26^{\prime} \mathrm{N}$ & $28^{\circ} 51^{\prime} \mathrm{E}$ & Denizli & Türkei \\
\hline Tefenü & Tefenni SW von Burdur & $37^{\circ} 19^{\prime} \mathrm{N}$ & $29^{\circ} 46^{\prime} \mathrm{E}$ & Burdur & Türkei \\
\hline $\begin{array}{l}\text { Telmessus } \\
\text { [Lycia] }\end{array}$ & Telmessos bei Fethiye & $36^{\circ} 37^{\prime} \mathrm{N}$ & $29^{\circ} 07^{\prime} \mathrm{E}$ & Muğla & Türkei \\
\hline $\begin{array}{l}\text { Termessus } \\
\text { [Pisidia] }\end{array}$ & $\begin{array}{l}\text { Termessos NW von } \\
\text { Antalya }\end{array}$ & $36^{\circ} 59^{\prime} \mathrm{N}$ & $30^{\circ} 28^{\prime} \mathrm{E}$ & Antalya & Türkei \\
\hline Tireh & Tire SE von İzmir & $38^{\circ} 05^{\prime} \mathrm{N}$ & $27^{\circ} 44^{\prime} \mathrm{E}$ & İzmir & Türkei \\
\hline Tlos [Lycia] & $\begin{array}{l}\text { Tlos` bei Güneşli E von } \\
\text { Fethiye }\end{array}$ & $36^{\circ} 34^{\prime} \mathrm{N}$ & $29^{\circ} 25^{\prime} \mathrm{E}$ & Muğla & Türkei \\
\hline Tokboi & Torbalı SE von İzmir & $38^{\circ} 10^{\prime} \mathrm{N}$ & $27^{\circ} 21^{\prime} \mathrm{E}$ & İzmir & Türkei \\
\hline Trysa [Lycia] & $\begin{array}{l}\text { Trysa W von Demre SW } \\
\text { von Antalya }\end{array}$ & $36^{\circ} 17^{\prime} \mathrm{N}$ & $29^{\circ} 54^{\prime} \mathrm{E}$ & Antalya & Türkei \\
\hline Ürkütlü & $\begin{array}{l}\text { Ürkütlü bei Kızılkaya SW } \\
\text { von Bucak }\end{array}$ & $37^{\circ} 19^{\prime} \mathrm{N}$ & $30^{\circ} 18^{\prime} \mathrm{E}$ & Burdur & Türkei \\
\hline Xanthus (Fluss) & Eşen Çayı (Fluss) & $\begin{array}{l}36^{\circ} 56^{\prime} \mathrm{N} \\
36^{\circ} 18^{\prime} \mathrm{N}\end{array}$ & $\begin{array}{l}29^{\circ} 50^{\prime} \mathrm{E} \\
29^{\circ} 16^{\prime} \mathrm{E}\end{array}$ & $\begin{array}{l}\text { Burdur, } \\
\text { Antalya }\end{array}$ & Türkei \\
\hline $\begin{array}{l}\text { XANTHUS } \\
\text { [Lycia] }\end{array}$ & $\begin{array}{l}\text { XANTHOs }{ }^{\star} \text { bei Kınık SE } \\
\text { von Fethiye }\end{array}$ & $36^{\circ} 21^{\prime} \mathrm{N}$ & $29^{\circ} 20^{\prime} \mathrm{E}$ & Antalya & Türkei \\
\hline Xanthusthal & $\begin{array}{l}\text { Eşen Ovasi* (Tal) SE von } \\
\text { Fethiye }\end{array}$ & $36^{\circ} 23^{\prime} \mathrm{N}$ & $29^{\circ} 19^{\prime} \mathrm{E}$ & Muğla & Türkei \\
\hline
\end{tabular}




\section{Das von LoEW während der Reise gesammelte zoologische Typenmaterial}

Im Folgenden wird in den Tabellen 4 bis 8 das gesamte uns bekannt gewordene von Hermann LoEw während seiner Reise in das Osmanische Reich gesammelte zoologische Typenmaterial zusammengestellt. In jeder Tiergruppe werden die Artnamen in der originalen Kombination der Erstbeschreibung aufgelistet und alphabetisch angeordnet. Des Weiteren wird die dazugehörige Literaturstelle angegeben und mit der gegenwärtig gülti- gen Namenskombination und der Familienzuordnung ergänzt. Die gegenwärtig gebräuchlichen Namen wurden der Website „Fauna Europaea“ entnommen (DE JONG et al. 2014). Dort fehlende Arten und Aktualisierungen wurden mittels der bei den einzelnen Ordnungen genannten speziellen Literatur ergänzt. Insgesamt sind aus dem mitgebrachtem Material mindestens 254 Arten beschrieben worden.

\section{1 Coleoptera}

Tabelle 4: Das von LoEw während der Reise gesammelte coleopterologische Typenmaterial. [Table 4: The coleopterological type material collected by Loew during the expedition.]

\begin{tabular}{|l|l|l|l|}
\hline \multicolumn{1}{|c|}{ Artname (Originalkombination) } & \multicolumn{1}{|c|}{ Literaturstelle } & \multicolumn{1}{|c|}{ Artname (rezente Kombination) } & \multicolumn{1}{c|}{ Familie } \\
\hline Cicindela octopunctata LoEw, 1843 & LoEw 1843d: 339 & Calomera fischeri (AdAMs, 1817) & Cicindelidae \\
\hline Cicindela quadrimaculata LoEw, 1843 & LoEw 1843d: 340 & Homodela ismenia (GoRY, 1833) & Cicindelidae \\
\hline
\end{tabular}

Typenfundorte sind Muhla und Rhodus. Rezente Namen nach LöвL \& LöBL (2017).

\subsection{Diptera}

In der Tabelle 5 werden insgesamt 218 Dipteren-Arten aufgeführt, die zu 38 sehr unterschiedlichen Familien gehören. LoEw hatte also die Fähigkeit, praktisch über die ganze Ordnung hinweg Arten zu beschreiben, was heutigen Dipterologen kaum mehr möglich ist. In dem Typenmaterial überwiegen sehr deutlich die Brachycera und unter ihnen die größeren Formen. Darunter sind die Asilidae mit 53 Arten und die Bombyliidae mit 43 Arten sehr bevorzugt vertreten. Beide sind im Medi- terraneum deutlich artenreicher als in Mitteleuropa und der Anteil unbeschriebener Arten war zu Loews Zeiten in diesen Familien deshalb besonders hoch. Aber auch einige sehr kleine Vertreter der Mücken sind unter den von Loew beschriebenen Arten, wie zum Beispiel eine Art der Cecidomyiidae, eine Culicidae, eine Dixidae und eine Psychodidae. Von den 218 beschriebenen Arten Loews sind heute noch 168 Artnamen gültig.

Tabelle 5: Das von Loew während der Reise gesammelte dipterologische Typenmaterial.

[Table 5: The dipterological type material collected by Loew during the expedition.]

\begin{tabular}{|c|c|c|c|}
\hline Artname (Originalkombination) & Literaturstelle & Artname (rezente Kombination) & Familie \\
\hline Amictus scutellaris LoEw, 1869 & LoEw 1869a: 234 & Amictus scutellaris LoEw, 1869 & Bombyliidae \\
\hline Amictus setosus LoEw, 1869 & LoEw 1869a: 243 & Amictus setosus LoEw, 1869 & Bombyliidae \\
\hline Amictus strigilatus LoEw, 1869 & LoEw 1869a: 239 & Amictus pulchellus (MACQUART, 1846) & Bombyliidae \\
\hline Amictus validus LoEw, 1869 & LoEw 1869a: 244 & Amictus validus LoEw, 1869 & Bombyliidae \\
\hline Anarolius jubatus LoEw, 1844 & LoEw 1844d: 165 & Anarolius jubatus LoEw, 1844 & Asilidae \\
\hline Anopheles pictus LoEw, 1845 & LOEW 1845: 4 & Anopheles hyrcanus (PALlAs, 1771) & Culicidae \\
\hline Anthrax albulus LoEw, 1869 & LoEw 1869a: 189 & Villa ixion (FABRICIUS, 1794) & Bombyliidae \\
\hline Anthrax blandus Loew, 1869 & LoEw 1869a: 181 & Villa cana (MeIGEN, 1804) & Bombyliidae \\
\hline Anthrax lotus LoEw, 1869 & LoEw 1869a: 164 & Thyridanthrax lotus (LoEw, 1869) & Bombyliidae \\
\hline Anthrax melanchlaenus LoEw, 1869 & LOEw 1869a: 175 & Exhyalanthrax melanchlaenus (LoEw, 1869) & Bombyliidae \\
\hline Anthrax perspicillaris LoEw, 1869 & LoEw 1869a: 157 & Thyridanthrax perspicillaris (LoEw, 1869) & Bombyliidae \\
\hline Anthrax stenozonus LoEw, 1869 & LoEw 1869a: 180 & Villa stenozona (LoEw, 1869) & Bombyliidae \\
\hline Anthrax unctus LoEw, 1869 & LoEw 1869a: 169 & Pachyanthrax unctus (LoEw, 1869) & Bombyliidae \\
\hline
\end{tabular}




\begin{tabular}{|c|c|c|c|}
\hline Artname (Originalkombination) & Literaturstelle & Artname (rezente Kombination) & Familie \\
\hline Anthrax vagans LoEw, 1862 & LOEW 1862b: 81 & Exhyalanthrax muscarius (PALLAS, 1818) & Bombyliidae \\
\hline Asilus acanthodes LoEw, 1849 & LoEw 1849a: 92 & Paritamus acanthodes (LoEw, 1849) & Asilidae \\
\hline Asilus adpressus LoEw, 1849 & LoEw 1849a: 125 & Antiphrisson adpressus (LoEw, 1849) & Asilidae \\
\hline Asilus albicans LoEw, 1849 & LoEw 1849a: 72 & Neomochtherus albicans (LoEw, 1849) & Asilidae \\
\hline Asilus angustifrons LoEw, 1849 & LoEw 1849a: 126 & Machimus angustifrons (LoEw, 1849) & Asilidae \\
\hline Asilus apiculatus LoEw, 1848 & LoEw 1848a: 457 & Eutolmus apiculatus (LoEw, 1848) & Asilidae \\
\hline Asilus calopus LoEw, 1848 & LoEw 1848a: 474 & Eutolmus calopus (LoEw, 1848) & Asilidae \\
\hline Asilus cognatus LoEw, 1849 & LoEw 1849a: 143 & Echthistus cognatus (LoEw, 1849) & Asilidae \\
\hline Asilus denticulatus LoEw, 1849 & LoEw 1849a: 77 & Cerdistus denticulatus (LoEw, 1849) & Asilidae \\
\hline Asilus elegans LoEw, 1849 & LoEw 1849a: 42 & Machimus elegans (LoEw, 1849) & Asilidae \\
\hline Asilus excisus LoEw, 1848 & LoEw 1848a: 483 & Eutolmus excisus (LoEw, 1848) & Asilidae \\
\hline Asilus facialis LoEw, 1848 & LoEw 1848a: 467 & Eutolmus facialis (LoEw, 1848) & Asilidae \\
\hline Asilus longimanus LoEw, 1849 & LoEw 1849a: 95 & Engelepogon naxia (MACQUART, 1838) & Asilidae \\
\hline Asilus modestus LoEw, 1849 & LoEw 1849a: 55 & Machimus modestus (LoEw, 1849) & Asilidae \\
\hline Asilus mordax LoEw, 1848 & LoEw 1848a: 485 & Eutolmus mordax (LoEw, 1848) & Asilidae \\
\hline Asilus mundus LoEw, 1849 & LoEw 1849a: 65 & Neomochtherus mundus (LoEw, 1849) & Asilidae \\
\hline Asilus nubecula LoEw, 1848 & LoEw 1848a: 428 & Erax nubeculus (LoEw, 1848) & Asilidae \\
\hline Asilus parricida LoEw, 1848 & LoEw 1848a: 490 & Eutolmus parricida (LoEw, 1848) & Asilidae \\
\hline Asilus polypogon LoEw, 1848 & LoEw 1848a: 480 & Eutolmus polypogon (LoEw, 1848) & Asilidae \\
\hline Asilus setibarbus LoEw, 1849 & LoEw 1849a: 45 & Machimus setibarbus (LoEw, 1849) & Asilidae \\
\hline Asilus setiger LoEw, 1848 & LoEw 1848a: 431 & Dysmachus setiger (LoEw, 1848) & Asilidae \\
\hline Asilus tenuicornis LoEw, 1848 & LoEw 1848a: 426 & Erax tenuicornis (LoEw, 1848) & Asilidae \\
\hline Asilus tessellatus LoEw, 1849 & LoEw 1849a: 98 & Machimus tessellatus (LoEw, 1849) & Asilidae \\
\hline Asilus thoracicus LoEw, 1849 & LoEw 1849a: 48 & Machimus thoracicus (LoEw, 1849) & Asilidae \\
\hline Asilus tricuspis LoEw, 1848 & LoEw 1848a: 446 & Dysmachus tricuspis (LoEw, 1848) & Asilidae \\
\hline Asilus trifarius LoEw, 1849 & LoEw 1849a: 128 & Antiphrisson trifarius (LoEw, 1849) & Asilidae \\
\hline Asilus truncatus LoEw, 1849 & LoEw 1849a: 139 & Antipalus truncatus (LoEw, 1849) & Asilidae \\
\hline Asyndulum geranias LoEw, 1869 & LoEw 1869a: 15 & Macrorrhyncha geranias (LoEw, 1869) & Keroplatidae \\
\hline Asyndulum halidayi Loew, 1871 & LoEw 1871: 29 & Antlemon halidayi (LoEw, 1871) & Keroplatidae \\
\hline Baryphora speciosa LoEw, 1844 & LoEW 1844b: 123 & Baryphora speciosa LoEw, 1844 & Therevidae \\
\hline Bibio brevipes LoEw, 1846 & LoEw 1846a: 360 & Bibio brevipes LoEw, 1846 & Bibionidae \\
\hline Bibio hirtipes LoEw, 1846 & LoEw 1846a: 347 & Bibio hortulanus (LinnaEus, 1758) & Bibionidae \\
\hline Blepharoptera pusilla LoEw, 1862 & LoEw 1862a: 128 & Neoleria pusilla (LoEw, 1862) & Heleomyzidae \\
\hline Bombylius albomicans LoEw, 1855 & LoEW 1855: 12 & Bombylius medius LinnaEus, 1758 & Bombyliidae \\
\hline Bombylius breviusculus LoEw, 1855 & LoEw 1855: 47 & Bombylisoma breviusculum (LoEw, 1855) & Bombyliidae \\
\hline Bombylius confrater LoEw, 1855 & LoEW 1855: 13 & Bombylius medius Linnaeus, 1758 & Bombyliidae \\
\hline Bombylius convergens LoEw, 1855 & LoEW 1855: 38 & Systoechus ctenopterus (MiKan, 1796) & Bombyliidae \\
\hline Bombylius expleta Loew, 1855 & LoEW 1855: 15 & Bombylius fimbriatus MEIGEN, 1820 & Bombyliidae \\
\hline Bombylius flavibarbus Loew, 1855 & LoEw 1855: 46 & Bombylisoma flavibarbum (LoEw, 1855) & Bombyliidae \\
\hline Bombylius imitator LoEw, 1855 & LoEW 1855: 46 & Bombylisoma imitator (LoEw, 1855) & Bombyliidae \\
\hline Bombylius pallipes LoEw, 1855 & LoEw 1855: 13 & Bombylius medius LinnaEus, 1758 & Bombyliidae \\
\hline Bombylius punctipennis LoEw, 1855 & LoEW 1855: 12 & Bombylius punctipennis LoEw, 1855 & Bombyliidae \\
\hline Bombylius rhodius LoEw, 1855 & LoEw 1855: 19 & Bombylius trichurus Pallas, 1818 & Bombyliidae \\
\hline
\end{tabular}




\begin{tabular}{|c|c|c|c|}
\hline Artname (Originalkombination) & Literaturstelle & Artname (rezente Kombination) & Familie \\
\hline Cecidomyia sarothamni LoEW, 1850 & LoEw 1850a: 38 & Asphondylia sarothamni (LoEw, 1850) & Cecidomyiidae \\
\hline Chalcochiton speciosus LoEw, 1844 & LOEw 1844d: 157 & Chalcochiton speciosus LoEw, 1844 & Bombyliidae \\
\hline Chrysogaster frontalis LoEw, 1843 & LoEw 1843c: 270 & Orthonevra frontalis (LoEw, 1843) & Syrphidae \\
\hline Chrysogaster fumipennis LoEw, 1843 & LoEw 1843c: 271 & Orthonevra fumipennis (LoEw, 1843) & Syrphidae \\
\hline Chrysogaster longicornis LoEw, 1843 & LoEw 1843b: 240 & Orthonevra longicornis (LoEw, 1843) & Syrphidae \\
\hline Chrysopila obscuribarba LoEw, 1869 & LOEw 1869a: 53 & Chrysopilus obscuribarbus LoEw, 1869 & Rhagionidae \\
\hline Chrysopila pallipes LoEw, 1869 & LoEw 1869a: 54 & Chrysopilus pallipes LoEw, 1869 & Rhagionidae \\
\hline Chrysops hamatus LoEw, 1859 & LoEw 1859b: 617 & Chrysops hamatus LoEw, 1859 & Tabanidae \\
\hline Chrysops ludens LoEw, 1859 & LoEw 1859b: 628 & Chrysops caecutiens (LinnaEus, 1758) & Tabanidae \\
\hline Chrysops nigriventris LoEw, 1856 & LoEw 1856: 26 & Chrysops italicus MEIGEN, 1804 & Tabanidae \\
\hline Chrysotus albibarbus LoEw, 1857 & LoEw 1857a: 50 & Chrysotus albibarbus LoEw, 1857 & $\begin{array}{l}\text { Dolichopod- } \\
\text { idae }\end{array}$ \\
\hline Chyliza gracilis LoEw, 1854 & LoEW 1854: 23 & Chyliza gracilis LoEw, 1854 & Psilidae \\
\hline Clinocera pusilla LoEw, 1858 & LoEW 1858c: 243 & Wiedemannia lota WALKER, 1851 & Empididae \\
\hline Conops brevicornis LoEw, 1847 & LoEw 1847f: 23 & Brachyceraea brevicornis (LoEw, 1847) & Conopidae \\
\hline Conops fraternus LoEw, 1847 & LoEw 1847f: 18 & Physocephala vittata (FABRICIUs, 1794) & Conopidae \\
\hline Crassiseta bimaculata LoEw, 1845 & LoEW 1845: 49 & Elachiptera bimaculata (LoEw, 1845) & Chloropidae \\
\hline Crassiseta megaspis LoEw, 1858 & LoEw 1858b: 74 & Elachiptera megaspis (LoEw, 1858) & Chloropidae \\
\hline Cyllenia marginata LoEw, 1846 & LoEw 1846a: 368 & Cyllenia marginata LoEw, 1846 & Bombyliidae \\
\hline Cyllenia obsoleta LoEw, 1846 & LoEw 1846a: 369 & Cyllenia obsoleta LoEw, 1846 & Bombyliidae \\
\hline Cyrtoneura simplex LoEw, 1857 & LoEw 1857b: 45 & Morellia simplex (LoEw, 1857) & Muscidae \\
\hline $\begin{array}{l}\text { Dasypogon anthophorinus LoEw, } \\
1847\end{array}$ & LoEw 1847d: 532 & Pycnopogon mixtus (LoEw, 1847) & Asilidae \\
\hline Dasypogon apiformis LoEw, 1847 & LoEW 1847d: 529 & Pycnopogon pallidipennis (BRULLÉ, 1836) & Asilidae \\
\hline Dasypogon eucerus LoEw, 1847 & LoEw 1847d: 440 & Saropogon eucerus (LoEw, 1847) & Asilidae \\
\hline Dasypogon hybotinus LoEw, 1847 & LOEw 1847d: 498 & Oligopogon hybotinus (LoEw, 1847) & Asilidae \\
\hline Dasypogon jugulum LoEw, 1847 & LoEw 1847d: 441 & Saropogon jugulum (LoEw, 1847) & Asilidae \\
\hline Dasypogon laevigatus LoEw, 1851 & LoEw 1851: 14 & Stenopogon laevigatus (LoEw, 1851) & Asilidae \\
\hline $\begin{array}{l}\text { Dasypogon megilliformis LoEw, } \\
1847\end{array}$ & LoEw 1847d: 534 & Crobilocerus megilliformis (LoEw, 1847) & Asilidae \\
\hline Dasypogon milvus LoEw, 1847 & LoEw 1847d: 454 & Stenopogon milvus (LoEw, 1847) & Asilidae \\
\hline Dasypogon mixtus LoEw, 1847 & LoEw 1847d: 531 & Pycnopogon mixtus (LoEw, 1847) & Asilidae \\
\hline Dasypogon platynotus LoEw, 1847 & LoEw 1847d: 443 & Saropogon platynotus (LoEw, 1847) & Asilidae \\
\hline Diaphorus lugubris LoEw, 1857 & LoEw 1857a: 45 & Diaphorus lugubris LoEw, 1857 & $\begin{array}{l}\text { Dolichopod- } \\
\text { idae }\end{array}$ \\
\hline Dixa laeta Loew, 1849 & LOEW 1849b: 344 & Dixella laeta (LoEw, 1849) & Dixidae \\
\hline Dolichopus excisus LoEw, 1859 & LoEW 1859c: 10 & Dolichopus excisus LoEw, 1859 & $\begin{array}{l}\text { Dolichopod- } \\
\text { idae }\end{array}$ \\
\hline Dorycera brevis LoEw, 1868 & LoEw 1868: 9 & Dorycera brevis LoEw, 1868 & Ulidiidae \\
\hline Eclimus gracilis LoEw, 1844 & LoEw 1844d: 156 & Eclimus gracilis LoEw, 1844 & Bombyliidae \\
\hline Eclimus perspicillaris LoEw, 1844 & LoEw 1844d: 154 & Eclimus perspicillaris LoEw, 1844 & Bombyliidae \\
\hline Empis lugubris LoEw, 1869 & LoEw 1869b: 75 & Empis lugubris LoEw, 1869 & Empididae \\
\hline Empis praecox LoEw, 1867 & LoEw 1867: 56 & Empis praecox LoEw, 1867 & Empididae \\
\hline Empis setosa LoEw, 1867 & LoEw 1867: 52 & Empis setosa LoEw, 1867 & Empididae \\
\hline
\end{tabular}




\begin{tabular}{|c|c|c|c|}
\hline Artname (Originalkombination) & Literaturstelle & Artname (rezente Kombination) & Familie \\
\hline Eumerus amoenus LoEw, 1848 & LoEW 1848c: 132 & Eumerus amoenus LoEw, 1848 & Syrphidae \\
\hline Eumerus angustifrons LoEw, 1848 & LoEw 1848b: 125 & Eumerus angustifrons LoEw, 1848 & Syrphidae \\
\hline Eumerus argyropus LoEw, 1848 & LoEw 1848c: 135 & Eumerus argyropus LoEw, 1848 & Syrphidae \\
\hline Eumerus basalis LoEw, 1848 & LoEw 1848b: 126 & Eumerus basalis LoEw, 1848 & Syrphidae \\
\hline Eumerus lucidus LoEw, 1848 & LoEW 1848c: 134 & Eumerus lucidus LoEw, 1848 & Syrphidae \\
\hline Eumerus pulchellus LoEw, 1848 & LoEW 1848c: 130 & Eumerus pulchellus LoEw, 1848 & Syrphidae \\
\hline Eumerus pusillus LoEw, 1848 & LoEW 1848c: 133 & Eumerus pusillus LoEw, 1848 & Syrphidae \\
\hline Exoprosopa baccha LoEw, 1869 & LoEw 1869a: 214 & Exoprosopa baccha LoEw, 1869 & Bombyliidae \\
\hline Exoprosopa dispar LoEw, 1869 & LoEw 1869a: 202 & Heteralonia dispar (LoEw, 1869) & Bombyliidae \\
\hline Exoprosopa minois LoEw, 1869 & LoEw 1869a: 221 & Exoprosopa minois LoEw, 1869 & Bombyliidae \\
\hline Exoprosopa telamon LoEw, 1869 & LoEw 1869a: 218 & Pachyanthrax telamon (LoEw, 1869) & Bombyliidae \\
\hline Geomyza pedestris LoEw, 1865 & LoEw 1865a: 23 & Trixoscelis pedestris (LoEw, 1865) & Trixoscelididae \\
\hline Gymnopternus angustus LoEw, 1857 & LoEw 1857a: 17 & Hercostomus nanus (MACQUART, 1827) & $\begin{array}{l}\text { Dolichopod- } \\
\text { idae }\end{array}$ \\
\hline Gymnopternus costatus LoEw, 1857 & LoEw 1857a: 19 & Hercostomus costatus (LoEw, 1857) & $\begin{array}{l}\text { Dolichopod- } \\
\text { idae }\end{array}$ \\
\hline $\begin{array}{l}\text { Habropogon longiventris LoEw, } \\
1847\end{array}$ & LoEw 1847d: 467 & Habropogon longiventris LoEw, 1847 & Asilidae \\
\hline Haemasson minutus Loew, 1844 & LoEw 1844b: 115 & Phlebotomus papatasi (Scopol, 1784) & Psychodidae \\
\hline $\begin{array}{l}\text { Halmopota mediterranea LoEw, } \\
1860\end{array}$ & LoEw 1860: 34 & Halmopota mediterranea LoEw, 1860 & Ephydridae \\
\hline Hecamede costata LoEw, 1860 & LoEW 1860: 14 & Hecamedoides costata (LoEw, 1860) & Ephydridae \\
\hline Helomyza foeda LoEw, 1862 & LoEw 1862a: 126 & Suillia notata (MEIGEN, 1830) & Heleomyzidae \\
\hline Helomyza variegata LoEw, 1862 & LoEw 1862a: 126 & Suillia variegata (LoEw, 1862) & Heleomyzidae \\
\hline Heteropogon scoparius LoEw, 1847 & LoEw 1847d: 489 & Heteropogon scoparius LoEw, 1847 & Asilidae \\
\hline Heteropogon succinctus LoEw, 1847 & LoEw 1847d: 491 & Heteropogon succinctus LoEw, 1847 & Asilidae \\
\hline Hydrotaea silvicola LoEw, 1857 & LoEw 1857c: 106 & $\begin{array}{l}\text { Hydrotaea cyrtoneurina (ZETTERSTEDT, } \\
1845 \text { ) }\end{array}$ & Muscidae \\
\hline Idia cyanescens LoEw, 1844 & LoEw 1844a: 24 & Rhyncomya cyanescens (LoEw, 1844) & Rhiniidae \\
\hline Idia speciosa LoEw, 1844 & LOEw 1844a: 23 & Rhyncomya speciosa (LoEw, 1844) & Rhiniidae \\
\hline Laphria dimidiata Loew, 1847 & LoEw 1847d: 550 & Lamyra dimidiata (LoEw, 1847) & Asilidae \\
\hline Laphria dizonias LoEw, 1847 & LoEw 1847d: 542 & Laphria dizonias LoEw, 1847 & Asilidae \\
\hline Laphria erythrura Loew, 1847 & LoEW 1847d: 552 & Andrenosoma albibarbe (MEIGEN, 1820) & Asilidae \\
\hline Laphystia sabulicola LoEw, 1847 & LoEw 1847d: 538 & Laphystia sabulicola LoEw, 1847 & Asilidae \\
\hline Lasiopogon pilosellus LoEw, 1847 & LoEw 1847d: 511 & Lasiopogon pilosellus LoEw, 1847 & Asilidae \\
\hline Lasiopogon tarsalis LoEw, 1847 & LoEw 1847d: 513 & Lasiopogon tarsalis LoEw, 1847 & Asilidae \\
\hline Leptogaster gracilis LoEw, 1847 & LoEw 1847d: 399 & Leptogaster gracilis LoEw, 1847 & Asilidae \\
\hline Leptogaster palparis Loew, 1847 & LoEw 1847d: 396 & Leptogaster palparis LoEw, 1847 & Asilidae \\
\hline Lispe pulchella LoEw, 1847 & LoEW 1847a: 29 & Lispe nana MACQUART, 1835 & Muscidae \\
\hline Lispe scalaris LoEw, 1847 & LoEw 1847a: 28 & Lispe scalaris LoEw, 1847 & Muscidae \\
\hline Lispe simplicissima LoEw, 1847 & LoEw 1847a: 30 & Lispe pygmea FALLÉN, 1825 & Muscidae \\
\hline Lomatia alecto LoEw, 1846 & LoEw 1846a: 381 & Lomatia alecto LoEw, 1846 & Bombyliidae \\
\hline Lomatia polyzona LoEw, 1869 & LoEw 1869a: 151 & Lomatia polyzona LoEw, 1869 & Bombyliidae \\
\hline Merodon velox LoEW, 1869 & LoEw 1869a: 253 & Merodon velox LoEW, 1869 & Syrphidae \\
\hline
\end{tabular}




\begin{tabular}{|c|c|c|c|}
\hline Artname (Originalkombination) & Literaturstelle & Artname (rezente Kombination) & Familie \\
\hline Microphorus rostellatus LoEw, 1864 & LoEw 1864b: 42 & Microphor rostellatus (LoEw, 1864) & Microphoridae \\
\hline Nemotelus argentifer LoEw, 1846 & LoEw 1846a: 453 & Nemotelus argentifer LoEw, 1846 & Stratiomyidae \\
\hline Nemotelus bipunctatus LoEw, 1846 & LoEw 1846a: 451 & Nemotelus bipunctatus LoEw, 1846 & Stratiomyidae \\
\hline $\begin{array}{l}\text { Nemotelus brachystomus LoEw, } \\
1846\end{array}$ & LoEw 1846a: 443 & Nemotelus brachystomus LoEw, 1846 & Stratiomyidae \\
\hline Nemotelus gracilis LoEw, 1846 & LoEw 1846a: 449 & Nemotelus pantherinus (LinnaEus, 1758) & Stratiomyidae \\
\hline Noterophila acutipennis LoEw, 1866 & LOEW 1866: 269 & Camilla acutipennis (LoEw, 1866) & Camillidae \\
\hline Notiphila australis LoEw, 1860 & LoEw 1860: 7 & Notiphila australis LoEw, 1860 & Ephydridae \\
\hline Ochthera mantispa LoEw, 1847 & LoEw 1847h: 372 & Ochthera mantispa LoEw, 1847 & Ephydridae \\
\hline Ocyptera costalis LoEw, 1844 & LoEW 1844f: 268 & Cylindromyia pusilla (MEIGEN, 1824) & Tachinidae \\
\hline Ocyptera pilipes Loew, 1844 & LoEw 1844e: 233 & Cylindromyia pilipes (LoEw, 1844) & Tachinidae \\
\hline Ocyptera rufifrons Loew, 1844 & LoEw 1844e: 232 & Cylindromyia rufifrons (LoEw, 1844) & Tachinidae \\
\hline Odontomyia discolor LoEw, 1846 & LoEw 1846a: 473 & Odontomyia discolor LoEw, 1846 & Stratiomyidae \\
\hline Odontomyia hydrophila LoEw, 1846 & LoEw 1846a: 486 & Odontomyia angulata (PANZER, 1798) & Stratiomyidae \\
\hline Odontomyia interrupta LoEw, 1846 & LoEw 1846a: 493 & Oplodontha viridula (FABRICIUs, 1775) & Stratiomyidae \\
\hline $\begin{array}{l}\text { Odontomyia signaticornis LoEw, } \\
1846\end{array}$ & LoEw 1846a: 477 & Odontomyia ornata (MeIGEN, 1822) & Stratiomyidae \\
\hline Oligodranes fumipennis LoEw, 1844 & LOEW 1844d: 162 & Apolysis fumipennis (LoEw, 1844) & Bombyliidae \\
\hline $\begin{array}{l}\text { Oligodranes obscuripennis LoEw, } \\
1844\end{array}$ & LoEw 1844d: 160 & Oligodranes obscuripennis LoEw, 1844 & Bombyliidae \\
\hline Ortalis albipennis LoEw, 1846 & LoEw 1846b: 93 & Hypochra albipennis (LoEw, 1846) & Ulidiidae \\
\hline Orthochile unicolor LoEw, 1850 & LOEW 1850b: 344 & Ortochile unicolor LoEw, 1850 & $\begin{array}{l}\text { Dolichopod- } \\
\text { idae }\end{array}$ \\
\hline Oscinis brevirostris LoEw, 1858 & LoEw 1858a: 60 & $\begin{array}{l}\text { Aphanotrigonum cinctellum (ZETTER- } \\
\text { STEDT, 1848) }\end{array}$ & Chloropidae \\
\hline Oscinis longirostris LoEw, 1858 & LoEw 1858a: 61 & Oscinimorpha longirostris (LoEw, 1858) & Chloropidae \\
\hline Oscinis marginata LoEw, 1858 & LoEw 1858b: 69 & Polyodaspis ruficornis (MACQUART, 1835) & Chloropidae \\
\hline $\begin{array}{l}\text { Pachymeria mediterranea LoEw, } \\
1864\end{array}$ & LoEw 1864a: 364 & Empis mediterranea (LoEw, 1864) & Empididae \\
\hline Pangonia fulvipes LoEw, 1859 & LoEw 1859c: 26 & Pangonius fulvipes LoEw, 1859 & Tabanidae \\
\hline Pangonia obscurata LoEw, 1859 & LoEW 1859c: 27 & Pangonius obscuratus Loew, 1859 & Tabanidae \\
\hline Philopota murina Loew, 1844 & LoEw 1844d: 163 & Oligoneura murina (LoEw, 1844) & Acroceridae \\
\hline Phthiria conspicua LoEw, 1846 & LoEw 1846a: 397 & Phthiria conspicua LoEw, 1846 & Bombyliidae \\
\hline Phthiria rustica LoEw, 1846 & LoEw 1846a: 403 & Phthiria subnitens LoEw, 1846 & Bombyliidae \\
\hline Phthiria subnitens LoEw, 1846 & LoEw 1846a: 401 & Phthiria subnitens LoEw, 1846 & Bombyliidae \\
\hline Phthiria vagans LoEw, 1846 & LoEw 1846a: 391 & Phthiria vagans LoEw, 1846 & Bombyliidae \\
\hline Phylloteles pictipennis LoEw, 1844 & LoEw 1844d: 168 & Phylloteles pictipennis LoEw, 1844 & Sarcophagidae \\
\hline $\begin{array}{l}\text { Platypygus chrysanthemi LoEw, } \\
1844\end{array}$ & LoEw 1844b: 127 & Platypygus chrysanthemi LoEw, 1844 & $\begin{array}{l}\text { Mythicomyi- } \\
\text { idae }\end{array}$ \\
\hline Platystoma pubescens LoEw, 1845 & LoEw 1845: 36 & Platystoma pubescens Loew, 1845 & $\begin{array}{l}\text { Platystomat- } \\
\text { idae }\end{array}$ \\
\hline Polyphonius laevigatus LoEw, 1848 & LoEw 1848a: 407 & Polyphonius laevigatus LoEw, 1848 & Asilidae \\
\hline Promachus leoninus LoEw, 1848 & LoEw 1848a: 404 & Promachus leoninus LoEw, 1848 & Asilidae \\
\hline Psilopa nana LoEw, 1860 & LoEW 1860: 9 & Psilopa nana LoEw, 1860 & Ephydridae \\
\hline Psilopa obscuripes LoEw, 1860 & LoEW 1860: 10 & Psilopa obscuripes LoEw, 1860 & Ephydridae \\
\hline
\end{tabular}




\begin{tabular}{|c|c|c|c|}
\hline Artname (Originalkombination) & Literaturstelle & Artname (rezente Kombination) & Familie \\
\hline Psilopus albonotatus LoEw, 1857 & LoEw 1857a: 4 & Sciapus pallens (WIEDEMANN, 1830) & $\begin{array}{l}\text { Dolichopod- } \\
\text { idae }\end{array}$ \\
\hline Psilopus flavicinctus LoEw, 1857 & LoEw 1857a: 4 & Sciapus flavicinctus (LoEw, 1857) & $\begin{array}{l}\text { Dolichopod- } \\
\text { idae }\end{array}$ \\
\hline Rhicnoessa pallipes LoEw, 1865 & LoEW 1865b: 37 & Tethina pallipes (LoEw, 1865) & Tethinidae \\
\hline Rhinophora laeviventris LoEw, 1847 & LoEw 1847e: 268 & Stevenia spec. [nomen dubium] & Rhinophoridae \\
\hline $\begin{array}{l}\text { Rhinophora lucidiventris LoEw, } \\
1847\end{array}$ & LoEw 1847e: 269 & Stevenia atramentaria (MEIGEN, 1824) & Rhinophoridae \\
\hline $\begin{array}{l}\text { Rhinophora pallidicornis LoEW, } \\
1847\end{array}$ & LoEw 1847e: 270 & Stevenia spec. [nomen dubium] & Rhinophoridae \\
\hline Rhinophora triangulata LoEw, 1847 & LoEw 1847e: 263 & Stevenia triangulata (LoEw, 1847) & Rhinophoridae \\
\hline Sapromyza biseriata LoEw, 1847 & LoEw 1847g: 29 & Minettia biseriata (LoEw, 1847) & Lauxaniidae \\
\hline Sapromyza dimidiata LoEw, 1847 & LoEw 1847g: 27 & Minettia rivosa (MEIGEN, 1826) & Lauxaniidae \\
\hline Sapromyza intonsa LoEw, 1847 & LoEw 1847g: 34 & Sapromyza intonsa LoEw, 1847 & Lauxaniidae \\
\hline Sapromyza subvittata LoEw, 1847 & LOEW 1847g: 28 & Minettia subvittata (LoEw, 1847) & Lauxaniidae \\
\hline Scatella gilva LoEw, 1860 & LoEw 1860: 41 & Scatella subguttata (MEIGEN, 1830) & Ephydridae \\
\hline Scatopse recurva LoEw, 1846 & LoEw 1846a: 330 & Coboldia fuscipes (MEIGEN, 1830) & Scatopsidae \\
\hline Scopolia anacantha LoEw, 1847 & LoEw 1847e: 275 & Periscepsia spec. [nomen dubium] & Tachinidae \\
\hline Silvius ochraceus LoEw, 1858 & LoEw 1858d: 351 & Silvius ochraceus LoEw, 1858 & Tabanidae \\
\hline Spongostylum pallipes LoEw, 1869 & LoEw 1869a: 227 & Xeramoeba pallipes (LoEw, 1869) & Bombyliidae \\
\hline Stichopogon inaequalis LoEw, 1847 & LoEw 1847d: 505 & Stichopogon inaequalis LoEw, 1847 & Asilidae \\
\hline Stichopogon nigrifrons LoEw, 1847 & LoEw 1847d: 506 & Stichopogon albofasciatus (MEIGEN, 1820) & Asilidae \\
\hline Stichopogon tener LoEw, 1847 & LoEw 1847d: 503 & $\begin{array}{l}\text { Stichopogon elegantulus (WIEDEMANN, } \\
\text { 1820) }\end{array}$ & Asilidae \\
\hline Syritta spinigera LoEw, 1848 & LoEw 1848d: 331 & Syritta flaviventris MACQUART, 1842 & Syrphidae \\
\hline Tabanus anthophilus LoEw, 1859 & LoEw 1859a: 593 & Tabanus bromius LinnaEus, 1758 & Tabanidae \\
\hline Tabanus gagates LoEw, 1859 & LoEw 1859a: 609 & Dasyrhamphis carbonarius (MEIGEN, 1820) & Tabanidae \\
\hline Tabanus pulchellus LoEw, 1859 & LoEw 1859a: 597 & Atylotus pulchellus (LoEw, 1859) & Tabanidae \\
\hline Tabanus rectus LoEw, 1859 & LoEw 1859a: 603 & Tabanus rectus LoEw, 1859 & Tabanidae \\
\hline Tabanus unifasciatus LoEw, 1859 & LoEw 1859a: 600 & Tabanus unifasciatus LoEw, 1859 & Tabanidae \\
\hline Tetanocera amoena LoEw, 1853 & LoEw 1853: 38 & Coremacera amoena (LoEw, 1853) & Sciomyzidae \\
\hline Tetanocera gracilis LoEw, 1845 & LoEw 1845: 43 & Dichetophora obliterata (FABRICIUS, 1805) & Sciomyzidae \\
\hline $\begin{array}{l}\text { Tetanocera obscuripennis LoEw, } \\
1845\end{array}$ & LoEW 1845: 38 & Coremacera obscuripennis (LoEw, 1845) & Sciomyzidae \\
\hline Tetanocera prominens LoEw, 1847 & LoEW 1847c: 120 & Euthycera prominens (LoEw, 1847) & Sciomyzidae \\
\hline Thereva claripennis LoEw, 1847 & LoEw 1847b: 23 & Thereva claripennis LoEw, 1847 & Therevidae \\
\hline Thereva didyma LoEw, 1847 & LoEw 1847b: 18 & Thereva spinulosa LoEw, 1847 & Therevidae \\
\hline Thereva flavescens LoEw, 1847 & LoEw 1847b: 3 & Thereva flavescens LoEw, 1847 & Therevidae \\
\hline Tipula selenis LoEw, 1873 & LoEW 1873: 37 & Tipula selenis LoEw, 1873 & Tipulidae \\
\hline Tomomyza europaea LoEw, 1869 & LoEw 1869a: 228 & Stomylomyia europaea (LoEw, 1869) & Bombyliidae \\
\hline Trypeta elongatula LoEw, 1844 & LOEW 1844c: 397 & $\begin{array}{l}\text { Dioxyna bidentis (RoBINEAU-DESVOIDY, } \\
1830 \text { ) }\end{array}$ & Tephritidae \\
\hline Trypeta lurida Loew, 1844 & LoEw 1844c: 331 & $\begin{array}{l}\text { Chaetostomella cylindrica (RoBINEAU- } \\
\text { DESvOIDY, 1830) }\end{array}$ & Tephritidae \\
\hline Trypeta matricariae LoEw, 1844 & LoEw 1844c: 389 & Tephritis matricariae (LoEw, 1844) & Tephritidae \\
\hline
\end{tabular}




\begin{tabular}{|c|c|c|c|}
\hline Artname (Originalkombination) & Literaturstelle & Artname (rezente Kombination) & Familie \\
\hline Trypeta nigricoma LoEw, 1844 & LoEW 1844c: 422 & Terella colon (MEIGEN, 1826) & Tephritidae \\
\hline Trypeta praecox LoEw, 1844 & LoEW 1844c: 391 & Tephritis praecox (LoEw, 1844) & Tephritidae \\
\hline Trypeta producta Loew, 1844 & LoEw 1844c: 399 & Campiglossa producta (LoEw, 1844) & Tephritidae \\
\hline Trypeta pulchra LoEw, 1844 & LoEw 1844c: 406 & Tephritis pulchra (LoEw, 1844) & Tephritidae \\
\hline Trypeta simplex LoEw, 1844 & LoEW 1844c: 379 & Tephritis simplex (LoEw, 1844 & Tephritidae \\
\hline Ulidia albidipennis LoEw, 1845 & LoEw 1845: 32 & Ulidia albidipennis LoEw, 1845 & Ulidiidae \\
\hline Ulidia atro-virens LoEw, 1845 & LoEw 1845: 32 & Ulidia albidipennis LoEw, 1845 & Ulidiidae \\
\hline Ulidia megacephala LoEw, 1845 & LoEw 1845: 33 & Ulidia megacephala LoEw, 1845 & Ulidiidae \\
\hline Usia lata LoEw, 1846 & LoEw 1846a: 407 & Usia lata LoEw, 1846 & Bombyliidae \\
\hline Usia punctipennis LoEw, 1846 & LoEW 1846a: 417 & Parageron punctipennis LoEw, 1846 & Bombyliidae \\
\hline
\end{tabular}

\subsection{Hymenoptera}

Tabelle 6: Das von Loew während der Reise gesammelte hymenopterologische Typenmaterial. [Table 6:The hymenopterological type material collected by Loew during the expedition.]

\begin{tabular}{|c|c|c|c|}
\hline Artname (Originalkombination) & Literaturstelle & Artname (rezente Kombination)* & Familie \\
\hline $\begin{array}{l}\text { Ceratina chrysomalla } \\
\text { GERSTAECKER, } 1869\end{array}$ & $\begin{array}{l}\text { GERSTAECKER 1869: } \\
183\end{array}$ & $\begin{array}{l}\text { Ceratina chrysomalla GERSTAECKER, } \\
1869\end{array}$ & Apidae \\
\hline Ceratina loewi Gerstaecker, 1869 & $\begin{array}{l}\text { GERSTAECKER 1869: } \\
184\end{array}$ & Ceratina loewi Gerstaecker, 1869 & Apidae \\
\hline $\begin{array}{l}\text { Ceratina nigroaenea GERSTAECKER, } \\
1869\end{array}$ & $\begin{array}{l}\text { GERSTAECKER 1869: } \\
181\end{array}$ & $\begin{array}{l}\text { Ceratina nigroaenea GERSTAECKER, } \\
1869\end{array}$ & Apidae \\
\hline Dioxys pumila GerstaeCKer, 1869 & $\begin{array}{l}\text { GERSTAECKER 1869: } \\
167\end{array}$ & Dioxys pumila Gerstaecker, 1869 & Apidae \\
\hline Tarpa loewii STEIN, 1876 & STEIN 1876: 56 & $\begin{array}{l}\text { Megalodontes eversmanni (FREYMUTH, } \\
1870 \text { ) }\end{array}$ & $\begin{array}{l}\text { Megalo- } \\
\text { dontesidae }\end{array}$ \\
\hline
\end{tabular}

Typenfundorte sind Adalia, Kos, Mermeriza, Patara und Rhodus.

\subsection{Lepidoptera}

Das von LoEw mitgebrachte Material enthielt bei den Lepidoptera 184 Arten. Aus diesem Fundus hat ZeLler 1846 und 1847 insgesamt 28 neue Arten beschrieben. Die Typenfundorte sind (in der Schreibweise von Zeller): Adirnas, Brussa, Carajasu, Istenas, Kellemish,
Macri, Makri, Mermeriza, Patara, Pera, Phinik, Phinika, Rhodus, Smyrna, Stanchio und Tlos. Die rezenten Artnamen wurden entsprechend den Informationen auf der Website „Lepiforum“ aktualisiert (RENNwALD \& RoDELAND 2019).

Tabelle 7: Das von Loew während der Reise gesammelte lepidopterologische Typenmaterial.

[Table 7: The lepidopterological type material collected by Loew during the expedition.]

\begin{tabular}{|l|l|l|l|}
\hline \multicolumn{1}{|c|}{$\begin{array}{c}\text { Artname } \\
\text { Originalkombination) }\end{array}$} & \multicolumn{1}{|c|}{ Literaturstelle } & \multicolumn{1}{|c|}{ Artname (rezente Kombination) } & \multicolumn{1}{c|}{ Familie } \\
\hline $\begin{array}{l}\text { Boarmia correptaria ZELLER, } \\
1847\end{array}$ & ZELLER 1847: 18 Nr. 88 & $\begin{array}{l}\text { Peribatodes correptaria (ZELLER, } \\
1847)\end{array}$ & Geometridae \\
\hline $\begin{array}{l}\text { Coleophora cuprariella ZELLER, } \\
1847\end{array}$ & $\begin{array}{l}\text { ZELLER 1847: } 36 \\
\text { Nr. } 175\end{array}$ & $\begin{array}{l}\text { Coleophora alcyonipenella (KoLLAR, } \\
1832)\end{array}$ & Coleophoridae \\
\hline $\begin{array}{l}\text { Coleophora fuscicornis ZELLER, } \\
1847\end{array}$ & ZELLER 1847: 37 & Coleophora fuscicornis ZELLER, 1847 & Coleophoridae \\
\hline
\end{tabular}




\begin{tabular}{|c|c|c|c|}
\hline $\begin{array}{l}\text { Artname } \\
\text { (Originalkombination) }\end{array}$ & Literaturstelle & Artname (rezente Kombination) & Familie \\
\hline $\begin{array}{l}\text { Cosmopteryx argyrogrammos } \\
\text { ZELLER, } 1847\end{array}$ & $\begin{array}{l}\text { ZELLER 1847: } 37 \\
\text { Nr. } 177\end{array}$ & $\begin{array}{l}\text { Pyroderces argyrogrammos (ZELLER, } \\
1847 \text { ) }\end{array}$ & Cosmopterigidae \\
\hline Dasycera imitatrix ZELLER, 1847 & $\begin{array}{l}\text { ZELLER 1847: } 35 \\
\text { Nr. } 169\end{array}$ & Esperia imitatrix (ZELLER, 1847) & Oecophoridae \\
\hline Epischnia venosa ZELLER, 1847 & $\begin{array}{l}\text { ZELLER 1847: } 31 \\
\text { Nr. } 159\end{array}$ & Polyocha venosa (ZELLER, 1847) & Pyralidae \\
\hline Eudorea coarctata ZELLER, 1847 & $\begin{array}{l}\text { ZELLER 1847: } 29 \\
\text { Nr. } 151\end{array}$ & Eudonia angustea (CuRTIs, 1827) & Crambidae \\
\hline Hapsifera luridella ZELLER, 1847 & $\begin{array}{l}\text { ZELLER 1847: } 33 \\
\text { Nr. } 162\end{array}$ & Hapsifera luridella ZELLER, 1847 & Tineidae \\
\hline $\begin{array}{l}\text { Hipparchia telmessia ZELLER, } \\
1847\end{array}$ & ZELLER 1847: 4 Nr. 8 & Maniola telmessia (ZELLER, 1847) & Nymphalidae \\
\hline Idaea luridata ZELLER, 1847 & $\begin{array}{l}\text { ZELLER 1847: } 20 \\
\text { Nr. } 100\end{array}$ & Scopula luridata (ZELLER, 1847) & Geometridae \\
\hline Lithosia costalis ZELLER, 1847 & ZELLER 1847: 16 Nr. 64 & Eilema costalis (ZELLER, 1847) & Erebidae \\
\hline Lycaena loewii ZELLER, 1847 & ZELLER 1847: 9 Nr. 35 & Plebejidea loewii (ZELLER, 1847) & Lycaenidae \\
\hline $\begin{array}{l}\text { Minoa flavicornata ZELLER, } \\
1847\end{array}$ & ZELLER 1847: 20 Nr. 97 & $\begin{array}{l}\text { Lithostege infuscata (EvERs- } \\
\text { MANN,1837) }\end{array}$ & Geometridae \\
\hline $\begin{array}{l}\text { Myelois argyrogrammos } \\
\text { ZELLER, } 1847\end{array}$ & $\begin{array}{l}\text { ZELLER 1847: } 29 \\
\text { Nr. } 152\end{array}$ & $\begin{array}{l}\text { Metallosticha argyrogrammos } \\
\text { (ZELLER, 1847) }\end{array}$ & Pyralidae \\
\hline $\begin{array}{l}\text { Myelois incompta ZELLER, } \\
1847\end{array}$ & $\begin{array}{l}\text { ZELLER 1847: } 30 \\
\text { Nr. } 153\end{array}$ & Eurhodope incompta (ZELLER, 1847) & Pyralidae \\
\hline Myelois obliqua ZELLER, 1847 & $\begin{array}{l}\text { ZELLER 1847: } 31 \\
\text { Nr. } 156\end{array}$ & Acrobasis obliqua (ZELLER, 1847) & Pyralidae \\
\hline $\begin{array}{l}\text { Nemotois barbatellus ZELLER, } \\
1847\end{array}$ & $\begin{array}{l}\text { ZELLER 1847: } 33 \\
\text { Nr. } 164\end{array}$ & $\begin{array}{l}\text { Nemophora barbatellus (ZELLER, } \\
\text { 1847) }\end{array}$ & Adelidae \\
\hline Oecophora apicalis ZELLER, 1847 & $\begin{array}{l}\text { ZELLER 1847: } 35 \\
\text { Nr. } 171\end{array}$ & Scythris apicalis (ZELLER, 1847) & Scythrididae \\
\hline Procris obscura ZELLER, 1847 & ZELLER 1847: 15 Nr. 60 & Adscita obscura (ZELLER, 1847) & Zygaenidae \\
\hline Pterophorus loewii ZELLER, 1847 & $\begin{array}{l}\text { ZELLER 1847: } 38 \\
\text { Nr. } 182\end{array}$ & $\begin{array}{l}\text { Stenoptilia zophodactylus (DUPON- } \\
\text { CHEL, 1840) }\end{array}$ & Pterophoridae \\
\hline $\begin{array}{l}\text { Rhodocera farinosa ZELLER, } \\
1847\end{array}$ & ZELLER 1847: 5 Nr. 17 & Gonepteryx farinosa (ZELLER, 1847) & Pieridae \\
\hline Sciaphila loewiana ZELLER, 1847 & $\begin{array}{l}\text { ZELLER 1847: } 25 \\
\text { Nr. } 135\end{array}$ & Cnephasia longana (HAwORTH, 1811) & Tortricidae \\
\hline $\begin{array}{l}\text { Sericoris artemisiana ZELLER, } \\
1847\end{array}$ & $\begin{array}{l}\text { ZELLER 1847: } 27 \\
\text { Nr. } 140\end{array}$ & Lobesia artemisiana (ZELLER, 1847) & Tortricidae \\
\hline Sesia leucomelaena ZELLER, 1847 & ZELLER 1847: 12 Nr. 49 & $\begin{array}{l}\text { Pyropteron leucomelaena (ZELLER, } \\
\text { 1847) }\end{array}$ & Sesiidae \\
\hline Sesia loewii ZELLER, 1847 & ZELLER 1847: 14 Nr. 53 & $\begin{array}{l}\text { Chamaesphecia masariformis } \\
\text { (OCHSENHEIMER, 1808) }\end{array}$ & Sesiidae \\
\hline Sesia trivittata ZELLER, 1847 & ZELLER 1847: 13 Nr. 50 & $\begin{array}{l}\text { Chamaesphecia alysoniformis } \\
\text { (HERRICH-SCHÄFFER, 1846) }\end{array}$ & Sesiidae \\
\hline Thecla caudatula ZELLER, 1847 & ZELLER 1847: 6 Nr. 24 & Satyrium ilicis (ESPER, 1779) & Lycaenidae \\
\hline Trichosoma loewii ZELLER, 1846 & ZELLER 1846: 5 & Ocnogyna loewii (ZELLER, 1846) & Erebidae \\
\hline
\end{tabular}




\subsection{Mollusca (Gastropoda)}

Tabelle 8: Das von LoEw während der Reise gesammelte malakologische Typenmaterial. [Table 8: The malacological type material collected by Loew during the expedition.]

\begin{tabular}{|l|c|l|c|}
\hline Artname (Originalkombination) & Literaturstelle & Artname (rezente Kombination) & Familie \\
\hline Bulimus loewii Philippi, 1844 & PHILIPPI 1844: 106 & Jaminia loewii (PhILIPPI, 1844) & Enidae \\
\hline
\end{tabular}

Abb. 11: Typenexemplare von Diptera, die Loew auf der Insel Stanchio gesammelt und später unter dem Namen Philopota murina LoEw, 1844 als neue Art beschrieben hat. Der sehr spezielle Körperbau dieser Acroceridae, ein Spinnenparasit, und ihr auffälliges Verhalten veranlassten LoEw zu einem besonderen Bericht darüber (siehe Seite 233).

[Fig. 11: Type specimens of Diptera collected by Loew on the island of Stanchio and later described as a new species by him under the name Philopota murina Loew, 1844. The very specific body shape of this Acroceridae, a spider parasite, and its conspicuous behavior prompted LoEw to report on it (see page 233).]

Abb. 12: Die historische Etikettierung von Typenmaterial aus der Sammlung Loew am Beispiel der Raubfliegenart Eutolmus mordax. Erklärung im Text.

[Fig. 12: The historical labeling of type material from the LoEw collection using the example of the robber fly species Eutolmus mordax. Explanation in the text.]

Abb. 13: Historische Etiketten aus der Sammlung Loew am Beispiel von Exemplaren aus den Aufsammlungen während seiner Reise nach Kleinasien. 1) „Furnas / Mai 42.“von Eumerus pulchellus; 2) „Patara / Mai 42.“von Odontomyia signaticornis; 3) „Leros / Jun. 42“ von Eumerus pulchellus; 4) „Tlos / Mai 42.“von Odontomyia signaticornis; 5) „Makri / Mai 42“von Villa stenozonus; 6) „Adalia / Oct. 40.“von Eumerus angustifrons; 7) „Klein Asien / Macri / H. Loew S. / 5. 1842“von Villa stenozonus; 8) von Geomyza pedestris; 9) „Brusa / 8/42 A. m.“von Conops brevicornis; 10) „Rhodus / Loew S. / Mai” von Chrysopila obscuribarba.

[Fig. 13: Historical labels from the Loew collection using examples of specimens from the collections during his trip to Asia Minor. 1) "Furnas / May 42." from Eumerus pulchellus; 2) "Patara / May 42." from Odontomyia signaticornis; 3) "Leros / June 42" from Eumerus pulchellus; 4) "Tlos / May 42." from Odontomyia signaticornis; 5) "Makri / May 42” from Villa stenozonus; 6) "Adalia / Oct. 40." from Eumerus angustifrons; 7) "Asia Minor / Macri / H. Loew S. / May 1842" from Villa stenozonus; 8) from Geomyza pedestris; 9) "Brusa / 8/42 A. m." from Conops brevicornis; 10) "Rhodus / Loew S. / May" from Chrysopila obscuribarba.]

Abb. 14: Historische Form- und Farbetiketten aus der Sammlung Loew, Fundorte seiner Reise 1841-1842 betreffend. „Kleinasien“ steht für nicht näher bestimmbare Fundorte auf dem anatolischen Festland. 1) „Kleinasien“; 2) Kellemisch; 3) unsicher; 4) Ephesus; 5) Patara; 6) Stanchio; 7) Mermeriza; 8) Makri; 9) Rhodus; 10) „Kleinasien“; 11) Makri; 12) Rhodus; 13) „Kleinasien“; 14) „Kleinasien“; 15) Rhodus; 16) Smyrna; 17) „Kleinasien“; 18) Lerus; 19) „Kleinasien“; 20) Furnas; 21-24) „Kleinasien“.

[Fig. 14: Historical shape and colored labels from the Loew Collection, regarding the locations of his trip in 1841-1842. "Asia Minor" stands for localities on the mainland of Anatolia that cannot be determined. 1) "Asia Minor"; 2) Kellemisch; 3) uncertain; 4) Ephesus; 5) Patara; 6) Stanchio; 7) Mermeriza; 8) Makri; 9) Rhodus; 10) "Asia Minor"; 11) Makri; 12) Rhodus; 13) "Asia Minor"; 14) “Asia Minor”; 15) Rhodus; 16) Smyrna; 17) “Asia Minor”; 18) Lerus; 19) “Asia Minor”; 20) Furnas; 21-24) "Asia Minor”. ] 


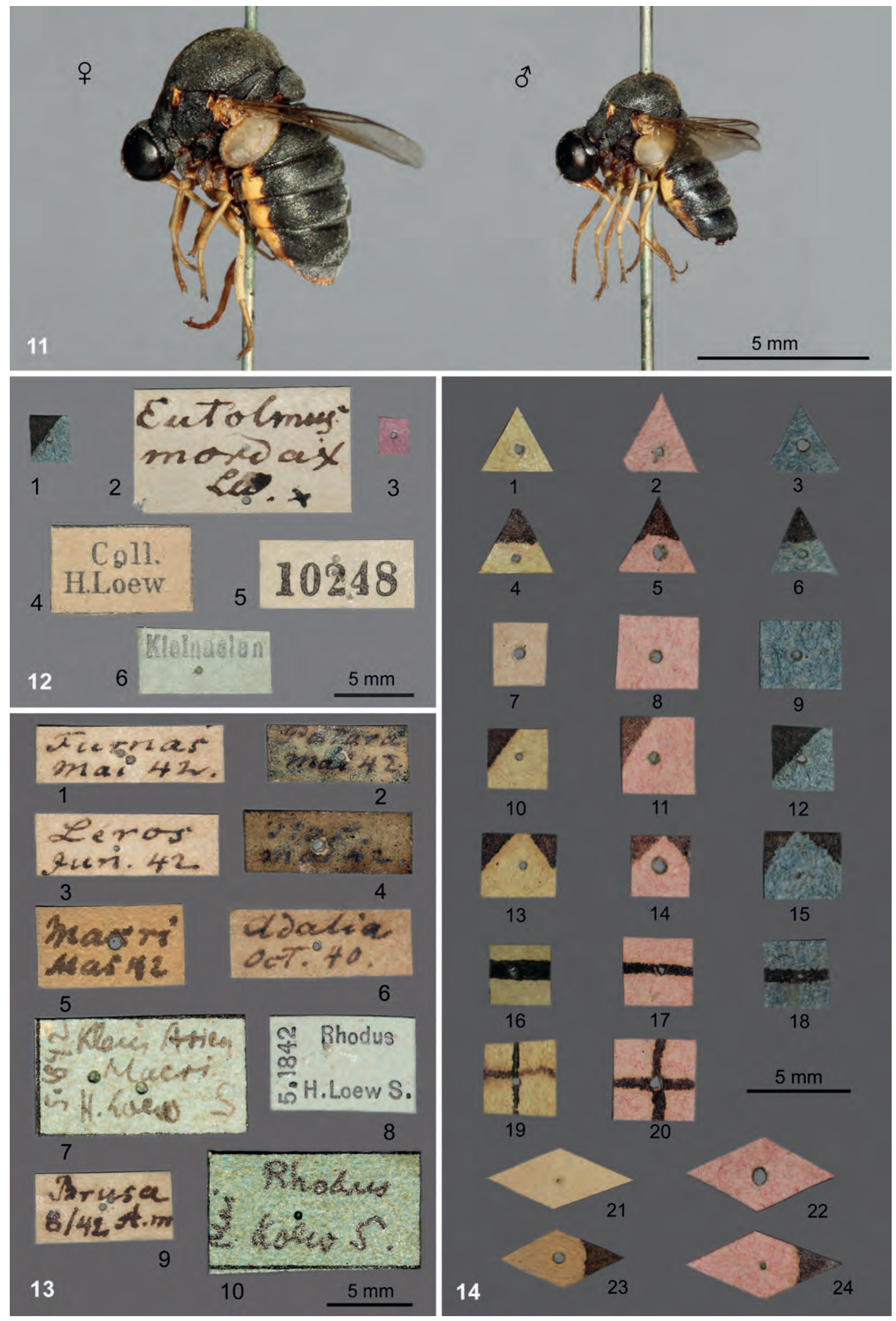




\subsection{LoEWs Sammlungsetiketten}

In Abbildung 12 auf Seite 253 sind beispielhaft die unterschiedlichen historischen Etiketten dargestellt, die an einem auf der Reise in das Osmanische Reich gefundenen und später von LoEw beschriebenen Typusexemplar vorkommen können. Darüber hinaus wurden später mitunter Etiketten mit Hinweisen zur Herkunft des Materials, zum Typenstatus, zu Determinationen und anderen Bemerkungen an den Sammlungsexemplaren angebracht.

Von Loew selbst stammen nur die Etiketten 1 und 2 in der Abbildung 12. Den einzigen Hinweis auf den konkreten Fundort gibt das kleine Etikett Nr. 1. Aus der Beschreibung von Eutolmus mordax ist bekannt, dass die Art ausschließlich auf Rhodus gefunden wurde. Deshalb kann man annehmen, dass dieses blau/schwarze Formund Farbetikett für den Fundort „Rhodus“ steht. Der auf dem hellen Etikett Nr. 2 in Abbildung 12 von LoEw handschriftlich vergebene Name (hier Eutolmus mordax) mit den Zusätzen $L w$. für Loew und $x$ oder ${ }^{*}$ oder $m$. für mihi hinter dem Namen, ist nur bei den von Loew selbst beschriebenen Arten zu finden. Das lateinische Personalpronomen "mihi“ steht für "mir“, für "meine Art". Solche Etiketten kennzeichnen Typenmaterial, sind aber oft nur am ersten Exemplar der Typenserie vorhanden. Nach der Übernahme der Dipteren-Sammlung durch das Zoologische Museum, das jetzige Museum für Naturkunde in Berlin, musste entschieden werden, wie sie aufgestellt werden sollte. So sprach sich zum Beispiel KraAtz (1879) dagegen aus, die Sammlung Loew mit den anderen Dipteren zu einer Hauptsammlung zu vereinen. Alles Material in einer systematisch aufgestellten Hauptsammlung zu haben, hat viele praktische Vorteile. Allerdings setzt es voraus, dass die einzelnen Objekte danach noch hinreichend den Sammlern, Determinatoren, Fundorten und übrigen Funddaten zugeordnet werden können. Das war weder in den schon in Berlin vorhandenen älteren Sammlungen der Fall, noch traf es auf die Sammlung Loew zu. Als Minimalkonsens wurden alle Exemplare der Sammlung Loew zuvor mit einem winzigen rosafarbenen Papierquadrat gekennzeichnet (Abbildung 12:3). Diese Kennzeichnung wurde später durch ein gedrucktes Etikett „Coll. H.Loew" ersetzt (Abbildung 12:4). Oftmals wurde jedoch das ältere rosa Etikett nicht entfernt und an den Objekten sind, wie am Beispiel in Abbildung 12, noch beide Etiketten vorhanden. Das Etikett 5 verweist auf die Nummer des Eintrags im historischen Sammlungskatalog des Museums. In diesem handschriftlichen Katalog sind auch (sehr knappe) Informationen zu Anzahl und Herkunft des Materials zu finden. Einigen Sammlungsexemplaren wurden später von Museumsmitarbeitern neue gedruckte Etiketten (Abbildung 12:6) zugeordnet, um Material zu kennzeichnen, dass Loew während seiner Reise in das Osmanische Reich gesammelt hatte. Meistens sind an den Diptera der Sammlung Loew aber viel weniger Etiketten vorhanden, als am Beispiel von Abbildung 12 dargestellt. Manchmal sind nur die Etiketten Nr. 3 und 4 zu finden, oder nur eines von beiden.

Über die in Abbildung 12 dargestellte Etikettierung hinaus sind nur sehr selten weitere Originaletiketten Loews mit konkreten handschriftlichen Vermerken zu Fundort und Zeitraum an dem auf der Reise gesammelten Material vorhanden. Die in Abbildung 13 unter Nr. 1-6 und 9 zusammengestellten Beispiele zeigen, dass diese von Loews Hand stammenden Etiketten nicht (oder jedenfalls nicht alle) bereits während der Reise an das Material gesteckt worden sind. In Abbildung 13 unter Nr. 6 und 9 hat Loew falsche Monats- und Jahresangaben gemacht. Das kann nur bei einem großen zeitlichen Abstand zwischen Aufsammlung und Etikettierung passiert sein. Ein handschriftliches Etikett „Bosdagh“ gibt weitere Rätsel auf. Dieser Ort wird in Loews Reisebeschreibungen nicht erwähnt und war nur an den Typusexemplaren von Asilus calopus zu finden. Nach der Originalbeschreibung (Loew 1848a) sind die Fundorte dieser Art jedoch Ephesus, Makri und Rhodus. Auch die am Typenmaterial selbst befindlichen Form- und Farbetiketten entsprechen Ephesus und Makri (Abbildung 14: 4, 8). Bosdagh oder Bozdağ (Grauer Berg) ist eine Bezeichnung für mehrere unterschiedliche Berge in der Türkei (siehe Tabelle 3). Alle befinden sich weit entfernt von den Typenfundorten.

Die später von Museumsmitarbeitern der Sammlung hinzugefügten grünen Etiketten enthalten die Worte „Kleinasien“ oder „Kleinasien H. Loew S.“ oder einen konkreten Fundort von der Reise. Sie sind gedruckt oder von Hand geschrieben. Das „S." hinter Loew steht dabei für "Sammler" (Abbildung 12: 6 und Abbildung 13: 7, 8, 10). Diese Etiketten waren ein Versuch, die mangelhafte Dokumentation des Materials nachträglich $\mathrm{zu}$ verbessern. Allerdings sind dabei zahlreiche fehlerhafte Zuordnungen gemacht worden und diese Etiketten sind in besonderem Maße nur unter Vorbehalt und nach kritischer Prüfung nutzbar. Bei unseren Untersuchungen hat sich zum Beispiel "Makri“ als Bedeutung des rosa Quadrates wie in Abbildung 14 Nr. 8 vielfach bestätigt. An einem Typenexemplar der Bombyliidae Anthrax albulus wurde dieses rosa Quadrat mit dem neuen grünen Etikett „Smyrna, 6. 1842“ kombiniert. Ein offensichtlicher Fehler, denn Smyrna wird in der Beschreibung der Art nicht als Fundort genannt, wohl aber Makri. Außerdem kann diese nachträgliche Etikettierung zu weiteren Missverständnissen führen, da der Begriff „Kleinasien“ eigentlich nur das anatolische Festland einschließt, hierbei aber oft auch für die vorgelagerten Inseln gebraucht wird (siehe z. B. Abbildung 12: 6 für einen Fund auf Rhodos).

In der vorgefundenen Situation sollten eigentlich alle Exemplare der Sammlung LoEw nachträglich mit schriftlichen Etiketten versehen werden, die als Klartext die durch 
Form- und Farbetiketten in Abbildung 14 verschlüsselten Informationen enthalten. Nach diesen Grundsätzen wurde zum Beispiel mit der Dipteren-Sammlung KeTEL verfahren, bevor sie in die Hauptsammlung eingefügt wurde (Ziegler \& Menzel 2000). Im Fall der Sammlung LoEw ist jetzt leider keine eindeutige Decodierung der vorgefundenen Form- und Farbetiketten mehr möglich. Möglicherweise fehlte schon bei der Übernahme der Sammlung Loew eine Liste, welche die Bedeutung dieser Etiketten erklärt. Einige Form- und Farbetiketten erlauben jedoch durch zahlreiche Übereinstimmungen mit den Texten Loews eine wahrscheinliche Zuordnung.

In Abbildung 14 sind nur solche Form- und Farbetiketten abgebildet, die in der Sammlung Loew für Material verwendet wurden, das von Fundorten seiner Reise in das Osmanische Reich stammt. Es gibt darüber hinaus weitere ähnliche Etiketten in LoEws Sammlung, mit denen von ihm selbst gesammeltes oder von Anderen erhaltenes Material gekennzeichnet ist. So finden sich in der Sammlung auch Etiketten in der Form von Rhomben, ähnlich denen in Abbildung 14: 21-24, allerdings aus blauem Papier. Sie sind nicht in Abbildung 14 aufgenommen worden, weil sie Funde anderer Sammler aus Griechenland (in den damaligen Grenzen) bezeichnen. Für die Interpretation der Etiketten ist auch wichtig zu wissen, dass LoEw mit den Form- und Farbetiketten nur die Codierung des Fundortes vorgenommen hat. Deshalb ist LoEw nicht zwangsläufig der Sammler des Materials. So sind an den Dipteren, die ERBER Jahre später auf Rhodus gesammelt und dann an LoEw gegeben hat, die gleichen blau/schwarzen Schildchen zu finden, wie an den von LoEw von Rhodus mitgebrachten (Abbildung 14: 12), allerdings mit dem Zusatzetikett „Rhodus, Erber".

Wir hoffen, mit dieser Übersicht zur Etikettierung der von Loew auf seiner Reise in das Osmanische Reich gesammelten Dipteren, den zahlreichen internationalen Bearbeitern dieser überaus typenreichen Sammlung eine hilfreiche Orientierung zu geben, auch wenn nicht in allen Fällen letzte Gewissheit vermittelt werden kann.

\section{English summary}

Hermann Loew (1807-1879), a Prussian teacher and natural scientist in the town Posen (now Poznań, Poland), who is known primarily as a dipterologist, had an opportunity to travel to the Ottoman Empire. To be able to do so, LoEw was fortunate enough to be allowed to suspend his teaching for a total of 13 months. From the summer of 1841 to the summer of 1842 , he took part in a scientific expedition to the today's western Turkey and eastern Greek islands organized by his colleague from Posen, archeologist and philologist Julius August SсHÖNBORN (1801-1857). At the beginning of the trip, LoEw and
SCHÖNBORN were accompanied by the young geographer Heinrich Kiepert (1818-1899) from Berlin University. Hermann Loew used this trip primarily for entomological collecting but also helped ScHÖNBORN with his field studies. In addition to numerous Diptera, Loew also collected Lepidoptera, Hymenoptera and Coleoptera. Loew's interest in natural history extended beyond insects, as he also collected molluscs, plants, fossils and rock samples. Together with ScHönBoRn, the two made geographical notes on routes and distances, the course of the rivers and mountain ranges, and carried out elevational measurements. At ancient settlement sites, both travelers discovered Lycian and Greek inscriptions and reproduced them by means of paper rubbings.

In addition to his profession as a teacher, LoEw was a wellknown taxonomist and, in his 41-year career, described 3,708 species of Diptera. LoEw's scientifically very valuable and type-rich Diptera collection is preserved primarily in the Museum of Natural History in Berlin, and contains the material he collected on this expedition to the Ottoman Empire. Since no summary of the trip has ever been published and his collected specimens are, for the most part, vaguely labeled and inadequately documented, there was a need to help clarify this information by conducting the current study. Accessing the scattered historical information to reconstruct the expedition route was a very time-consuming and lengthy process. In addition to Loew's publications and the information left by his fellow travelers, numerous archives were used to study historical files containing handwritten documents pertaining to various aspects of the trip. Some of these documents are reproduced here as facsimiles. The aim of this study was to pinpoint at least the type localities with their geographical coordinates for all zoological specimens collected, to determine the modern equivalents in addition to the historical names and to place them within the current administrative and political jurisdictions of these places.

The difficult basic conditions of such an expedition almost 180 years ago are exemplified by putting them in their historical context. This report is also intended to be an example of how individual enthusiastic entomologists in the 19th and 20th centuries achieved great scientific achievements with enormous personal commitment, with little or no financial support from the state (but also without state interference).

The itineraries for each of 1841 and 1842 are shown separately on two maps (Figures 4 \& 9) and all the locations mentioned are listed in three tables (Tables 1-3). Once we began tracing their activities, it became clear that the paths of LOEW and SCHÖNBORN on their journey separated several times after September 1841. This allowed larger parts of the country to be explored and personal interests to be better taken into account. The travel report also contains extracts from personal letters where they 
document their scientific, geographical and cultural impressions. The historical sources used to reconstruct the itinerary are listed in a separate directory and are accessed using superscript numbers.

The study of the numerous ancient settlement sites is also mentioned. SchönBorN's discovery of the so-called "Heroon of Trysa" was one of the most important archeological finds of that era. It is a very unusual ancient grave complex in southwestern Turkey built in 380 BC, possessing figure-decorated friezes that have Greek, Lycian, and even Egyptian cultural elements. It was brought to the Kunsthistorisches Museum in Vienna in 1882-1884 where is planned to be shown in 2022 for the first time in its entirety.

At least 254 species have been described from the zoological material collected by Loew (mostly Diptera, but also Coleoptera, Hymenoptera, Lepidoptera, and Mollusca). They are listed with the corresponding references (Tables 4-8). In order to facilitate further taxonomic work with the Loew Diptera collection, an overview of the historical labels and their meaning is added. The labeling of the material brought back from the trip by LoEw is dealt with in particular.

\section{Danksagung}

Bei der für uns ungewöhnlichen Arbeit in den historischen Archiven erhielten wir fachliche Unterstützung durch die zuständigen Archivarinnen Frau Stefanie Bellach, Geheimes Staatsarchiv, Preußischer Kulturbesitz, Berlin; Frau Beate EBeLt-Borchert, Zentralarchiv der Staatlichen Museen zu Berlin, Preußischer Kulturbesitz; Frau Sandra Miehlbradt, Museum für Naturkunde Berlin, Leibniz-Institut für Evolutions- und Biodiversitätsforschung, und Frau Editha Schubert, Senckenberg Deutsches Entomologisches Institut Müncheberg. In der Handschriftenabteilung der Staatsbibliothek zu Berlin, Preußischer Kulturbesitz, ermöglichte Frau Dr. Monika LINDER, Referatsleiterin Nachlässe und Autographen, die Arbeit. Frau Ute ScheIch, Museum für Naturkunde, Leibniz-Institut für Evolutions- und Biodiversitätsforschung, Sekretariat des Forschungsbereiches 3, unterstützte uns bei der Interpretation der historischen französischen Texte. Dafür möchten wir uns bei allen ganz herzlich bedanken.

Einen besonderen Dank möchten wir auch den Gutachtern, insbesondere der Gutachterin Frau Editha Schubert, Senckenberg Deutsches Entomologisches Institut in Müncheberg, und dem Gutachter Herrn Dr. Hans-Peter Tschorsnig, Staatliches Museum für Naturkunde Stuttgart, für ihre konstruktive und hilfreiche Arbeit aussprechen. Ebenso danken wir Frau Cornelia Grunow und Herrn Christian Kutzscher, Senckenberg Deutsches Entomologisches Institut in Müncheberg, und der gesamten Redaktion der Zeit- schrift „Beiträge zur Entomologie“ für die angenehme Zusammenarbeit und vielseitige Unterstützung.

\section{Personenregister}

Zum besseren Verständnis des Textes werden hier die wichtigsten Namen der im Aktenmaterial des Geheimen Staatsarchivs erwähnten Personen und Institutionen sowie weiterer im Text erwähnter Unterstützer der Reisenden mit ihrer Funktion genannt.

Вӧскн: Philipp August BöскH (auch BоєскH) (1785-1867), Geheimer Regierungsrat, Professor und mehrfach Rektor an der Berliner Universität, Philologe und Altertumsforscher.

Bülow: Heinrich Wilhelm von BüLOW (1792-1846), Preußischer Außenminister vom 2. April 1842 bis 1845 .

EICHноRN: Johann Albrecht Friedrich EICHHORN (1779-1856), preußischer Kultusminister (Minister der geistlichen, Unterrichts- und Medizinalangelegenheiten) von 1840-1848.

Flottwell: Eduard Heinrich von Flottwell (1786-1865), Oberpräsident der Provinz Posen von 1830-1841.

KLUG: Johann Christoph Friedrich KLUG (1775-1856), Professor für Medizin und Entomologie an der Berliner Universität, Direktor des Botanischen Gartens und zweiter Direktor des Zoologischen Museums Berlin mit der besonderen Zuständigkeit für die entomologischen Sammlungen.

KöNIGSMARCK: Hans Karl Albrecht Graf von KöNIGsMARCK (1799-1876), außerordentlicher Gesandter Preußens bei der Hohen Pforte zu Constantinopel von 1834-1842.

Maeulen: Johann August Maeulen, preußischer VizeKonsul in Brussa.

Maltzan: Joachim Carl Ludwig Mortimer Graf von Maltzan (1793-1843), Preußischer Außenminister von Oktober 1841 bis März 1842. Er erkrankte in seiner kurzen Amtszeit und von Werther führte das Außenministerium zwischenzeitlich provisorisch weiter.

MAtтheI: Jacques Matthei, preußischer Konsul auf Zypern.

OLfERS: Ignaz von Olfers (1793-1871), Generaldirektor der Königlichen Museen von 1839-1869.

PARThey: Gustav Friedrich Constantin Parthey (1798-1872), Geheimer Oberregierungsrat, Inhaber der Nikolaischen Buchhandlung Berlin.

Pezzer: Michel Pezzer, Kommerzienrat und preußischer Konsul in Smyrna.

Pinder: Moritz Pinder (1807-1871), Geheimer Oberregierungsrat, Archivar und Numismatiker

RitTer: Carl Ritter (1779-1859), Geograph, Professor für Erdkunde an der Berliner Universität seit 1820.

Stiepovich: Mathieu Stiepovich, Erster Dragoman (oder Drogman) der preußischen Gesandtschaft in Constantinopel (Dolmetscher, speziell für den Verkehr 
zwischen den Landesbehörden und den Gesandtschaften im Orient).

VAN LeNNeP \& Co.: Das niederländische Handlungshaus mit Vertretung in Smyrna übernahm Auszahlungen an die Reisenden, die von der General-Direktion der Seehandlungs-Sozietät (dem Vorläufer der Preußischen Staatsbank), avisiert wurden.

WAGNER: Johann Emil vON WAGNER (1805-1888), Legationsrat in der preußischen Gesandtschaft in Constantinopel und Vertreter von Königsmarck ab dem 9. Oktober 1841.

Werther: Heinrich Wilhelm von WerTHER (17721859), Preußischer Außenminister von 1837 bis 6. Oktober 1841.

\section{Archivalische Quellen}

Die historischen Titel der Akten werden generell in ihrer Originalschreibweise zitiert. Das führt zum Nebeneinander unterschiedlicher Schreibformen wie Kleinasien und Klein-Asien, Schönborn und Schoenborn, Loew und Löw.

Museum für Naturkunde, Leibniz-Institut für Evolutions- und Biodiversitätsforschung

Historische Arbeitsstelle. Akte Hermann Loew.

Acta 1: Brief vom 18. Juli 1841 von LoEw, unter der Angabe der Adresse seines Vaters in Magdeburg, an ERICHSON, Entomologe und Kustos am Berliner Museum (3 Seiten). Auszug: „[...] Da der Lithograph Schmidt die Tafeln in seiner Manier nicht ausführen zu können erklärte, sind mit Winkelmann Unterhandlungen zur Ausführung derselben eingeleitet worden, deren Abschluß der Candidat Kiepert (Heilige Geist Str. No II.) übernommen hat. Gewiß haben Sie die Güte, die Probedrücke nebst den Originalzeichnungen von denselben anzunehmen, erstere nöthigen Falls zu korrigiren ed eventuell durch eine kurze schriftliche Notiz zu approbiren, letztere aber für mich aufzubewahren. Sollte die Unterhandlung mit Winkelmann nicht zu Stande kommen, so bin ich ganz rathlos. Ich bitte Sie dann nur darum, die Originalzeichnungen nebst den Contraktsbedingungen aus den Händen des Dr. Kiepert entgegenzunehmen. Wollen Sie die Tafeln dann auf irgend eine Weise ausführen lassen, so ehre ich das als eine ganz besondere Gefälligkeit, um die ich aber nicht bitten darf, da ich sehr wohl weiß, was für Mühe Sie daran haben müssen. Noch bin ich mit meiner Litanei nicht ganz zu Ende; der schlimmste Fall kömmt erst noch. Es wird nämlich das von mir zur Reise bestellte Mikroskop nicht mehr zur rechten Zeit fertig. Das von mir bisher benutzte war nicht mein Eigenthum und ist nicht disponibel. Ich bin daher in die Nothwendigkeit versetzt in Wien ein Plösselsches, wenn anders eines vorräthig ist, zu kaufen ed mit jeder Qualität ed jedem beliebten Preise zufrieden zu sein, da mir das Instrument absolut unentbehrlich ist. Viel lieber hätte ich ein Schick- sches, an dessen Gebrauch ich gewöhnt bin. Auf starke Vergrößerungen würde es mir wenig ankommen, wenn die bis 100 (Linear) untadelhaft sind. Vielleicht ist in Berlin eines entbehrlich ed verkäuflich. Sie würden mich durch die Vermittelung eines solchen Ankaufes auf das äußerste verpflichten. Gern gehe ich auch die Bedingung ein, es, wenn es glücklich zurückkömmt, wieder zurückzugeben. Wäre die Zeit nicht gar zu kurz, so hätte sich wohl ein Weg gefunden unter Stellung der nöthigen Sicherheit ein Instrument für die Dauer der Reise geliehen zu bekommen, was der Reisekasse eine bedeutende Hülfe gewesen wäre; jetzt dürfte es zu spät dazu sein. Ohne Instrument der Art reise ich gewiß nicht, da mikroskopisch-anatomische Untersuchungen über alle Klassen der Evertebraten Haupttheil der Reiseausbeute bilden müssen. Haben Sie mir wegen des Insektenfanges und namentlich des Insektentransportes noch besondere Anweisungen zu geben so bitte ich dringend sie mir vor dem 28. Aug. hierher, oder bis zu derselben Zeit an Oberlehrer Schönborn, (jetzt in Berlin, Rosenstraße No 1, 2 Treppen) gelangen zu lassen $[\ldots]$ “.

Acta 2: Brief (undatiert, aber offensichtlich von Anfang 1843) von LoEw an ERICHSON im Berliner Museum (3 Seiten).

\section{Geheimes Staatsarchiv, Preußischer Kulturbesitz [GStA PK]}

GStA PK, I. HA Rep. 76, Kultusministerium, Ve Sektion 1 Abteilung XV, Nr. 115. Die von dem Oberlehrer Dr. Schoenborn und dem Professor Dr. Loew vom Friedrich-Wilhelms-Gymnasium zu Posen unternommenen wissenschaftlichen Reisen nach Kleinasien und die denselben bewilligten Unterstützungen.

Acta 3: Brief vom 15. Februar 1841 von SchÖNBORN an das Kultusministerium, eingereicht über das Provinzial Schul-Collegium. Beglaubigte Abschrift mit Transkriptionsfehlern. Original in der Staatsbibliothek zu Berlin, Preußischer Kulturbesitz, Handschriftenabteilung, Autographensammlung Darmstaedter: 2b 1842, Schönborn, A.S. (3 Seiten). Betrifft: Die Antragstellung SCHÖNBORNS.

Acta 4: Brief vom 15. April 1841 von Carl RitTer an Kultusminister EICHHORN (11 Seiten). Betrifft: Das Gutachten von RitTeR zum Reiseantrag SCHÖNBORNs.

Acta 5: Brief vom 26. April 1841 von Loew an das Kultusministerium, eingereicht über das Provinzial Schul-Collegium Posen (4 Seiten). Auszug: „Einem Hohen Ministerio der geistlichen, Unterrichts- und Medizinalangelegenheiten erlaubt sich der gehorsamst unterzeichnete ehrfurchtsvoll vorzutragen, daß er von einem mehrjährigen Nervenleiden zu rüstiger Amtsthätigkeit unfähig gemacht, die von dem Oberlehrer 
Schönborn und dem Herrn Kiepert intendirte wissenschaftliche Reise nach Klein-Asien als Naturhistoriker $\mathrm{zu}$ begleiten dringend wünscht und dazu pflichtschuldigst die Urlaubsgenehmigung und eine vorschußweise Gehaltszahlung bei Einem vorgesetzten Königl. Provinzial-Schulkollegio nachgesucht hat $[\ldots]^{“}$.

Acta 6: Vorlage für einen Brief vom 8. Mai 1841 von Kultusminister EıchHorN an Seine Majestät den König (8 Seiten). Betrifft: Antrag des Ministers beim König zur Genehmigung der Reise SchönBorns.

Acta 7: Brief vom 9. Mai 1841 vom Provinzial SchulCollegium Posen an das Kultusministerium, mit dem beigelegten Antrag Loews vom 26. April 1841 (8 Seiten und 4 Seiten Anlage). Betrifft: Urlaubsantrag LoEws zur Begleitung von SCHÖNBORN.

Acta 8: Brief und Allerhöchste Kabinetts-Order vom 23. Mai 1841 von Seiner Majestät dem König an Kultusminister EICHHORN (2 Seiten). Betrifft: Genehmigung der Reise sowie 600 Taler Unterstützung und Vorauszahlung des Jahresgehaltes von 700 Talern für SснӧNBORN durch den König.

Acta 9: Brief vom 24. Mai 1841 vom Direktor des Friedrich-Wilhelms-Gymnasium in Posen, WendT, an das Kultusministerium (8 Seiten). Betrifft: Ablehnung des Urlaubsantrags von Loew durch die Schulleitung.

Acta 10: Brief vom 1. Juni 1841 von Professor Friedrich KLUG (Berlin) an das Kultusministerium (3 Seiten). Betrifft: Gutachten von KLUG zum Antrag LoEws auf Freistellung zu der Reise nach Kleinasien.

Acta 11: Brief vom 6. Juni 1841 von Loew an den Kultusminister EichHorn (4 Seiten). Auszug: „[...] Durch einen besonderen ganz gehorsamen Vortrag in Betreff eines nachgesuchten längeren Urlaubes $\mathrm{zu}$ belästigen, würde sich der Unterzeichnete nicht erlaubt haben, wenn ihm nicht ein in der betreffenden Angelegenheit von seinem nächsten Vorgesetzten, dem Herrn Direktor Wendt gethaner außerordentlicher Schritt, wenn auch nicht das Recht, so doch die Hoffnung gäbe, von Ew. Excellenz als andere Partei ebenfalls gehört zu werden, und dieß um so mehr, je mehr die betreffende Darstellung des Herrn Direktor Wendt, so weit ich nach seinen eigenen Mittheilungen den Inhalt derselben kenne, durch Übergehung der mich bestimmenden Hauptgründe, meine ganz gehorsamste Bitte in ein höchst ungünstiges Licht stellt $[\ldots]^{“}$.

Acta 12: Vorlage für einen Brief vom 24. Juni 1841 von Kultusminister EICHHORN an das Provinzial SchulCollegium in Posen (2 Seiten). Betrifft: Stellungname des Ministers zur geplanten Reise von LoEw.
Acta 13: Brief vom 12. Juli 1841 vom Provinzial SchulCollegium in Posen an Kultusminister EICHHORN (5 Seiten). Betrifft: Zustimmung des Schul-Collegiums zur geplanten Reise von LoEw.

Acta 14: Vorlage für einen Brief vom 26. Juli 1841 (abgesandt am 28. Juli) von Kultusminister EICHHORN an das Provinzial Schul-Collegium in Posen (2 Seiten). Betrifft: Urlaubsgenehmigung des Ministers für LoEw.

Acta 15: Vorlage für einen Brief vom 28. Juli 1841 (abgesandt am 28. Juli) von Kultusminister EICHHORN an Hermann Loew, derzeit in Magdeburg (2 Seiten). Betrifft: Urlaubs- und Reisegenehmigung des Ministers für LoEw.

Acta 16: Brief vom 30. Juli 1841 von Hermann Loew, derzeit in Magdeburg, an Kultusminister EICHHORN. Beglaubigte Abschrift mit Transkriptionsfehlern. Ein Auszug vom Original, das in der Staatsbibliothek zu Berlin aufbewahrt wird, ist in korrekter Transkription unter Acta $56 \mathrm{zu}$ finden.

Acta 17: Brief vom 6. Oktober 1841 von SchönBorn und Loew an den Kultusminister EICHHORN. 4 Seiten. GStA PK, I. HA Rep. 76, Kultusministerium, Ve Sektion 1 Abteilung XV, Nr.115. Beglaubigte Abschrift, mit Transkriptionsfehlern. Ein Auszug vom Original, das in der Staatsbibliothek zu Berlin aufbewahrt wird, ist in korrekter Transkription unter Acta $57 \mathrm{zu}$ finden.

Acta 18: Vorlage für einen Brief vom 3. Dezember 1841 von Kultusminister EICHHORN an SCHÖNBORN und Loew in Smyrna [abgesandt am 8. Dez.] (2 Seiten). Betrifft: Genehmigung der Urlaubsverlängerung und der Reiseunterstützung von 500 Thalern.

Acta 19: Brief vom 26. März 1842 von Loew an den Kultusminister EICHHORN (8 Seiten). Auszug: „[...] Mehrtägige Thermo-hypsometrische Beobachtungen zeigten, daß Tefenü am Fuße des Gebürges auf einer Ebene von etwa 5000 Fuß Meereshöhe liege. Das Thermometer fiel hier gegen Ende des Oktobers des Morgens bis ganz nahe zum Gefrierpunkte. Die Vegetation war bereits soweit abgestorben, wie um diese Zeit auf der Parallele von Berlin [...] Der Unterzeichnete durch Führung des gemeinschaftlichen Reisegepäckes und durch die Art seiner Untersuchungen zu langsamerem Reisen genöthigt, gieng unter dieser Zeit zuerst um den bisherigen geographischen Bestimmungen mehr Zusammenfassung zu geben, von Adalia nach Istenas, in dessen Ebene er zu Anfang Novembers einen Bach bereits mit Eise überfroren fand [...] Das Wetter fieng an alle Untersuchungen sehr zu erschweren, indem mit den ersten Tagen des Decembers die gewaltigsten Regen eintraten. Einige etwas bessere Tage und falsche Nachrichten über die Beschaffenheit der Wege bestimmten den Unterzeichneten zu dem Versuche ganz an der Meeresküste mit dem Gepäcke gegen die Mündung des 
Xanthus vorzugehen $[\ldots]$ Die Tour würde sehr lehrreich geworden sein, wenn nicht die über Beschreibung große Schwierigkeit des Weges für den Transport der Effekten und Sammlungen, die selbst hier fast unerhörten ununterbrochenen Regen und Hagelstürme und der durch Unterbrechung aller Kommunikation in dem armen und ungastlichem Landstriche herbei geführte Mangel der nothwendigsten Nahrungsmittel nicht der Untersuchung zu große Schwierigkeiten in den Weg gestellt hätte. Das häufig nöthige ab und aufladen des Gepäckes, die zur Passirung unumgänglich nöthige Besserung vieler Wegstrecken, Ermattung der Menschen und Thiere, ließen nur ganz kleine Tagemärsche zu. Die Nächte wurden größtentheils mit Trocknungsversuchen der gesammelten Naturalien in Hütten, die längst nicht mehr vor dem Regen schützten, zugebracht. Ein Theil der Mineralien mußte zurückgelassen werden und von Pflanzen und Insekten gieng viel durch Wasser und Feuer, mehr noch durch später eintretenden Moder verloren [...] Sobald es ihm möglich war setzte er die Reise weiter bis Makri fort, wo trotz einem 7-tägigen Aufenthalte seine Kräfte außer Kopirung der Mehrzahl der vorgefundenen Inschriften, keine weitere Unternehmung zuließen. Im Ganze hat er bei der Reise durch Lycien etwa 160 Inschriften, darunter 40-50 lycische mit möglichster Sorgfalt kopirt. Um Weihnachten schiffte er nach Rhodus über; die Regen hielten noch an, so daß die ersten zwei Wochen zur Ordnung der Tagebücher, Wiederherstellung der nöthigen Geräthschaften und Rettung der übriggebliebenen Naturalien benutzt worden mußten. Nach Verlauf dieser zwei Wochen traf auch der Oberl. Schönborn, von den Anstrengungen des letzten Theiles seiner Reise sehr ermattet in Rhodus ein. Verständigung über viele der gemachten Wahrnehmungen, Berichtigung und Vergleichung der geographischen Beobachtungen nahmen die ersten Tage hin. Dann wandten wir uns bei etwas günstigerem Wetter der Untersuchung der Stadt und Insel zu [...] Die genauere Untersuchung dieser tertiären Formationen nun und besonders der in ihnen vorkommenden Versteinerung machte ich mir zur nächsten Aufgabe; ich darf hoffen sie in einiger Vollständigkeit gelöst zu haben; wenigstens 4000 Stück gesammelte Versteinerungen dürften bei genauerer Untersuchung leicht über 200 verschiedene Spezies nachweisen, unter denen gar vieles Neue und Schöne ist. Diese Untersuchung aber zu ganz wissenschaftlichem Ende zu führen, knüpft sich daran als nothwendige zweite eine möglichst genaue Beobachtung der jetzt lebenden Konchilien des Mittelmeeres [...] die Unterbrechung aller Verbindung mit Rhodus durch mehrfache Havarie der Dampfschiffe dieser Lienie und durch die Stärke der Aequinoktialstürme hielt mich dort bis zum 15st März fest und erst am 22st gelangte ich nach einer schwierigen Fahrt in einem kleinen türkischen Kutter hier [in Smyrna] an. Keine Zeit zu versäumen war aber Oberl. Schönborn schon am 14st März wieder in das Innere abgereist [...]“.
Acta 20: Brief ohne Datum (angekommen in Berlin am 17. Juli 1842) von Ottilie Loew, Ehefrau des Hermann LOEW, an den Kultusminister EICHHORN (3 Seiten). Betrifft: Die erwartete Rückkehr von Hermann Loew von der Reise.

Acta 21: Brief vom 2. August 1842 von Loew aus Berlin an den Kultusminister EichHORN (2 Seiten). Betrifft: Bitte um Verlängerung des Urlaubs.

Acta 22: Brief vom 16. August 1842 von Loew aus Berlin an den Kultusminister EICHHORN (4 Seiten).

Acta 23: Brief vom 20. August 1842 von Loew in Berlin an den Kultusminister EichHorn (27 Seiten). Auszug: „Unterthänigster Bericht des Professor Loew aus Posen über die Fortsetzung und Schluß seiner Reise in KleinAsien. Ew. Excellenz haben die hohe Gnade gehabt den unterthänigen Berichte des unterzeichneten über den zweiten Theil der vom Oberlehrer Schönborn und ihm gemachten Reise in Kleinasien huldvoll entgegen zu nehmen. Dieser Bericht reichte bis zur Ankunft desselben in Smyrna, wo ihn die Gewährung der erbetenen Urlaubsverlängerung hoch beglückte. So dringend er wünschen mußte in dieser der Beobachtung günstigsten Zeit keinen Tag unnütz zu verlieren, war doch die Fortsetzung seiner Untersuchungen leider erst am 5ten April möglich. Die bereits längst bei dem Königl. Konsul eingetroffne gnädige Verfügung eines hohen Ministerii hatte derselbe einem Segelschiff nicht anvertrauen zu dürfen geglaubt und sie deshalb, da die Dampfschiffverbindung unterbrochen war, zurückbehalten, so daß der unterzeichnete jetzt erst davon in Kenntniß gesetzt, genöthigt war von Neuem sämmtliche Reiseutensilien anzuschaffen, davon er sich bei aufgegebener Hoffnung auf Fortsetzung der Reise bereits in Rhodus entledigt hatte. [Absatz] Zuerst untersuchte er das von Smyrna aus sich westlich erstreckende Küstengebirge, fand hier das bereits von anderen Reisenden Beobachtete meist bestätigt, indeß auch mehrere interessante neue Thatsachen. Dann wendete er sich südlich, oder vielmehr südöstlich, den Westrand des sich von Smyrna in jener Richtung erstreckenden Thales verfolgend, um den noch nicht sicher bekannten Lauf der kleinen Flüsse zu ermitteln, welche sich zwischen Sigadschick und Aiasoluk in das Meer ergießen sollen, und um zugleicher Zeit die Lienie festzustellen, auf welcher sich hier die hebenden Glimmerschiefer mit den gehobenen Kalken berühren. [Absatz] Diese Verhältnisse wurden auf einer Lienie von Nord nach Süd, von der Thalmündung bis oberhalb Karajasu, und auf einer westöstlichen von Karajasu nach Gera ermittelt. Die ziemlich bedeutende Meereshöhe beider Orte, die Nähe noch viel höherer, weitherab noch mit Schnee bedeckter Berge und die dadurch bedingte Kälte der Wasserzuflüsse hatten hier (Mitte April) die eben erst erwachte Vegetation sichtlich zurückgehalten. Ein zweitägiger Aufenthalt in und um Karajasu gab so nur mittelmäßige botanische und entomologische 
Ausbeute, unter letzterer indeß einige noch unbeschriebene interessante Insektenspezies. Ein zweiter Aufenthalt wurde an der Nordseite des Thales in Gera beschlossen, da sich voraussetzen ließ, daß da in günstigerer Lage Pflanzen- und Thierwelt sich weiter entwickelt haben werde. Leider wurde das Wetter so ungünstig, daß sich nichts unternehmen ließ [,] die Kopie einer Reihe von Inschriften, meist der Zeit römischer Herrschaft angehörend und die Ansicht der großartigen, aber einer eben so späten Periode angehörigen architektonischen Reste, waren die einzige Ausbeute des so bald als möglich abgebrochenen Aufenthaltes. [Absatz] Nach diesen Untersuchungen bei und südlich von Davas schlug der Reisende in südwestlicher Richtung den Weg nach Mulah ein. Die oben als südlich von Davas anstehend bezeichneten Gebürgsarten fand er bis in die Nähe von Mulah, dann einen hohen, weithin noch mit Schnee bedeckten Rücken von Uebergangskalkstein und von da ab diesen stets mehr westlich streichenden Uebergangskalk mit serpentinartigen Gesteinen und der Serpentinhebung untergeordneten eisenhaltigen Kalken so manchfaltig sich durchkreuzend, daß bei der Eile der Reise an ein Erforschen in das Einzelne nicht weiter zu denken war, sondern die Aufmerksamkeit vorzugsweise der Configuration der Bodenoberfläche zugewendet wurde. Hier wie im Norden von Lycien bilden die sich durchkreuzenden Gebürgssysteme ringsum, geschlossene Thäler, meist von geringer Erstreckung, in denen die Bildung eines Flußlaufes ohne besondere hinzutretende Umstände nicht möglich ist. Ein solches Thal ist das von Mulah; von einem Flusse bei dieser Stadt, wie ihn Landkarten angeben, nicht die Rede. Nachdem jenseits dieses Thales in der Richtung auf Mermeriza noch einige solche Thäler durchritten waren, stieg der Weg allmälig und dann steiler einen sich fast westlich erstreckenden Gebürgsrücken an. Der Anblick der sich von der Höhe desselben darbot war überraschend. Vor mir lag eine in üppiger Blüthenfülle weit ausgedehnte Ebene; rechts war sie vom Meere bei Giwa [Gjöwa], links von dem Meere bei Ködschaß (Keughez) begrenzt; gegenüber die Halbinsel von Mermeriza mit ihren manchfaltig gestalteten, der Serpentinhebung angehörigen Bergen. Fast von Schritt $\mathrm{zu}$ Schritt bei dem stundenlangen Hinabsteigen am schroffen Gehänge des Berges, mehrte sich Reichthum und Entfaltung der Vegetation und der flüchtigste Blick erkannte, daß jetzt Ort und Zeit zu einer reichen botanischen und entomologischen Beute gefunden sei. Leider führte die Verwundung des Dieners durch einen Skorpionen Störung und bei der Hitze des Tages selbst Gefahr herbei. Nachdem eine starke Skarifikation [Setzen kleiner Schnitte] sich erfolglos bewiesen, führte der Gedanke an die den natürlichen Tumor vernichtende Wirkung des heißten Wassers, auf die Anwendung dieses. Es erwies sich als ein Mittel von der außerordentlichsten Wirksamkeit, daß für ähnliche Fälle nicht genug angerathen werden kann. Am nächsten Tage wurde die Reise bis Makri fortgesetzt. Trotz dem ohne alle Ausnahme ungünstigen Wetter war hier der Pflanzen und Thier- reichthum bereits so groß, daß alle Kräfte zum Sammeln desselben aufgeboten und jede Ruhestunde zur Fortführung des darauf bezüglichen Tagebuchs benutzt werden mußte. Nach einem längeren Aufenthalte in Mermeriza wurde eine Schiffsgelegenheit benutzt um nach Rhodus $\mathrm{zu}$ gelangen [Absatz] Das Wetter war fortwährend ungünstig durch schroffen Wechsel glühender Hitze und großer Kühle, so wie durch fast ununterbrochenen heftigen Wind, ein Charakter den dies im Süden durch seine Witterung so außerordentliche Jahr daselbst bis zum Schluß der Reise beibehalten hat. In der Verlegenheit um eine Schiffsgelegenheit nach der lycischen Küste boten die Offizire des zur Abholung der Antiken in Xanthus bestimmten englischen Kriegsdampfbotes eine willkommene Auskunft durch das Anerbieten eines Platzes an ihrem Bord. Unmittelbar nach der Landung an der Mündung des Xanthus und nach Besichtigung sämmtlicher von ihnen nach Xanthus überzuführenden Antiken, verließ der unterzeichnete ihre Gesellschaft, da bei der dieses Jahr ganz besonders großen Gefahr der Fiebergegend, die Menge der das Klima ungewohnten Menschen und ihre demselben in keiner Art angemessene Lebensweise dringende Gefahr zu drohen schien, eine Befürchtung die leider bald auf eine bedauerliche Weise, besonders an der Mannschaft der zugleich eingetroffenen Fregatte (Monarch) in Erfüllung gieng. Ein anderer Grund zur Trennung waren die durch die Gegenwart der Engländer auf eine für den Unterzeichneten unerschwingbare Höhe gesteigerten Preise aller der nothwendigsten Bedürfnisse. Genauere Untersuchung der Gegend zeigte, daß die sumpfigen Umgebungen von Kellemisch (Patara) die reichste Ausbeute bieten würden. Obgleich die dieses Jahr so tödtlich auftretenden typhösen Fieber die Bevölkerung längst weit weg gescheucht hatten und die ungeheuren Schwärme der Mosquitos wenig Ruhe hoffen ließen, konnte doch ein längerer Aufenthalt in dieser Gegend nicht vermieden werden. Fast gänzlicher Mangel an Nahrungsmitteln und Trinkwasser und die wahrhaft unbeschreibliche Menge der Mosquitos wurden leicht über den Reichthum der Ausbeute vergessen, deren Erlangung vom ersten Grauen des Morgens bis in die Nacht hinein reiche Beschäftigung gab. Nachdem ein in den letzten Tagen durch reichliche Bezahlung zur Herbeischaffung von Milch und Wasser bewogener Gebürgshirt dem Fieber erlegen und sich bei dem unterzeichneten wie bei dessen Diener beunruhigende Krankheitssymptome zu zeigen anfingen, wurde dieser Aufenthalt, wiewohl mit Bedauern aufgegeben und die Reise über Furnas in das Gebürge der Südküste fortgesetzt. Entomologische und botanische Forschungen beschäftigten hier so sehr, daß keine andere Untersuchung auf nur einigermaßen befriedigende Weise geführt werden [konnte.] Makris Umgegend zeigte fast denselben Pflanzen und Insektenreichthum, wie die Gegend von Kellemisch; Fieber waren hier äußerst häufig, doch viel weniger gefährlich, so daß ein längerer Aufenthalt rathsam schien. Exkursionen weit in den Kragus hinein, nördlich an der Küste hin und höher 
hinauf in das Küstengebürge lohnten durch reichliche Ausbeute, besonders an Insekten, deren Erscheinen jetzt so aufeinander drängte, daß selbst die Ermittlung der Vegetationsverhältnisse größten Theils aufgegeben werden mußte. Mit wahrhaftem Schmerz mußten am 26ten Mai alle Untersuchungen abgebrochen werden, um eine Schiffsgelegenheit nach Rhodus zu benutzen und von da über Smyrna in das Vaterland zurückzukehren. Leider war das von Rhodus nach Smyrna gehende Dampfschiff indeß wegen der in Syrien sich verbreitenden Pest mit 14tägiger Quarantaine belegt. So zog es der unterzeichnete vor mit einem Segelschiffe zu reisen. Die Zwischenzeit bis zur Abfahrt desselben benutze er $\mathrm{zu}$ einer Exkursion in den südlichen Theil der Insel bis auf den Monte Ateiro. In den ersten Tagen des Juni segelte er auf einer türkischen Goelette ab. Wind und Meer waren ihm auch diesmal nicht gewogen. Windstillen mit fürchterlicher Hitze und heftige Stürme, die den Reisenden eiskalt schienen, wechselten, so daß am 15ten Tage erst Skalanova erreicht und noch bei gleichem Wetter eine weitere Reise von etwa fünf Tagen in Aussicht stand. Von Smyrna wurde die Reise dann mit dem Dampfschiffe nach Syra weiter fortgesetzt, um da 14 Tage Quarantaine zu halten. Die Verhältnisse dieses Aufenthaltes, außerordentliche Hitze mit einem dadurch hervorgerufenem Unterleibsübel, und das der Desinfektion wegen nöthige Aus- und Wiedereinpacken sämmtlicher Sammlungen, machten nicht nur Beobachten und Sammeln sondern auch alles arbeiten unmöglich. Nachdem noch 5 Tage außer der Quarantaine bei gleichem dort entstandenen und noch fortdauernden Unterleibsübel vergangen waren, eilte der Reisende dem Vaterlande $\mathrm{zu}$, mit dem Dampfschiffe über Athen und Ankona bis Triest und von da in sieben mal vierundzwanzig Stunden fast ununterbrochener Landreise hierher [...]“.

Acta 24: Vorlage für einen Brief vom 10. November 1842 von Kultusminister EICHHORN an Seine Majestät den König (3 Seiten). Betrifft: Eine Übersicht zur Antragstellung und Finanzierung der Reise von LoEw und SCHÖNBORN.

Acta 25: Vorlage für einen Brief vom 15. Juli 1844 von Kultusminister EICHHORN an Seine Majestät den König (2 Seiten). Betrifft: Bitte um nachträgliche Genehmigung der Reiseunterstützung von 500 Talern für ScHÖNBORN und LoEw im Jahre 1842.

GStA PK, I. HA Rep. 81, Gesandtschaft Constantinopel, nach 1807, XI. Nr. 9.

Acta 26: Abberufung von Graf v. Königsmarck als Gesandter an der Hohen Pforte und seine Ernennung zum königlichen Gesandten am Niederländischem Hof.
GStA PK, I. HA Rep. 81, Gesandtschaft Constantinopel, nach 1807, XI. Nr. 27. Die archäologischen Reisen der Gelehrten Loew, Kiepert und Schönborn 1841-1842.

Acta 27: Abschrift eines Briefs vom 26. Juli 1841 von Generaldirektor v. Olfers an den Außenminister v. Werther (1 Seite). Text: „Drei junge Gelehrte, die Herrn Kiepert, Schönborn und Löw haben sich vereinigt, um theils auf eigenen Kosten, theils mit Unterstützung mehrerer Regierungen eine Reise in den weniger besuchten Gegenden des Orients zu machen, von welcher mit allem Grunde die herrlichsten Ergebnisse zu hoffen sind. Eine Empfehlung von Euerer Excellenz an die Gesandtschaft in Constantinopel würde ihrem Vorhaben sehr förderlich seÿn. Da ihre Abreise sehr nahe ist, so habe ich es gern übernommen, das Empfehlungsschreiben für sie von Euerer Excellenz Gewogenheit zu erbitten, und werde mit Vergnügen dasselbe an diese Herrn befördern, wenn Euere Excellenz nicht etwa vorziehen, es denselben durch die Königliche Gesandtschaft in Wien, wo sie sich nur wenige Tage aufzuhalten denken, behändigen zu lassen. Genehmigen Euere Excellenz den Ausdruck meiner tiefen Verehrung und Ergebenheit. Berlin, d 26ten Juli 1841. gez. Olfers“.

Acta 28: Brief vom 28. Juli 1841 von Außenminister v. Werther aus Berlin an den Grafen v. KöNIGSMARCK, den Gesandten Preußens in Constantinopel, mit dem beigelegten Brief von v. Olfers vom 26. Juli (2 Seiten). Auszug: „Euer Hochgeboren theile ich in der Anlage Abschrift eines Schreibens des Herrn Generaldirektors der Königlichen Museen zur gefälligen Kenntnissnahme ergebenst mit, worin derselbe den Wunsch ausdrückt, das die Gelehrten Kiepert, Schönborn und Löw, welche auf einer Reise in die weniger besuchten Gegenden des Orients begriffen sind, sich Ihrer Unterstützung zu erfreuen haben mögen. Obgleich es meiner Empfehlung, bei Eurer Hochgeboren mir bekannten und oft bewährten Freundlichkeit und Theilnahme für diesseitige Reisende zu diesem Zweck nicht weiter bedarf, so habe ich doch geglaubt, dem Wunsche des Herrn von Olfers nachkommen zu müssen, indem ich dieselben ergebenst ersuche, den genannten Reisenden, welche sich Ihnen vorstellen werden, zur Erreichung ihrer Zwecke nach Möglichkeit gefällig förderlich sein zu wollen $[\ldots]^{\text {“. }}$

Acta 29: Begleitschreiben vom 19. August 1841 von Außenminister v. Werther für ein beiliegendes Schreiben des Vaters von Hermann LoEw, dem Regierungsrat Loew aus Magdeburg, an den Gesandten zu Constantinopel Graf KöNigsmarck (1 Seite). Betrifft: Bitte um Übergabe des Schreibens an den Reisenden Hermann Loew.

Acta 30: Vorlage für einen Brief vom 30. August 1841 von Graf v. KöNIgsmarck an den Ersten Drogman der Gesandtschaft zu Constantinopel, Stiepovich (3 Seiten, 
in Französisch). Betrifft: Auftrag zur Unterstützung der drei Reisenden KiePert, Schönborn und Loew.

Acta 31: Vorlage für einen Brief vom 5. September 1841 von Graf v. KöNIGSMARCK (Gesandter in Konstantinopel) an Herrn MAEULEN (Konsularbeamter in Brussa), Herrn Pezzer (Konsul in Smyrna), und Herrn Matthei (Konsul auf Zypern) (2 Seiten, in Französisch). Betrifft: Auftrag zur Unterstützung der drei Reisenden Kiepert, SCHÖNBORN und LOEW.

Acta 32: Brief vom 9. September 1841 von SchönBorN aus Pera an den Gesandten Preußens zu Constantinopel, Graf v. KöNigsmarck (2 Seiten). Text: „Ew. Excellenz haben die Gewogenheit gehabt sich meiner Reisegefährten und meiner so gnädigst rücksichtlich unserer Reise nach Kleinasien anzunehmen, daß wir um die Ehre Ew. Excellenz nochmals persönlich aufwarten und unsren ergebensten Dank mündlich aussprechen zu dürfen sicherlich würden angehalten haben, wenn uns nicht die manchfaltigen Ankäufe und Besorgungen, die uns für unsere wissenschaftlichen Untersuchungen nöthig schienen, so anhaltend in Constantinopel festgehalten hätten, daß wir selbst auf jede Tour in die Umgebungen haben verzichten müssen und uns bis $\mathrm{zu}$ dieser Stunde dennoch mancherlei zu besorgen obliegt; so erlauben denn Ew. Excellenz unsern ergebensten Dank schriftlich darbringen zu dürfen und uns dero Hoher Gewogenheit, die wir gebührend zu schätzen wissen, rücksichtlich unserer Unternehmung auch für die Zukunft empfehlen zu dürfen. Was von unserer Seite geschehen kann, um den Zweck der Reise zu erreichen wird gern mit Aufbietung aller Kräfte geschehen und was namentlich den Auftrag, mit dem Ew. Excellenz uns beehrt haben, die Handelsverhältnisse in Kleinasien zu erforschen, betrifft, so sind wir von der Wichtigkeit dieser Aufgabe so vollkommen überzeugt, dass wir gewiß mit Eifer streben werden der Aufklärungen in dieser Beziehung uns möglichst viele und sichere $\mathrm{zu}$ verschaffen, nur müssen wir im Voraus um Nachsicht bitten, wenn Vollständigkeit der Untersuchung auch für einen kleineren Landestheil kaum zu erlangen möglich sein wird, da die großen Handelsstraßen nur selten von uns eingehalten werden können und der Umsatz im Großen, mehrere Seeplätze ausgenommen, daher wohl meist uns entgehen dürfte. Genehmigen Ew. Excellenz nochmals die Versicherung des ergebensten Dankes und der vollkommensten Hochachtung mit der ich die Ehre habe zu verharren. Ew. Excellenz ergebenster Diener A. Schönborn“.

Acta 33: Brief der Witwe Kiepert, Mutter des Heinrich KiePert, vom 20. Januar 1842 an die Gesandtschaft zu Constantinopel (1 Seite). Betrifft: Bitte um Geldüberweisung an Heinrich KIEPERT.

Acta 34: Brief vom 27. Januar 1842 von SchÖNBORN aus Rhodus an den Geschäftsführer der Gesandtschaft
Preußens zu Constantinopel, Legationsrat v. WAGner (2 Seiten). Auszug: „Ew: Hochwohlgeb: mögen verzeihen, wenn ich mich erdreiste, Sie mit einer Bitte zu belästigen, die nicht sowohl vom eignem Interesse hervorgerufen, als wirklich im Kunstinteresse des Preuß Staats begründet, mir wohl einige Beachtung werth scheint. Bei meiner Reise von Myra nach Xanthus habe ich in geringer Entfernung von ersterem $<$ Orte $>$, und zwar zunächst auf den Bergen über dem kleinen Dorf oder Tschistlik Gjöl Baschü (oder wie die Ruinen in der Umgegend bezeichnet werden: bei dem freilich 1 Stunde davon entfernten Dorf Tschakal Bejat) die Ruinen einer antiken Stadt, die den Europäern bisher unbekannt geblieben zu seyn scheinen, aufgefunden, und in ihnen ein Grabmonument angetroffen, das mir einer besondren Beachtung werth scheint $[\ldots]^{\prime \prime}$.

Acta 35: Brief vom 7. Februar 1842 von Generaldirektor v. Olfers an den Außenminister v. Werther (1 Seite). Betrifft: Bitte, die Beschaffung eines Fermans zur Ausfuhr „alten Marmors“ zu erwirken.

Acta 36: Brief vom 9. Februar 1842 von Legationsrat v. WAgNer an den Generaldirektor v. Olfers mit dem beigelegten Schreiben von SchöNBORN vom 27. Januar (2 Seiten und 2 Seiten Anlage). Auszug: „[...] werde bei der Pforte die Erlaubniß zur Ausführung der [...] Basreliefs zu erwirken suchen $[\ldots]$ “.

Acta 37: Brief vom 10. Februar 1842 von Außenminister v. WERTHER an den Geschäftsführer der Gesandtschaft zu Constantinopel v. WAGNER, mit beigelegtem Schreiben von v. OlfERS vom 7. Februar (1 Seite und 1 Seite Anlage). Betrifft: Bitte an die Gesandtschaft, einen Firman entsprechend dem beigelegtem Schreiben von v. OlfERs zu beantragen.

Acta 38: Vorlage für einen Brief vom 12. Februar 1842 von Legationsrat v. WAgner an den Ersten Dragoman der Gesandtschaft Stiepovich, mit der Bitte bei der Hohen Pforte einen Ferman zu erwirken. (3 Seiten, in Französisch).

Acta 39: Vorlage für einen Brief vom 8. März 1842 von Legationsrat v. WAgner an den Dragoman Stiepovich (1 Seite, in Französisch). Auszug: " Monsieur le Prof. Schoenborn et Loew viennent d'arriver à Smyrne; ils quitteront cette ville vers le 25 de ce mois. Vous voudrez bien faire observer à la Porte que si elle ne délivre pas les lettres vizirielles ou le firman pour l'exportation des vieux marbres, avant que ces Messieurs aient quitté Smyrne le but pour lequel ces documents est été demandé sera entièrement manqué $[. .]$.$» .$

Acta 40: Kopie eines Vizirialschreiben vom 9. März 1842, übertragen in das Französische vom Dragoman Stiepovich. Das Original war in osmanischem Türkisch in arabischer Schrift verfasst und ist an den Monetin 
d'Aïdin [an die lokalen Behörden der Region Aydın] gerichtet. Auszug: « [...] la Mission de Prusse a demandé que des obstacles à l'achat et au transport dites pierres ne soient pas mis de la part des autorités locales. Vu les bonnes relations existant entre les 2 Cours, il convient aquiescer à de pareilles sollicitations, puisque de telles antiquités sont très estimées en Europe [...]».

Acta 41: Vorlage für einen Brief vom 17. März 1842 von Legationsrat v. WAGNER an SCHÖNBORN in Smyrna (4 Seiten). Betrifft: Die Erlangung eines Fermans für Schönborn. Diese sei auf „unerwartete Hindernisse gestoßen“. Der an die Engländer gegebene Ferman, den Fellows in Xanthus nutzte, sei eine besondere Vergünstigung wegen ihrer Rolle während der „syrischen Ereignisse“ gewesen. „Nach vielen Bemühungen“ sei es aber gelungen, wenigstens ein Vizirialschreiben zum Kauf und Transport von Antiquitäten zu erlangen.

Acta 42: Brief vom 25. März 1842 von LoEw an Legationsrat v. WAgner (1 Seite). Text: „Ew. Hochwohlgeboren haben die große Geneigtheit gehabt uns ein Vizirialschreiben zu erwirken, wofür wir unseren gehorsamsten Dank auszusprechen uns erlauben. Die Verknüpfung von mancherlei ungünstigen Umständen macht die Erwerbung der bezeichneten Monumente für den Augenblick unmöglich, was ich Hr. Geh. Rath von Olfers pflichtschuldigst darzulegen mir erlaubt habe, mit unmaßgeblichen Gesuche die Sache von der Hand ganz ruhen zu lassen, um nicht eine unwillkommene Aufmerksamkeit darauf zu lenken. Ich vermute, daß diese Lage der Sache auch Ew. Hochwohlgeboren bestimmen wird, in dieser Angelegenheit weiter nichts zu thuen. Schließlich darf ich mir wohl die Bemerkung erlauben, daß die Monumente von solcher Bedeutung sind, daß es die Direktion der Königl. Museen zu größten Danke verpflichten wird, einen Wink zu erhalten, wenn die Umstände die Erlangung eines guten Firmans auch nur zur Ausführung eines Monumentes, wieder schwer erscheinen lassen. [Absatz] Ew. Hochwohlgeboren genehmigen die Versicherung ausgezeichnetste Hochachtung H. Loew“.

Acta 43: Auszahlungsbeleg vom 4. April 1842 ausgestellt in Smyrna (1 Seite). Betrifft: Quittung, unterschrieben von LoEw, ausgestellt in osmanischer Währung (Piaster = kuruş) als Äquvalent für 500 Preußische Taler.

Acta 44: Brief vom 7. Juli 1842 von ScHÖNBORN an Legationsrat v. WAGner (2 Seiten). Text: „Ew: Hochwohlgeboren für die wirklichen und großen Bemühungen, dern Hochdieselber Sich Behufs Erlangung des gütigst übersandten Vizirialschreibens unterzogen haben, erst jetzt meinen ganz ergebensten und gehorsamsten Dank dabringen $\mathrm{zu}$ können, thut mir von ganzem Herzen Leid, da ich sehr wohl weiß, wie sehr ich Ew: Hochwohlgeb: dafür verpflichtet bin. Ich bin aber seit Mitte März nicht mehr nach Smyrna gekommen, und habe darauf Ew Hochwohlgeb: geehrtes Schreiben erst vor wenigen Tagen empfangen. Zu gleicher Zeit habe ich auch einen Brief von den Generaldirektor der Königl Museen, $\mathrm{Hr}$ von Olfers vorgefunden, und in demselben die Ermächtigung erhalten, das fragliche Monument für das Königl. Museum zu Berlin fortzuschaffen. Ich würde daher sogleich jetzt, das von Ew Hochwohlgeb: gnädigst übersandte Vizirialschreiben benutzend, an die Ausführung des Werkes gehen, wenn nicht in dem Brief des Hr Generaldirektors der Königl Museen Bedingungen aufgestellt wären, die mir eine mündliche Rücksprache in Berlin vor Beginn des Werkes als höchst wünschenswerth erscheinen lassen. Ich gedenke darum, heut die Rückreise nach Europa anzutreten, und mir genaue Verhaltungsbefehle für das Unternehmen gehorsamst auszubitten, dabei aber bald möglichst die Ausführung selbst zu betreiben. Sollte aber die Erwerbung der Sculpturen für das Königl. Museum nicht beliebt werden; so hatte ich jedenfalls privatim dern Exportation zu versuchen. Des durch Ew Hochwohlgeborn Gewogenheit und eifrige Bemühungen erlangte Vizirialschreiben wie der früher durch Hochwohlgeborn erlangte Ferman sind mir darum von der höchsten Wichtigkeit, und Ew: Hochwohlgeboren für die Erlangung desselben, wie überhaupt für das gnädige Wohlwollen, das sie mir und meinen Freunden bei unserem Unternehmen geschenkt haben, meinen ergebensten und innigsten Dank zu sagen, ist mir eine so höchst angenehme Verpflichtung, daß ich mich deshalb in keiner Weise entziehen kann. Ew: Hochwohlgeborn haben überdies die Gewogenheit gehabt anzufragen, ob ein zweites Vizirialschreiben oder ein ander Ferman für die Ausführung dieser und ander Werke der alten Kunst nöthig seyn dürfte, und Sich gnädigst erbeten, auch dafür Sorge tragen zu wollen. Indem ich auch für dieses Anerbieten meinen ganz ergebensten Dank ausspreche, werde ich mir die Freiheit nehmen, Ew. Hochwohlgeb: mit einer Bitte in dieser Beziehung ganz gehorsamst anzugehen, falls dieser unumgänglich nothwendig seyn sollte; hoffe aber, so weit ich jetzt darüber zu entscheiden im Stande bin; daß die bereits erlangten Schreiben wohl zureichen dürften. Indem ich mich der fernern Gewogenheit von Ew: Hochwohlgeb: ganz ergebenst <angehalten>, genehmigen Hochdiselben die Versicherung meiner vollkommensten Hochachtung, mit der ich die Ehre habe zu [...]. Ew: Hochwohlgeborn ganz ergebenster Diener Dr Schönborn“.

GStA PK, I. HA Rep. 137, Generaldirektion der Staatlichen Museen, I Nr. 77. Gutachten der Artistischen Kommission bzw. Ignaz v. Olfers über nicht museumseigene Gegenstände, Band 2: Oktober 1841 bis Ende Mai 1842 \& Band 3: Ende Mai 1842 bis März 1843.

Acta 45: Brief vom 29. Dezember 1841 von LoEw aus Rhodus an Generaldirektor v. Olfers (2 Seiten). Auszug: „Ew. Hochwohlgeboren haben die Geneigtheit gehabt durch einen an den Kandidat Kiepert gerichteten Brief denselben und die unterzeichneten Reisenden zu beauf- 
tragen für Erwerbung von Antiquitäten thätig zu sein. Die unterzeichneten haben es sich bei ihrer Reise durch Phrygien, Pamphilien und Lycien angelegen sein lassen diesem ehrenvollen Auftrage Genüge zu leisten und erlauben sich, Ew. Hochwohlgeboren kurz Rechenschaft über ihre Bemühungen abzulegen“ [...] „Endlich erlauben sich die unterzeichneten schließlich noch die gehorsame Bemerkung, daß zur Ausführung obiger Statuen der Regel nach ein Firman nöthig ist, der die ausdrückliche Erlaubniß ,alten Marmor' auszuführen enthält [...]“.

Acta 46: Brief vom 27. Januar 1842 von SCHÖNBORN aus Rhodus an den Generaldirektor v. OlfERs (2 Seiten). Auszug: „Ew Hochwohlgeboren sprachen im vergangenen Sommer, als ich die Ehr hatte, Hochdenselben meine Hochachtung zu bezeigen gegen mich den Wunsch aus, antike Kunstwerke in Kleinasien für das Königl. Museum entweder anzukaufen, aber, falls dis in irgend einer Beziehung Bedenken hätte, Hochdenselben über diselben Nachricht zu ertheilen. Ich habe nun in Lycien, einige Stunden vom Meer fern, unter den Ruinen einer alten Stadt, dern Nahmen ich nicht habe ermitteln können, ein Grabmonument gefunden, das mir besondre Beachtung werth scheint, und wage deshalb, nachfolgenden Zeilen an Ew. Hochwohlgeb. zu richten. [...]“.

Acta 47: Vorlage für einen Brief vom 17. Februar 1842 von Generaldirektor v. OlfERs an LOEW und SCHÖNBORN in Smyrna, mit Duplikat nach Rhodus (2 Seiten). Auszug: „Ew. Schreiben vom 29. Dec. v. J. ist in den ersten Tagen dieses Monates [Februar 1842] mir zugegangen. Obwohl ich S. K. M. Befehle, wegen Abwesenheit Desselben nicht einholen kann, stehe ich doch nicht an, dies Schreiben nach Ihrem Wunsche sogleich zu beantworten [...] Sie sagen aber, daß die weibliche Statue wenigstens von mittelmäßigen Werthe, die männliche aber gut und mit Ausnahme der fehlenden Theile vortrefflich erhalten sei [...] Ich schicke Ihnen daher hirbei ein Wechsel für die genannte Summe von dreitausend Thalern auf J. van Lennep K. C. in Smyrna, und schließe den Brief ein an den K. Preuß. Consul Commerzienrath Pezzer daselbst. Ein Duplikat geht, einer Andeutung unter Ihren gemeinschaftlichen Schreiben zufolge, an den Hr Professor Loew nach Rhodus durch die Adresse des Griechischen Consulats deselbst. Wegen eines Firmans zur Ausfuhr alten Marmors habe ich gleich an den Minister der auswg. Angelegenheiten geschrieben und ihn ersucht, denselben Ihnen unter der Adresse des Hr Prof. Löw durch das K Consulat zu Smyrna zu übersenden [...] Die Sache bitte ich wohl verpackt, in dem Hafen wohin sie verbracht werden, am besten nach Hamburg an das K Consulat daselbst, für die Generaldirektion der K. Museen zu Berlin, zu adressieren und mich zugleich von der nahen oder geschehenen Absendung, behufs Besorgung der Abholung und nöthigen Vorkehrungen zu benachrichtigen $[\ldots]^{\star}$.
Acta 48: Vorlage für einen Brief vom 10. März 1842 von Generaldirektor v. OlfERs an Legationsrat v. WAGNER mit eingeschlossenem Schreiben an Schönborn in Smyrna (1 Seite). Text: „Ew. ersuche ich ergebenst das anliegende für die gelehrten jungen Reisenden Prof. Löw und Schönborn bestimmtes Schreiben möglichst bald auf sichere Weise an dieselben zu befördern, oder falls dies nicht geschehen könnte ihnen von der Ankunft Befehles Nachricht zu geben. Zugleich darf ich wohl bitten, diese Herren in ihren wissenschaftl. Untersuchungen so wie bei etwaiger Verladungen von gesammelten Gegenstände mit Rath und Tath unterstützen zu wollen. Ich benutze gern den Anlass, Ew [...] meine ausgezeichnete Hochachtung zu versichern“.

Acta 49: Vorlage für ein eingeschlossenes Schreiben vom 10. März 1842 von Generaldirektor v. OlfERS an SCHÖNBORN (3 Seiten).

Acta 50: Brief vom 26. März 1842 von Loew an den Generaldirektor v. OlfERs (4 Seiten). Auszug: „Ewer Hochwohlgeboren erlaube ich mir auf ein hochgeneigtes Schreiben vom 14. [abgesandt am 17.] Febr. a. c., welches mir heute vom Königl. Konsul hierselbst nebst den Kreditbriefen der Königl. Seehandlung übergeben worden ist, ganz gehorsamst zu berichten, daß sich alle Umstände auf eine unglückliche Weise so gestaltet haben, daß für den Augenblick es unmöglich ist, wegen der beiden Statuen und des Grabmonumentes etwas zu unternehmen. Unser Urlaub lief bereits mit dem 1st April ab; wie bereits mit den ersten Tagen des Oktober erbetene Bewilligung einer 3 monatlichen Verlängerung, erhofften wir von Tage zu Tage vergeblich. Wir sahen uns so genöthigt, Pferde, Waffen, Reisegeräth u. s. w. zu verkaufen, einzupacken u alles zu schleunigster Abreise vorzubereiten. Oberlehrer Schönborn versuchte noch auf ein paar Wochen in das Innere von Montecha einzudringen. Mitte des März war zum gemeinschaftlichen Eintreffen in Smyrna bestimmt. Der unerhört harte Nachwinter hat den Oberlehrer Schönborn alle weiteren Vordringen gehindert und schon $\mathrm{zu}$ Anfang des Monats nach Smyrna genöthigt. Hier hat er die Hohe Bewilligung des erbetenen Urlaubes vorgefunden, mich über den verabredeten Termin vergeblich erwartet und ist dann in das Innere abgereist um noch einmal durch Pamphilien womöglich bis $\mathrm{zu}$ den thaurischen Städten vorzudringen. Bei der Schwierigkeit einer Route hat er mir über diselber gar nichts bestimmtes hinterlassen können. Ew. Hochwohlgeboren hochgeneigtes Schreiben ist leider erst einige Tage nach seiner Abreise angelangt und ihm so der Inhalt desselben unbekannt geblieben. Ich selbst wurd in Rhodos wider Willen festgehalten; Stürme u Havarien verzögerten meine Ankunft in Smyrna bis zum gestrigen Tage. - Sähe ich eine Möglichkeit dazu, so würde ich es für erste Pflicht halten Ew. Hochwohlgeboren Befehlen zu genügen und es würde mir die größte Freude sein dem Vaterlande besonders das von Schönborn entdeckte merkwürdige Monument zuzuführen, über dessen Auffindung 
er im Februar Ew. Hochwohlgeboren von Rhodos aus berichtet hat. Leider bin ich es nicht im Stande. Ankauf der nothwendigen Instrumente und Maschienen, der nur hier in Smyrna, und auch hier schwer zu erhaltenden Breter [Bretter] von gehöriger Stärke für die nöthigen 200 und mehr Kisten, deren Maaß ich hier ohne Schönborns Tagebücher nicht einmal zu bestimmen vermag, Anwerbung und Hinführung der nöthigen Arbeiter würde sehr viel Zeit kosten. Außerdem sind, wie ich aus Schönborns Mittheilungen weiß, die Steine viel zu groß um auf Kamelen transportirt zu werden, der Weg für Wagen, die überdies auch von hier mitgenommen werden müßten, ganz unbrauchbar, so daß die Alternative einträte entweder den Weg herzustellen, oder Steinmetze zur Abnahme der Hinterseite der Steine mit zu nehmen. Alles dies würde die Arbeit in eine Zeit verschieben, wo sie theils des Klimas, theils des ablaufenden Urlaubes wegen nicht mehr möglich wäre. Wäre Schönborn nur hier, oder wüßte ich ihn zu erlangen, so sollte den vereinten Kräften es doch wohl noch gelingen. Mich tröstet das, daß ich Ew. Hochwohlgeboren die bestimmte Versicherung geben zu können glaube, daß dennoch die Erwerbung dieses merkwürdigen Denkmales für die vaterländischen Museen, und zwar ohne große Kosten, als ziemlich sicher angesehen werden kann. Den näheren Plan hoffe ich bei der Rückkehr in das Vaterland Ew. Hochwohlgeboren darlegen zu dürfen, hier Hauptbedingung des Gelingens dieser Unternehmung dürfte aber vollkommenes Schweigen über diselbe auch in Europa sein. Schon ist die Aufmerksamkeit der antiken Händler auf unsere Reise gerichtet und es ist mir gleich bei meiner Ankunft hier eine ansehnliche Summe für die bloße Nennung der Orte geboten worden, wo sich transportable Reste dieser Art finden. Auch die Bemühungen um einen Ferman dürften nach meiner ganz unmaßgeblichen Meinung einzustellen. Den unermüdeten Bemühungen des Hr Geh. Legat. Rath von Wagner in Constantinopel ist es <nur> gelungen ein Vizirialschreiben zu erlangen, das doch noch einen der türkischen Hinterhalte enthält und keine rechte Sicherheit gewährt. Erlauben mir die Umstände nicht in Beziehung auf dieses bei weitem wichtigste Monument etwas Erfolgreiches zu unternehmen, so ist es um so mehr zu bedauern, daß Zufall und Natur auch die Wegführung der beiden Statuen unmöglich machen. Die von mir in Hochlycien aufgefundene ist durch die unglaublichen Schneefälle dieses Frühjahres, besonders zu Ende Februar und Anfang März noch auf 2 Monate und mehr dem Transporte unzugänglich. Die andere fand Oberlehrer Schönborn auf einer mehrtägigen Excursion von Tireh in die Umgegend von Birkeh auf [nach Benndorf \& Niemann (S. 11) in Hypaipa], während ich auf einer Excursion nach Eski Baindir begriffen war. Ich bin ohne seine Tagebücher nicht einmal im Stande den Namen des Dorfes genau anzugeben. Die Richtung seines Weges weiß ich zwar ziemlich genau, doch ist es in der nächsten Zeit wegen der Ueberschwemmungen des kleinen Mendere-Su unmöglich diesen die Thalebene von Tireh nach Birkeh in nordöstlicher Richtung schneidenden Weg zu verfolgen.
Kehrt Oberlehrer Schönborn nicht gar zu kurz vor Ablauf des Urlaubes nach Smyrna zurück so wird es ihm Wohl bei Vorfindung von Ew. Hochwohlgeboren Bestimmungen möglich sein in 12 bis 14 Tagen diese Statue hierher nach Smyrna zu schaffen. Wollen Ew. Hochwohlgeboren übrigens überzeugt sein, daß der angestrengteste Versuch gemacht werden wird wenigstens einen Theil jenes Basreliefes hierher zu schaffen $[\ldots]$ ].

Acta 51: Auszug aus dem Bericht vom 15. Juni 1842 vom Geschäftsführer der Gesandtschaft zu Constantinopel v. WAGNER an den Außenminister v. BülOw in Berlin (1 Seite). Auszug: „[...] Schon vor Eingang des diesfälligen Auftrages des auswärtigen Ministeriums hatte der Geschäftsträger bei der Pforte Schritte gethan, einen Firman zur freien Ausführung der von dem Prof. Schönborn zu Mentesche im Disdrict Aidin entdeckten Marmor, Sculpturen zu erwirken. Die Pforte sehe solche Ausführung ungern, und habe einen dergleichen Firman neuerdings nur ausnahmsweise während der syrischen Ereignisse (1840) [der sogenannten Orientkrise] einigen Engländern gewährt. Er habe daher nur mit Mühe das abschriftlich angeschlossene Vizirialschreiben erhalten, und dasselbe dem [...] Schönborn mit dem Ersuchen übersandt, ihm anzuzeigen, ob ein Firman nöthig sei. Da ihm nun hierauf der Prof. Löw geschrieben, daß der Ankauf in Mentesche aufgegeben sei, auf seine nochmalige Anfrage in Bezug auf einen Firman aber keine Antwort erfolgt sei, habe er die Sache auf sich beruhen lassen $[\ldots] . . "$

Acta 52: Brief vom 3. Juli 1842 von Außenminister v. BülOW an Generaldirektor v. OlfERs (1 Seite). Auszug: „Dem in Ew. Hochwohlgeboren gefälligem Schreiben vom 7ten Februar c, ausgedrückten Wunsche gemäß ist seiner Zeit die Königliche Gesandtschaft in Constantinopel beauftragt worden sich bei dem türkischen Ministerium dahin zu verwenden, daß den Professoren Löw, Schönborn und Kiepert ein Firman zur Ausfuhr alten Marmors ertheilt werden möge. Was der einstweilige dortige Geschäftsträger hierauf angezeigt hat, wollen Ew. Hochwohlgeboren aus dessen nebst seiner Anlage urschriftlich und mit dem Ersuchen um demnächstige gefällige Rückgabe hier beigefügten Berichte vom 15ten v. M., ersehen [...].“

GStA PK, III. HA, Ministerium für auswärtige Angelegenheiten, III No 35-44 Reisepaßerteilungen und Empfehlungen für Reisende).

Acta 53: Reisepasserteilung No 38 für KIEPERT, SchÖNBORN und Löw vom 28. Juli 1841. 
Staatsbibliothek zu Berlin, Preußischer Kulturbesitz, Handschriftenabteilung

\section{Nachlass Heinrich KIEPERT}

Acta 54: Einzelblätter des Reisetagebuchs von Heinrich KIEPERT. Betrifft den 19. und 23. September 1841.

Acta 55: Einzelblätter des Reisetagebuchs von Julius August SCHÖNBORN. Betrifft den 8. und 9. Oktober 1841.

\section{Autographensammlung Darmstaedter}

Acta 56: Brief vom 30. Juli 1841 von Hermann Loew, derzeit in Magdeburg, an Kultusminister EICHHORN. Original. Lc 1850 Loew, Hermann (2 Seiten). Auszug: „Ew. Excellenz Den allerunterthänigsten, aber auch innigsten und wärmsten Dank für die hochgeneigte Gewährung des gehorsamst erbetenen Urlaubes und Gehaltsvorschusses sagend, darf ich zu gleicher Zeit nicht verfehlen pflichtschuldigst anzuzeigen, dass ich die beabsichtigte Reise nach Kleinasien in Gemeinschaft mit dem Oberlehrer Schönborn soeben anzutreten im Begriff stehe. Ew. Excellenz Gnade hat eine Frage, die ich als wichtige Lebensfrage anzusehen genöthigt war, zu meinen Gunsten entschieden und mich so zum unauslöschlichsten Dank verpflichtet, welchen ich ganz auszusprechen nicht im Stande bin. Möchte es mir gelingen, ausser dem egoistischeren Gewinn körperlicher und geistiger Wiederherstellung und Kräftigung, auch der Wissenschaft einen Gewinn zu sichern welcher es Ew. Excellenz gestattet, ohne Unwillen auf die mir hochgeneigtest gewährte Gnade zurückzublicken und der geeignet wäre dem wissenschaftlichen Bestrebungen, welchen mein Leben gewidmet ist, Ew. Excellenz hohes Wohlwollen zu erwerben $[\ldots]^{\text {“ }}$

Acta 57: Brief vom 6. Oktober 1841 von SCHÖNBORN und Loew an den Kultusminister EichHorn. Original. 2b 1842, Schönborn, A. S. (4 Seiten). Auszug: „Ew. Excellenz über den bisher vollendeten Theil ihrer Reise durch Klein-Asien ganz gehorsamst in der Kürze $\mathrm{zu}$ berichten, halten sich die Unterzeichneten um so mehr verpflichtet, je inniger der Dank für die gewährte Möglichkeit dieser Reise in ihnen fortlebt und je mehr sie Ew. Excellenz huldvolles Wohlwollen zur endlichen Lösung der gestellten Aufgabe ferner bedürfen werden. [Absatz] Von Gemlik über Brussa, Adirnas, Serdschilar, Bolat, Bohadsch, Kysarköi, Baluksissar, Soma und Bergama nach Manissa führte der Weg die Reisenden durch Gegenden, welche ohne Ausnahme als bisher völlig unbekannt, sowohl nach ihren geographischen Details, als in jeder andern Beziehung genannt werden müssen. Als bekannte und bereits untersuchte Orte berührt wurden, wurden sie wenigstens auf neuen Wegen erreicht und auf eben solchen wieder verlassen. Erst von Manissa nach Smyrna betraten wir eine bekannte Straße. Von allen den durchreisten Gegenden ist eine genaue geographische Aufnahme gemacht worden. Zur Aufnahme des Olympus und der seinem Systeme angehörigen Gebirgszüge, zur genauen Messung seiner Meereshöhe und der Höhe einiger der interessanteren Vegetationsgrenzen auf ihm, sowie einer freilich nur oberflächlichen Untersuchung seiner höchst interessanten geognostischen Verhältnisse, der an seinem Fuße bei Brussa entspringenden heißen Quellen, sowie zur Ermittlung von mehreren lehrreichen zoologischen und botanischen Verhältnissen reichte ein Zeitraum von 8 Tagen nur notdürftig aus. Die Höhe des Berges dürfte sich nach genauerer Berechnung der Beobachtungen ganz nahe auf $2500 \mathrm{~m}$ [2.543 m] herausstellen. Die zoologischen Ermittlungen erhielten dadurch eine besondere Wichtigkeit, daß hier die Entdeckung eines Jahre lang von Naturalienhändlern betriebenen absichtlichen Betrugs über die Fauna von Ungarn, Siebenbürgen, die Balkangegend und die Umgebung von Constantinopel vollständig gelang. Eingeleitete Verbindungen mit in Brussa wohnenden Deutschen werden noch nachträglich reiche Belehrung gewähren. [Absatz] Der Weg von Brussa nach Adirnas und Serdschilar gab reiche Aufschlüsse über die noch unbekannten, südwestlichen Ausläufer des Aynoz, von denen mehrere quer überstiegen wurden. Jene Orte selbst boten Gelegenheit zu Untersuchungen über die Lage des alten Adrianoi und zur Copierung mehrerer Inschriften. Nicht weit hinter Serdschilar traten wir in ein bisher völlig unbekanntes vulkanisches Terrain von außerordentlicher Ausdehnung und durchschritten es dann in einer Linie von vielen Meilen; weitverbreitete Trachyte von außerordentlich veränderlichem oryctognossischen Charakter, mit den mannigfaltigsten zum Theil deutlich verschlackten Einschlüssen und durch Hitze veränderte Kalke waren das vorherrschende Gestein, von dem später die gesammelten Proben vorzulegen wir die Ehre haben werden. Eine große Menge von Resten antiker Sarkophage und viele in den Felsen ausgehauene Gräber machen es durch ihre Lage unzweifelhaft, daß auf der Stelle des heutigen Bolat ein antiker Ort gestanden habe. Auch Bohadsch hatte antike Reste und Ruinen eines großen byzantinischen Kastells aufzuweisen. Nachrichten von angeblichen antiken Resten führten uns von da nach Hisarköi, das ausserdem durch seine heißen Quellen ein besonderes Interesse darbot, welche merkwürdig genug auf derselben geraden Linie mit dem oben erwähnten vulkanischen Terrain des Kotschatach, den heissen Quellen in Brussa und mehreren anderen ähnlichen Quellen liegen. Daß der Ort schon im Altertum von nicht geringer Bedeutung war, zeigten nebst vielen andern im Dorfe verstreuten architektonischen Resten besonders die noch deutlich erkennbaren großartigen Säulenreihen innerhalb einer späteren kastellartigen Mauerumschließung. Die allmäliche Erhöhung des Bodens auf die Errichtung andrer Gebäude a demselben Platze erlaubten leider nicht den Umfang und Grundriß 
des antiken Gebäudes in alle Einzelheiten zu verfolgen. Die spätere Tour gab zu antiquarischen Beobachtungen weniger Veranlassung, da namentlich die antiken Reste von Pergamon hinlänglich bekannt und die anderwärts vorhandenen völlig unbedeutend sind. Doch dürfen wir glauben, daß unsere Reise zu einer genaueren topographischen Darstellung dieser Gegend verhelfen werde, die bisher zwischen den Orten in den von uns eingeschlagenen Richtungen völlig unmöglich war. Außerdem sind wir im Stande die wichtigsten der beobachteten geologischen Thatsachen durch mitgebrachte Handstücke $\mathrm{zu}$ belegen. Wie arm auch die Ausbeute an lebenden Pflanzen wegen der bereits zu weit vorgerückten Jahreszeit war, so besitzen wir doch manche interessante Notiz über Pflanzenverbreitung und von vielen Gewächsen wenigstens den Samen. Die zoologische Sammlung enthält über 700 Arten Insekten, darunter verhältnismäßig ziemlich viel neue Arten, auch ein neues Genus. Zum Sammeln von Wirbelthieren fand sich mehrfach gute Gelegenheit, doch mußten wir sie wegen der zu großen Kostspieligkeit und Schwierigkeit des Transportes unbenutzt lassen. Das Beobachtete ist in die Verzeichnisse eingetragen worden. [Absatz] Diejenige Erfahrung dieser 20tägigen Reise von Constantinopel nach Smyrna aber, welche für die Reisenden selbst von der größten Wichtigkeit war, ist die unabweisbare Bemerkung, daß Landessitte und Klima derartige Untersuchungen zeitraubender und kostspieliger machen als voraus berechnet war und daß somit der vorgestreckte Kreis der Untersuchungen nicht in der gegebenen Zeit vollendet werden kann. Um ihrerseits alles zu thun, was möglich ist um dem Ziele nahe zu kommen, haben sie Trennung und Theilung der Arbeit beschlossen. Die gehorsamst unterzeichneten haben die Untersuchung der östlichen Landestheile bis zum Anschlusse an die Aufnahme des Major Fischer im Meridian von Ikonium zu Kap Anamur übernommen. Jetzt wo die durch Trockenheit und Hitze des vergangenen Sommers zu großer Heftigkeit gesteigerten Fieber eben nachzulassen beginnen und die $\mathrm{zu}$ untersuchenden Gegenden zugänglich werden, beeilen sie sich dieselben schleunigst zu erreichen, und werden deshalb möglichst schnell ostwärts bis in die Gegend von Egerdir [Egidir] gehen, um nicht durch die später eintretenden Regen an der Erreichung des östlichen Zieles ihrer Reise gehindert zu werden Nach den sorgfältig eingezogenen Erkundigungen werden die zu untersuchenden Gegenden beiweitem größten Theils von Mitte Novembers, spätestens vom Anfang Dezembers an durch das Anschwellen aller Gewässer so schwer zu bereisen, daß die Untersuchungen deshalb, wie wegen der fortdauernden Regen nur langsam vorrücken können und die Rückkehr nach Smyrna auf dem Landwege, dem der Untersuchungen wegen einzig möglichen, selbst mit Beiseitelassung vieler der wichtigsten Untersuchungen, vor Mitte April nicht möglich erscheint. Diese Umstände und der Wunsch viele der wichtigsten topographischen und antiquarischen Fragen, deren Lösung ihnen so nahe liegt, nicht unerledigt zu lassen, der Wunsch ferner wenigstens einen Frühlingsmonat in jenen Gegende untersuchen zu können und eine lohnendere Ausbeute zu gewinnen, als es die nur mit vieler Mühe gewonnene des vergleichsweise so armen Spätherbstes ist, veranlassen die Unterzeichneten Ew. Excellenz ganz gehorsamst und dringendst: um eine dreimonatliche Verlängerung ihres Urlaubes und um die hochgeneigte Gewährung einer weiteren Reiseunterstützung von 500 Taler $\mathrm{zu}$ bitten oder, wenn letztere Bitte $\mathrm{zu}$ weit gehen sollte, ihnen wenigstens eine vorschußweise Zahlung im gleichen Betrage durch Anweisung an einen der preussischen Consule gewähren wollen. [Absatz] An den Untersuchungen selbst nichts weiter zu vergeben, glauben sie, Ew Excellenz weitere Befehle auf dem Felde derselben selbst erwarten zu müssen. Bei der großen Unsicherheit der Briefbeförderung nach jenen Gegenden aber, und in der Unmöglichkeit so weit hinaus den Ort ihres Aufenthaltes genau zu berechnen, wagen sie es um doppelte Ausfertigung derselben an die Consule in Attalia und Larnaka ganz gehorsamst zu bitten. Daß die Gewährung der gehorsamst erbetenen Urlaubsverlängerung und der unterthänigst bezeichneten Unterstützung die Untersuchungen zu dem gewünschten Abschlusse führen, auf dem vorgezeichneten Felde keine der wichtigen Fragen unerledigt lassen und die naturwissenschaftliche Ausbeute fast verdoppeln werde, glauben die Unterzeichneten nach der bisher gewonnenen Uebersicht desselben mit voller Bestimmtheit versichern zu können $[\ldots]^{\prime \prime}$.

\section{Die in folgenden Archiven gelagerten Akten enthielten keine Unterlagen zur Reise:}

Deutsches Archäologisches Institut [DAI], Archiv der Zentrale. Berlin, Podbielskiallee 69-71. Reste des Nachlasses von Heinrich Kiepert (Briefe).

Staatliche Museen zu Berlin, Preußischer Kulturbesitz, Zentralarchiv. Berlin, Geschwister-Scholl-Straße 6. Der historische Aktenbestand der Generaldirektion der Königlichen Museen zu Berlin gehört zu den umfangreichen Kriegsverlusten. Ein kleiner Teil sehr alter Akten wird im Geheimen Staatsarchiv, Preußischer Kulturbesitz, aufbewahrt (s. o.). Schriftliche Mitteilung von Frau Beate Ebelt-Borchert, Archivarin, vom 11.02.2019.

Senckenberg Deutsches Entomologisches Institut, Archiv [SDEI]. Müncheberg, Eberswalder Straße 90. Handschriften in der Akte Hermann Loew ohne Bezug zu der Reise. 


\section{Literaturverzeichnis}

Anonymus 1841: Tageszeitung „Oesterreichischer Beobachter", Wien. Ausgabe 300 vom 27. Oktober 1841, Seite 1, Notiz unter „Türkei“. - Digitale Version unter www.onb.ac.at.

ANONYmus 1846: Tafeln zur Statistik der Österreichischen Monarchie für das Jahr 1842. Zusammengestellt von der kaiserl. königl. Direktion der administrativen Statistik, 15. Jahrgang. - K. k. Hof- und Staatsdruckerei Wien. Digitale Version unter www.onb.ac.at.

Anonymus 1890: Meyers Konversations-Lexikon. Eine Encyklopädie des allgemeinen Wissens. 4. Aufl., 16 Bände. - Bibliographisches Institut, Leipzig und Wien.

Benndorf, O. \& Niemann, G. 1889: Das Heroon von Gjölbaschi-Trysa. - Jahrbuch der kunsthistorischen Sammlungen des allerhöchsten Kaiserhauses. Sonderdruck Band 9, 262 Seiten, 34 Tafeln. - Holzhausen, Wien.

Böскн, A. \& Franz, J. (Hrsg.) 1853: Corpus inscriptionum Graecarum, Band 3. 1271 Seiten. - Officina Academica, Berlin.

de Jong, Y.; Verbeek, M.; Michelsen, V.; Bjørn, P.; Los, W.; Steeman, F; Bailly, N.; Basire, C.; Chylarecki, P.; Stloukal, E.; Hagedorn, G.; Wetzel, F.; Glöckler, F.; Kroupa, A.; Korb, G.; HofFmann, A.; Häuser, C.; Kohlbecker, A.; Müller, A.; Güntsch, A.; Stoev, P.; Penev, L. 2014: Fauna Europaea - all European animal species on the web. Biodiversity Data Journal 2: e4034. - https://doi. org/10.3897/BDJ.2.e4034

Débarre, S. 2016: Cartographier l'Asie Mineure. L'orientalisme allemand à l'épreuve du terrain (18351895). Collection Turcica 21. 406 pp. - Peeters, Leuven.

DÉbarre, S. 2017: Cartographier l'Asie Mineure. L'orientalisme allemand à l'épreuve du terrain (1835-1895). - URL: http://hal.archives-ouvertes.fr/ hal-01585504/document

EICHLER, F. 1950: Die Reliefs des Heroon von GjölbaschiTrysa: 77 Seiten. - Deuticke, Wien.

Evenhuis, N. 1997: Litteratura taxonomica dipterorum (1758-1930), vols. 1 and 2: 871 pp. - Backhuys, Leiden.

Evenhuis, N. L.; Pape, T. \& Ziegler, J. (in Vorb.): Nomenclatural studies toward a world list of Diptera genus-group names. Part VIII: Hermann Loew. Zootaxa.

Fauna Europaea - Database version 2017.06. http://www. faunaeur.org [Aufgerufen 16.12.2019].

Gerstaecker, A. 1869: Beiträge zur näheren Kenntniss einiger Bienen-Gattungen. - Stettiner entomologische Zeitung 30: 139-184.

Kiepert, H. 1843: Karten Ephesus, Taf. I \& II. - In: GuHL, E.: Ephesiaca: 210 Seiten. - Nicolaische Buchhandlung, Berlin (in Latein).
Kiepert, H. 1844: Karte von Klein-Asien. Entworfen und gezeichnet nach den neuesten und zuverläßigsten Quellen, hauptsächlich nach den in den Jahren 1838-39 von Baron v. VINCKE, FisCHER und Baron Helmuth v. Moltke, und 1841-43 von H. Kiepert; A. Schönborn und K. KocH ausgeführten Recognoscirungen, sowie nach den besten neueren Reiserouten, vorzüglich der Engländer. In Stein gest. von $\mathrm{H}$. Mahlmann 1: 1.000.000. - Schropp, Berlin.

KieperT, H. 1890-1892: Spezialkarte vom westlichen Kleinasien. Nach eigenen Reisen und nach anderen grösstentheils noch unveröffentlichten Routenaufnahmen, 1:250.000. - Reimer, Berlin.

KraAtz, G. 1879: Loew's Fliegensammlung. - Deutsche entomologische Zeitschrift 23: 23-24.

LANDSKron, A. 2016: Das Heroon von Trysa. Ein Denkmal in Lykien zwischen Ost und West. Untersuchungen zu Bildschmuck, Bauform und Grabinhaber. - Schriften des Kunsthistorischen Museums, Band 13 A und B: 546 und 222 Seiten. - Holzhausen, Wien.

LöвL, I. \& LöвL, D. (Eds) 2017: Catalogue of Palaearctic Coleoptera; Volume 1: Archostemata, Myxophaga, Adephaga, revised and updated edition, 1443 pp. Brill, Leiden.

Loew, H. 1843a: Über die Caprification der Feigen. Stettiner entomologische Zeitung 4: 66-77.

Loew, H. 1843b: Bemerkungen über die bekannten europäischen Arten der Gattung Chrysogaster Meig. [Teil]. - Stettiner entomologische Zeitung 4: 240-255.

Loew, H. 1843c: Bemerkungen über die bekannten europäischen Arten der Gattung Chrysogaster MEIG. [Schluss]. - Stettiner entomologische Zeitung 4: 258-281.

LoEw, H. 1843d: Beschreibung zweier neuen Cicindelen und Bemerkungen über eine angebliche Varietät der Cicindela campestris. - Stettiner entomologische Zeitung 4: 337-343.

Loew, H. 1844a: Ueber die europäischen Arten der Gattung Idia. - Stettiner entomologische Zeitung 5: $15-25$.

LoEw, H. 1844b: Beschreibung einiger neuen Gattungen der europäischen Dipternfauna [Teil]. - Stettiner entomologische Zeitung 5: 114-130.

Loew, H. 1844c: Kritische Untersuchung der europäischen Arten des Genus Trypeta MeIg. - Zeitschrift für die Entomologie 5: 312-437.

LoEw, H. 1844d: Beschreibung einiger neuen Gattungen der europäischen Dipternfauna [Schluss]. - Stettiner entomologische Zeitung 5: 154-173.

Loew, H. 1844e: Zur Kenntnis der Ocyptera-Arten [Teil]. - Stettiner entomologische Zeitung 5: 226-240.

Loew, H. 1844f: Zur Kenntnis der Ocyptera-Arten [Schluss]. - Stettiner entomologische Zeitung 5: 266-269. 
Loew, H. 1845: Dipterologische Beiträge. - In: Kiessling, F. G.: Zu der öffentlichen Prüfung der Schüler des königlichen Friedrich-WilhelmsGymnasiums zu Posen am 17. März 1845: Seiten $1-50+[2] .-$ Decker \& Comp., Posen.

Loew, H. 1846a: Fragmente zur Kenntnis der europäischen Arten einiger Dipterengattungen. - Linnaea entomologica. 1: 319-530.

Loew, H. 1846b: Ueber die Gattung Ortalis und zwei neue Arten derselben. - Stettiner entomologische Zeitung 7: 92-96.

Loew, H. 1847a: Ein Paar neue Fliegen zum neuen Jahre! - Stettiner entomologische Zeitung 8: 23-32.

Loew, H. 1847b: Dipterologische Beiträge. Zweiter Theil Thereva. - In: Kiessling, F. G.: Zu der öffentlichen Prüfung der Schüler des königlichen FriedrichWilhelms-Gymnasiums zu Posen am 26. März 1847: Seiten 1-50. - Decker \& Comp., Posen.

Loew, H. 1847c: Ueber Tetanocera stictica und ihre nächsten Verwandten, nebst der Beschreibung zweier anderen neuen Tetanocera-Arten. - Stettiner entomologische Zeitung 8: 114-124.

Loew, H. 1847d: Ueber die europäischen Raubfliegen (Diptera asilica) [Teil]. - Linnaea entomologica 2: 384-568.

Loew, H. 1847e: Einige neue Tachinarien. - Stettiner entomologische Zeitung 8: 259-276.

Loew, H. 1847f: Ueber die italienischen Arten der Gattung Conops. - Jahresbericht des naturwissenschaftlichen Vereins zu Posen 1846: 1-24.

LoEw, H. 1847g: Ueber die europäischen Arten der Gattung Sapromyza. - Jahresbericht des naturwissenschaftlichen Vereins zu Posen 1846: 25-44.

Loew, H. 1847h: Dipterologisches. - Stettiner entomologische Zeitung 8: 368-376.

Loew, H. 1848a: Über die europäischen Raubfliegen (Diptera asilica) [Teil]. - Linnaea entomologica 3: 386-495.

Loew, H. 1848b: Ueber die europäischen Arten der Gattung Eumerus [Teil]. - Stettiner entomologische Zeitung 9: 108-128.

Loew, H. 1848c: Ueber die europäischen Arten der Gattung Eumerus [Schluss]. - Stettiner entomologische Zeitung 9: 130-136.

LoEw, H. 1848d: Dipterologisches. - Stettiner entomologische Zeitung 9: 329-332.

LoEw, H. 1849a: Über die europäischen Raubfliegen (Diptera asilica) [Schluss]. - Linnaea entomologica 4: $1-155$.

LoEw, H. 1849b: Cylindrotoma nigriventris, Dixa laeta, Dixa puberula und Dixa obscura, vier neue Arten. Stettiner entomologische Zeitung 10: 341-349.

LoEw, H. 1850a: Dipterologische Beiträge, Vierter Theil. Die Gallmücken. - Programm des königlichen Friedrich-Wilhelms-Gymnasiums zu Posen für das Schuljahr von Ostern 1849 bis dahin 1850: Seiten 1-40. - Decker \& Comp., Posen.
Loew, H. 1850b: Beschreibung zweier neuen Arten der Gattung Orthochile LATR. - Stettiner entomologische Zeitung 11: 341-345.

Loew, H. 1851: Bemerkungen über die Familie der Asiliden. - Programm der königlichen Realschule zu Meseritz 1851: Seiten 1-22. - Lorenz, Meseritz.

Loew, H. 1853: Neue Beiträge zur Kenntnis der Dipteren. Erster Beitrag. - In: Loew, H.: Programm der königlichen Realschule zu Meseritz 1853: Seiten 1-38. - Lorenz, Meseritz.

Loew, H. 1854: Neue Beiträge zur Kenntnis der Dipteren. Zweiter Beitrag. Neue Dipteren. - In: Loew, H.: Programm der königlichen Realschule zu Meseritz 1854. Seiten 1-24. - Lorenz, Meseritz.

Loew, H. 1855: Neue Beiträge zur Kenntnis der Dipteren. Dritter Beitrag. Bombylius. - In: Loew, H.: Programm der königlichen Realschule zu Meseritz 1855: Seiten 1-52. - Lorenz, Meseritz.

Loew, H. 1856: Neue Beiträge zur Kenntnis der Dipteren. Vierter Beitrag. - In: Loew, H.: Programm der königlichen Realschule zu Meseritz 1856. Seiten 1-57: - Lorenz, Meseritz.

Loew, H. 1857a: Neue Beiträge zur Kenntnis der Dipteren. Fünfter Beitrag. Die Familie der Dolichopoden. - In: Loew, H.: Programm der königlichen Realschule zu Meseritz 1857: Seiten 1-56. - Lorenz, Meseritz.

Loew, H. 1857b: Dipterologische Mittheilungen IV. Cyrtoneura hortorum WiED. und die ihr verwandten europäischen Arten. - Wiener entomologische Monatsschrift 2: 44-47.

LoEw, H. 1857c: Eine dipterologische Razzia auf dem Gebiete des naturwissenschaftlichen Vereins für Sachsen und Thüringen. - Zeitschrift für die gesammten Naturwissenschaften 10: 97-112.

Loew, H. 1858a: Zwanzig neue Diptern [Teil]. - Wiener entomologische Monatsschrift 2: 57-62.

Loew, H. 1858b: Zwanzig neue Diptern [Schluss]. Wiener entomologische Monatsschrift 2: 65-79.

Loew, H. 1858c: Ueber die Arten der Gattung Clinocera MeIG. [Teil]. - Wiener entomologische Monatsschrift 2: $238-253$

Loew, H. 1858d: Ueber die europäischen Arten der Gattung Silvius. - Wiener entomologische Monatsschrift 2: 350-352.

Loew, H. 1859a: Zur Kenntnis der europäischen TabanusArten. - Verhandlungen der kaiserlich-königlichen zoologisch-botanischen Gesellschaft in Wien [1858] 8: $573-612$.

Loew, H. 1859b: Versuch einer Auseinandersetzung der europäischen Chrysops-Arten. - Verhandlungen der kaiserlich-königlichen zoologisch-botanischen Gesellschaft in Wien [1858] 8: 613-634.

Loew, H. 1859c: Neue Beiträge zur Kenntnis der Dipteren. Sechster Beitrag. Europäische Dolichopoden. - In: Loew, H.: Programm der königlichen Realschule zu Meseritz 1859: Seiten 1-50. - Lorenz, Meseritz. 
Loew, H. 1860: Neue Beiträge zur Kenntnis der Dipteren. Siebenter Beitrag. Die europaeischen Ephydrinidae und die bisher in Schlesien beobachteten Arten derselben. In: LoEw, H.: Programm der königlichen Realschule zu Meseritz 1860: Seiten 1-46. - Lorenz, Meseritz.

Loew, H. 1862a: Novae Helomyzidarum in Europa viventium species. - Wiener entomologische Monatsschrift 6: 126-128.

Loew, H. 1862b: Ueber griechische Dipteren. - Berliner entomologische Zeitschrift 6: 69-89.

Loew, H. 1862c: Ueber die europäischen Heleomyziden und die in Schlesien vorkommenden Arten derselben. - Zeitschrift für Entomologie (Breslau) [1859] 13: $1-80$.

Loew, H. 1864a: Ueber die Pachymeria-Arten aus dem Verwandtschaftskreise der P. femorata FBR. - Wiener entomologische Monatsschrift 8: 353-366.

Loew, H. 1864b: Diptera. Ueber die schlesischen Arten der Gattungen Tachypeza MeIG. (Tachypeza, Tachista, Dysaletria) und Microphorus MAcQ. (Trichina und Microphorus). - Zeitschrift für Entomologie (Breslau) [1860] 14: 1-50.

Loew, H. 1865a: Ueber die europäischen Arten der Gattung Geomyza. - Berliner entomologische Zeitschrift 9: 14-25.

Loew, H. 1865b: Ueber die europäischen Arten der Gattung Rhicnoessa. - Berliner entomologische Zeitschrift 9: 34-39.

Loew, H. 1866: Ueber die europäischen NoterophilaArten. - Berliner entomologische Zeitschrift [1865] 9: 268-269.

LoEw, H. 1867: Ueber diejenigen mit Empis chioptera MeIG. verwandten Arten, welche dunkle Schwinger haben. Berliner entomologische Zeitschrift 11: 25-62.

Loew, H. 1868: Die europäischen Ortalidae. - Zeitschrift für die gesammten Naturwissenschaften 32: 1-11.

LoEw, H. 1869a: Beschreibungen europäischer Dipteren. Systematische Beschreibung der bekannten europäischen zweiflügeligen Insecten. Von Johann Wilhelm Meigen. Achter Theil oder zweiter Supplementband. Beschreibung europäischer Dipteren, erster Band: XVI + 310 Seiten + [1]. - Schmidt, Halle.

Loew, H. 1869b: Ueber einige Empis-Arten, welche zu den im XI. Bande besprochenen Verwandtschaftskreisen gehören. - Berliner entomologische Zeitschrift 13: 65-94.

Loew, H. 1871: Beschreibungen europäischer Dipteren. Systematische Beschreibung der bekannten europäischen zweiflügeligen Insecten. Von Johann Wilhelm Meigen. Neunter Theil oder dritter Supplementband. Beschreibung europäischer Dipteren, zweiter Band: VIII + 319 Seiten. - Schmidt, Halle.

Loew, H. 1873: Beschreibungen europäischer Dipteren. Systematische Beschreibung der bekannten europäischen zweiflügeligen Insecten. Von Johann Wilhelm Meigen. Zehnter Theil oder vierter Supplementband. Beschreibung europäischer Dipteren, dritter Band: VIII + 320 Seiten. - Schmidt, Halle.
Marksteiner, T. 2002: Trysa - eine zentrallykische Niederlassung im Wandel der Zeit: Siedlungs-, Architektur- und kunstgeschichtliche Studien zur Kulturlandschaft Lykien: 292 S., 194 Abb., 193 Taf., 1 Faltplan. - Phoibos, Wien.

Oberleitner, W. 1994: Vergangenheit und Zukunft des Heroons von Trysa. - In: BorchHardT, J. \& Dobesch, G.: Akten des II. Internationalen LykienSymposions, Wien, 6.-12. Mai 1990: 211 Seiten.

Partsch, J. 1901: Heinrich Kiepert. Ein Bild seines Lebens und seiner Arbeit. - Geographische Zeitschrift 7. Sonderabdruck, 40 Seiten. - Teubner, Leipzig.

Philippi, R. A. 1844: Nachtrag zum zweiten Bande der Enumeratio Molluscorum Siciliae. - Zeitschrift für Malakozoologie 7: 100-112.

Pinder, M. \& Friedlaender, J. 1851: Münzen Kleinasiens. - In: Pinder, M. \& Friedlaender, J. (Hrsg.): Beiträge zur älteren Münzkunde. Band 1: Seiten 70-84, 2 Tafeln. - Nicolaische Buchhandlung, Berlin.

Rennwald, E. \& Rodeland, J. 2019: Lepiforum. Bestimmungshilfe für die in Europa nachgewiesenen Schmetterlingsarten. - http://www.lepiforum.de [Aufgerufen 16.12.2017].

Ritter, C. 1859: Die Erdkunde von Asien, Band 19 Klein Asien, Theil 2: 1200 Seiten. - Reimer, Berlin.

Schmidt, M. 1868: The Lycian inscriptions after the accurate copies of the late Augustus Schoenborn with a critical commentary and an essay on the alphabet and language of the Lycians: $14+20$ pages, 10 plates. - Mauke, Jena.

SchönboRN, C. 1858: Vorwort. - In: SchönBoRN, J. A.: Die Skene der Hellenen. Ein Versuch: Seiten III-VIII. - Hirzel, Leipzig.

Schönborn, C. 1868: The life of the late Augustus Schoenborn. - In: Schmidt, M.: The Lycian inscriptions after the accurate copies of the late Augustus Schoenborn with a critical commentary and an essay on the alphabet and language of the Lycians: Pages 13-20. - Mauke, Jena.

Schönborn, J. A. (als Schönborn, A. S.) 1835-1861: Lateinisches Lesebuch zur Einübung der lateinischen Formenlehre: 108 Seiten, 1.-11. Auflage. - Mittler, Berlin.

SchönboRN, J. A. 1843: Ueber einige Flüsse Lyciens und Pamphyliens nach Mittheilungen des Prof. Dr. Loew und nach eigenen Notizen von Schönborn. - In: Wendt, C. H. A.: Zu der öffentlichen Prüfung der Schüler des Königlichen Friedrich-WilhelmsGymnasiums zu Posen am 11. April 1843: Seiten 1-24. - Decker \& Comp., Posen.

Schönborn, J. A. 1849: Beiträge zur Geographie Kleinasiens. Einige Bemerkungen über den Zug Alexander's durch Lycien und Pamphylien. Der Zug Alexander's durch Lycien. - In: KiessLing, F. G.: Zu der öffentlichen Prüfung der Schüler des Königlichen FriedrichWilhelms-Gymnasiums zu Posen am 2. April 1849: Seiten 1-27. - Decker \& Comp., Posen. 
Schönborn, J. A. 1851: Communication from Professor Schoenborn, of Posen, relative to a Monument recently discovered by him in Lycia. - The Museum of Classical Antiquities 1: 41-43.

Schönborn, J. A. (als Schönborn, A.) 1854: Ueber das Wesen Apollon's und die Verbreitung seines Dienstes. Ein Versuch: 80 Seiten. - Mittler, Berlin.

Schönborn, J. A. 1858: Die Skene der Hellenen. Ein Versuch. Herausgegeben von C. SchönborN: 361 Seiten. - Hirzel, Leipzig.

Spratt, T. \& Forbes, E. 1847: Travels in Lycia, Milyas, and the Cibyratis, vol. 1 and 2: 302 and 322 pp. - van Voorst, London.

Starke, I. H. 1884: Zur Geschichte des Königlichen Friedrich-Wilhelms-Gymnasiums zu Posen: 68 Seiten. - Merzbach, Posen.

SteIN, J.P. E. F. 1876: Einige neue dalmatinische, griechische und kleinasiatische Tenthredinoiden. - Stettiner entomologische Zeitung 37: 53-61.

SteIN, P. 1924: Die verbreitetsten Tachiniden Mitteleuropas nach ihren Gattungen und Arten. - Archiv für Naturgeschichte, 90 A (6): 1-271.

Stewig, R. 1970: Bursa, Nordwestanatolien. Strukturwandel einer orientalischen Stadt unter dem Einfluß der Industrialisierung. - Schriften des Geographischen Instituts der Universität Kiel, Band 32: 177 S.

Stuke, J.-H. \& Ziegler, J. 2019: Type catalogue of the thick-headed flies (Diptera, Conopidae) in the collection of the Museum für Naturkunde Berlin, Germany. - Deutsche entomologische Zeitschrift 66: 41-53. DOI: 10.3897/dez.66.33814.
Szemethy, H. D. 2005: Die Erwerbungsgeschichte des Heroons von Trysa. Ein Kapitel österreichischtürkischer Kulturpolitik: 707 Seiten, 56 Tafeln. - Phoibos, Wien.

Turan, R.; Nusser, H. \& Mayer, S. 2008: Istanbul als antike und islamische Stadt. 3. Aufl. - Materialien zur Geschichte und Sozialkunde 50: 1-155.

Zeller, P. C. 1846: Beschreibung der Trichosoma löwii n. sp. nebst Bemerkungen über Carrennós "Insecte, dont l'ordre est incertain". - Stettiner entomologische Zeitung 7: 5-11.

Zeller, P. C. 1847: Verzeichniß der vom Professor Dr. Loew in der Türkey und Asien gesammelten Lepidoptera. - Isis: Encyclopädische Zeitschrift, vorzüglich für Naturgeschichte, vergleichende Anatomie und Physiologie [von Oken] 40: 3-39, Jena.

Ziegler, J. 2010: Vom Wert der Fliegen. - In: Damaschun, F.; Hackethal, S.; Landsberg, H. \& Leinfelder, R.: Klasse, Ordnung, Art. 200 Jahre Museum für Naturkunde: 154-157. - BasiliskenPresse, Rangsdorf.

Ziegler, J. \& Menzel, F. 2000 (Hrsg.): Die historische Dipteren-Sammlung Carl Friedrich Ketel. Revision einer zwischen 1884 und 1903 angelegten Sammlung von Zweiflüglern (Diptera) aus MecklenburgVorpommern. - Nova Supplementa Entomologica 14: 1-266.

Zögner, L. 1999: Antike Welten - Neue Regionen. Heinrich KIEPERT 1818-1899. Staatsbibliothek zu Berlin, Preußischer Kulturbesitz, Austellungskataloge, Neue Folge 33, 197 Seiten. - Kiepert KG, Berlin. 